\title{
CROSS SECTION MEASUREMENTS IN THE MAIN INJECTOR PARTICLE PRODUCTION (FNAL-E907) EXPERIMENT AT 58 GEV ENERGY
}

\author{
by \\ Yusuf Oğuzhan Günaydın
}

\begin{abstract}
An Abstract
Of a thesis submitted in partial fulfillment of the requirements for the Doctor of Philosophy degree in Physics in the Graduate College of The University of Iowa
\end{abstract}

December 2009

Thesis Supervisor: Professor Yasar Onel 
Cross-sections are presented for $58 \mathrm{GeV} \pi, \mathrm{K}$, and $\mathrm{p}$ on a wide range of nuclear targets. These cross-sections are essential for determining the neutrino flux in measurements of neutrino cross-sections and oscillations. The E907 Main Injector Particle Production (MIPP) experiment at Fermilab is a fixed target experiment for measuring hadronic particle production using primary $120 \mathrm{GeV} / c$ protons and secondary $\pi, K$, and $\mathrm{p}$ beams. The particle identification is made by $\mathrm{dE} / \mathrm{dx}$ in a time projection chamber, and by time-of-flight, differential Čherenkov and ring imaging Čherenkov detectors, which together cover a wide range of momentum from $0.1 \mathrm{GeV} / c$ up to $120 \mathrm{GeV} / c$. MIPP targets span the periodic table, from hydrogen to uranium, including beryllium and carbon. The MIPP has collected $\sim 0.26 \times 10^{6}$ events of $58 \mathrm{GeV} / c$ secondary particles produced by protons from the main injector striking a carbon target.

Abstract Approved:

Thesis Supervisor

Title and Department

Date 


\title{
CROSS SECTION MEASUREMENTS IN THE MAIN INJECTOR PARTICLE PRODUCTION (FNAL-E907) EXPERIMENT AT 58 GEV ENERGY
}

\author{
by \\ Yusuf Oğuzhan Günaydın
}

A thesis submitted in partial fulfillment of the requirements for the Doctor of Philosophy degree in Physics in the Graduate College of The University of Iowa

December 2009

Thesis Supervisor: Professor Yasar Onel 
Copyright by YUSUF OĞUZHAN GÜNAYDıN 2009 All Rights Reserved 
Graduate College

The University of Iowa

Iowa City, Iowa

\section{CERTIFICATE OF APPROVAL}

PH.D. THESIS

This is to certify that the Ph.D. thesis of

\section{Yusuf Oğuzhan Günaydın}

has been approved by the Examining Committee for the thesis requirement for the Doctor of Philosophy degree in Physics at the December 2009 graduation.

Thesis Committee:

Yasar Onel, Thesis Supervisor

Edwin Norbeck

Robert L. Merlino

Jane M. Nachtman

Tuong Ton-That 
To my wife Tuğba and our daughter İrem 


\section{ACKNOWLEDGMENTS}

First, I would like to thank my advisor, Professor Yaşar Önel, for his support and encouragement and his allowing me to work freely. He opened the door to the world of particle physics for me, allowing me to meet and work with additional prominent people in the field. I am grateful for the opportunity to have been one of his $\mathrm{PhD}$ students.

Special thanks to the other members of my committee: Edwin Norbeck, Robert L. Merlino, Tuong Ton-That, and Jane M. Nachtman. Their suggestions were invaluable to me. Professor Edwin Norbeck specifically helped with editing the dissertation.

I want to thank all the collaborators at MIPP, too numerous to mention by name, for their assistance on this experiment, collecting data twenty-four hours a day; without this data, there would have been no experiment. I especially appreciate the help of Dr. Holger Meyer, who supervised me for the last one and a half years; without his guidance and support I could not have achieved my goal. Professor Nicholas Solomey gave me a job at Wichita State University during the past year and a half that allowed me to complete my $\mathrm{PhD}$. In addition, whenever I needed to spend time at the Fermilab, I was able to go because Anna Solomey took over my classes for me. I also thank Professor Erhan Gülmez for his advice and counsel concerning the choice of a PhD topic and for his unforgettable help and support. Thanks, in additions, to my friend Burak Bilki, who helped me study for the qualifying exam.

Thanks also go to my classmate and colleague, Güral Aydın who first encouraged me to apply to the University of Iowa. I shared the entire process of getting our PhDs in particle physics at the University of Iowa and at the Fermilab with him. His friendship was a valuable support to me during these past years.

I want to thank Professor Mithat Kaya, with whom I never worked, but with 
whom I hope I can work someday. His encouragement motivated my study.

Thank you to Bill and Caryl Lyons, who provided my family with a temporary home during the 2008 floods and once again during the final weeks of work on this dissertation. Caryl also helped with editing this thesis for English grammar and style.

I would like to say thank you to my parents and my sisters. After I had gotten B.S. degree, my mother Ayşe's dedication and support provided the inspiration for my $\mathrm{PhD}$ education.

Most of all, I thank my wife Tuğba, and my daughter İrem, who were always with me during my $\mathrm{PhD}$ education. They provided endless love and support through both the good and the bad times. They are the reason for it all. 


\begin{abstract}
Cross-sections are presented for $58 \mathrm{GeV} \pi, \mathrm{K}$, and $\mathrm{p}$ on a wide range of nuclear targets. These cross-sections are essential for determining the neutrino flux in measurements of neutrino cross-sections and oscillations. The E907 Main Injector Particle Production (MIPP) experiment at Fermilab is a fixed target experiment for measuring hadronic particle production using primary $120 \mathrm{GeV} / c$ protons and secondary $\pi$, K, and p beams. The particle identification is made by $\mathrm{dE} / \mathrm{dx}$ in a time projection chamber, and by time-of-flight, differential Čherenkov and ring imaging Čherenkov detectors, which together cover a wide range of momentum from $0.1 \mathrm{GeV} / c$ up to $120 \mathrm{GeV} / c$. MIPP targets span the periodic table, from hydrogen to uranium, including beryllium and carbon. The MIPP has collected $\sim 0.26 \times 10^{6}$ events of $58 \mathrm{GeV} / c$ secondary particles produced by protons from the main injector striking a carbon target.
\end{abstract}




\section{TABLE OF CONTENTS}

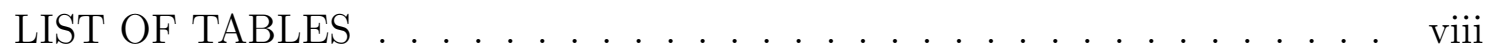

LIST OF FIGURES . . . . . . . . . . . . . . . . . . . ix

CHAPTER

$1 \quad$ INTRODUCTION . . . . . . . . . . . . . . . . 1

2 THE MIPP EXPERIMENT AND DETECTORS . . . . . . . . . . . 3

2.1 The MIPP Experiment . . . . . . . . . . . . . . . . . 3

2.2 Beam Chambers (BC) and Beam Čherenkov (BCkov) . . . . 5

2.3 Drift Chambers . . . . . . . . . . . . . . . 6

2.4 Multi-Wire Proportional Chambers . . . . . . . . . . . . . 7

2.5 Time Projection Chamber . . . . . . . . . . . . . . . . . . 10

2.6 Threshold Čherenkov . . . . . . . . . . . . . . . . . . 12

2.7 Beam Time of Flight . . . . . . . . . . . . . . . . . . . . . . 12

2.8 Time of Flight Wall . . . . . . . . . . . . . . . . . . . . . . . 13

2.9 Ring Imaging Čherenkov . . . . . . . . . . . . . . . . . . . . 13

2.10 Electromagnetic and Hadron Calorimeters . . . . . . . . . . . . 15

2.11 Analysis Magnets . . . . . . . . . . . . . . . . . . . . . 16

3 THE MIPP BEAMLINE AND TARGETS . . . . . . . . . . . . . 17

3.1 The MIPP Beamline . . . . . . . . . . . . . . . . . . . . . . . . 19

3.2 The MIPP Targets . . . . . . . . . . . . . . . . . . 20

4 THE MIPP TRIGGER SYSTEM AND DATA ACQUISITION SYS-

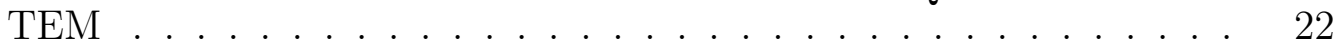

4.1 The MIPP Trigger System . . . . . . . . . . . . . . . . . 22

4.1.1 Beam Particle Identification . . . . . . . . . . . . 22

4.1.2 Interaction Trigger System . . . . . . . . . . . . . . . 25

4.1.3 End of Spill and Calibration Triggers . . . . . . . . . . 26

4.2 The MIPP Data Acquisition System . . . . . . . . . . . . 26

5 EVENT RECONSTRUCTION . . . . . . . . . . . . . . . 27

5.1 Track Reconstruction . . . . . . . . . . . . . . . . . . 27

5.2 Particle Identification . . . . . . . . . . . . . . . . . . . . . . 30

5.2.1 Likelihood .................. . . 30

5.2 .2 TPC PID . . . . . . . . . . . . . . . . 31

5.2 .3 ToF PID ........................... 32

5.2.4 CkoV PID ................... 36

5.2 .5 RICH PID ................. . . 37

5.3 Global Particle Identification . . . . . . . . . . . . . . . . . . . 39

6 CROSS SECTION MEASUREMENTS . . . . . . . . . . . . . 42 
6.1 Cross Section Terminology . . . . . . . . . . . . . . . . . 42

6.2 Calculation of Cross Sections . . . . . . . . . . . . . . . 44

6.3 Bin Selection . . . . . . . . . . . . . . . . 45

6.4 Trigger Efficiency . . . . . . . . . . . . . . . . . 46

6.5 Target-Out Subtraction . . . . . . . . . . . . . . . 47

6.6 Detector Acceptance . . . . . . . . . . . . . . . . . . . . . . 49

6.7 Beam Flux Determination . . . . . . . . . . . . . . . . . . 56

6.8 Error Measurements . . . . . . . . . . . . . . . 60

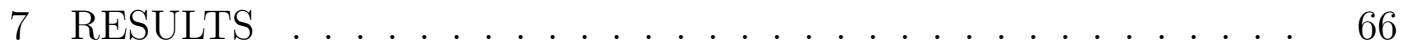

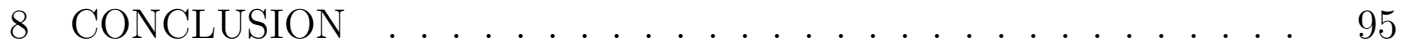

REFERENCES . . . . . . . . . . . . . . . . . . 97 


\section{LIST OF TABLES}

Table

2.1 The MIPP detector system's electronics modules list . . . . . . . 5

3.1 The MIPP data summary at the end of the production run . . . . . 18

3.2 The MIPP experimental targets list and their properties . . . . . . 21

4.1 A summary of the MIPP experiment's trigger bits . . . . . . . . . 23

4.2 Beam PID tagging combinatorics . . . . . . . . . . . . 24

6.1 Beam flux numbers from two different calculation methods . . . . . 57

6.2 After applying pre-scale beam interaction trigger values on beam fluxes, the beam flux numbers are derived to use in cross-section calculations. . . . . . . . . . . . . . . . .

7.1 Cross section numbers and errors for $\pi^{+}+C \rightarrow \pi^{+}+X$. All errors are shown in percentage except the total errors that are shown next to the cross-section. . . . . . . . . . . . . .

7.2 Cross section numbers and errors for $\pi^{+}+C \rightarrow \pi^{-}+X$ All errors are shown in percentage except the total errors that are shown next to the cross-section. . . . . . . . . . . . . . .

7.3 Cross section numbers and errors for $\pi^{+}+C \rightarrow p+X$ All errors are shown in percentage except the total errors that are shown next to the cross-section. . . . . . . . . . . . . . . . .

7.4 Cross section numbers and errors for $K^{+}+C \rightarrow \pi^{+}+X$ All errors are shown in percentage except the total errors that are shown next to the cross-section. . . . . . . . . . . . . . . . .

7.5 Cross section numbers and errors for $K^{+}+C \rightarrow \pi^{-}+X$ All errors are shown in percentage except the total errors that are shown next to the cross-section. . . . . . . . . . . . . . . .

7.6 Cross section numbers and errors for $p+C \rightarrow \pi^{+}+X$ All errors are shown in percentage except the total errors that are shown next to the cross-section.

7.7 Cross section numbers and errors for $p+C \rightarrow \pi^{-}+X$ All errors are shown in percentage except the total errors that are shown next to the cross-section. . . . . . . . . . . . . . .

7.8 Cross section numbers and errors for $p+C \rightarrow p+X$ All errors are shown in percentage except the total errors that are shown next to the cross-section. 


\section{LIST OF FIGURES}

Figure

2.1 The MIPP detector system layout . . . . . . . . . . . . . . 4

2.2 Beam Čherenkov detectors system layout . . . . . . . . . . . . . . 6

2.3 MIPP experimenters are working on one of the MIPP's drift chamber. 7

2.4 Iowa Multi-Wire Proportional Chamber 6 is located downstream of the RICH detector. . . . . . . . . . . . . . . . . 8

2.5 Layout of the RMH system that is used for MWPCs' readout in the MIPP experiment. . . . . . . . . . . . . . . . 9

2.6 Time Projection Chamber 3D schematic picture [6] . . . . . . . . . 10

2.7 TPC wire system layout $[6] \ldots \ldots \ldots$

2.8 Threshold Čherenkov Detector and its Toroidal Mirrors . . . . . . . 12

2.9 The RICH detector schematic side view . . . . . . . . . . . . . . . 14

2.10 The MIPP calorimeters, HCAL and EMCAL were used for neutral particles. . . . . . . . . . . . . . . . . 15

2.11 Jolly Green Giant analysis magnet creates $0.7 \mathrm{~T}$ magnetic field to bend charge particles inside the TPC volume. . . . . . . . . . . . 16

3.1 The view of the MIPP beamline . . . . . . . . . . . . . . 17

3.2 The MIPP beam line schema shows how secondary beam processed before it hit the experimental target. . . . . . . . . . . . . . . . . 20

3.3 The MIPP's experimental thin targets are installed in a rotating wheel. 21

4.1 The MIPP Trigger System Counters . . . . . . . . . . . . . . 24

5.1 Reconstructed tracks inside the TPC volume . . . . . . . . . . . . 29

5.2 Reconstructed global tracks . . . . . . . . . . . . . . . . 29

5.3 Primary vertex $\mathrm{z}$ position distributions for different experimental targets[19] . . . . . . . . . . . . . . . . 30

5.4 TPC energy loss $(\mathrm{dE} / \mathrm{dx})$ PID distribution . . . . . . . . . . 31

5.5 A sample of ToF PID distribution . . . . . . . . . . . . . 33

5.6 Fitted $\left(t^{\text {meas }}-t_{\pi}^{\text {pred}}\right)$ plots . . . . . . . . . . . . . 34

5.7 Corrected distribution $\left(t^{\text {meas }}-t_{\pi}^{\text {pred }}\right)$ plots . . . . . . . . . . 35

$5.8\left(t^{\text {meas }}-t_{\pi}^{\text {pred }}\right)$ distribution with extra peak . . . . . . . 36

5.9 These plots show the RICH PID capability. . . . . . . . . . . . . 38

5.10 Likelihoods of weighted $\pi^{+}$and $p \ldots \ldots$. . . . . . . . 40

5.11 Probabilites of $\pi^{+}$and $p$ for each track with respect to momentum . 41 
6.1 MC Truth $\pi^{+}$distribution. Angle bins start from lowest $\cos \theta$ to highest, and momentum bin start from lowest momentum to highest.

6.2 Interaction trigger effciencies that are calculated by using Monte Carlo files. . . . . . . . . . . . . . . . . . . . .

6.3 Primary vertex $\mathrm{z}$ position distribution. The blue line shows the fit on a target-in distribution, and the red line shows the fit on a target-out distribution. . . . . . . . . . . . . . .

6.4 MCTruth $\pi,{ }^{ \pm}$and $p$ yields, and their matched tracks in MCReco. Angle bins start from lowest $\cos \theta$ to highest, and momentum bins start from lowest momentum to highest.

6.5 Track finding efficiency plots for produced $\pi,{ }^{+} \pi,{ }^{-}$and $p$. Angle bins start from lowest $\cos \theta$ to highest, and momentum bins start from lowest momentum to highest. . . . . . . . . . . . . . . . . . . .

6.6 MCReco and MCTruth PID distribution plots for produced $\pi,^{+} \pi,^{-}$ and $p$. Angle bins start from lowest $\cos \theta$ to highest, and momentum bins start from lowest momentum to highest. . . . . . . . . . . . . .

6.7 PID efficiency plots for produced $\pi,^{+} \pi,^{-}$and $p$. Angle bins start from lowest $\cos \theta$ to highest, and momentum bins start from lowest momentum to highest.

6.8 Momentum migration matrices plots for produced positive and negative particles . . . . . . . . . . . . . . . .

6.9 MCTruth and MCReco weighted PID distribution plots for produced $\pi,^{+} \pi,^{-}$and $p$. Angle bins start from lowest $\cos \theta$ to highest, and momentum bins start from lowest momentum to highest. . . . . . .

6.10 Purity efficiency plots for produced $\pi,{ }^{+} \pi,{ }^{-}$and $p$. Angle bins start from lowest $\cos \theta$ to highest, and momentum bins start from lowest momentum to highest.

6.11 In the first bin of this plot, there is no cut applied but the following seven bins show applied cuts on events and last two bins show applied cuts on vertex.

6.12 Systematic errors of the $\pi^{+}$cross-section that is produced by pioncarbon interactions at $58 \mathrm{GeV}$ energy. . . . . . . . . . . . . . .

6.13 Systematic errors of the $\pi^{+}$cross-section that is produced by kaoncarbon interactions at $58 \mathrm{GeV}$ energy. . . . . . . . . . . . .

6.14 Systematic errors of the $\pi^{+}$cross-section that is produced by protoncarbon interactions at $58 \mathrm{GeV}$ energy. . . . . . . . . . . . . .

6.15 Systematic errors of the $\pi^{-}$cross-section that is produced by pioncarbon interactions at $58 \mathrm{GeV}$ energy. . . . . . . . . . . . .

6.16 Systematic errors of the $\pi^{-}$cross-section that is produced by kaoncarbon interactions at $58 \mathrm{GeV}$ energy. . . . . . . . . . . . .

6.17 Systematic errors of the $\pi^{-}$cross-section that is produced by protoncarbon interactions at $58 \mathrm{GeV}$ energy. . . . . . . . . . . . 
6.18 Systematic errors of the $\boldsymbol{p}$ cross-section that is produced by pioncarbon interactions at $58 \mathrm{GeV}$ energy. . . . . . . . . . . .

6.19 Systematic errors of the $\boldsymbol{p}$ cross-section that is produced by protoncarbon interactions at $58 \mathrm{GeV}$ energy. . . . . . . . . . . .

7.1 These are $\pi^{+}$cross section graphs that are created using impact of $p, K,{ }^{+} \pi^{+}$beams on a carbon target at $58 \mathrm{GeV}$ energy with respect to angle bins. The momentum bins can be found at the top right of each graph.

7.2 These are $\pi^{-}$cross section graphs that are created using impact of $p, K,{ }^{+} \pi^{+}$beams on a carbon target at $58 \mathrm{GeV}$ energy with respect to angle bins. The momentum bins can be found at the top right of each graph. . . . . . . . . . . . . . . . .

7.3 These are $p$ cross section graphs that are created using impact of $p$, and $\pi^{+}$beams on a carbon target at $58 \mathrm{GeV}$ energy with respect to angle bins. The momentum bins can be found at the top right of each graph. . . . . . . . . . . . . . . . .

7.4 These are $\pi^{ \pm}$, and $p$ cross section graphs that are created using impact of $\pi^{+}$beam on a carbon target at $58 \mathrm{GeV}$ energy with respect to momentum bins. The angle bins can be found at the top left of each graph.

7.5 These are $\pi^{ \pm}$cross section graphs that are created using impact of $K^{+}$ beam on a carbon target at $58 \mathrm{GeV}$ energy with respect to momentum bins. The angle bins can be found at the top left of each graph. . .

7.6 These are $\pi^{ \pm}$, and $p$ cross section graphs that are created using impact of $p$ beam on a carbon target at $58 \mathrm{GeV}$ energy with respect to momentum bins. The angle bins can be found at the top left of each graph. . . . . . . . . . . . . . . .

7.7 These are $\pi^{+}$cross section graphs that are created using impact of $p$, $K,^{+}$and $\pi^{+}$beams on a carbon target at $58 \mathrm{GeV}$ energy with respect to momentum bins. The angle bins can be found at the top right of each graph. . . . . . . . . . . . . . .

7.8 These are $\pi^{-}$cross section graphs that are created using impact of $p$, $K,^{+}$and $\pi^{+}$beams on a carbon target at $58 \mathrm{GeV}$ energy with respect to momentum bins. The angle bins can be found at the top right of each graph. . . . . . . . . . . . . . . .

7.9 These are $p$ cross section graphs that are created using impact of $p$, and $\pi^{+}$beams on a carbon target at $58 \mathrm{GeV}$ energy with respect to momentum bins. The angle bins can be found at the top right of each graph. . . . . . . . . . . . . . . .

$7.10 \pi^{-} / \pi^{+}$ratio is extracted from $\pi^{+}$beam interactions on a carbon target at $58 \mathrm{GeV}$ energy. . . . . . . . . . . . . . .

$7.11 \pi^{-} / \pi^{+}$ratio is extracted from $K^{+}$beam interactions on a carbon target at $58 \mathrm{GeV}$ energy. . . . . . . . . . . . . . . .

$7.12 \pi^{-} / \pi^{+}$ratio is extracted from $p$ beam iinteractions on a carbon target at $58 \mathrm{GeV}$ energy. . . . . . . . . . . . . . . . . . . . 


\section{CHAPTER 1 INTRODUCTION}

Research on hadronic interaction is the main goal of the Main Injector Particle Production (MIPP or FNAL E907) [24] experiment, which is targeted to produce high statistics on hadron production. The MIPP experiment allows a study of entire particle identification with all hadronic interactions. This study contributes to knowledge of the hadronic particle production process.

The MIPP experiment used the $120 \mathrm{GeV}$ Main Injector (MI) proton beam as a primary source to collect data on several nuclear targets for hadronic particle production. This combination of several nuclear targets and different beam energies assists the MIPP in investigating its physics interests. These are particle physics, nuclear physics, and service measurement. Obtaining unbiased high statistics data with complete particle identification coverage for hadron interactions, studying nonperturbative QCD hadron dynamics, scaling laws of particle production, investigating light meson spectroscopy, and searching for glueballs are included in the particle physics interests of this experiment. On the nuclear physics side, strangeness production, nuclear scaling, and propagation of flavor through nuclei are studied. The experiment further aims to provide data to determine NuMI \& atmospheric neutrino fluxes, improve shower models in MARS [22], Geant4 [15], and obtain similar hadronic shower simulations.

Achieving statistically significant results about produced hadrons is useful for estimating neutrino flux. Some other experiments collect data with the aim of observing the neutrino flux through their experimental setup. The MINOS(Main

Injector Neutrino Oscillation Search) [1] experiment is one of the neutrino flux experiments which uses the MI beam at Fermi National Accelerator Laboratory (FNAL). This experiment's beam source is exactly the same as MIPP's, and it creates neutrino particles by using this beam on the NuMI [2] target. These cross 
section measurements on the carbon target will contribute to the estimation of the number of produced neutrinos.

Using a $120 \mathrm{GeV}$ MI proton beam, the MIPP also collected data with the NuMI target. The NuMI target is a $0.64 \mathrm{~m}$ long water-cooled graphite rod, 8 interaction-lengths long, that is used to create a neutrino beam for the MINOS experiment. In this work, the cross section measurement at $58 \mathrm{GeV}$ secondary beam energy on the thin carbon target is presented. The reason to choose this target is based on structure of the NuMI target, which is made out of carbon. In principle, if we knew the cross section of the microscopically thin carbon at all beam energies, we would not need to measure the cross sections on the NuMI target. Using these cross section measurements, we can model complex structure targets. When the hit occurs at $120 \mathrm{GeV}$ energy, we most often have newly produced particles and nuclear fragments with energy around $58 \mathrm{GeV}$. After that, we can continue modeling this cascade of interactions progressively to lower energies. At the end, most of the neutrinos are produced by particles that have $5 \mathrm{GeV}$ or less energy. At first, 58 GeV energy interactions should be modeled correctly, then we can proceed to the next step. Therefore, cross sections on thin carbon with $58 \mathrm{GeV} \pi^{ \pm},\left(K^{ \pm}\right)$, and $p \bar{p}$ beam species are measured that give us a good understanding of the produced particles at this energy. The MIPP was supposed to have $58 \mathrm{GeV}$ There have been no previous measurements of these cross sections.

The following chapters will explain what we need to do and how we achieved these measurements. A brief description of the MIPP experiment and detector spectroscopy is explained in chapter 2. The experiment beam line and target information is given in chapter 3 . In chapter 4, working principles of the MIPP trigger system and data acquisition system are described. The event reconstruction process is presented in chapter 5. Finally, cross section measurements can be found in chapter 6 with analysis results. 


\section{CHAPTER 2 \\ THE MIPP EXPERIMENT AND DETECTORS}

\subsection{The MIPP Experiment}

The MIPP is a fixed target experiment located in the Meson Center (MC) area at Fermi National Accelerator Laboratory (FNAL). The MIPP, with its four particle ID detectors, is capable of identifying charged particles whose energies are between $0.5 \mathrm{GeV}$ and $100 \mathrm{GeV}$ [20]. In addition to these particle ID detectors, there are four Drift Chambers (DC1, DC2, DC3, and DC4), two Iowa Multi-Wire Proportional Chambers (MWPC1, and MWPC2) [10] and two calorimeters. All detectors are explained in detail in the following sections.

The MIPP experiment has a number of detectors, shown in Figure 2.1, that are capable of tracking and identifying charged particles via its readout electronics system, Table 2.1. The experimental target of the MIPP is located upstream of the Time Projection Chamber (TPC) detectors. The TPC is able to reconstruct tracks in three dimensional at a very low momentum. The Jolly Green Giant (JGG) and ROSIE analyzing magnets, with their vertically opposite magnetic field direction, are the two magnets of the experiment. The four drift chambers (DCs) and the two multi wire proportional chambers (MWPCs) are used for high-momentum charged particle tracking.

The experiment utilizes four types of detectors to identify charged particles at various momenta. The momentum ranges for particle identification (PID) are 1 $\mathrm{GeV} / \mathrm{c}$ and below with TPC, $1-3 \mathrm{GeV} / \mathrm{c}$ by time of flight wall (TOF), 3-17 GeV/c with threshold Cherenkov (CKOV), and $20-80 \mathrm{GeV} / \mathrm{c}$ in ring imaging Cherenkov (RICH) detectors. The MIPP also has two subsystems, electromagnetic (EMCAL), and hadron (HCAL) calorimeters, to identify neutral particles, gamma rays, and electrons. This experiment's results will contribute to other experiments. 


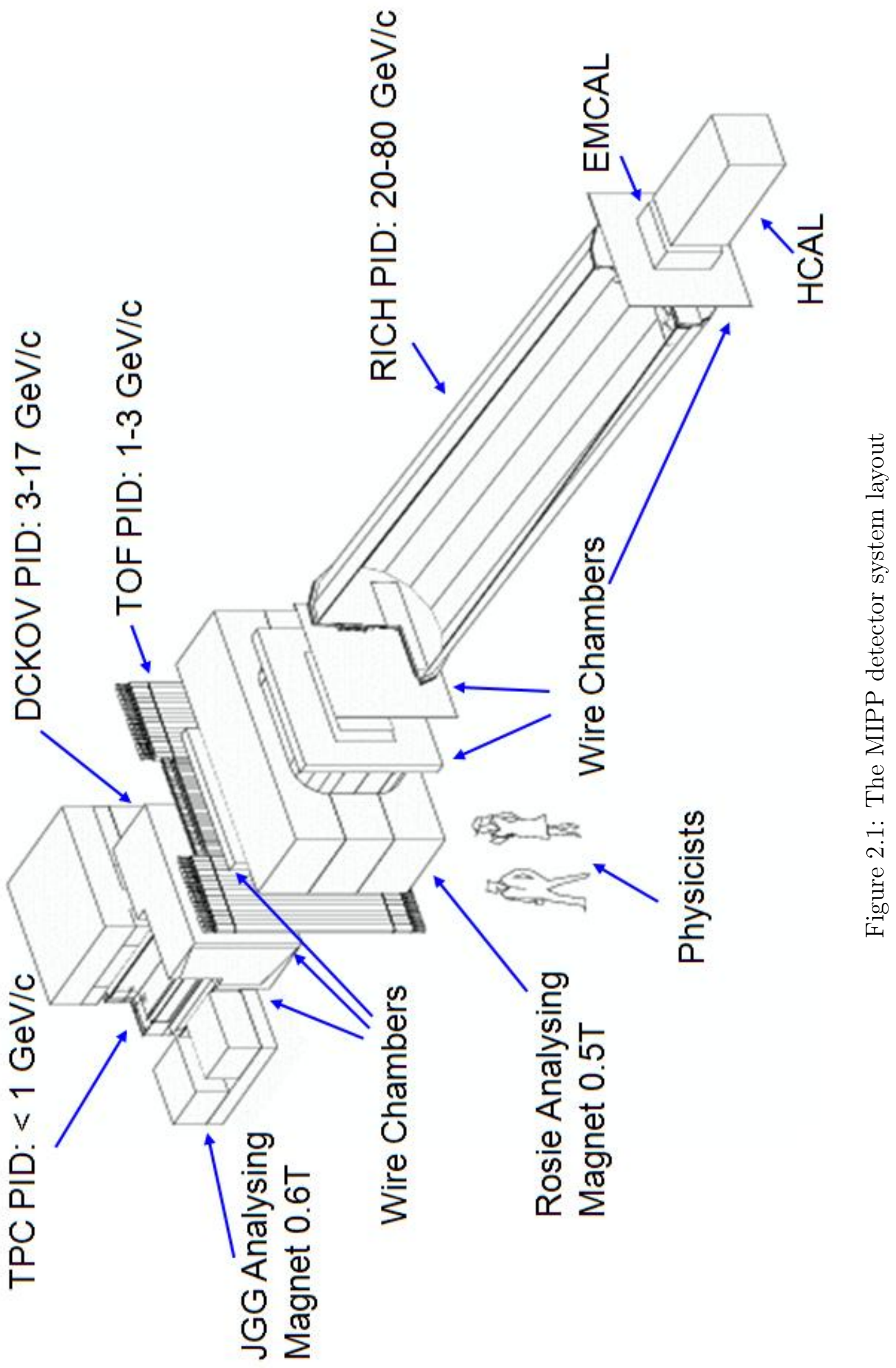


Table 2.1: The MIPP detector system's electronics modules list

\begin{tabular}{|l|l|}
\hline Detector & Module \\
\hline BC1-3 & LRS 4291 TDC \\
\hline BCKV & LRS 4300 ADC \\
\hline DC1-4 & LRS 4291 TDC \\
\hline DC56 & RMH TDC \\
\hline TPC & Clock Module \\
\hline & LRS 4291 \\
\hline CKOV & LRS 4300 \\
\hline & LRS 2229 \\
\hline TOF & LRS 4300 \\
\hline RICH & VME Latch \\
\hline HCAL & LRS 2249 \\
\hline ECAL & \\
\hline
\end{tabular}

\subsection{Beam Chambers (BC) and Beam Čherenkov (BCkov)}

There are three beam chambers and two beam Čherenkov [5] cylindrical radiators upstream of the experimental target. These detectors' purpose is to identify secondary beam particle species: kaon, pion, and proton. While BC detectors are filled with $C_{4} F_{10}$ or nitrogen, MIPP uses $C_{4} F_{8} O$ or nitrogen for the beam Čherenkov radiators. Beam chambers allow tracking of the beam particle that are aligned with each side of the beam Čherenkov, (Figure 2.2). Each beam Čherenkov vessel consists of a head and two photomultiplier (PMT) tubes. When the beam passes through the BCkovs, Čherenkov Radiation (CR) occurs, which means there is emission of 
Čherenkov light. There is a focusing mirror inside the head which reflects the radiated light towards a PMT that is covered by a second mirror. The second mirror has a hole that allows the inner PMT to catch the light at certain angles. The light that is emitted at large angles is reflected towards the outer PMT.

We can set the pressure of gas inside the BCkov detectors by using a MIPP slow monitoring computer. In the first BCkov, the kaon and pion beams can be identified. When the gas pressure is set to its required value for kaons, Čherenkov light focuses onto the inner PMT. At the same energy, the light emitted by a pion beam at a large angle is reflected by a second mirror and focused onto the outer PMT.

Likewise, the density of the second BCkov can be set to send all proton beam Čherenkov light onto the inner PMT. At large angles, but less than $30 \mathrm{mrad}$, pion beam Čherenkov light is caught by the outer PMT.

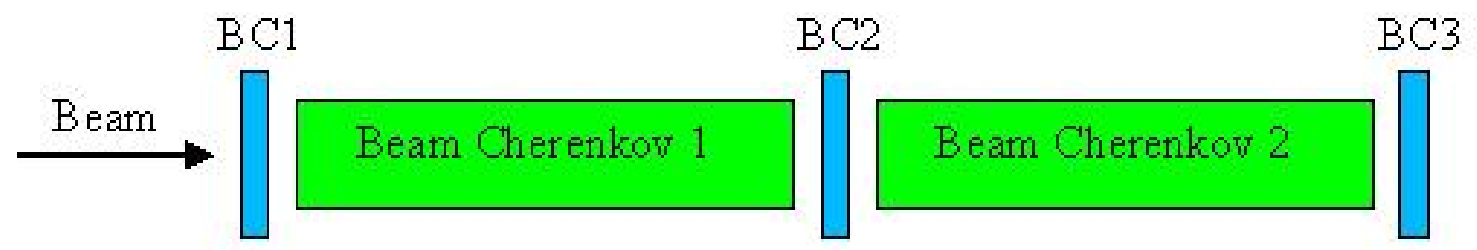

Figure 2.2: Beam Čherenkov detectors system layout

\subsection{Drift Chambers}

Four drift chambers are in use to track produced particles, (Figure 2.3). Three are located between the MIPP's magnets JGG and ROSIE, and the other is located downstream of the ROSIE magnet. All drift chambers have four planes of sense wires. Although DC1 has 512 wires on each plane, DC2, DC3, and DC4 have 512 wires on the first and third planes, and 448 wires on the second and fourth planes. 
All chambers are filled with "magic gas" which is a mixture of $82 \%$ argon, $15 \%$ isobutane, and 3\% methyl-al.

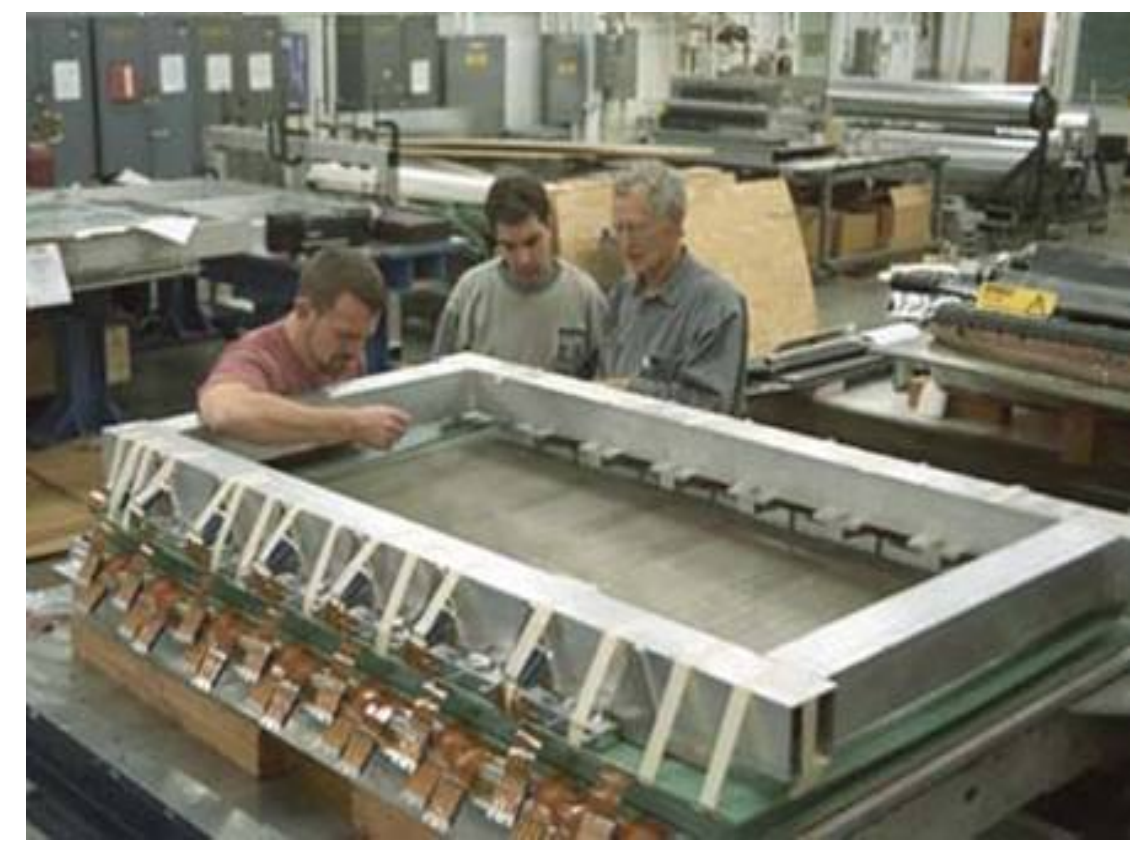

Figure 2.3: MIPP experimenters are working on one of the MIPP's drift chamber.

\subsection{Multi-Wire Proportional Chambers}

Iowa MWPCs were constructed at CERN in the 1970s. These chambers were used in the NA24 experiment at CERN and in the SELEX experiment at FNAL where MIPP inherited them. There are four Iowa MWPCs available to use in the MIPP experiment. Two of them are held as spare detectors and the other two are located both upstream and downstream of the RICH detector to track charged particles, (Figure 2.4).

All chambers have four anode wire planes, which consist of 640 wires. Those planes are aligned vertically, horizontally, and slanted \pm 28.07 degrees with respect to a vertical axis. A gas mixture of $80 \%$ argon and $20 \% \mathrm{CO}_{2}$ is used to get ionized electrons. 


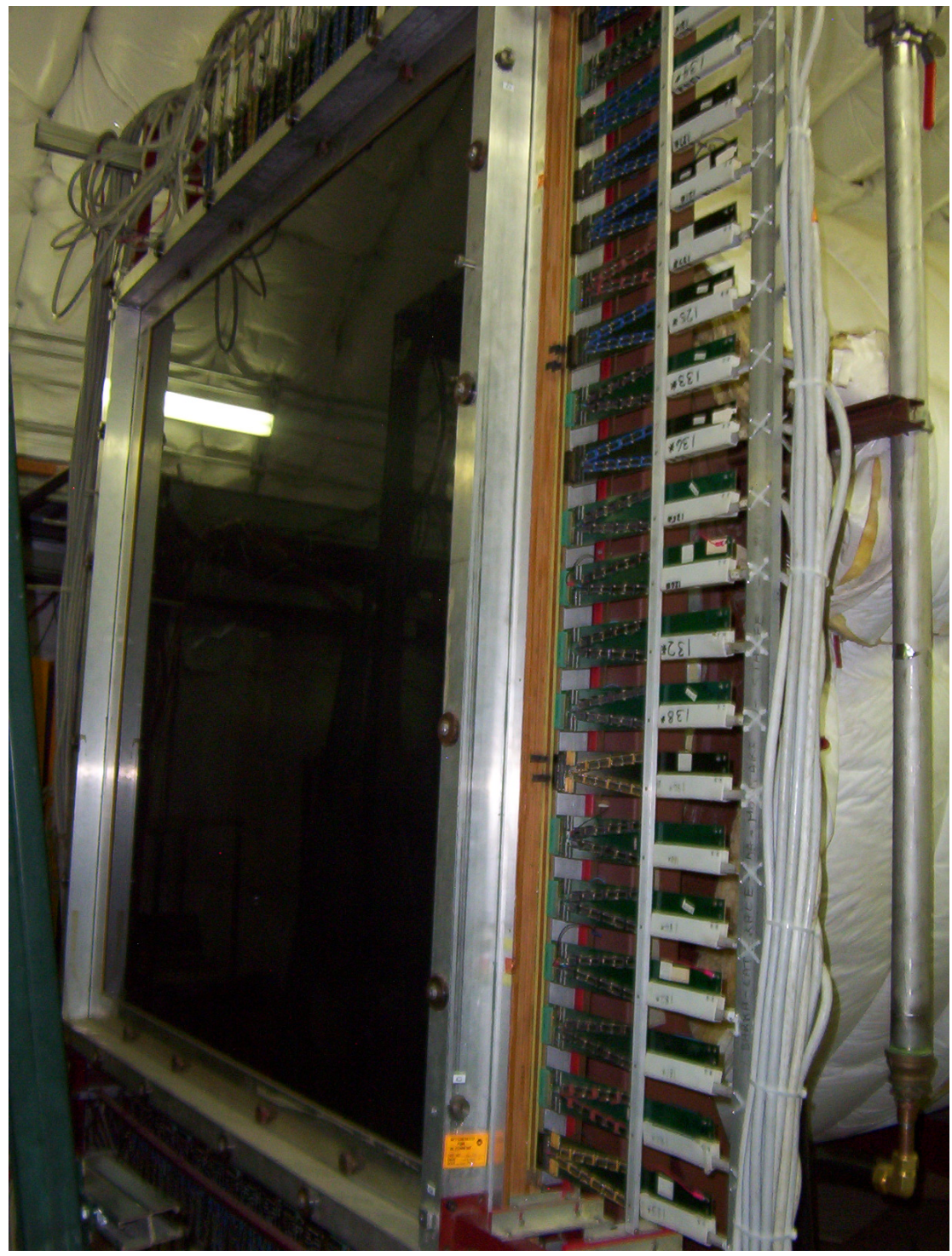

Figure 2.4: Iowa Multi-Wire Proportional Chamber 6 is located downstream of the RICH detector. 
RMH [16] electronics, which were also constructed at CERN when the chambers were created, are used as a readout system,. The RMH electronics are composed of RMH modules, the Crate Encoder (CE), the Control Unit (CU), the Branch Receiver (BR), the System Encoder (SE), and the Interface (IF) unit, (Figure 2.5). The RMH [4] modules, CE and CU, are housed in the same crate. Unlike the other modules, the CE has two connectors in the front face to allow a daisy chain connection with other crates. The last crate is connected to the CAMAC crate, which sends the data to the DAQ.

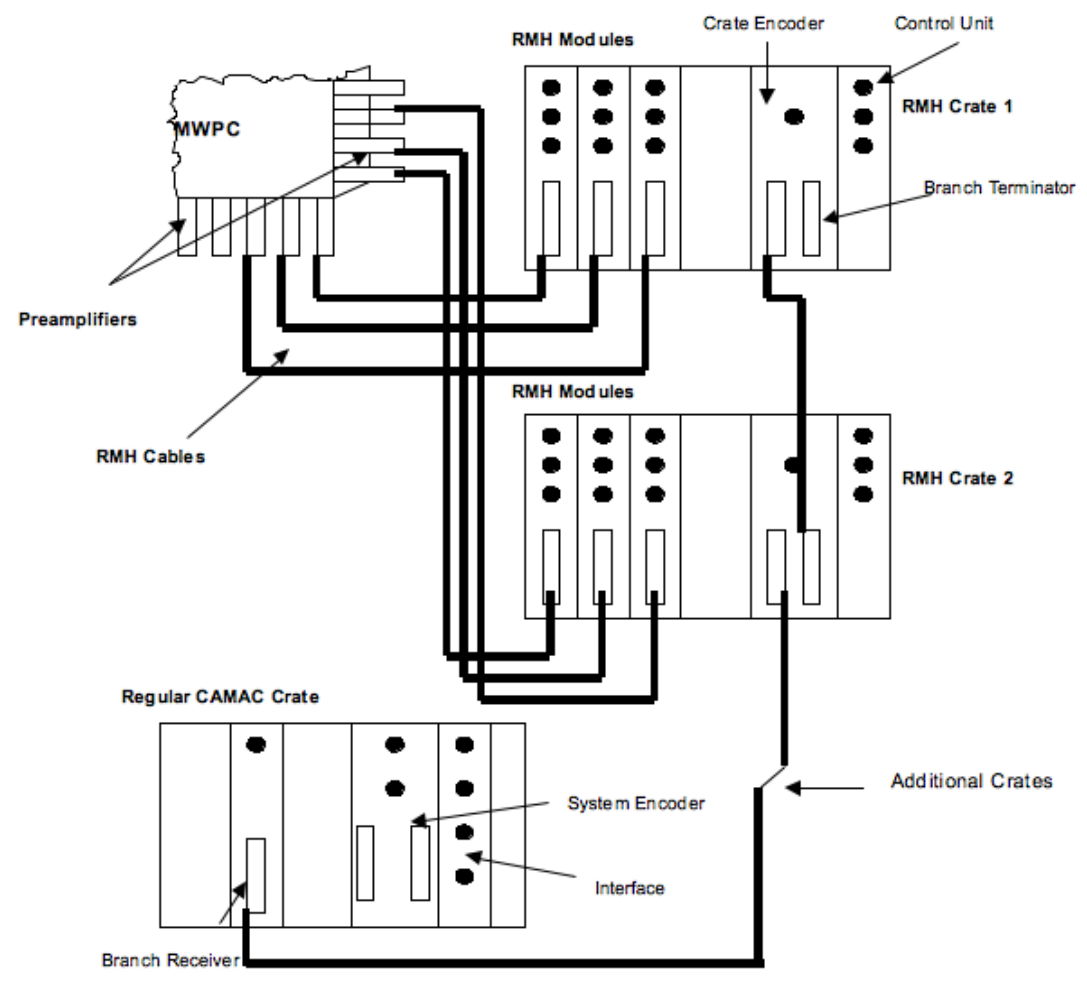

Figure 2.5: Layout of the RMH system that is used for MWPCs' readout in the MIPP experiment. 


\subsection{Time Projection Chamber}

The Time Projection Chamber (TPC) is the most sophisticated detector in the FNAL E907 experiment with two aspects to its capabilities, (see Figure 2.6). Those aspects are three dimensional (3D) tracking and particle identification of the low momentum charged particles. Looking at 3D tracks makes our analysis more effective. The TPC is filled with a 90\% argon and $10 \%$ methane gas mixture at atmospheric pressure. The TPC was used in the EOS experiment at the Bevalac $[6$, $18,9,3,23,7]$ where it was constructed by Lawrence Berkeley National Laboratory (LBL). The TPC is placed inside the 0.7 Tesla JGG magnet, just downstream of the experimental target. Because of the magnetic field, the trajectories of the charged particles are bent according to their charged types. The TPC can identify charged particles with momentum below $1 \mathrm{GeV} / \mathrm{c}$.

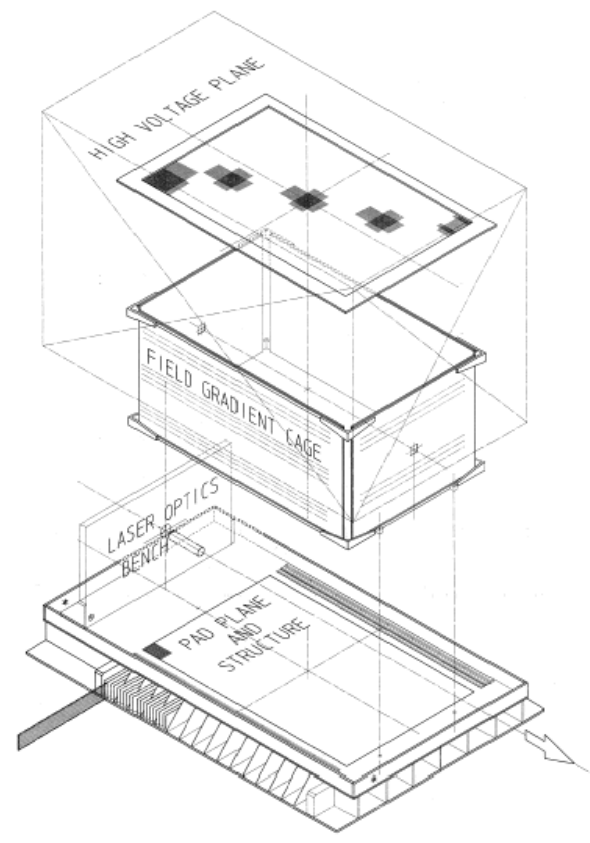

Figure 2.6: Time Projection Chamber 3D schematic picture [6]

Particles that are produced in the target pass through the gas, and while being bent by the magnetic field, they ionize the gas. Between the top and bottom of the 
TPC and parallel to JGG's magnetic field, a $10 \mathrm{kV}$ electric field makes ionization electrons drift down to ground wires while ions are drifting up. Ground wires are spaced widely, and below the ground wires there are anode wires. Between the ground and anode wires, a strong electric field is applied which causes immediate acceleration. At the bottom, an avalanche of electrons is accumulated on the anode wires rather than drift. Then, due to this accumulated charge, an image charge takes place on the TPC copper-readout pads which are $4 \mathrm{~mm}$ below the anode wires, (see Figure 2.7). These image charges are digitized by readout electronics and then sent to a Data Acquisition(DAQ) system which writes data to storage tapes. In order to avoid unwanted drifts, a gating grid that is slightly above the ground wires and in the drift region becomes switched on when no event is triggered.

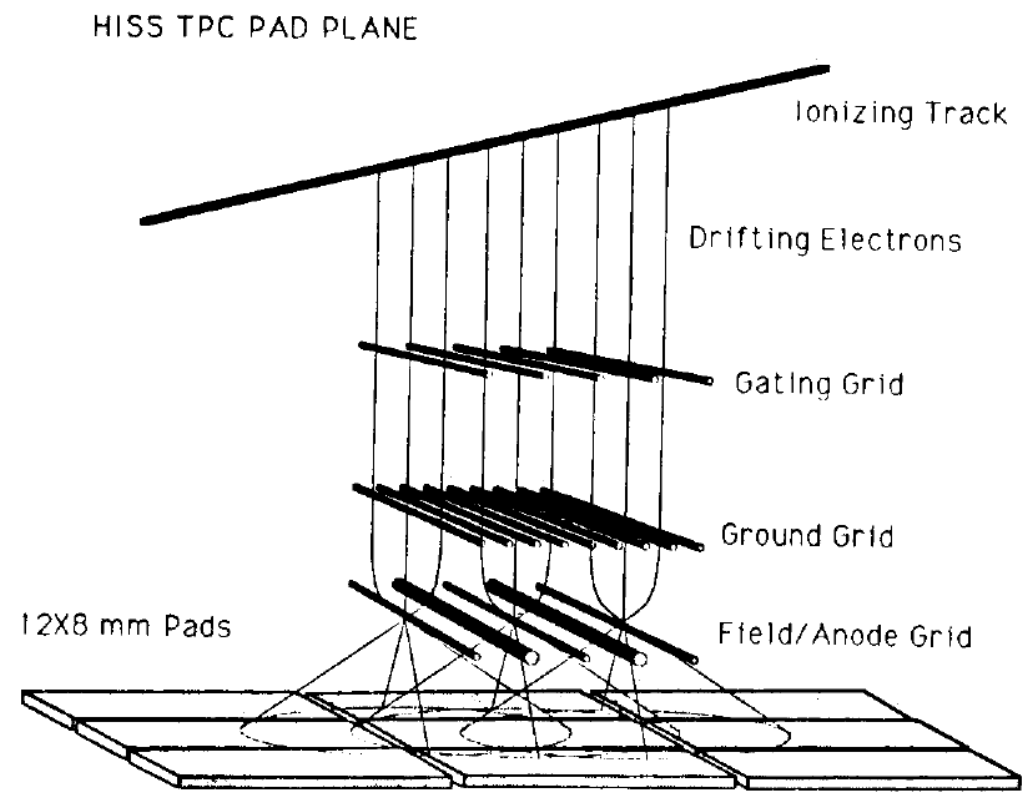

Figure 2.7: TPC wire system layout [6] 


\subsection{Threshold Čherenkov}

The Threshold Čherenkov (Ckov) has 96 toroidal mirrors positioned to focus Čherenkov light, and 96 photo multiplier tubes (PMTs) that are located at the top and bottom of the chamber, (Figure 2.8). Ckov uses $C_{4} F_{10}$ gas to get Čherenkov Radiation (CR). Threshold levels of pion, kaon, and proton species are 2.6, 8, and $17 \mathrm{GeV} / \mathrm{c}$ respectively at atmospheric pressure.
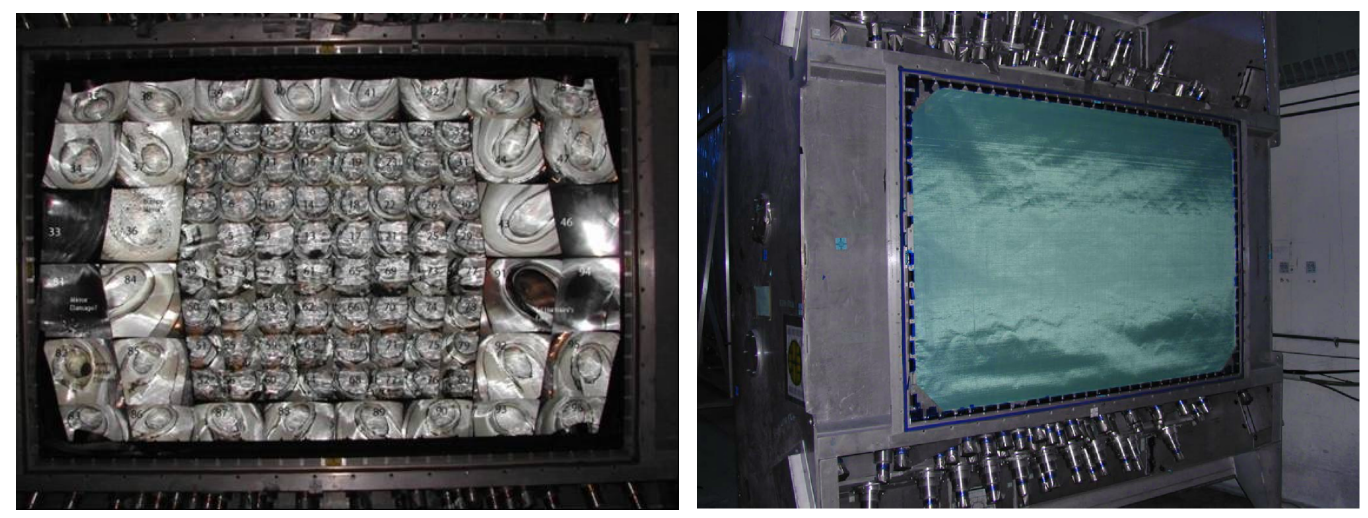

Figure 2.8: Threshold Čherenkov Detector and its Toroidal Mirrors

\subsection{Beam Time of Flight}

The Beam time of flight detectors consist of T01, TBD, and T00 scintillator counters which are placed between upstream of the experimental target and downstream of the secondary beam line collimators. The purposes of the scintillator counters are forming beam trigger signals, determining pileups, providing a start time for ToF wall, and distinguishing incoming beam particles at very low momenta (lower than $10 \mathrm{GeV} / \mathrm{c}$ ).

Basically, each scintillator counter has four Hamamatsu R5900U PMTs on each side. Although T00 and T01 have light guides which make better timing resolution, TBD does not have any light guides, so TBD is not used for measuring 
the time of flight of beam particles.

\subsection{Time of Flight Wall}

The Time of Flight Wall (TOF) detector is located upstream of the ROSIE magnet. This detector is implemented as vertical bars because the magnetic field bends particles in the horizontal plane. The TOF wall consists of $543-\mathrm{m}$ long vertical scintillator bars, and its horizontal width is $3.5 \mathrm{~m}$. Forty $5 \times 5 \mathrm{~cm}$ bars cover the central $2 \mathrm{~m}$, and fourteen $10 \times 10 \mathrm{~cm}$ bars cover the wings which are placed upstream and outside of the ROSIE magnet. In oder to collect light, the top and bottom ends of the bars have Hamamatsu R5900U PMTs that are identical with beam counters.

At most, one particle track hits the given bar. Beam counters are used for time reference of the incident particles. That is, TOF is triggered when the hit happens at the target position. Then, as a particle crosses one of the TOF bars, the PMTs catch scintillation light that provides a stop signal for the TDC. The velocity of the particle is calculated from the track length and the time of flight. TOF is also able to measure particle momentum from curvature in tracking. Measuring the $\beta$ value and the momentum of the particle, the mass of the particle can be computed giving us particle identification. TOF identifies produced charged particles in the 1-3 GeV/c momentum band.

\subsection{Ring Imaging Čherenkov}

The Ring Imaging Čherenkov (RICH) detector is refurbished from the SELEX $[12,13,8]$ experiment and is composed of a low carbon radiator vessel $10.22 \mathrm{~m}$ in length, $2.4 \mathrm{~m}$ in diameter, with a 0.5 inch wall and a $32 \times 89$ array of 0.5 inch of PMTs, (Figure 2.9). The RICH detector is at the downstream ROSIE magnet which bends particles back inwards. The RICH can identify all three species of 
charged particles for momenta between $20 \mathrm{GeV} / \mathrm{c}$ and $80 \mathrm{GeV} / \mathrm{c}$. The RICH vessel is filled with $\mathrm{CO}_{2}$ at room temperature and at a pressure such that the index of refraction causes Čherenkov radiation to produce light for the high momentum particle threshold. Rather than measuring the threshold, we can measure the ring diameter itself.

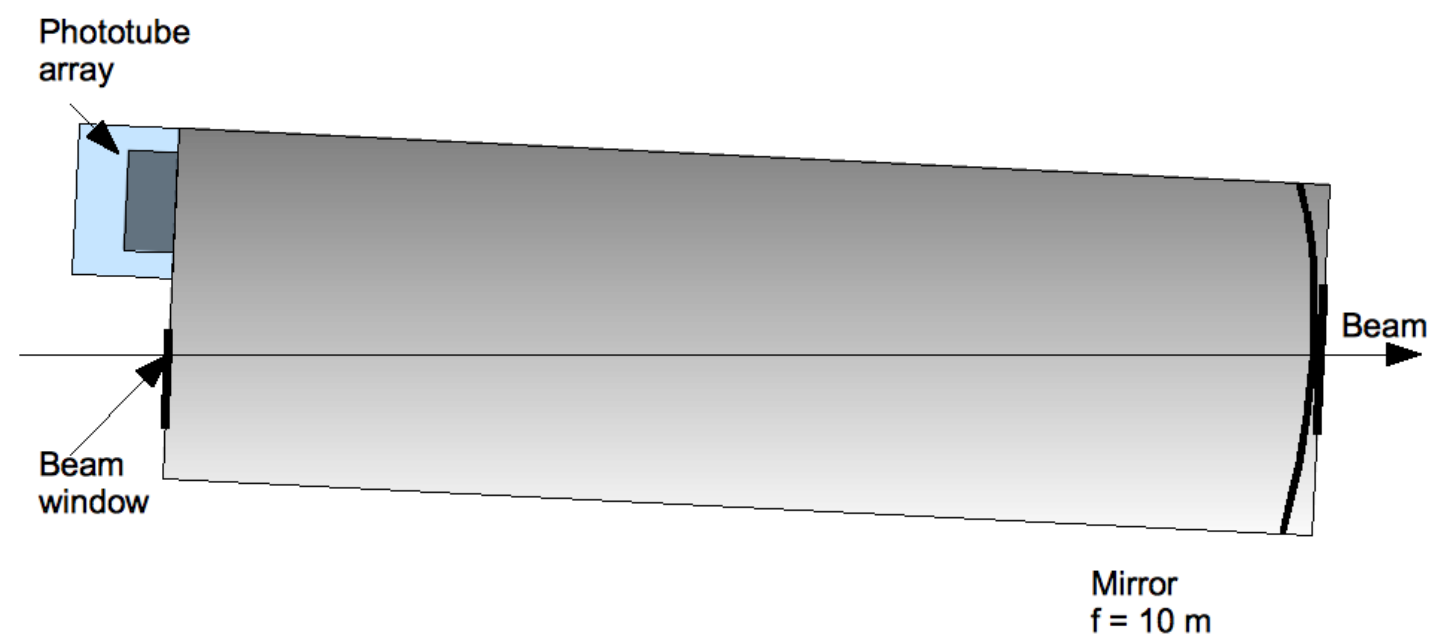

Figure 2.9: The RICH detector schematic side view

The RICH is tilted $2.4^{\circ}$ to make particles pass through the RICH front window. As a charged particle is passing through the RICH volume, light is emitted at certain angles. There are sixteen hexagonal spherical focusing mirrors at the bottom downstream side of the RICH which reflect light back onto an array of 3000 PMTs. Some of the PMTs are missing due to a fire incident during the commissioning run in summer 2004. Each 0.5 inch phototube is one pixel and we image using these 3000 PMTs to see rings and fit the ring radius. Due to the optics, the opening angle translates to the ring radius. 


\subsection{Electromagnetic and Hadron Calorimeters}

The purpose of the MIPP calorimeters is to measure the production of forwardgoing neutrons and photons [11]. Due to this goal, both EMCAL and HCAL detectors are located at the end of the detector system, just after the MWPC6, (Figure $2.10)$.

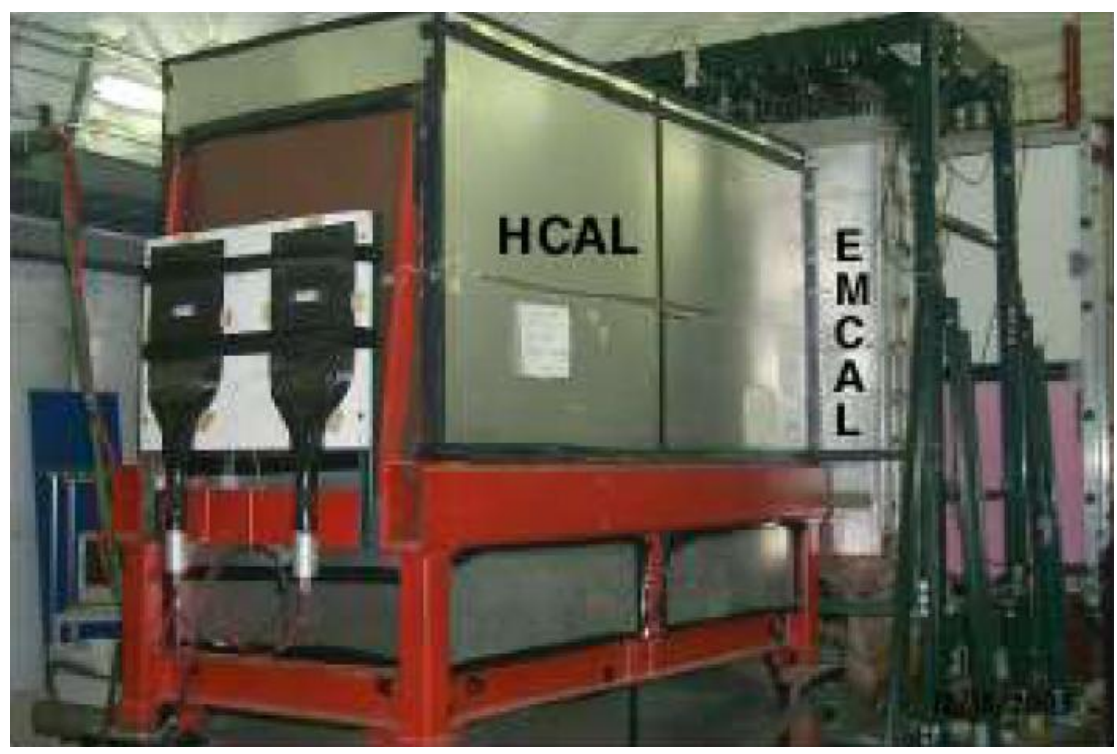

Figure 2.10: The MIPP calorimeters, HCAL and EMCAL were used for neutral particles.

EMCAL consists of 10 layers of 5.08 mm-thick lead plates which are interspersed with planes of gas proportional chambers. The chambers use a mixture of $76.6 \%$ argon, $8.5 \%$ methane and $15 \% \mathrm{CF}_{4}$. This detector's active area is $1.6 \mathrm{~m}$ wide, $1.5 \mathrm{~m}$ high, and $0.3 \mathrm{~m}$ in the beam direction.

The HCAL is composed of 64 layers of $24.1 \mathrm{~mm}$ iron plates that are interspersed with $5 \mathrm{~mm}$ thick scintillators. Its active area is $0.99 \mathrm{~m}$ wide, $0.98 \mathrm{~m}$ high, and $2.4 \mathrm{~m}$ in the beam direction. 


\subsection{Analysis Magnets}

The MIPP spectrometer contains two dipole magnets, each having a vertical magnetic field in opposite directions. The Jolly Green Giant(JGG) magnet (Figure 2.11), which was built by Harvard University, has given long term service, over 40 years, in particle physics experiments. The JGG analysis magnet covers the TPC detector downstream of the experimental target. One of the other analysis magnet is ROSIE, which is located downstream of the ToF detector. While the JGG has a $0.7 \mathrm{~T}$ magnetic field at the $+\mathrm{y}$ direction, the ROSIE has a $0.6 \mathrm{~T}$ magnetic field at $-\mathrm{y}$ direction. When the produced particles are passing through the TPC volume, the JGG affects charged particles by its magnetic field and all charged particles are bent with respect to their signs. After that, the ROSIE magnet works as a focusing magnet to bend particles back along the beam axis.

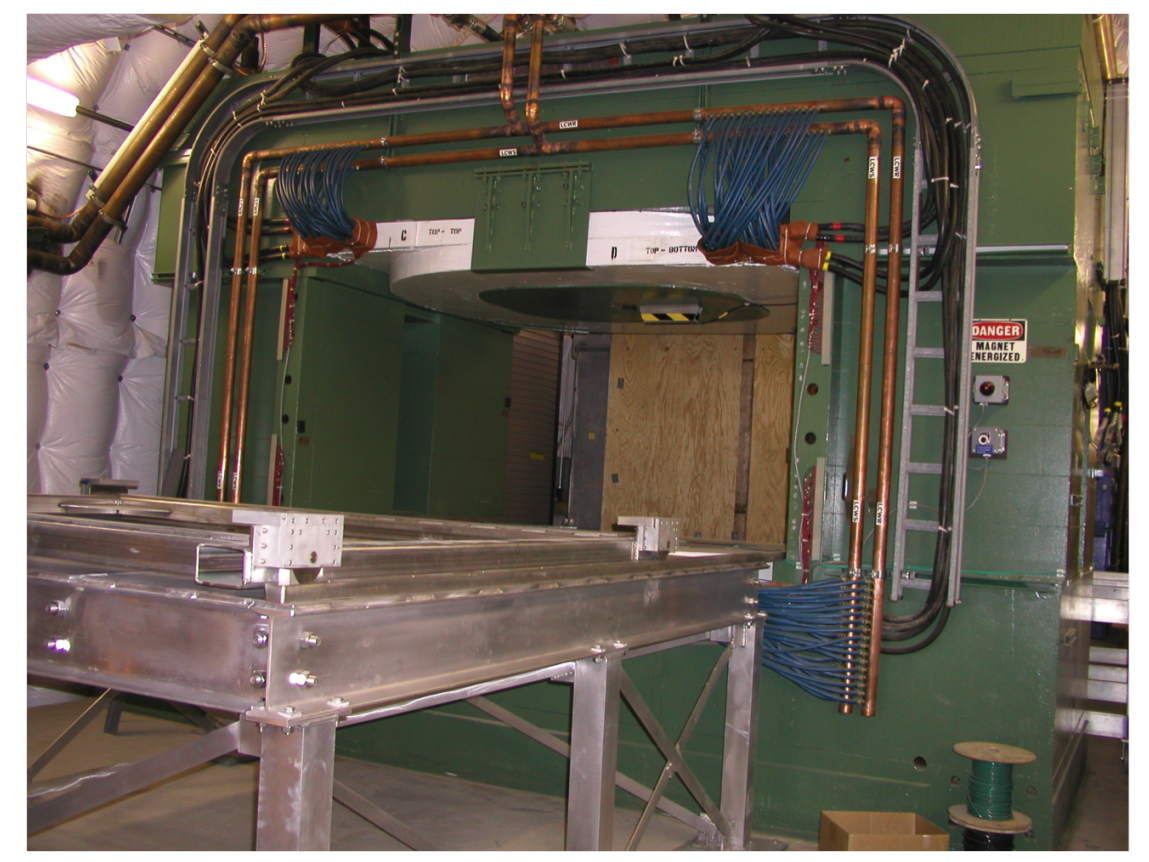

Figure 2.11: Jolly Green Giant analysis magnet creates $0.7 \mathrm{~T}$ magnetic field to bend charge particles inside the TPC volume. 


\section{CHAPTER 3 \\ THE MIPP BEAMLINE AND TARGETS}

The MIPP experiment acquires the desired particle beam directly from the FNAL Main Injector. The $120 \mathrm{GeV} / \mathrm{c}$ primary beam, a proton beam, comes to the experimental area passing through the Meson Center beamline, (Figure 3.1). To get particles at lower momenta and other particle species, the primary beam hits the copper target before arriving at the MIPP experiment hall. These extracted particles from the primary target beam are called the secondary beam. Using primary and secondary beams, MIPP collected data on several targets ranging from hydrogen to bismuth, (Table 3.1). Collection of data started in summer 2004 and ended in February 2006.

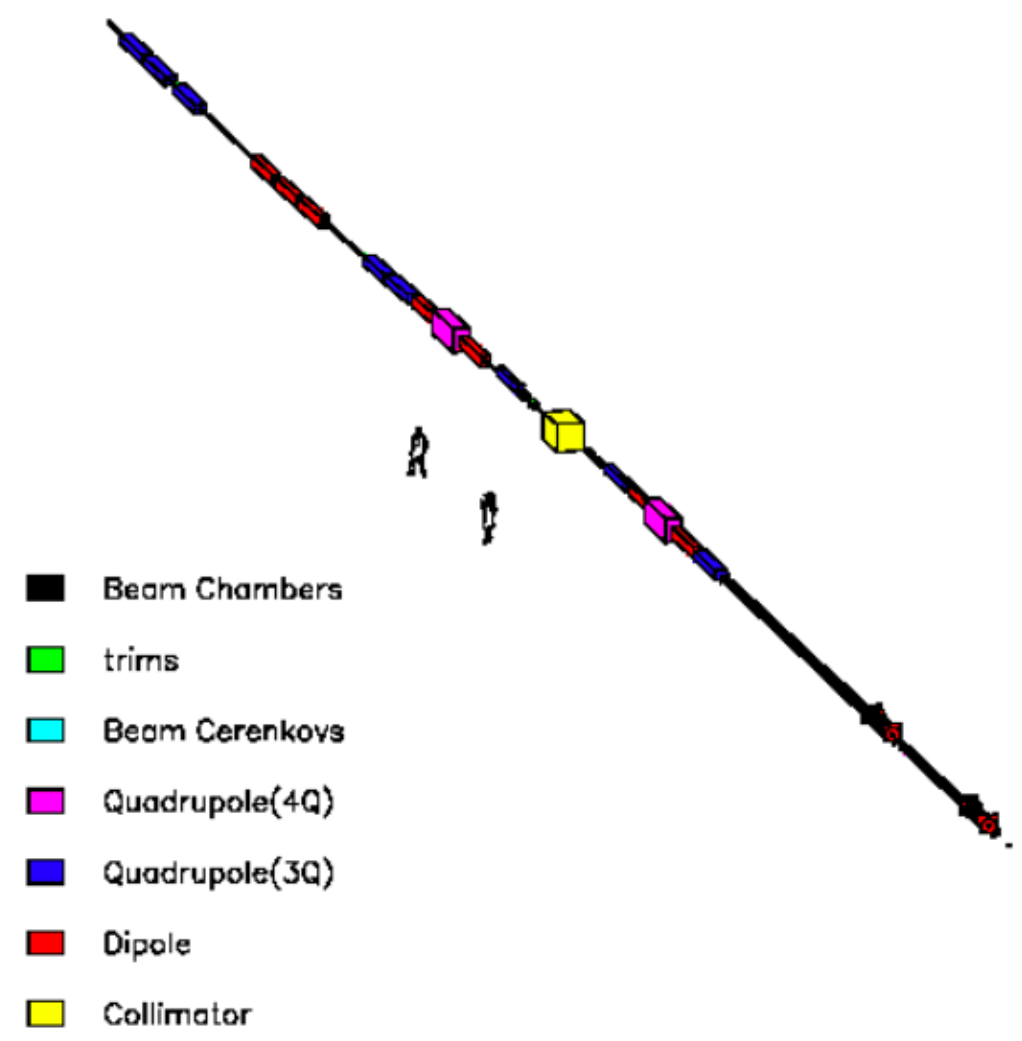

Figure 3.1: The view of the MIPP beamline 


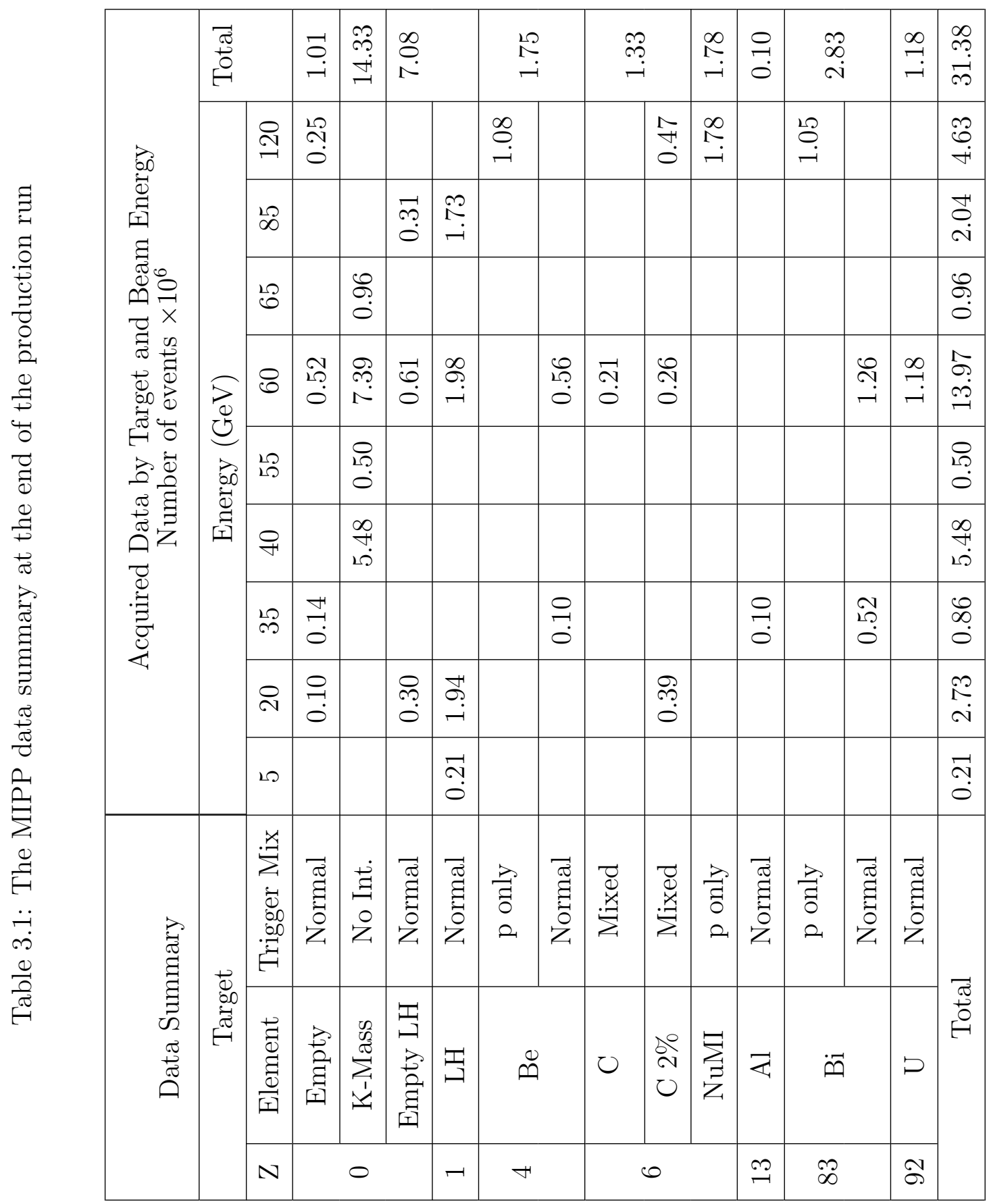


In the following sections are explanations of the MIPP beamline and the MIPP targets.

\subsection{The MIPP Beamline}

The MIPP beamline has two parts the beamline and the secondary beamline, (Figure 3.2). I studied cross sections at $58 \mathrm{GeV} / \mathrm{c}$ momentum, so I will give an explanation of how the MIPP experiment gets its secondary beam onto the experimental targets.

The $120 \mathrm{GeV} / \mathrm{c}$ Main Injector proton beam feeds the primary beamline directly. Then the primary beam is shaped by a focusing quadrupole doublet and adjustable collimators for collision with the primary target. Because of the TPC readout capability, it is not possible to operate TPC with more than $10^{5}$ particles per second. Usually, the Main Injector extracts a proton beam at about $10^{8}$ particles per second. So, the primary beam intensity must be lowered to the desired number. The desired primary beam intensity was accomplished by adjusting the primary optics and collimators through the primary beamline.

The secondary beamline tunes up the secondary beam particles that hit the MIPP experimental targets. So, well-focused primary beam particles hit a $0.5 \times 0.5 \times 20$ cm copper target (primary target) that is located $97 \mathrm{~m}$ upstream of the experimental target at the Meson Center area. This strike creates secondary beam particles at lower momenta which go through the quadrupole for focusing and the dipole for bending. After those steps, the desired beam momentum is selected via momentum collimators. The selected secondary beam heads toward the Beam Čherenkov chambers and vessels for particle species identification (see details in section 2.2). Then, the MIPP trigger system takes charged particles of the wanted beam type during the creation of the events at the target position. 


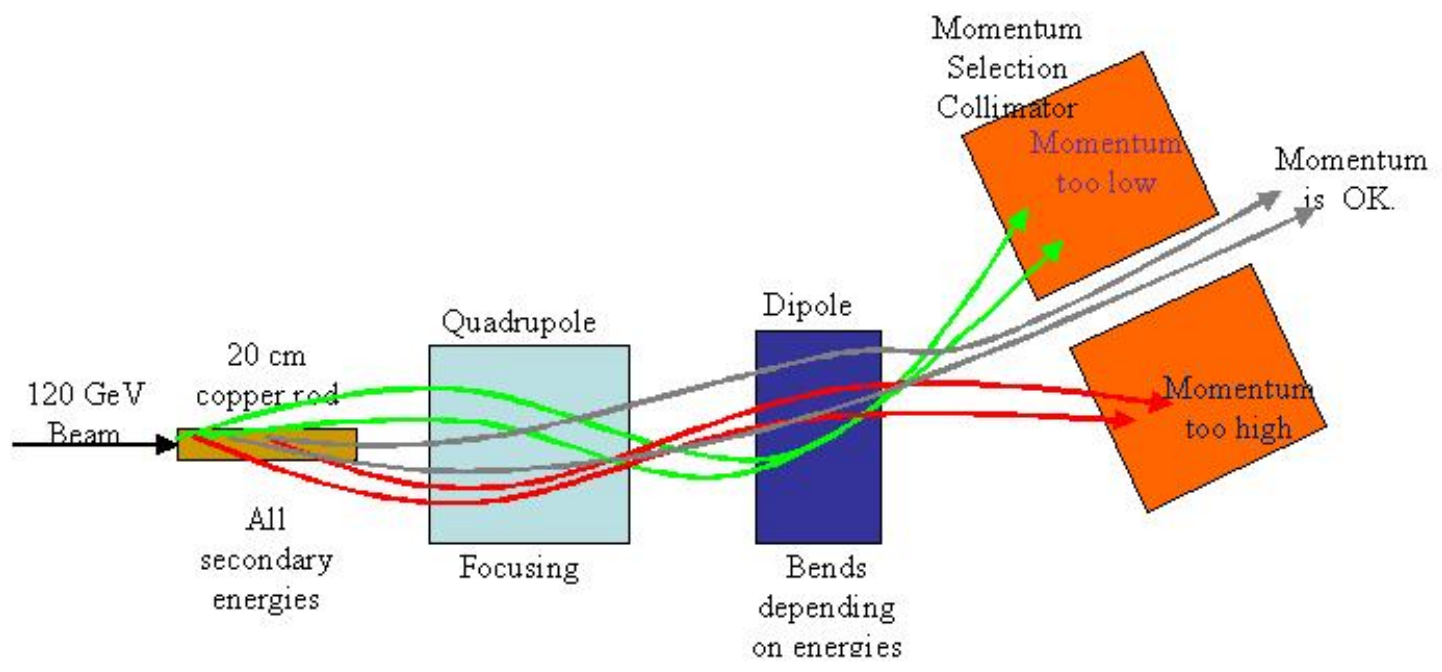

Figure 3.2: The MIPP beam line schema shows how secondary beam processed before it hit the experimental target.

\subsection{The MIPP Targets}

The MIPP experiment's targets can be categorized into three types. These are nuclear thin targets Table 3.2, cryogenic target (LH2), and NuMI target. Target selection was decided based on the purposes of the experiment's physics interests. One of the MIPP targets is the NuMI target, which contains aligned graphite matter. Studying the carbon target is useful for understanding particle production with the NuMI target. We also took data for the empty target (no target) to get and subtract background events. The MIPP's thin targets were placed in the target wheel (Figure 3.3), which could be controlled remotely from the MIPP ACNET computer. 


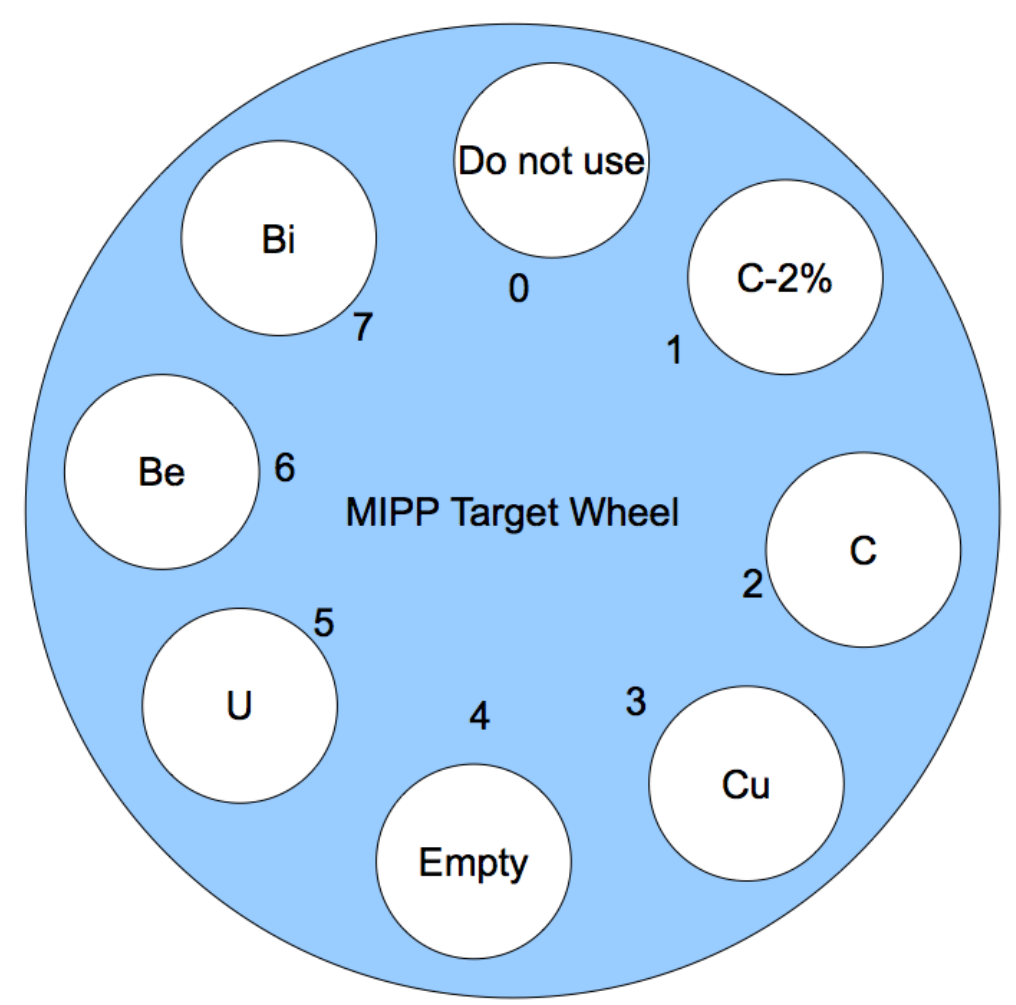

Figure 3.3: The MIPP's experimental thin targets are installed in a rotating wheel.

Table 3.2: The MIPP experimental targets list and their properties

\begin{tabular}{|l|c|c|c|c|c|}
\hline Material & Mass & Thickness & Areal & Interaction & Radiation \\
$(\mathrm{g})$ & $\mathrm{cm})$ & $\begin{array}{c}\text { Density } \\
\left(\mathrm{g} / \mathrm{cm}^{2}\right)\end{array}$ & $\begin{array}{c}\text { Length } \\
(\%)\end{array}$ & $\begin{array}{c}\text { Length } \\
(\%)\end{array}$ \\
\hline Beryllium & 14.4 & 0.399 & 0.710 & 0.94 & 1.1 \\
\hline Carbon & 16.6 & 0.498 & 0.819 & 0.94 & 2 \\
\hline Carbon $2 \%$ & 34 & 1.003 & 1.667 & 1.94 & 3.9 \\
\hline Bismuth & 34.25 & 0.173 & 1.69 & 0.87 & 27 \\
\hline Aluminum & 21.4 & 0.399 & 1.056 & 0.992 & 4.4 \\
\hline Silver & 62.6 & 0.294 & 3.088 & 3.15 & 31 \\
\hline Copper & 26.6 & 0.152 & 1.31 & 0.97 & 10 \\
\hline Uranium & 38 & 0.1 & 1.875 & & \\
\hline
\end{tabular}




\section{CHAPTER 4 \\ THE MIPP TRIGGER SYSTEM AND DATA ACQUISITION SYSTEM}

\subsection{The MIPP Trigger System}

Basically, triggers perform beam particle selection, particle identity tagging, and nuclear interaction selection. This performance is separated into two stages. First, the trigger determines the beam particle species, and then it looks to see if particle interacts with the target or not. In Table 4.1, trigger bit number 0 is an untagged beam particle, trigger bits numbers 4, 5, and 6 represent beam particle species, and trigger bits numbers 8, 9, and 10 correspond to three particle species, which intervene in an interaction. These seven physics trigger bits are used to complete two stages of the trigger system. The trigger process is complete in 250 ns after the incoming beam particle goes through the target.

The T00 and T01 scintillator counters, made of $1 \times 6 \times 6 \mathrm{~cm}$ quartz, are placed $60 \mathrm{~m}$ and $3 \mathrm{~m}$ upstream from the target, respectively. These time differences are also used to identify pions and kaons at the lowest momentum beam setting $(5 \mathrm{GeV} / \mathrm{c})$ outside the range of the $\mathrm{BCkOV}$. The scinteraction trigger is installed to make clear selection of the events. The detectors' read out system includes ACME light guides and four BC408 phototubes, one on each of the four sides.

\subsubsection{Beam Particle Identification}

Beam particle identification (PID) was done by the beam Čherenkov (BCkov1 and BCkov2) counters and the T00-T01 scintillator counters, (Figure 4.1). We separated the beam PID selection based on the incident beam momentum e.g. above $5 \mathrm{GeV} / \mathrm{c}$, above $20 \mathrm{GeV} / \mathrm{c}$, and above $35 \mathrm{GeV} / \mathrm{c}$. We achieved the last two momenta range beam PID by using BCkov1 and BCkov2 with their inner and outer PMTs. Beam particles have got a tag depending on their radiation angles inside the BCkovs 
Table 4.1: A summary of the MIPP experiment's trigger bits

\begin{tabular}{|c|c|}
\hline Trigger bit number & Name \\
\hline 0 & Beam Trigger \\
\hline 1 & T01 Trigger \\
\hline 2 & TBD Trigger \\
\hline 3 & ScIntLo $\times$ DC1Int \\
\hline 4 & Beam PID - Kaon Trigger \\
\hline 5 & Beam PID - Pion Trigger \\
\hline 6 & Beam PID - Proton Trigger \\
\hline 7 & NuMI trigger \\
\hline 8 & Kaon with Interaction \\
\hline 9 & Pion with Interaction \\
\hline 10 & Proton with Interaction \\
\hline 11 & Negative trigger with Interaction \\
\hline 12 & Pulser \\
\hline 13 & Inter-spill Pulser \\
\hline 14 & Scinteraction Hi \\
\hline 15 & DC1 $1+$ Hit \\
\hline 16 & Unvetoed beam \\
\hline
\end{tabular}


and momenta.

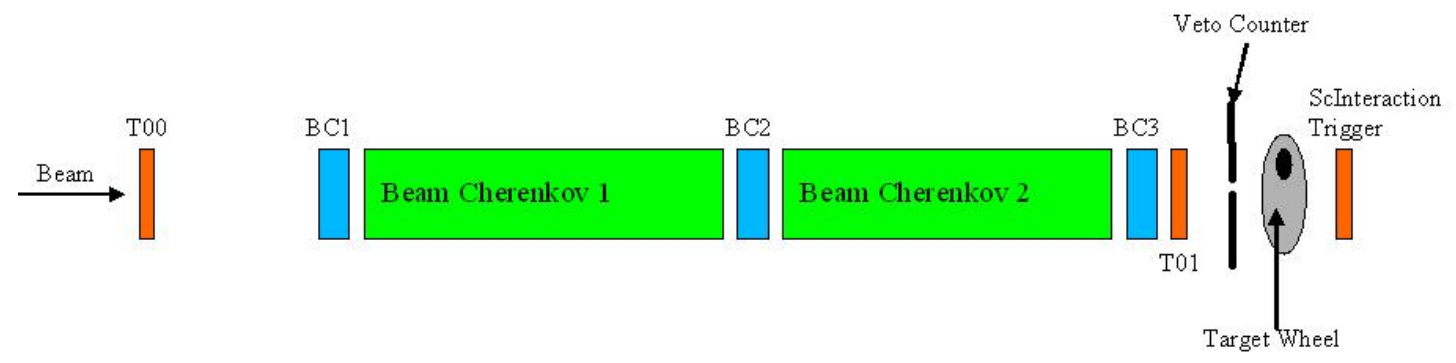

Figure 4.1: The MIPP Trigger System Counters

There are four PMTs whose names are upstream inner (UI), upstream outer (UO), downstream inner(DI), and downstream outer(DO) attached to BCkov counters. Beam PID tagging are listed in Table 4.2; if the symbol has a line over it, it means that no Čherenkov radiation was caught by that PMT. As can be seen in Table 4.2, all four PMTS take place at $35 \mathrm{GeV} / \mathrm{c}$ momentum and above for beam particle tagging because the pion and kaon Čherenkov angles in the BCkov2 are below 30 mrad.

Table 4.2: Beam PID tagging combinatorics

\begin{tabular}{|c|c|c|}
\hline & \multicolumn{2}{|c|}{ Beam Momenta } \\
\hline Beam Particles & $>20 G e V / c$ & $>35 G e V / c$ \\
\hline$\pi$ & $\overline{\mathbf{U I}} \cdot U O$ & $\overline{\mathbf{U I}} \cdot U O \cdot \overline{\mathbf{D I}} \cdot D O$ \\
\hline$K$ & $U I . \overline{\mathbf{U O}}$ & $U I . \overline{\mathbf{U O}} \cdot \overline{\mathbf{D I}} \cdot D O$ \\
\hline$p$ & $D I . \overline{\mathbf{D O}}$ & $\overline{\mathbf{U I}} \cdot \overline{\mathbf{U O}} \cdot D I . \overline{\mathbf{D O}}$ \\
\hline
\end{tabular}


Proton beams below about $20 \mathrm{GeV} / \mathrm{c}$ momentum and kaon beams below 11 $\mathrm{GeV} / \mathrm{c}$ momentum cannot be distinguished by the beam Čherenkov counters, which require high gas density. This causes multiple scattering in the beam Čherenkov, which leads to incorrect information about the incident beam's direction and position. This obstacle is overcome by looking at particle time of flight at $5 \mathrm{GeV} / \mathrm{c}$, where the system can tag kaons and protons.

\subsubsection{Interaction Trigger System}

The first setup of the MIPP used the first drift chamber, DC1, as an interaction trigger (iDC). In order to trigger detectors, iDC requires two or more receptions on at least three out of its four planes. However, iDC showed some weakness in triggering the system because of several problems. These problems are noise due to a low discriminator threshold, poor beam conditions because of the large chamber area, and low efficiency of a two-particle state [19]. To avoid these problems, a scintillator interaction trigger detector was built, but both trigger systems were used for determining systematic effects.

The interaction trigger detector is a $3.175 \mathrm{~mm}$ thick and $5.40 \times 7.62 \mathrm{~cm}$ piece of solid scintillator. $81.9 \mathrm{~g} / \mathrm{cm}^{2}$ of interaction length and $1.032 \mathrm{~g} / \mathrm{cm}^{3}$ of density can be listed as its specification. The scintillator interaction trigger is located $1.5 \mathrm{~cm}$ after the experimental target with its shorter edge horizontal and its taller edge vertical. Clear fibers were attached to each of its shorter edges and the detector itself was covered with aluminized mylar. There is a safety rule that all high voltages must be kept away from the liquid hydrogen target. So, $3 \mathrm{~m}$ of fibers were attached to the scintillator and the other ends packed onto two Burle 83054H PMTs that create 73 photoelectrons per minimum ionizing particle (mip). Then, the LeCroy 612 AM PMT amplifier module amplifies the PMT current and generates two copies of the signal. These identical copies were sent to the ADC and an analog splitter. We set 
two different thresholds, SciHi $(\approx 3 \mathrm{mip})$ and $\mathrm{SciLo}(\approx 1.5 \mathrm{mip})$, digital signals to discriminate the splitter output.

\subsubsection{End of Spill and Calibration Triggers}

Every accelerator beam spill has an end-of-spill trigger and a few pulser calibration triggers information. Calculation of pedestals and identification of the hot channels are performed by using these trigger data. Receiving the end of spill trigger data takes several steps. During these steps, detectors are not triggered but other actions take account:

1. Scalers are receipted information and cleared out for whole spill;

2. Different triggers data, documented in the spill, are saved to the database;

3. These buffered data were moved to DAQ server.

\subsection{The MIPP Data Acquisition System}

The MIPP Data Acquisition (DAQ) system was controlled by seven computers at FNAL E907 port camp. The detector data signals were processed by readout systems. All detectors have their own readout system working with VMA or CAMAC crates. When the MIPP computers receive a signal from the readout system, all data are stored via FNAL E907 DAQ at two different locations, which are local disk storage, and the tape storage facility at Feynman Computing Center, FNAL. Most of the DAQ control software has been written by the MIPP experimenters. We are able to select any detector subsystem by switching it on or off to make data acquisition on purpose from the DAQ controller. 


\section{CHAPTER 5 \\ EVENT RECONSTRUCTION}

Event reconstruction is the technique of figuring out the electronic signals generated by detectors to discover tracks of original particles, primary vertex positions and particles' energies. The MIPP event reconstruction is based on various actions. These actions are TPC hit reconstruction, track reconstruction, and vertex reconstruction. To measure a particle's trajectory, charge and momentum, hit reception of TPC and chambers were used along with the analysis magnet fields. The mass

of each particle and its momentum must be determined precisely to get a complete reconstruction by finding the $3 \mathrm{D}$ spatial coordinates. This step is achieved using MIPP 4 particle identification detectors. In my analysis, I am interested in $\pi^{ \pm}, K^{ \pm}$, and $p \bar{p}$ particles. The MIPP detector subsystem is capable of determining PID at above $20 \mathrm{GeV} / \mathrm{c}$ momentum by RICH and at below $20 \mathrm{GeV} / \mathrm{c}$ momentum by TPC, ToF, and DCkov.

\subsection{Track Reconstruction}

First, some cuts are applied to eliminate unwanted events. The cuts include pileup, SciHi triggered, multiple beam, and out of spill-events cuts that leave the real interaction events for analysis at the end of the process. The remaining events are tracked by a tracking algorithm. Global tracking is achieved by combining information from all tracking detectors. These detectors are grouped into three sets, which are BC $1 / 2 / 3$, DC $1 / 2 / 3$, and DC4/MWPC 5/6. These groups build three dimensional track segments. A chamber track candidate can be determined by matching each group's track segments. Global tracks are fitted based on the ROSIE magnetic field's curvature for momentum. Although a non-uniform magnetic field complicates the task, TPC tracks are fitted to helices. Using track template fits, the TPC tracks (Figure 5.1) are matched to the chambers' tracking wires to form 
global tracks, (Figure 5.2).

The detailed track reconstruction follows these steps:

1. It starts with hit wire clusters in each plane of each chamber.

2. All possible wire crosses are found between planes.

3. To find reliable track segments, all crosses are examined across three chambers in a group.

4. $\chi^{2}$ of the track segment must be acceptable at this point to continue the procedure.

5. Match the track segments of two tracking detector groups, DC1/2/3 and DC4/MWPC5/6, to determine chamber track candidates.

6. If it is possible, match track segment of $\mathrm{BC} 1 / 2 / 3$.

In a magnetic field free zone, each track segment corresponds to a set of chambers [25]. Hence, these segments shape unbending lines that demonstrate entrance and exit points to the magnetic field. Momentum and direction of the particle can be computed using this information.

The other step is TPC track reconstruction, which is adjusted from the tracking algorithm of the BNL E910 experiment. Reconstructed TPC tracks are integrated with chamber track candidates. Detailed information about TPC track reconstruction can be found in MIPP-Doc-129 [17]. Then, the origin of the track is checked to determine if it is coming from the primary vertex or not (Figure 5.3). Vertex finding is performed with a selective filter. All tracks of each vertex are refitted to find the final momentum and direction of the particles as a reconstruction. 

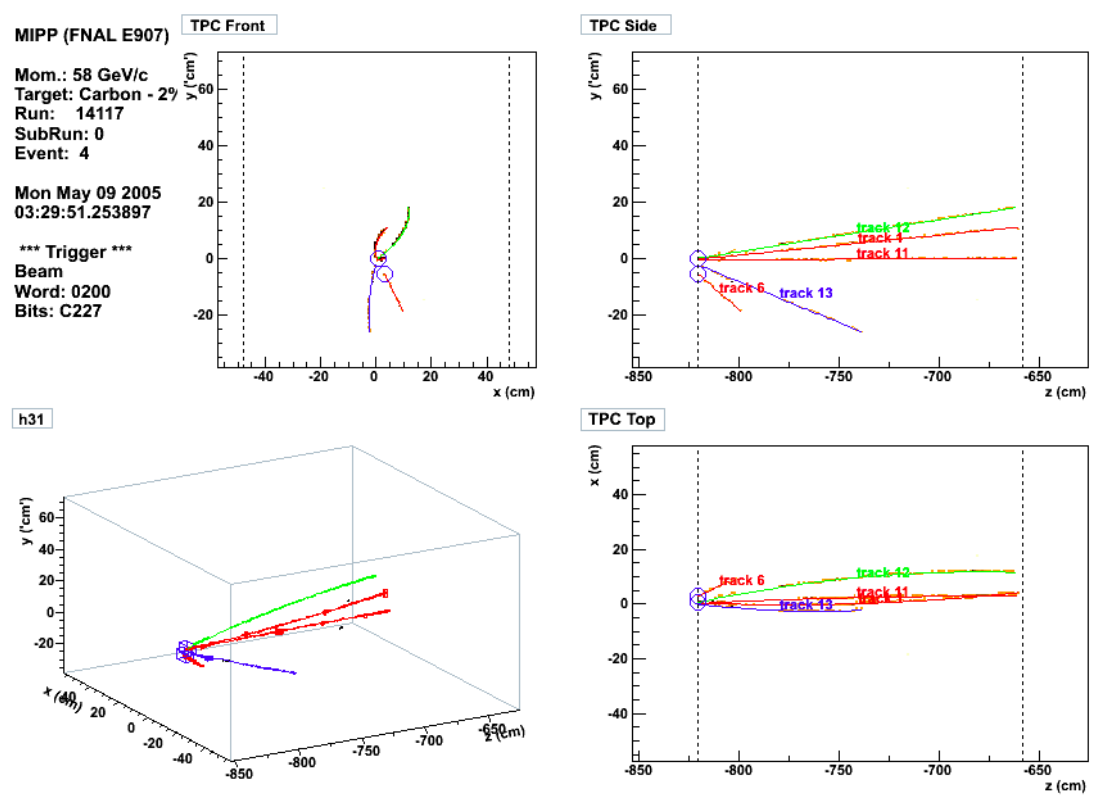

Figure 5.1: Reconstructed tracks inside the TPC volume

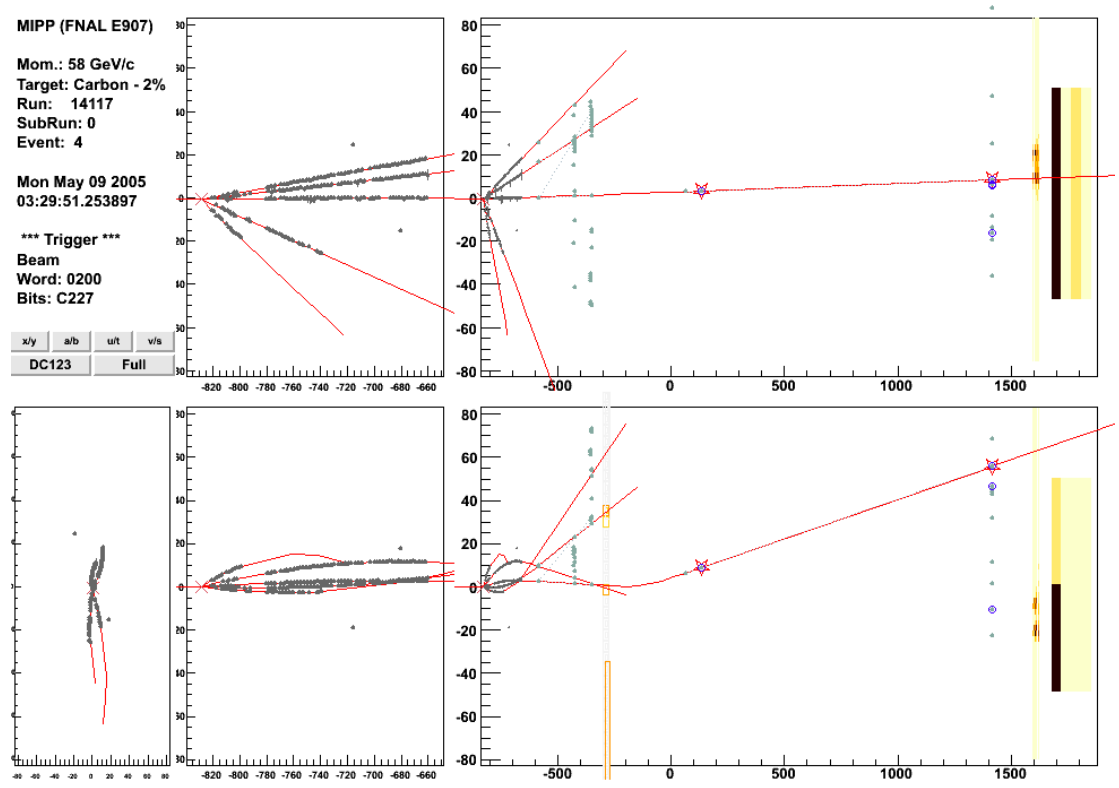

Figure 5.2: Reconstructed global tracks 
Primary vertex Z

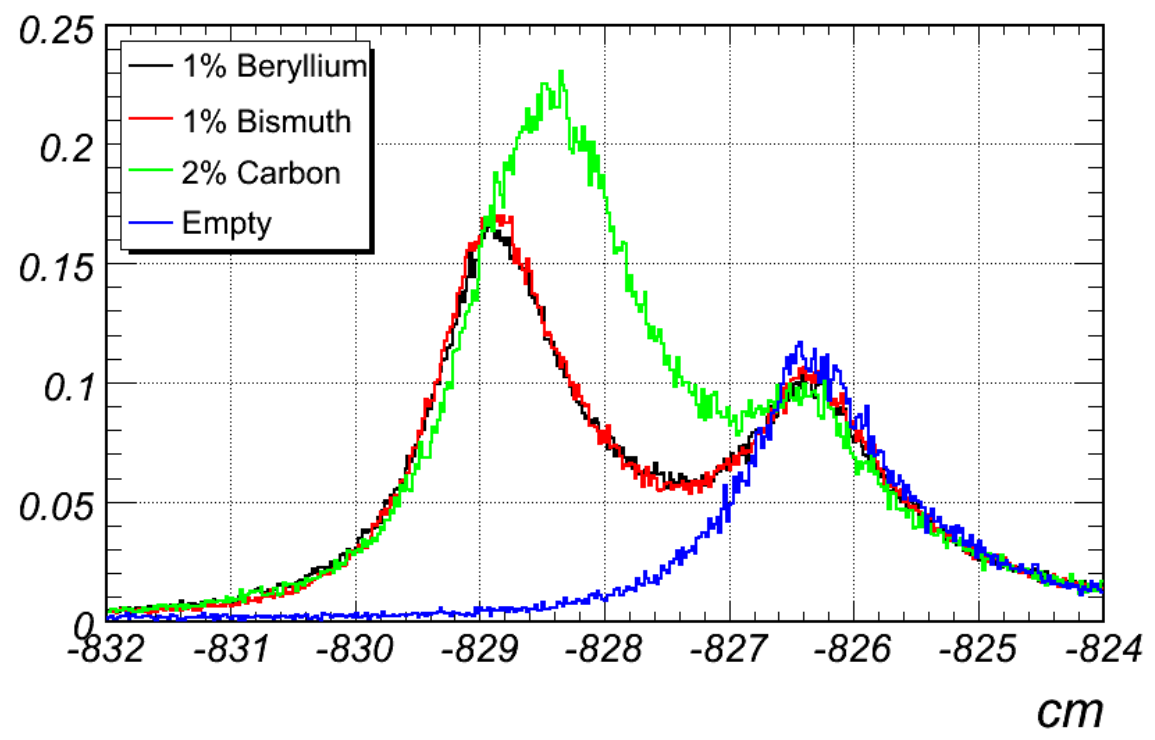

Figure 5.3: Primary vertex $\mathrm{z}$ position distributions for different experimental targets[19]

\subsection{Particle Identification}

\subsubsection{Likelihood}

Likelihood can be simply described as an estimation of unknown parameters based on known outcomes. We can say that it is a reversed version of conditional probability. The numerical value of likelihood alone is unimportant, but ratios of different models of likelihood do matter. In my analysis, the unknown parameter is a PID of the track. The likelihoods of PIDs that are obtained from different models are compared in ratios. Commonly, regular logarithm of the likelihoods are used instead of the likelihoods themselves, which converts the ratio of likelihoods into differences of log-likelihoods.

$$
\begin{aligned}
D & =-\alpha \ln \left(\frac{\text { likelihood }_{\text {first model }}}{\text { likelihood }_{\text {second model }}}\right) \\
& =-\alpha\left(\ln \left(\text { likelihood }_{\text {fist model }}\right)-\ln \left(\text { likelihood }_{\text {second model }}\right)\right)
\end{aligned}
$$

In the MIPP experiment, we need to use normalized log-likelihoods because 
the four PID detectors of the MIPP give different log-likelihoods that can be combined by this method.

\subsubsection{TPC PID}

The TPC working principle is based on exploiting particle energy loss ( $\mathrm{dE} / \mathrm{dx}$ ), (Figure 5.4), which happens when a particle is passing through the TPC volume. Measurement of $\mathrm{dE} / \mathrm{dx}$ for a track, qmeas, reveals particle identification for the TPC. On the other hand, we can calculate the theoretical (or predicted) particle track identification, $q_{\text {pred }}$, using the Bethe-Bloch equation 5.2.

$$
-\frac{d E}{d x}=K z^{2} \frac{Z}{A} \frac{1}{\beta^{2}}\left[\frac{1}{2} \ln \frac{2 m_{e} c^{2} \beta^{2} \gamma^{2} T_{\max }}{I^{2}}-\beta^{2}-\frac{\delta(\beta \gamma)}{2}\right]
$$

\section{$d E / d x$ in TPC}

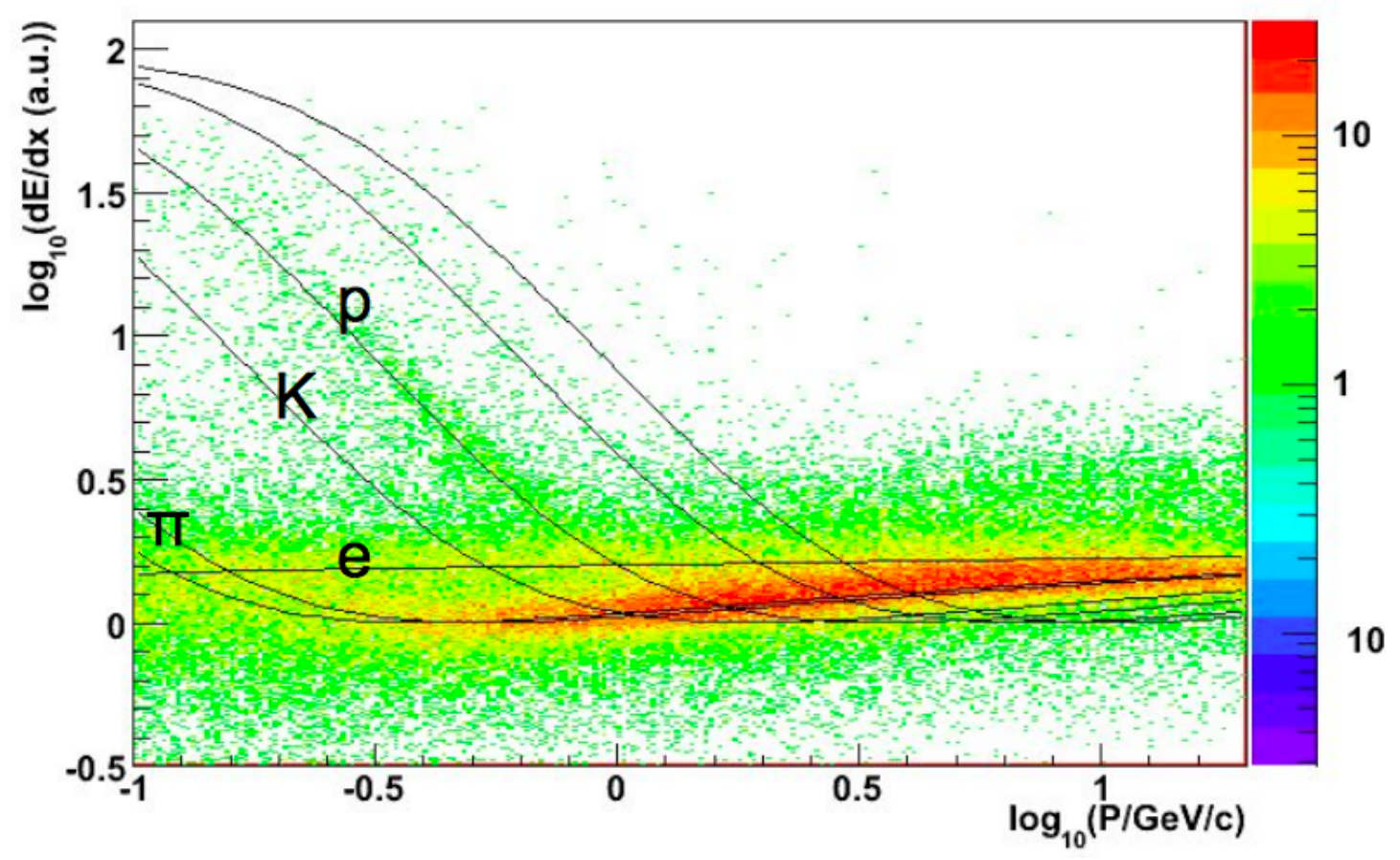

Figure 5.4: TPC energy loss (dE/dx) PID distribution 
Because of the resolution $\sigma$, measurement varies from the theoretical value. That is, accumulating a lot of particles of the same PID at a fixed momentum would give a Gaussian distribution with a width of $\sigma$ and a mean value at $q_{\text {pred }}$. Therefore, observing a particular $q$ meas probability is given by

$$
P\left(q_{\text {meas }} \mid q_{\text {pred }}(P I D), \sigma\right)=\frac{1}{\sigma \sqrt{2 \pi}} e^{\frac{-\left(q_{\text {meas }}-q_{\text {pred }}\right)^{2}}{2 \sigma^{2}}}
$$

where $\frac{1}{\sigma \sqrt{2 \pi}}$ is a normalization factor for the probability.

If we know the predicted value of $\mathrm{q}$ (PID), the likelihood (equation 5.4) can be obtained by the same equation. Then, natural logarithms are utilized to simplify the likelihood.

$$
\begin{aligned}
& L \equiv L\left(q_{\text {pred }}(P I D) \mid q_{\text {meas }}, \sigma\right)=\frac{1}{\sigma \sqrt{2 \pi}} e^{\frac{-\left(\text { qmeas }_{\text {m }}-q_{\text {pred }}\right)^{2}}{2 \sigma^{2}}} \\
& L L \equiv \ln L=\ln \frac{1}{\sigma \sqrt{2 \pi}} e^{\frac{-\left(\text { qmeas }_{\text {pred }}\right)^{2}}{2 \sigma^{2}}} \\
&=\left(\ln \frac{1}{\sqrt{2 \pi \sigma^{2}}}\right)+(-0.5)\left(\frac{q_{\text {meas }}-q_{\text {pred }}}{\sigma}\right)^{2} \\
&=-0.5\left(\left(\frac{q_{\text {meas }}-q_{\text {pred }}}{\sigma}\right)^{2}+\ln (2 \pi \sigma \sigma)\right)
\end{aligned}
$$

These calculations are the same as those we did in the TPCRPID module. It allows us to determine the produced particle track PID within the $0.2 \mathrm{GeV} / \mathrm{c}$ to 1.2 $\mathrm{GeV} / \mathrm{c}$ momentum interval.

\subsubsection{ToF PID}

A Time of Flight (ToF) detector was used to find the particle flight duration from the target position to the ToF bars to reveal particle track ID, (Figure 5.5). We also need to get likelihood ratios and extract information like log-likelihood from the TPC PID procedure. For the calculations the ToF, q represents the time of flight of the track and $\sigma$ is the time of flight resolution. The ToF is capable of giving PID in the $1-3 \mathrm{GeV} / \mathrm{c}$ momentum band. 


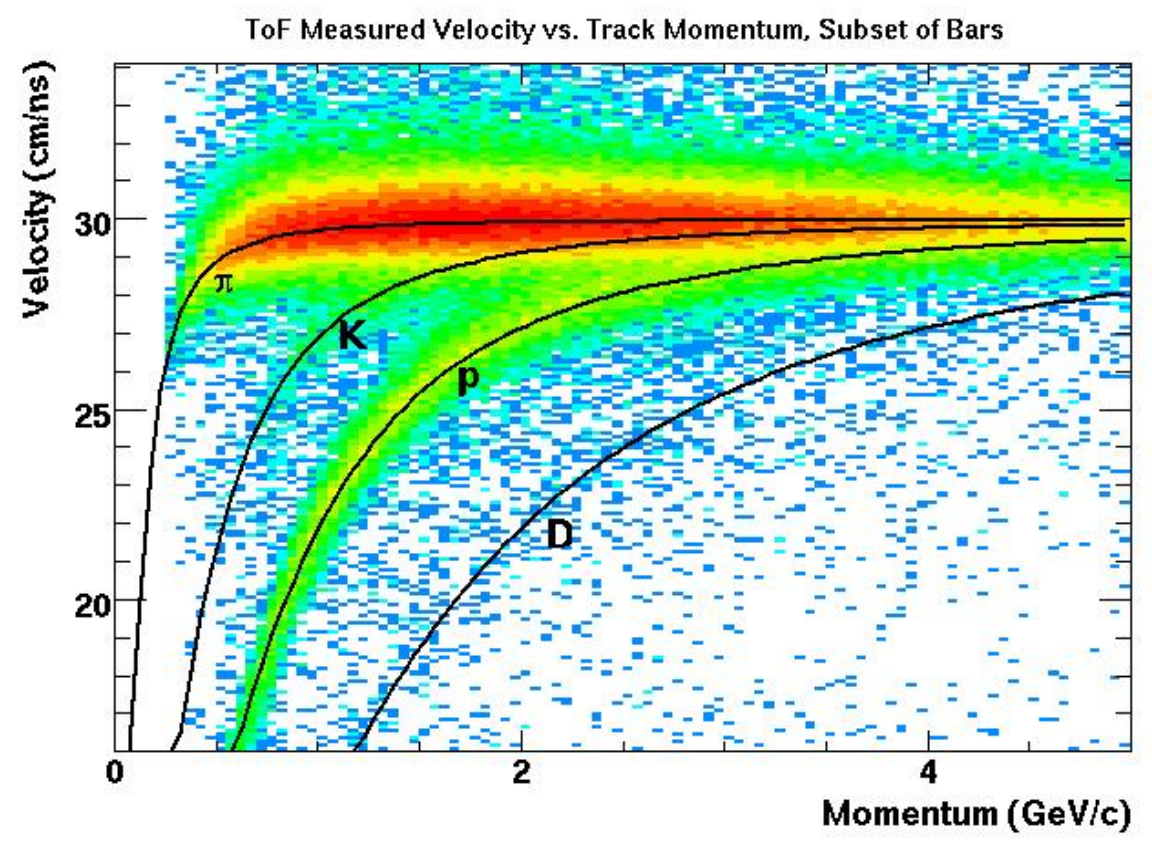

Figure 5.5: A sample of ToF PID distribution

\subsubsection{ToF Cross Talk}

ToF particle identification seems unreasonable because of adjacent hits in neighboring ToF bars. First we obtain ToF time distributions by only looking at ToF track matches where there are no hits in adjacent bars. This technique is approximately correct, but the electronics involvement is also important. We should place a cut based on the TDC channel instead of the bar numbers. So, we checked the difference between a particle's measured and predicted flight times, where the cut was based on whether or not there where hits in TDC channels that are \pm 1 and \pm 2 away from the channel in question.

To correct the cross-talk timing effect, distributions of $\left(t^{\text {meas }}-t_{\pi}^{\text {pred }}\right)$ are used for different combinatorics of hit TDC channels. The effect seems to be largest for adjacent channels, so instead of making $2^{7}$ distributions per channel, only are 
needed $2^{4}$. Example:

\begin{tabular}{|c|c|c|c|c||c|}
\hline $\mathrm{O}$ & $\mathrm{X}$ & $\mathrm{X}$ & $\mathrm{O}$ & $\mathrm{O}$ & 01100 \\
\hline $\mathrm{X}$ & $\mathrm{O}$ & $\mathrm{X}$ & $\mathrm{O}$ & $\mathrm{O}$ & 10100 \\
\hline $\mathrm{O}$ & $\mathrm{X}$ & $\mathrm{X}$ & $\mathrm{X}$ & $\mathrm{O}$ & 01110 \\
\hline
\end{tabular}

For each bar, $32\left(t^{\text {meas }}-t_{\pi}^{\text {pred }}\right)$ distribution plots are created, 16 of them for the top PMTs and other 16 for the bottom PMTs, (Figure 5.6). The mean values of all the shifted distributions are obtained by applying a Gaussian fit to each of them. Then, these values are used to correct ToF cross talk hits, (Figure 5.7).

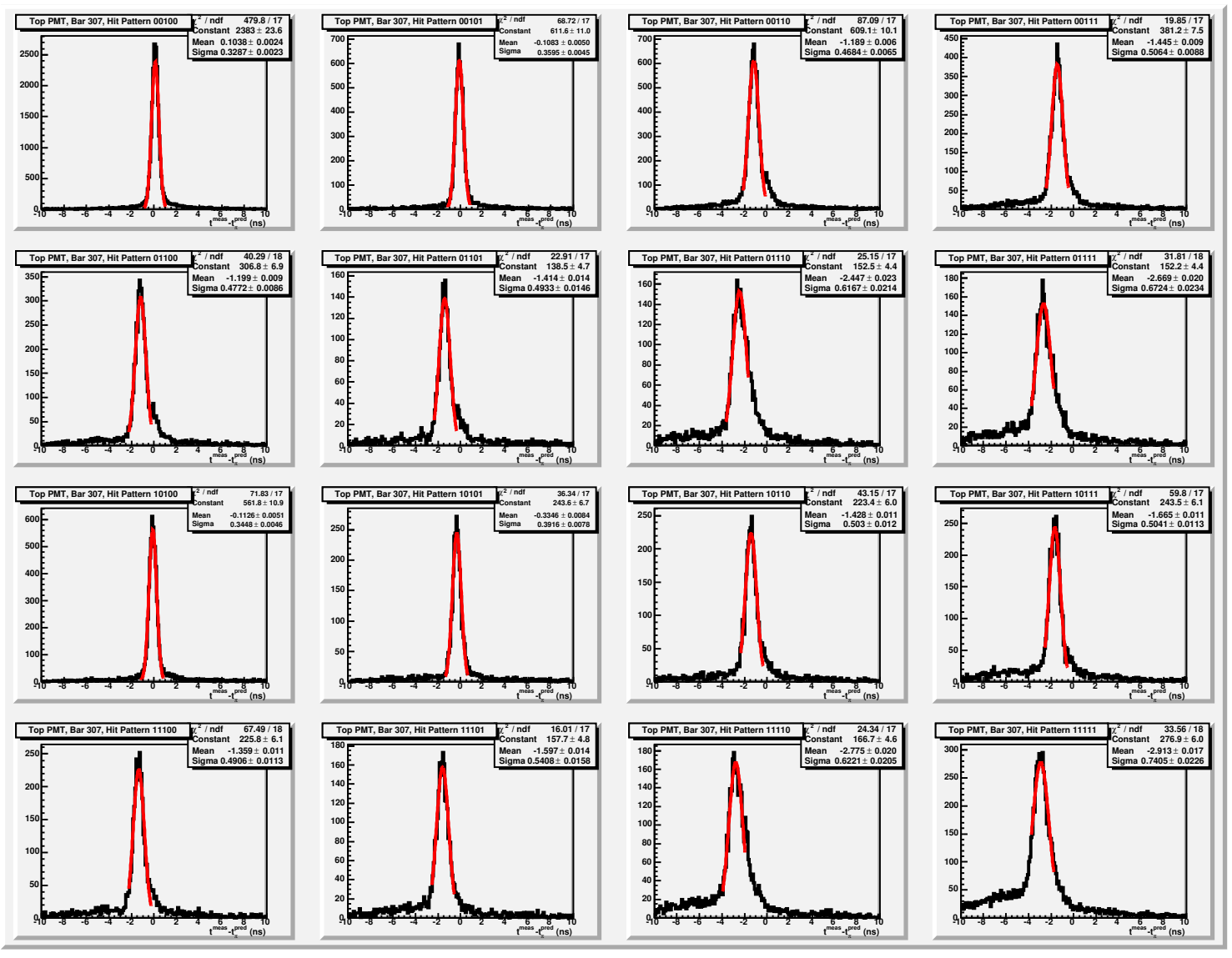

Figure 5.6: Fitted $\left(t^{\text {meas }}-t_{\pi}^{\text {pred }}\right)$ plots 

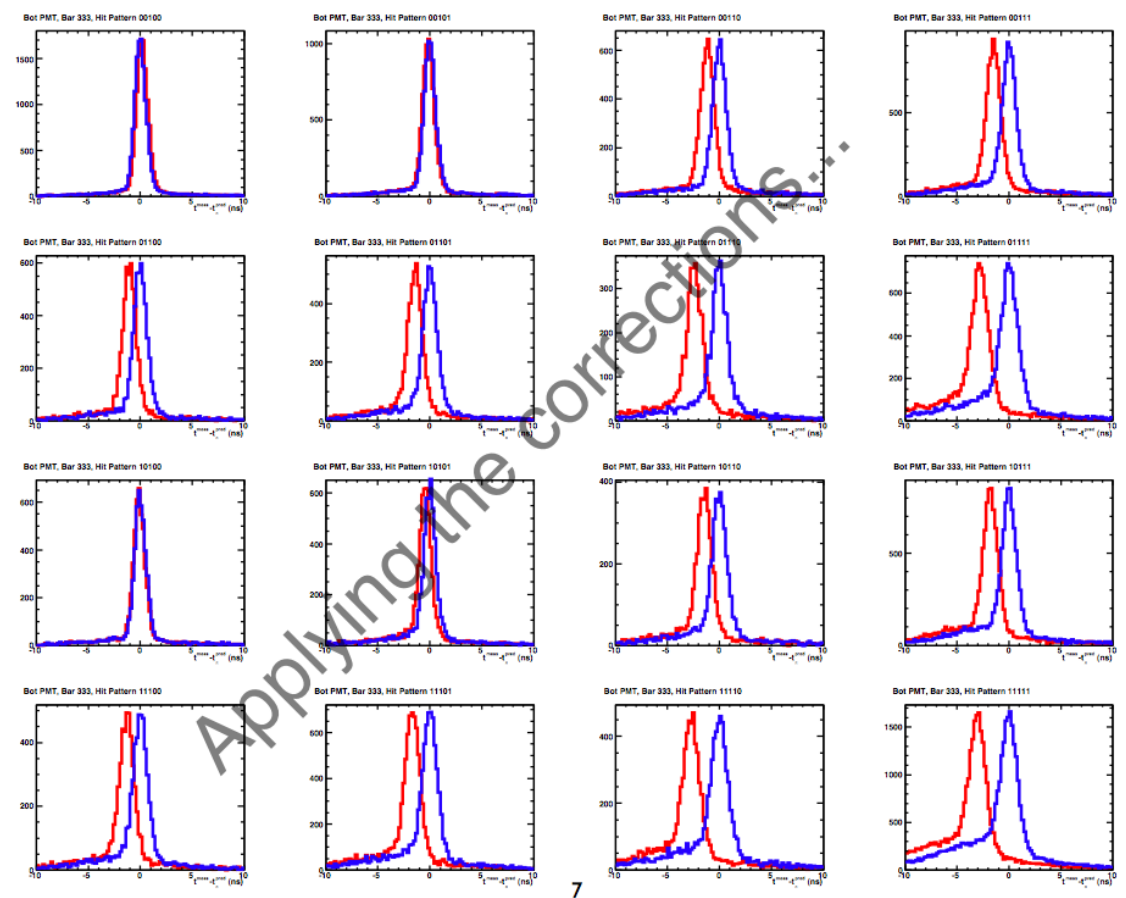

Figure 5.7: Corrected distribution $\left(t^{\text {meas }}-t_{\pi}^{\text {pred }}\right)$ plots

This approach is successful when there is only one peak in the $\left(t^{\text {meas }}-t_{\pi}^{\text {pred }}\right)$ distribution. However, there are several bars with two peaks in their distribution plots, (Figure 5.8). Preliminarily, we rejected these channels, but we did further investigation on this issue.

Our electronics have TDC modules and discriminators. There are 16 wires which are connected to two different TDC modules by splitting them into two parts, but 16 of them are connected to the discriminator in one slot. Eight wires go into one slot of TDC module, and the other 8 are connected to the other slot. While we were looking at $2^{4}$ bits of these channels we missed some combinations of our pattern. This resulted in misleading us about those channels. On the other hand, we can use information from discriminator's connection, which allows us the use of all the combination patterns to get a better result. 


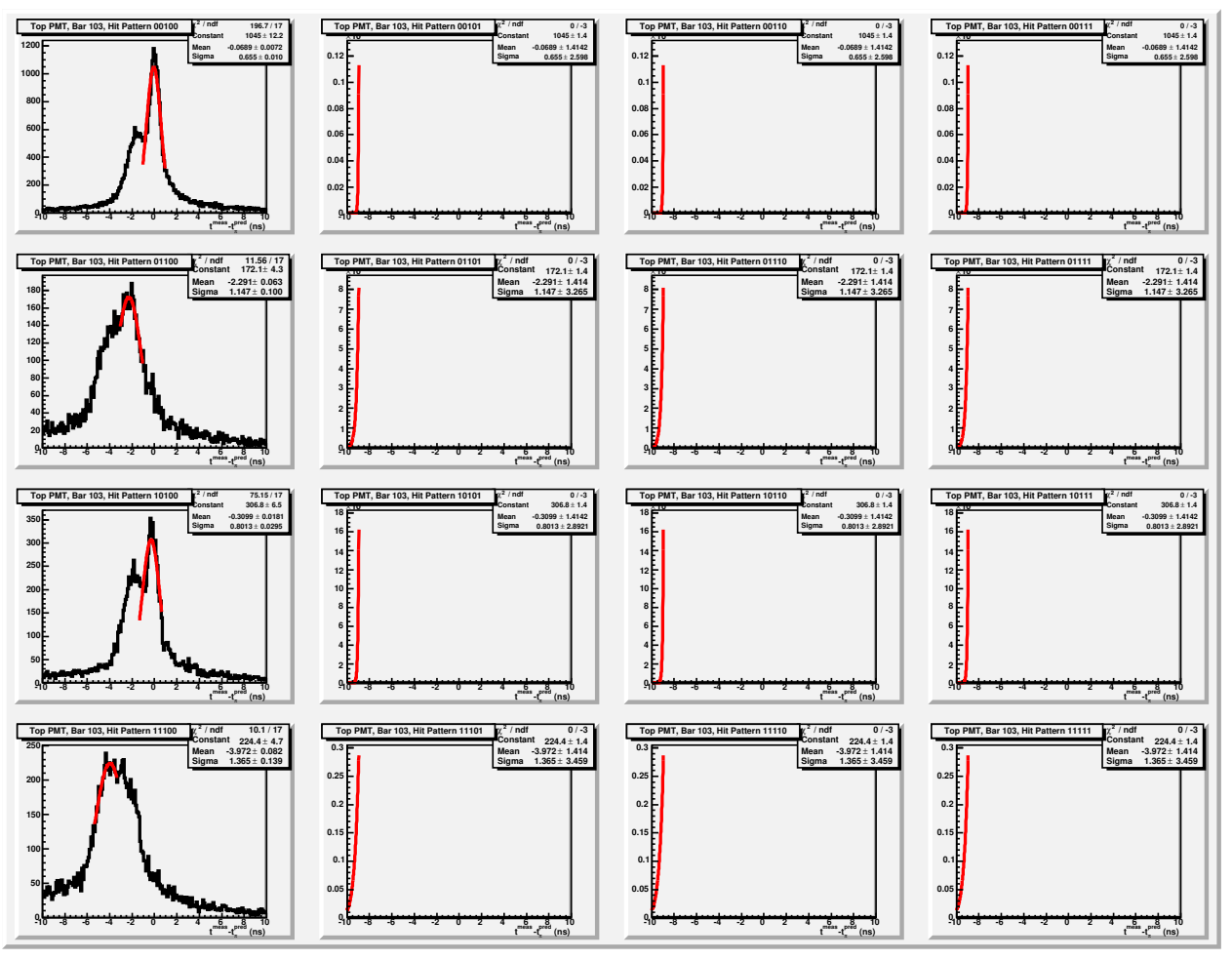

Figure 5.8: $\left(t^{\text {meas }}-t_{\pi}^{\text {pred }}\right)$ distribution with extra peak

\subsubsection{CkoV PID}

The differential Čherenkov detector PID can be obtained by log-likelihood methods. We need to calculate the expected number of photons for each particle theoretically and find the number of captured photons by CkoV's PMTs and its resolution from the data set. However, the situation is not straightforward for this detector since the number of received photons can be caught in a given photomultiplier tube from more than one track, which creates overlapping tracks. There is also another case in which a track passing through the CkoV volume without emitting Čherenkov radiation in the matching set of PMTs collects track identity information. We can simply say that the absence of the light in a given set of PMTs sends information to the DAQ as the track is identified. So, the likelihoods are computed individually for these different cases.

At the beginning, the log-likelihood in $\mathrm{CkoV}$ is calculated using only isolated 
tracks. This has allowed us to calibrate our calculations, and then we can continue on overlapping cases. Equation 5.6 shows our calculation algorithm:

$$
L L_{\text {Ckov }}=N_{\text {meas }} \ln \left(N_{\text {pred }, i}\right)-N_{\text {pred }, i}-\ln \left(\Gamma\left(N_{\text {meas }}+1\right)\right)
$$

where $\mathrm{i}$ is the particle type, $N_{\text {pred }, i}$ is the number of predicted photoelectrons for the hypothesized particle type, and $N_{\text {meas }}$ is the number of measured photoelectrons.

If the hypothesized particle is below the threshold but the number of measured photoelectrons is larger than zero, the log-likelihood is calculated by using the observed value assumption, which is electronic noise:

$$
L L_{C k o V}=-0.5\left(\frac{A D C_{\text {meas }}}{\sigma_{P E D}}\right)^{2}
$$

The carbon $2 \%$ target has around $60 \%$ isolated tracks, and we need to deal with overlapping tracks correctly. If we have " $\mathrm{n}$ " times overlapping tracks and " $\mathrm{p}$ " times particle types, our log-likelihood calculation would be $p^{n}$. We place an upper limit on the number of overlapping tracks to pick the best PID combination. CkoV's PID capability varies by the received signal in different momentum ranges. So, a signal below $2.5 \mathrm{GeV} / \mathrm{c}$ momentum is identified as an electron. Then, particles between 2.5 and $9 \mathrm{GeV} / \mathrm{c}$ can be identified as electrons or pions, otherwise they are either kaons or protons. Another momentum band is between 9 and $17 \mathrm{GeV} / \mathrm{c}$, in which we can identify particles as electrons, pions, or kaons if there is a signal. The situation with no signals represents a proton PID. Electron and pion separation is done by a RICH detector.

\subsubsection{RICH PID}

When the particles are passing through the RICH volume, they create light that is called Čherenkov radiation. The RICH detector exploits this light to uncover 
charged particles PID. RICH mirrors focus the Čherenkov light onto the PMT array.

$$
\cos \theta=\frac{1}{\beta n}
$$

The Čherenkov effect gives the opening angle (Equation 5.8), that translates to the ring radius based on the geometry of the detector. Using the refractive index of the filling gas and the Čherenkov angle, the velocity of the particle is computed. The momentum of the particle can be obtained from tracking. Then, the mass of the particle is computed using the equations below to reveal the particle identity.

$$
E=\gamma m, \beta=\frac{P}{E}, m=\frac{P}{\beta \gamma}
$$

where $\mathrm{E}$ is energy, $\mathrm{P}$ is momentum, $\mathrm{m}$ is mass, $\beta=\frac{v}{c}$, and $\gamma=\frac{1}{\sqrt{1-\beta^{2}}}$.
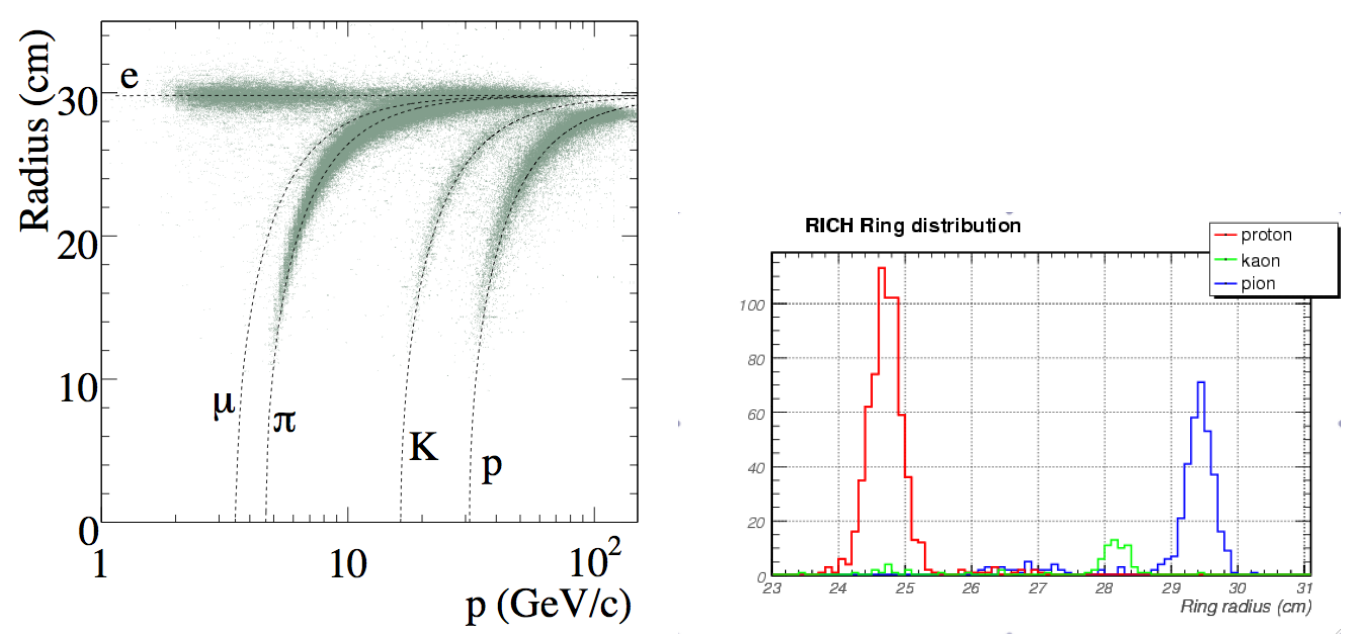

Figure 5.9: These plots show the RICH PID capability.

Particle PID can be obtain by the RICH in two different ways. One way is by using the maximum log-likelihood, as is explained in detail in S. M. Seun's Ph.D [25]. thesis. The other way is by calculating the particle mass squared, as described in A. Lebedev's Ph.D. thesis [19]. 


\subsection{Global Particle Identification}

Using MIPP particle identification detectors TPC, ToF, DCkoV and RICH, we can calculate global particle identification. The GlobalPid package has been setup under the DSTAnalysis directory to achieve this goal. All PID detectors' likelihoods are normalized so that a global pid algorithm is able to integrate these separate log-likelihoods. This package is made of several combined software codes.

Its main module is the PidAll which calls needed functions and classes and runs them. GlobalPid is one of the class that performs initialization, an event loop, and finish functions. TPCPid, ToFPid, DCkovPid, and RICHPid are created in the event loop where all PID detectors calculate the likelihood of PID of a track within a specified momentum interval. Sometimes overlap can occur. At this point, the method for calculating likelihood is also an important part of this package. To achieve this, first the pre-determined Priors should be extracted by the Priors class, which is inherited by all subID classes. Here, class Priors reads in the appropriate Priors from subdirectories in a common ReadSpecialData ROOT file.

It is worth mentioning at this point that what the Priors means is the likelihood of weighted particles with respect to their momentum, (Figure 5.10). Using this hypothesis, weight is given for each particle. The GlobalPid package basically gives the weight of the particle type for given track information. In order to determine Priors precisely, an iterative weighting method is used to give weight to each particle species. We can specify the number of iterations. After several iterations, the particle track ID will be revealed to composed of four different particles, $e, \pi$, $K$, and $p$. Figure 5.11 shows $\pi^{+}$and $p$ probabilities for the first iteration and $14^{t h}$ iteration. These weighted particle IDs are then used in the analysis code. 

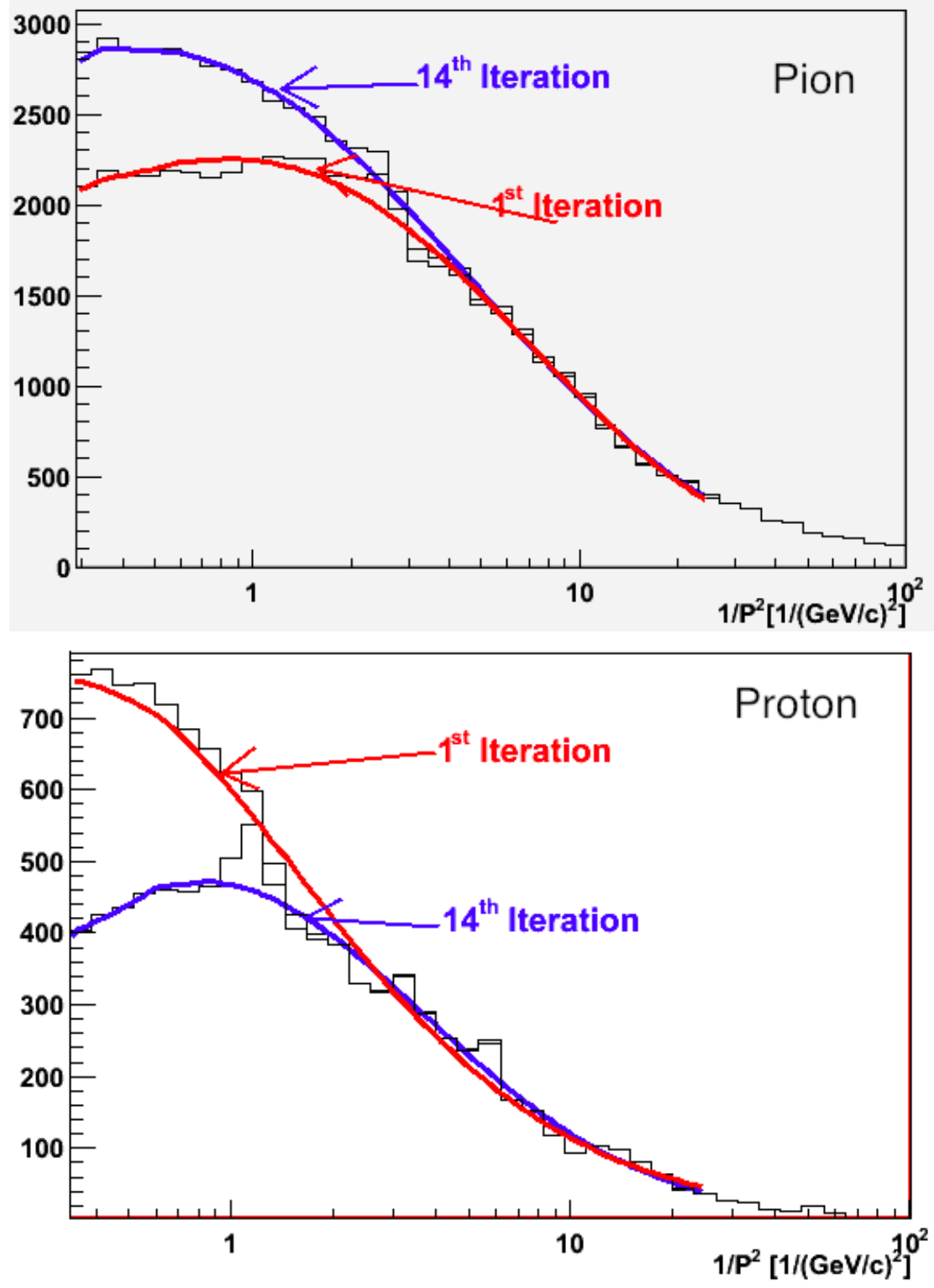

Figure 5.10: Likelihoods of weighted $\pi^{+}$and $p$ 

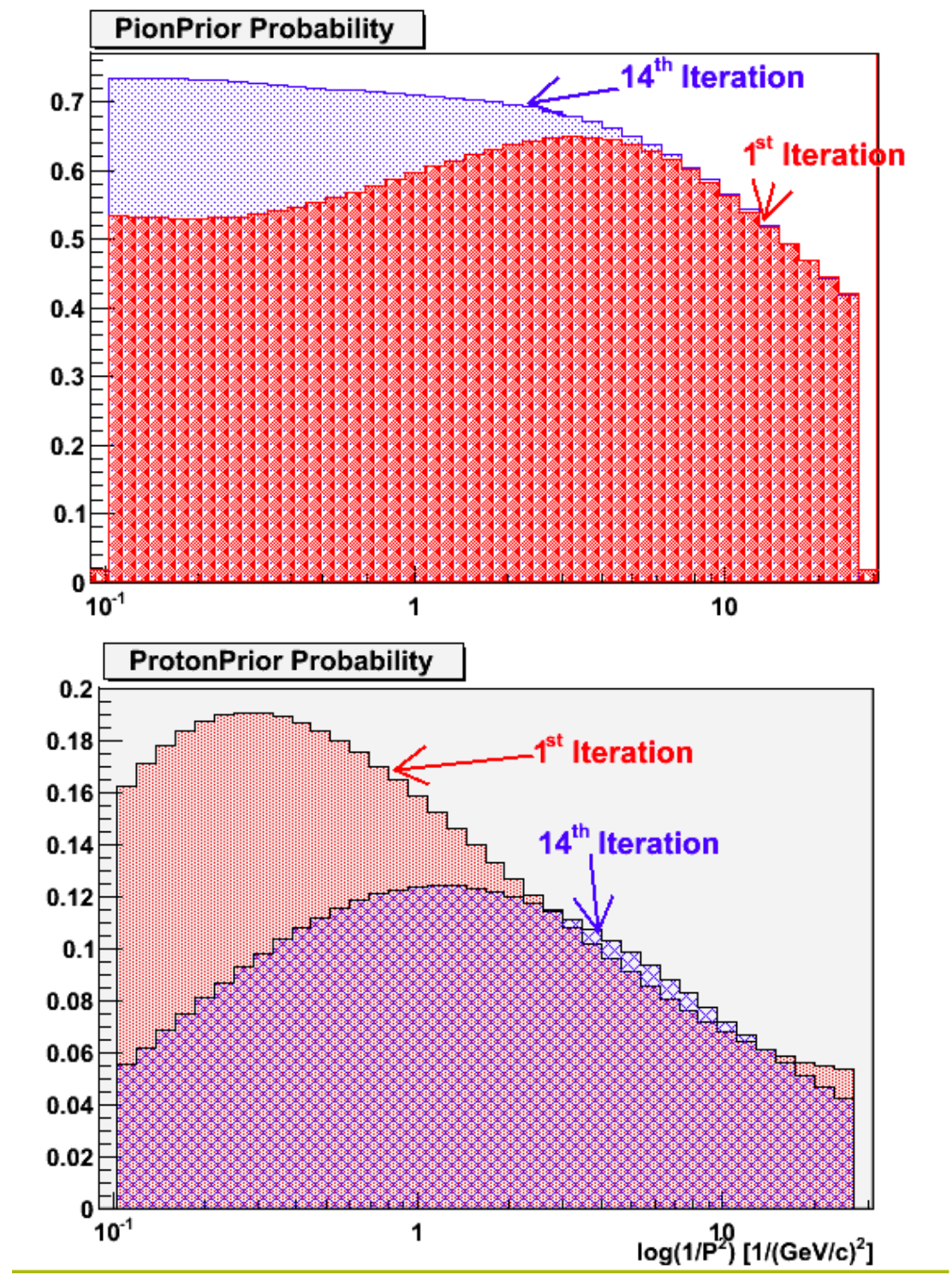

Figure 5.11: Probabilites of $\pi^{+}$and $p$ for each track with respect to momentum 


\section{CHAPTER 6 \\ CROSS SECTION MEASUREMENTS}

In particle physics, the concept of a cross section is utilized to articulate the probability of an interaction. Measuring a cross section value is a convenient way of showing the probability of an interaction, for which we need collisions of particles, tracking and identification detectors, a reliable readout system, Monte Carlo studies for systematic errors, detector's efficiencies, and hard work. This collision can be attained by either smashing two sets of particle beams or sending a particle beam to a fixed target. MIPP has four particle identification detectors which can be used to reveal the cross section value of the interaction. As explained in chapter 2 , the detectors' capability for particle identification varies.

\subsection{Cross Section Terminology}

In general, two types of cross section measurements could be performed. The exclusive cross section measurement determines the probability of exclusive final state particles (e.g. $p p \rightarrow p \pi^{+} n$ ) [21]. As can be seen in this example, all interacting and produced particle identities are known at the initial and final states, respectively. The other type of cross section measurement is called the inclusive cross section. Inclusive cross section measurements show the probability of distinguishing some final state particles from any other particles (e.g. $p p \rightarrow \pi^{+} X$ ). In this instance, $\mathrm{X}$ represents disregarded final states.

Measuring the ratio of the two single particle cross sections, known as a production ratio, is a simple determination due to some error cancellation experimentally. Physicists, however, generally evaluate differential cross sections $\frac{d \sigma}{d \Omega}$ where $d \Omega$ is the solid angle that a produced particle moves into. Owing to rotational symmetries around the beam axis, the differential cross section depends on the polar angle $\theta$, not the azimuthal angle $\phi$. If an integral of the differential cross section 
is computed over the full solid angle, $\sigma=\oint_{4 \pi} \frac{d \sigma}{d \Omega} d \Omega$, the total cross section can be obtained.

Other quantities relating to the final state particles can also be used to express cross sections. For instance, we can detect the momentum of the final state particle. Then the differential cross section can be expressed with respect to momentum, $\frac{d \sigma}{d p}$. If the cross section is computed as a function of two variables, it is called a double differential cross section, $\frac{d^{2} \sigma}{d p d \Omega}$.

Another point inside the concept of the cross section is its unit. Working on a very small cross sectional area brings in another unit representation, which is called a barn. One barn equals $10^{-28} \mathrm{~m}^{2}$ or $10^{-24} \mathrm{~cm}^{2}$.

Ideally, in order to calculate cross sections, a number of interactions with preferred final state particles and a number of incident beam particles must be diagnosed.

In this equation

$$
\frac{d \sigma}{d \Omega}=\frac{d N_{i n t}}{N_{\text {beam }} \cdot \rho_{t g t} \cdot d \Omega}
$$

- $d N_{\text {int }}$ is the number of interactions with a final state particle moving into a solid angle $d \Omega$ (or having momentum $d p$ or transverse momentum $d p_{t}$ or whichever other differential variable characterize the final state)

- $N_{\text {beam }}$ is the number of incident beam particles

- $\rho_{t g t}=\frac{N_{A}}{V_{m o l}} \cdot L_{t g t}$ is the area target density, the number of target particles per area $\left(N_{A}\right.$ is Avogadro's number, $V_{m o l}$ is the molar volume, molar mass divided by density), and $L_{t g t}$ is the target length along the beam direction

In principle, the number of beam particles would be calculated directly and the recorded events would reveal a number of interactions. In this case, geometric acceptance of the final state and detector efficiency corrections have to be applied to the recorded events. However, it is not workable to carry out the experiment for 
small cross sections owing to the fact that obtaining adequate statistics takes too long with this approach.

Alternatively, scalers can be used to measure the number of incident beam particles. With this technique, an error occurs that can be corrected by data analysis. There is a disagreement between the total beam flux and what the scalers count. When two particles pass through the beam counters at the same time, only one recordable signal remains.

\subsection{Calculation of Cross Sections}

In this work, produced $\pi^{+}, \pi^{-}$, and $p$ double differential cross sections are studied with respect to their momentum and solid angle values. Basically, there are three species of the beam particles $\left(\pi^{+}, K^{+}, p\right)$ with $58 \mathrm{GeV} / \mathrm{c}$ momentum that hit the fixed carbon target. In the interaction area, millions of events are created, and all final state particles pass through the MIPP detector system by their scattering angles. Then, if a event triggers the system, the MIPP detectors start to do a readout, which takes time. During this time, the trigger is self-inhibited because until the readout process is completed and the electronics are cleared, ADCs and TDCs are not ready to record new data. The time that the detectors are not capable of sending a signal to the readout system is called dead-time.

Double differential cross section values are calculated by equation 6.2 in these studies.

$$
\frac{d^{2} \sigma_{i}}{d p d \Omega}(p, \cos \theta)=\frac{A}{2 \pi \rho_{\text {tgt }} N_{A}} \frac{1}{a(p, \cos \theta)} \frac{N_{i}(p, \cos \theta)-N_{E}(p, \cos \theta)}{N_{\text {beam }}(\Delta p)(\Delta \cos \theta)}
$$

In this equation:

- A is the atomic weight of the experimental target and $N_{A}$ is Avogadro's number. Both values are constant.

- $N_{\text {beam }}$ is the incident beam flux, which is determined by MIPP beam counters. 
- $\rho_{t g t}$ is the area density of the experimental target.

- $a(p, \cos \theta)$ is a detectors' acceptance value, which is determined by a Monte Carlo simulation.

- $\Delta p, \Delta \cos \theta$ are polar angle bin sizes which are chosen to get sufficient statistics.

- $N_{i}(p, \cos \theta)$ is the number of produced particles in a given bin. $i$ represents a particle type.

- $N_{E}(p, \cos \theta)$ is the number of produced particles in a given bin with an empty target (no target at all). To apply background events reduction, $N_{E}(p, \cos \theta)$ is used.

In my calculations, $12.0107 \mathrm{amu}$ is used as the carbon atomic weight and 1.677 $\mathrm{g} / \mathrm{cm}^{2}$ is used as the area density of the carbon target. Calculation of area density

is explained in section 6.1. Here, $\frac{A}{2 \pi \rho_{t g t} N_{A}}$ is calculated as 1893 mbarn. In order to obtain precise measurements, we must apply several cuts on events to get produced particle identification. All cuts are presented in detail in section 6.7. The other parameters' calculations in this formula are presented in the following sections.

\subsection{Bin Selection}

Bin selection is the first step of the cross-section calculations. In this work, six angle and six momentum bins are defined for aiming to accumulate particle yield evenly in each bins. To achieve this goal, several factors should be considered. First, the size of bins must be bigger than angle and momentum resolutions. Then at least $60 \%$ track finding efficiency should be required, as is explained in section 6.6 .

There are several ways to make these selections. The way that I used was looking at Monte Carlo truth particle yield distribution and changing bin boundaries to get a close number for each bin point. Figure 6.1 shows the particle yield 


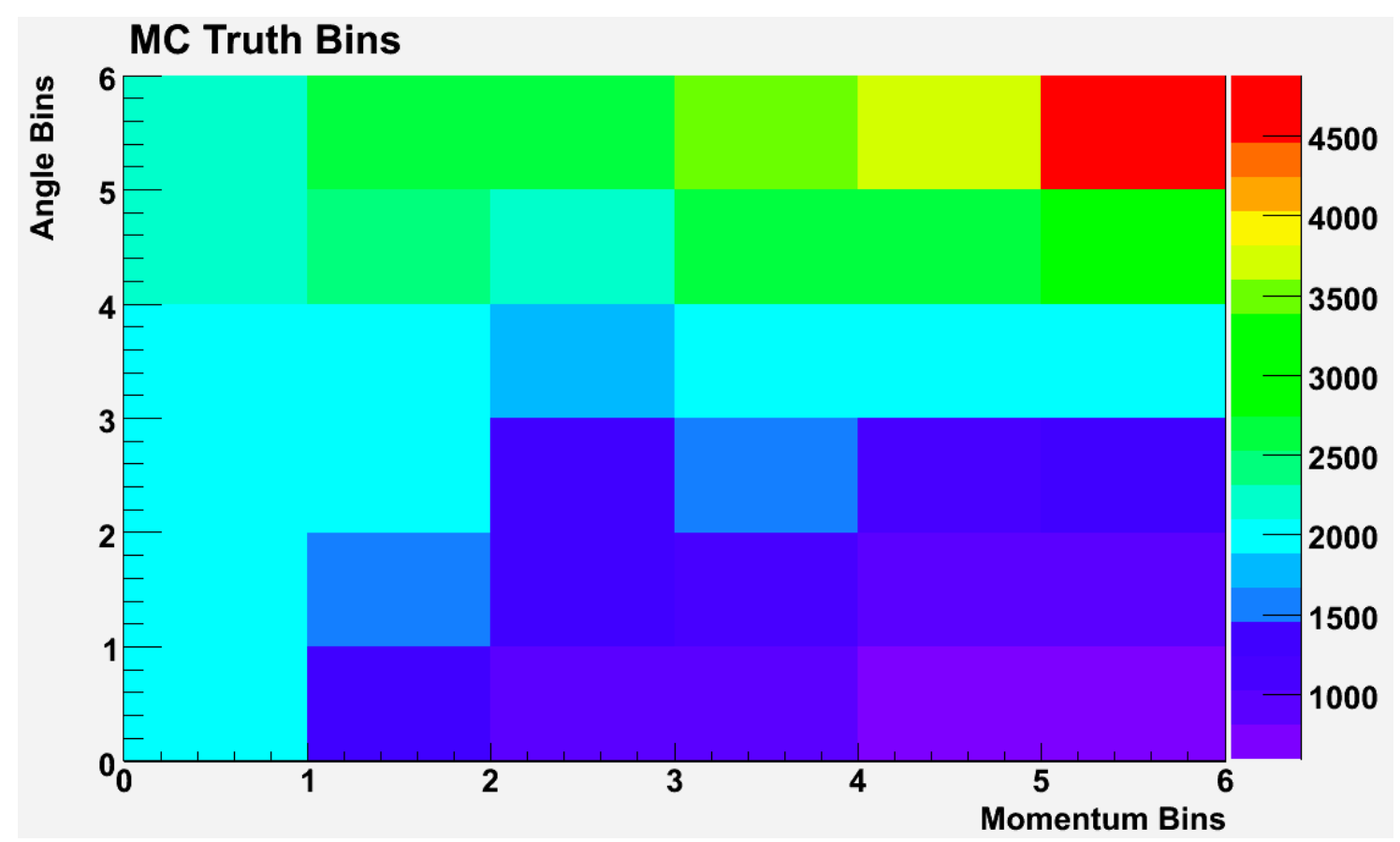

Figure 6.1: MC Truth $\pi^{+}$distribution. Angle bins start from lowest $\cos \theta$ to highest, and momentum bin start from lowest momentum to highest.

distribution in each bin for MCTruth. In this figure, produced $\pi^{+}$MCTruth distribution is shown. The same study has been done for produced $\pi^{-}$and $p$. At the end of this study, momentum and angle bin boundaries come out as seen below:

- Momentum Bins $[\mathrm{GeV} / \mathrm{c}]=\{0.27,0.43,0.55,0.65,0.76,0.87,1.0\}$

- Angle Bins $[\cos \theta]=\{0.76,0.81,0.86,0.90,0.93,0.97,1.0\}$

These numbers are the bin boundaries mentioned above. Midd point of the neighboring numbers gives the bin points of this analysis.

\subsection{Trigger Efficiency}

At the beginning of the MIPP experiment, there was only a drift chamber in use (iDC) to trigger the detectors read-out. After the scintillator interaction trigger (SciHi) detector was installed, both of the triggers were in use at the same time for a while. Then, SciHi was only trigger the rest of the time. It is important to 
know how we triggered our detector system and identified events coming from real interactions. So, SciHi plays a crucial role in cross section calculations. Using SciHi information, events are selected for analysis only when the SciHi is fired up.

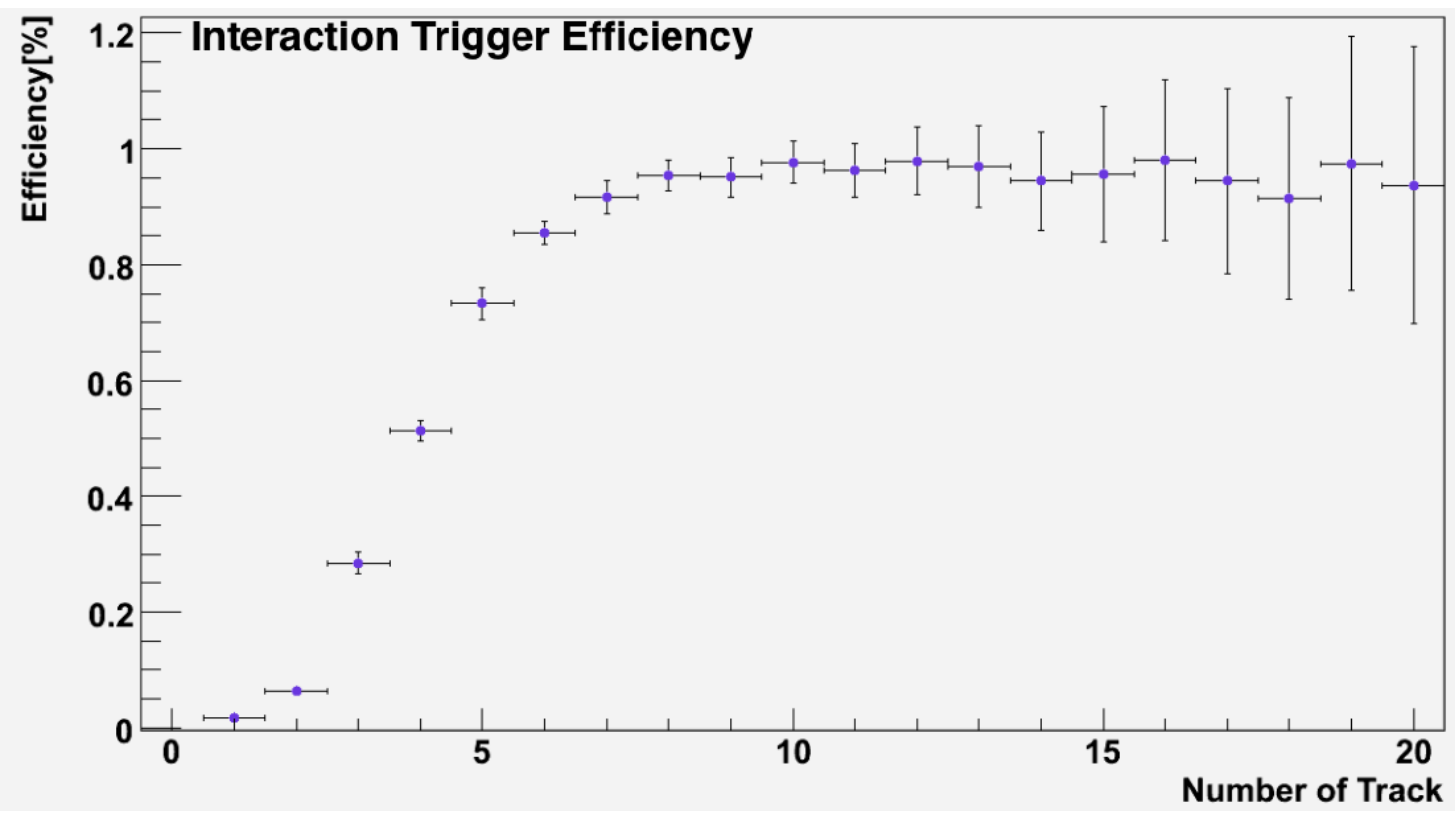

Figure 6.2: Interaction trigger effciencies that are calculated by using Monte Carlo files.

From the Monte Carlo simulation of the SciHi, efficiency numbers are extracted for each number of tracks. Then, produced particle tracks are divided by these numbers according to their respective number of tracks. As can be seen in figure 6.2, trigger efficiency for one track is less than $5 \%$ and the following tracks' trigger efficiencies are increased. After there are eight tracks, it is almost $100 \%$ and so on. This application elevates particle yields for a small number of tracks, and these efficiency number are applied to both target-in and target-out data.

\subsection{Target-Out Subtraction}

The MIPP has collected data at all energies with no target to remove background effects on the total particle yield. In order to do this removal, looking at the 
primary vertex z position distribution is helpful. In the MIPP experimental setup, an interaction scintillator counter is installed $2 \mathrm{~cm}$ after the experimental target position. When the target is installed, two peaks are observed on the primary vertex z position distribution plot, where one peak is positioned at the target position and the other is at the scintillator counter position (Figure 6.3). When there is no target installed in the target wheel, only one peak is seen at the scintillator counter position. Both plots are fitted by the Gaussian function separately. Then the scale factor is calculated from the ratio of the amplitudes of the fits at the scintillator positions. Finally, this scale factor is multiplied by the empty target yield, and this value is subtracted from target yield. This gives the total yield of the particle production (Equation 6.3).

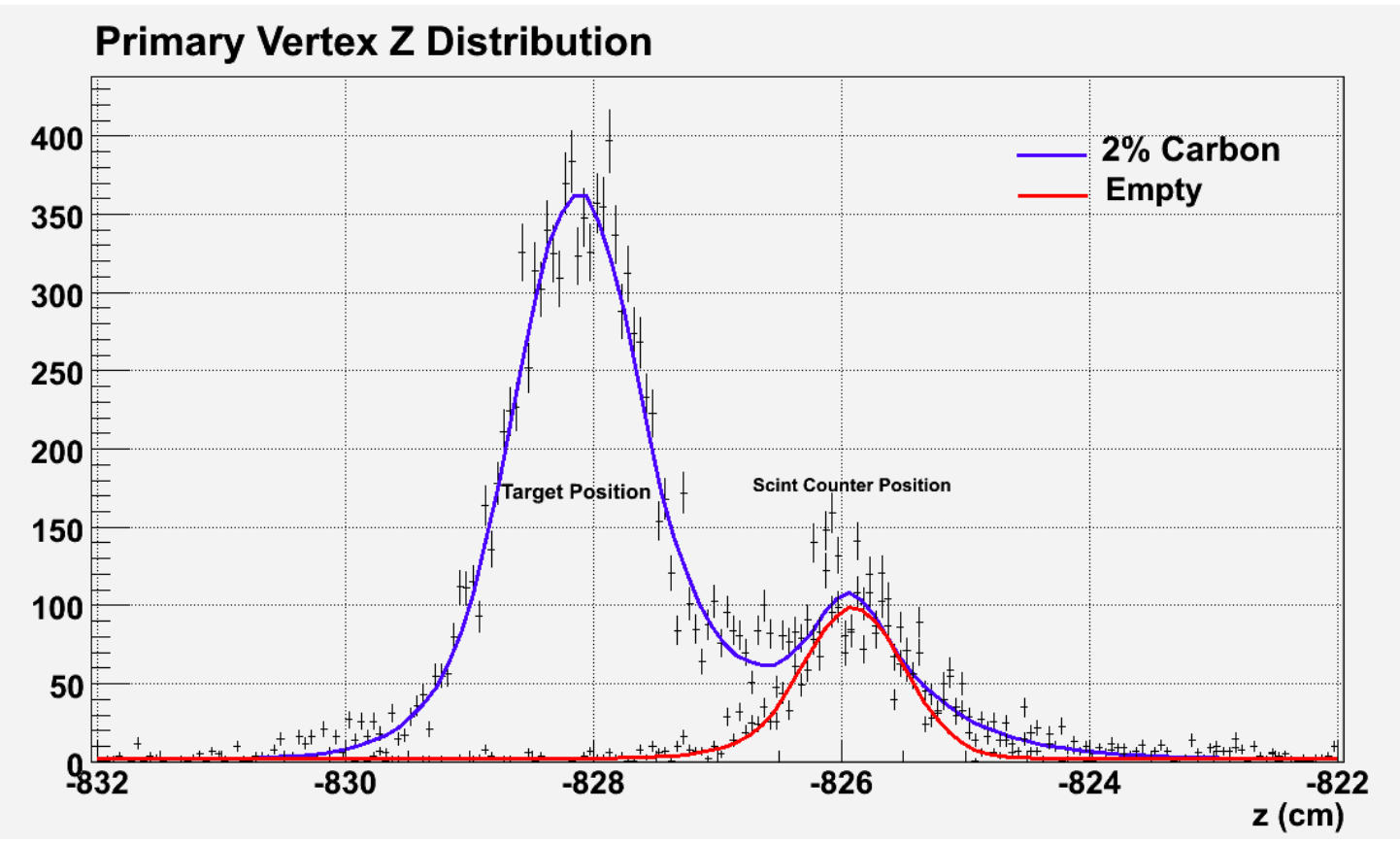

Figure 6.3: Primary vertex z position distribution. The blue line shows the fit on a target-in distribution, and the red line shows the fit on a target-out distribution.

$$
\begin{aligned}
& N_{E}(p, \cos \theta)=\text { Empty Target Yield } \times \text { Scale Factor } \\
& \text { Total Yield }=N_{i}(p, \cos \theta)-N_{E}(p, \cos \theta)
\end{aligned}
$$




\subsection{Detector Acceptance}

In the cross section formula, acceptance presents as a denominator, which is another important component of the cross section calculation. So, we have to determine detector acceptance very carefully. In this study, detector acceptance has been determined by combinations of several factors. These are track finding efficiency, PID efficiency, momentum migration, and purity efficiency. All calculations for acceptance were done based on matched Monte Carlo reconstructed (MCReco) tracks with Monte Carlo true (MCTruth) tracks. Then, PID efficiency has been checked because detector acceptance varies for different types of produced particles. Therefore, all particle-antiparticle PID efficiencieny should be calculated and applied to the cross-section calculation separately. Momentum migration correction and purity efficiency are applied afterwards.

In order to have acceptance values, I selected six angle bins and six momentum bins (Figure 6.1) that are the same as for the cross-section calculations. I chose the angle bins between $0^{\circ}$ and $40^{\circ}$ and the momentum bins from $0.2 \mathrm{GeV}$ to $1.0 \mathrm{GeV}$. I did not look at particle yield below the $200 \mathrm{MeV} / \mathrm{c}$ momentum because our Monte Carlo reconstruction simulation does not have good resolution for protons. Actually, in this region it is difficult to reconstruct particles.

I created two dimensional angle bins versus momentum bins graphs for each particle-antiparticle species by using Monte Carlo (MC) simulation Root files. First of all, I checked the number of particles created by MCTruth, (Figure 6.4), and how many of them have matched tracks with MCReco particles. This ratio gives the MIPP track finding efficiency at $58 \mathrm{GeV} / \mathrm{c}$ using MC simulation. These efficiencies are mostly more than $91 \%$ for produced $\pi,{ }^{+} \pi,{ }^{-}$and more than $80 \%$ for produced $p,($ Figure 6.5). 

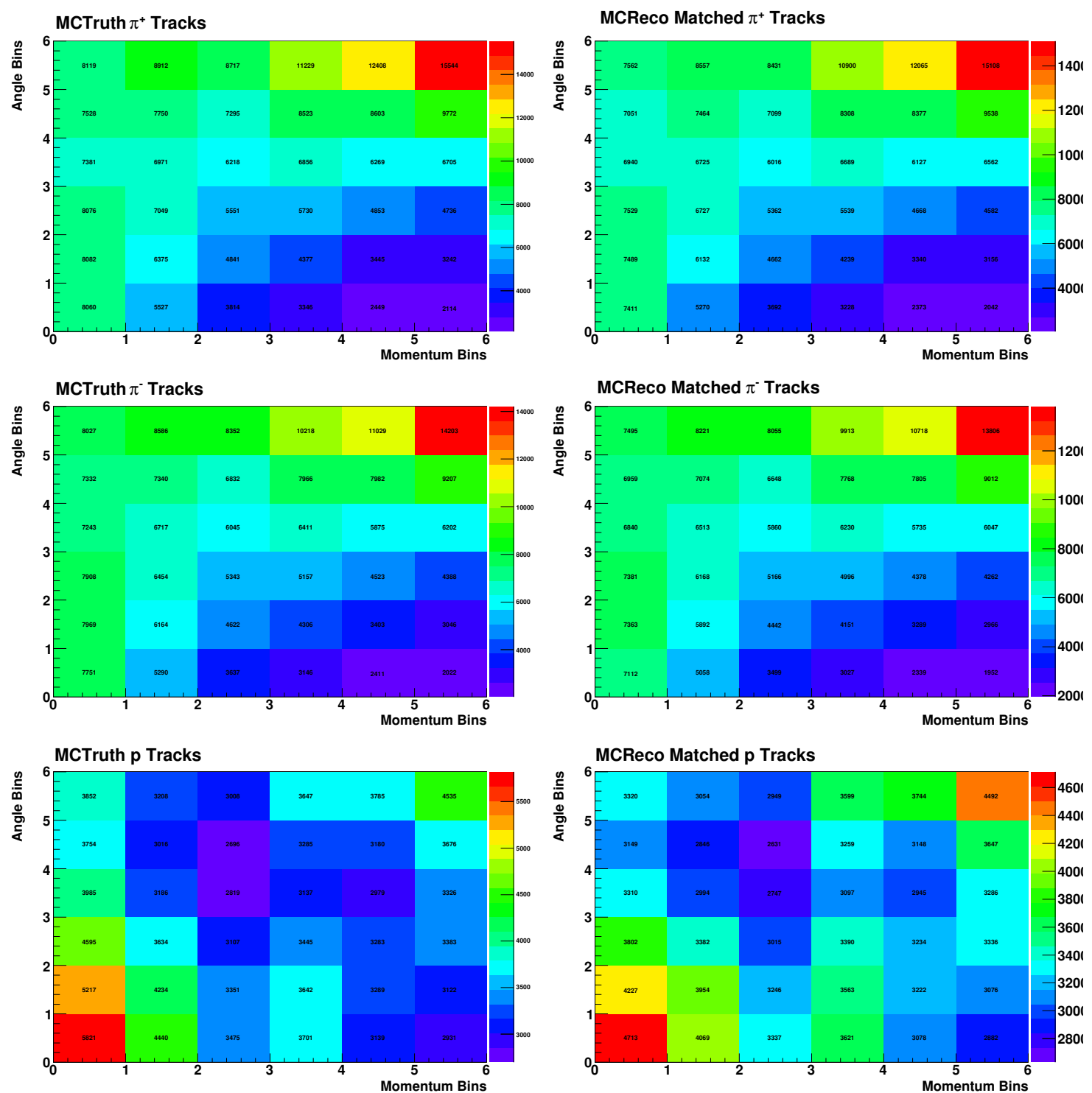

Figure 6.4: MCTruth $\pi,^{ \pm}$and $p$ yields, and their matched tracks in MCReco. Angle bins start from lowest $\cos \theta$ to highest, and momentum bins start from lowest momentum to highest. 

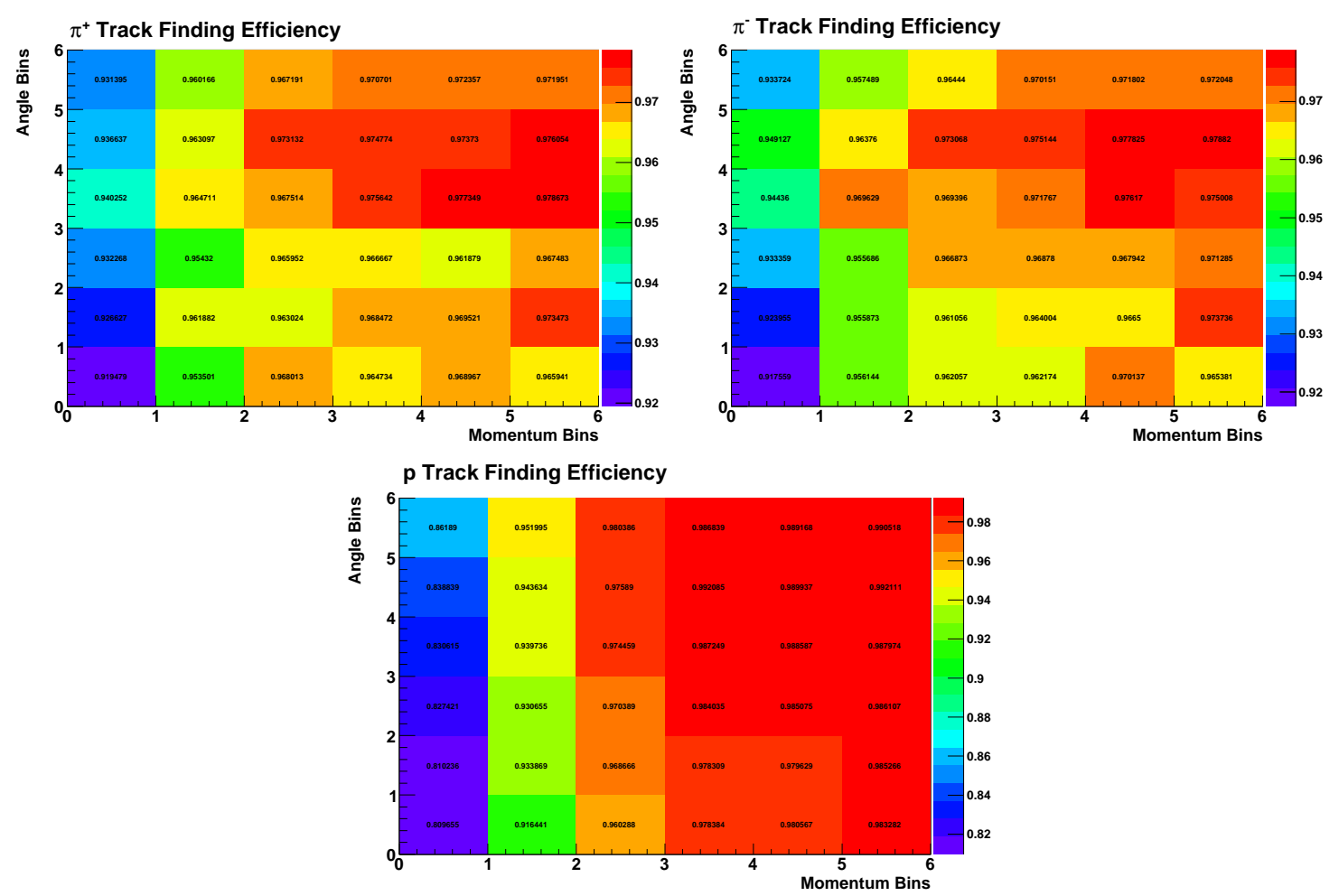

Figure 6.5: Track finding efficiency plots for produced $\pi,^{+} \pi,{ }^{-}$and $p$. Angle bins start from lowest $\cos \theta$ to highest, and momentum bins start from lowest momentum to highest.

After looking at track finding efficiency, we need to see how many of the matched tracks are reconstructed with correct particle identification, which we called PID efficiency. If the detector system can identify particles properly, the PID efficiency should be above $90 \%$. Then, when the both efficiencies are multiplied together, it reveals the detector systems' full acceptance based on produced particle types. So, I required matched tracks' reconstructed PID in my code and filled out angle bins versus momentum bin plots with this information, (Figure 6.6).

Next, all plots created from MCReco with PID distribution and from MCTruth are divided by each others with respect to their produced particle species. When this ratio is calculated, ROOT software also calculates errors automatically. Three different PID efficiency plots are ready to use when cross-section values are 


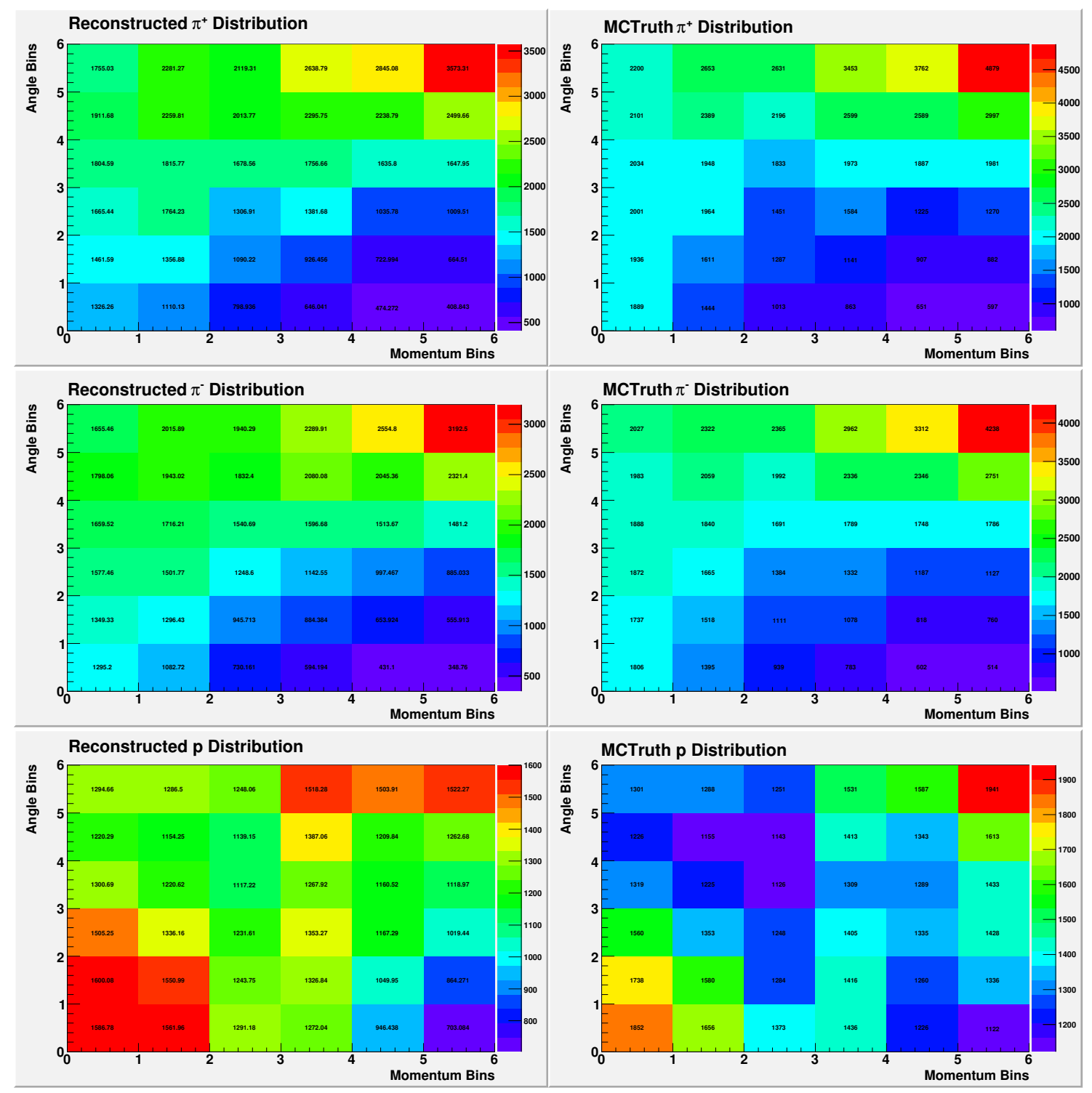

Figure 6.6: MCReco and MCTruth PID distribution plots for produced $\pi,^{+} \pi,^{-}$ and $p$. Angle bins start from lowest $\cos \theta$ to highest, and momentum bins start from lowest momentum to highest. 
computed. Figure 6.7 shows PID efficiencies for produced pions and protons.

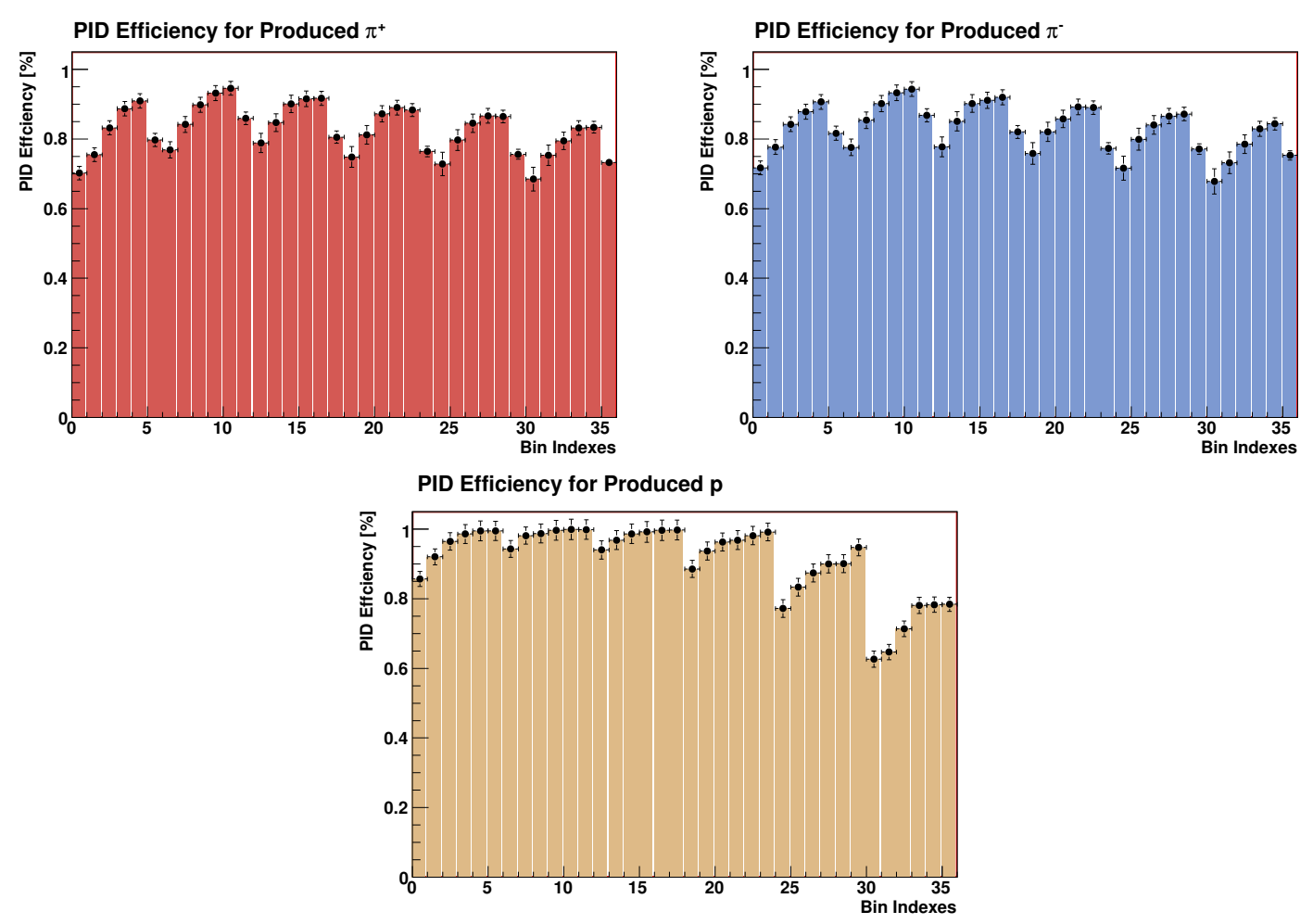

Figure 6.7: PID efficiency plots for produced $\pi,{ }^{+} \pi,^{-}$and $p$. Angle bins start from lowest $\cos \theta$ to highest, and momentum bins start from lowest momentum to highest.

When the momentum bins are reconstructed, migration occurs between neighboring bins. So, how many reconstructed momentum bins' entries actually fall into the same true bins should be answered correctly to get real momentum bins. To do this, momentum migration matrices were created and matrices' elements have been calculated for positive particles and negative particles separately. This matrices' entries are shown in Figure 6.8. The summation of all the neighboring entries for given bins are multiplied by the total particle yield as a correction factor for detector acceptance.

The last part of the detector acceptance is purity efficiency. This time, over the matched tracks, reconstructed particles' weighted PID distributions are filled in on two dimensional plots, and then true particles' distributions are filled in on 


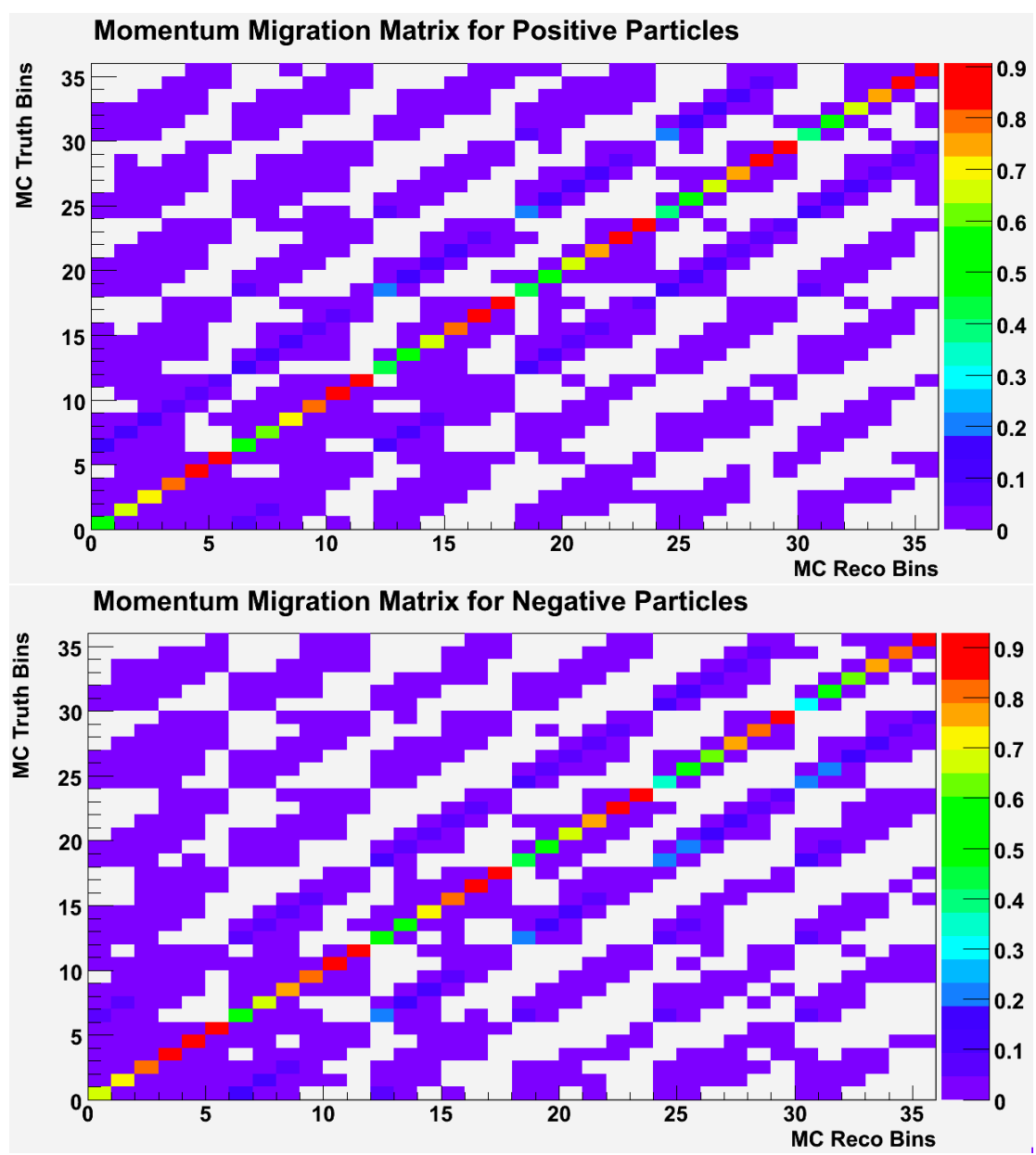

Figure 6.8: Momentum migration matrices plots for produced positive and negative particles 
other two dimensional plots (Figure 6.9). Purity efficiencies are obtained by getting MCTruth-MCReco ratios (Figure 6.10). This ratio tells how many particles were misidentified in a given bin that must be applied to cross-section calculations.
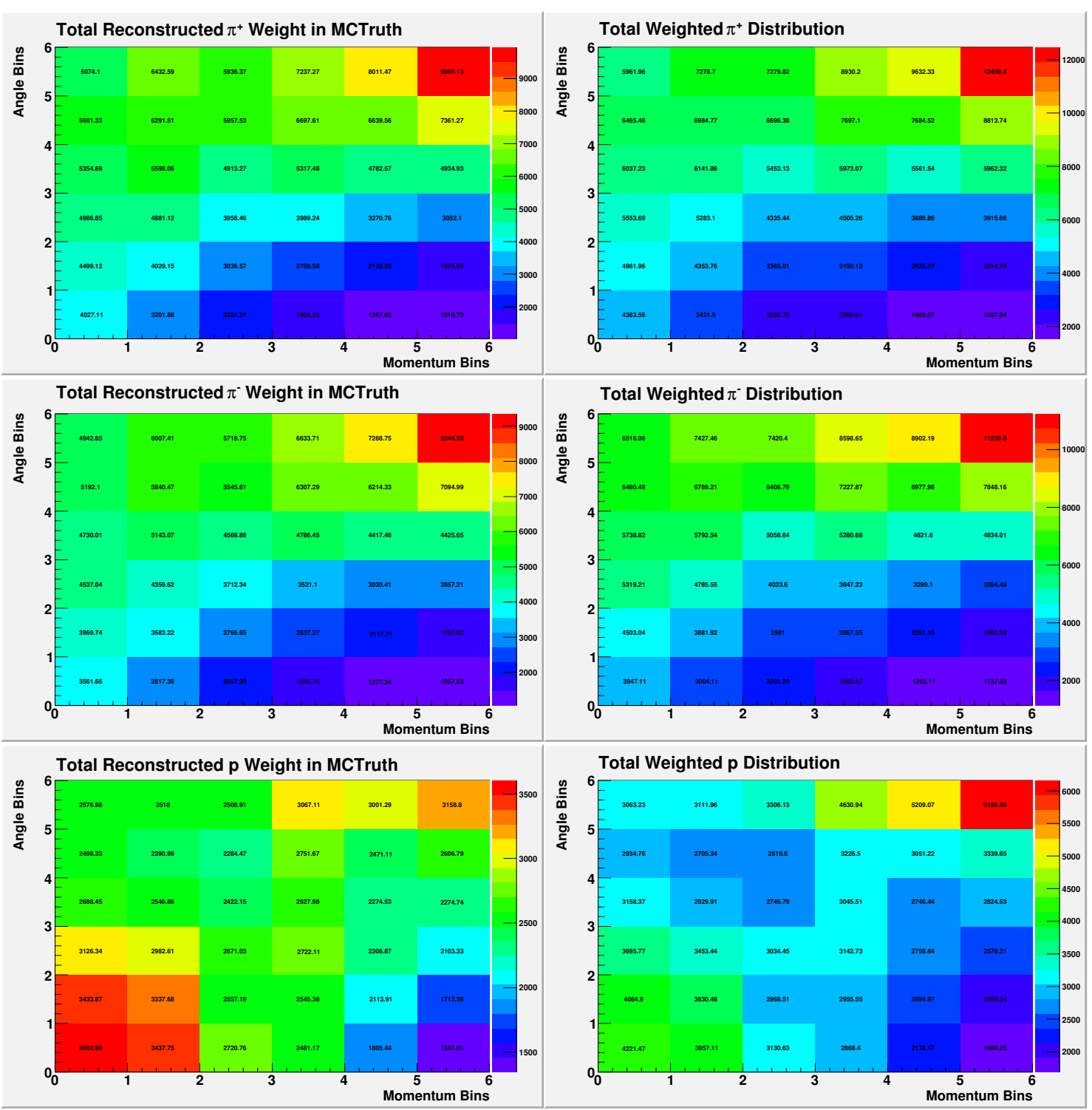

Figure 6.9: MCTruth and MCReco weighted PID distribution plots for produced $\pi,^{+} \pi,^{-}$and $p$. Angle bins start from lowest $\cos \theta$ to highest, and momentum bins start from lowest momentum to highest. 

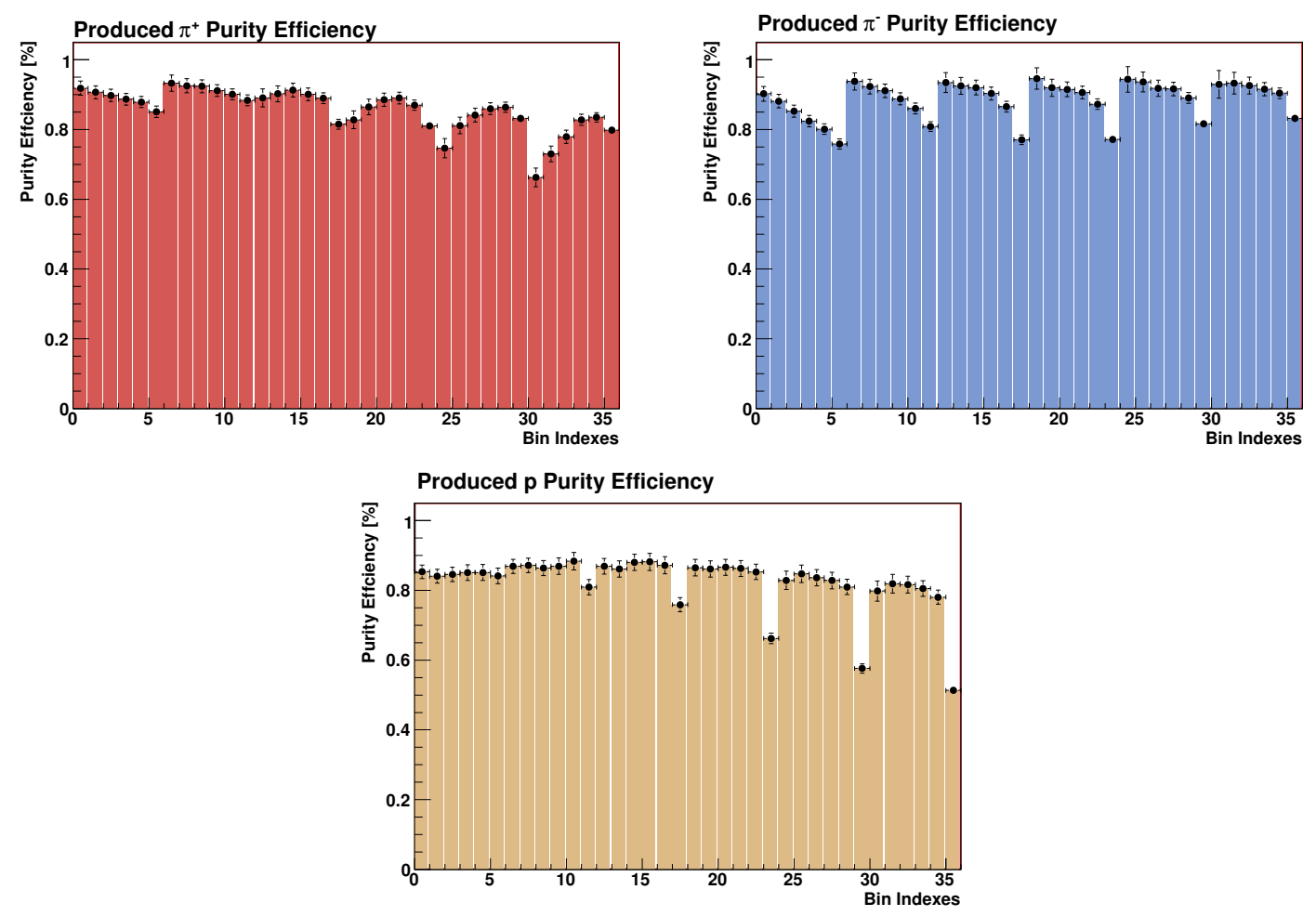

Figure 6.10: Purity efficiency plots for produced $\pi,{ }^{+} \pi,{ }^{-}$and $p$. Angle bins start from lowest $\cos \theta$ to highest, and momentum bins start from lowest momentum to highest.

\subsection{Beam Flux Determination}

Another parameter needed for cross-section calculations is the beam flux. We can look for beam flux using two different approaches. Adding up the number of beam fluxes by using a spill summary is one approach. The other is by looking at a beam particle pre-scaler. The information from both approaches is available in the MIPP database. These approaches can also be called the "spill method" and the "pre-scaler method," respectively. The DSTUtil module has two different sets of functions for performing these separate calculations. Each function has its own algorithm for calculating beam flux. 
Table 6.1: Beam flux numbers from two different calculation methods

\begin{tabular}{|c|c|c|}
\hline \multirow{2}{*}{ Beams Species } & \multicolumn{2}{|c|}{ Methods } \\
\cline { 2 - 3 } & Pre-scaler & Spill Summary \\
\hline Kaon Beam Flux & 559,480 & 561,958 \\
\hline Pion Beam Flux & $4,532,089$ & $4,541,030$ \\
\hline Proton Beam Flux & $13,029,663$ & $12,946,500$ \\
\hline
\end{tabular}

The spill method simply browses the MIPP spill summary and adds up gated trigger bit values for each beam particle species separately. The pre-scaler methods sums up pre-scaled beam particle values. That is, there are three beam particles, $\pi^{+}, K^{+}$, and $\mathrm{p}$, at $58 \mathrm{GeV} / \mathrm{c}$ momentum, and all have their own pre-scale numbers. So, using these functions, what we calculate as beam flux is summarized in Table 6.1. These numbers are direct numbers from each method.

In order to calculate the inclusive cross section, it is critical to know how many interactions are required to trigger the detector for processing data over the DAQ. So, we have placed three different interaction pre-scale numbers to trigger an event base based on beam-particle identity. For $58 \mathrm{GeV} / \mathrm{c}$ beam momentum and a carbon target, we mostly set interactions at pre-scale 24 for a proton beam, 7 for a pion beam and 1 for a kaon beam. For example, we need at least 24 interactions by a proton beam to trigger an event. When these pre-scale interaction numbers are applied to direct beam fluxes, we get the numbers to use in the cross-section analysis, (Table 6.2). However, more work is needed to determine really useful beam fluxes because every single triggered event is not useful for analysis. So, we placed some cuts on events, and Figure 6.11 shows these cuts.

As can be seen in Figure 6.11, we are selecting in-spill events and good spills in the first two cuts, where a good spill means that beam position and intensity 
Table 6.2: After applying pre-scale beam interaction trigger values on beam fluxes, the beam flux numbers are derived to use in cross-section calculations.

\begin{tabular}{|c|c|c|}
\hline Interacted Beam Particles & \multicolumn{2}{|c|}{ Methods } \\
\cline { 2 - 3 } & Pre-scaler & Spill Summary \\
\hline Kaon & 559,480 & 561,958 \\
\hline Pion & 661,520 & 663,652 \\
\hline Proton & 626,789 & 622,006 \\
\hline
\end{tabular}

satisfy our interest. After that, I select only the events that are triggered by SciHi. Then the pileup event cut follows, which also affects our beam flux rates. The rest of the steps for having analyzable events involve the following cuts: multiple beam tracks, raw trigger, beam species, primary vertex, and vertex z-position. Now, it is the time to look at the effect of pileup events on beam fluxes.

After rejecting pileup events, a number of events were dropped from the total initial events. That is, pileup events were not analyzed and so pileup-flux should not be counted in cross sections. Hence, we need to determine the fraction of flux that has pileup. It is the same fraction as in the pileup events because the events sample the flux randomly. I looked at how may pileup events were removed by the DSTUtil::HavePileup60 function from the all events registry before applying any cut. In equation $6.4, R_{p}$ represents the ratio of removed pileup events to all events.

$$
R_{p}=\frac{\text { pileup events }}{\text { all events }}
$$

However, reducing the flux by this factor over-corrects because only pileups of identical beam particles are counted in the flux for beam PID. The pileup of different beam particles will result in a signature that is counted towards neither of the two particle fluxes. That's why the flux for 'beam' (bit 0) is larger than the sum 


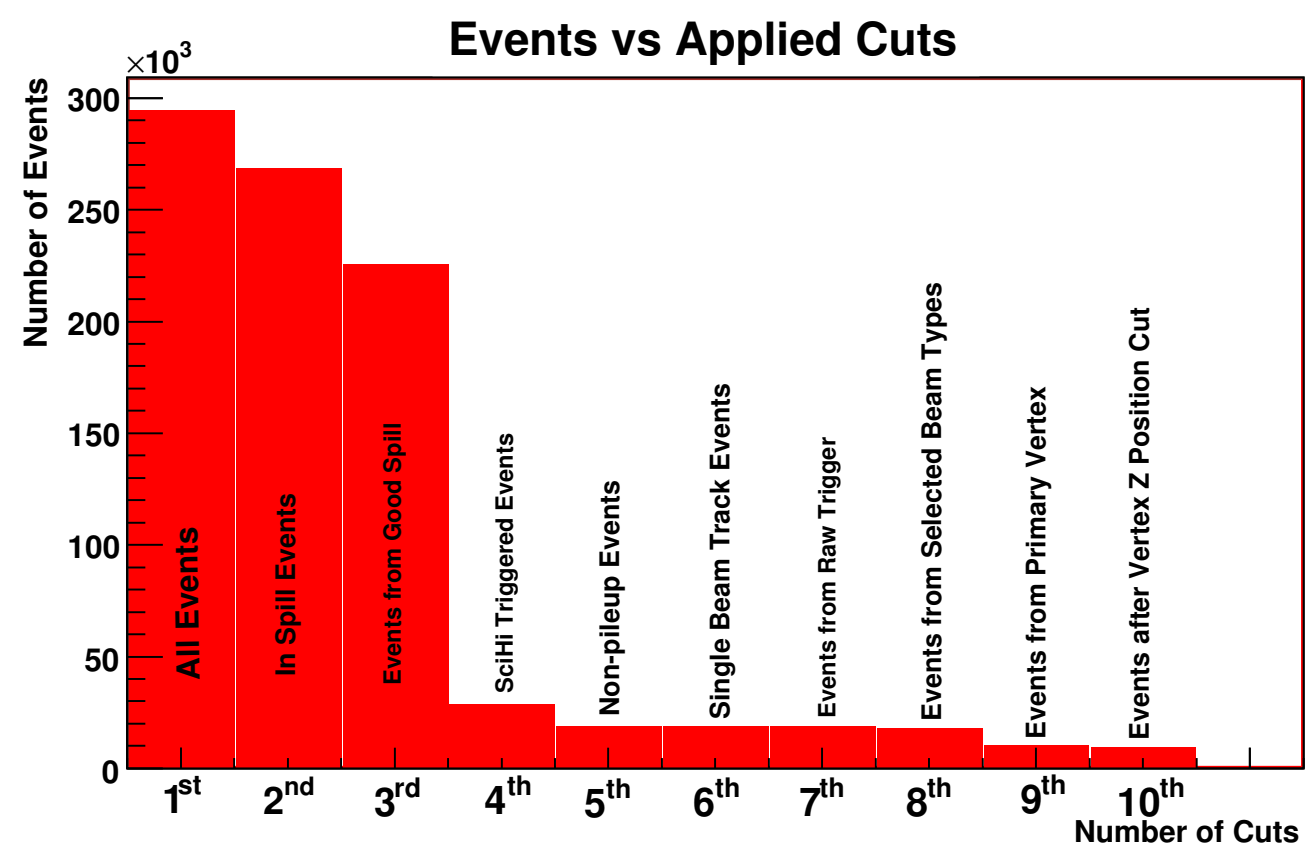

Figure 6.11: In the first bin of this plot, there is no cut applied but the following seven bins show applied cuts on events and last two bins show applied cuts on vertex.

of the 'pid-beams' (bits 4,5,6). Thus we also need to determine the beam pileup of nonidentical particles. As the second beam particle in a pile-up is random, we need to get the three particle fractions of $\pi,{ }^{+} K,^{+}$and $p$ in the beam using events triggered by bit 0 (of which there are around $5 \%$ in each run). We applied these fractions to correct our $R_{p}$ ratio.

In order to achieve my goal, I checked beam particle fractions in trigger-bit zero. Then I obtained each beam particles' fraction and labeled it in equation 6.5 as a $R_{b f r a c t i o n}$. So, the beam particles $K,{ }^{+} \pi,{ }^{+}$and $p$ had their own fraction numbers. After that, I subtracted the square of each fraction multiplied by the event pileup ratio, $R_{p}$, from 1 to calculate the corrected beam flux numbers, labeled in equation 6.5 .

$$
R_{\text {plux }}=1-\left(R_{b f r a c t i o n}^{2} \times R_{p}\right)
$$

where, 
- $R_{p f l u x}=$ Corrected ratio to apply to beam flux

- $R_{\text {bfraction }}=$ Beam particle fractions in trigger bit 0

These corrections to beam fluxes have an effect on the cross-section values since $p, K^{+}$, and $\pi^{+}$beam fluxes were reduced by factors of $23.4 \%, 0.01 \%$, and $1.3 \%$ respectively. Finally, when I applied these beam flux numbers to the crosssection calculations, the values of the cross sections increased based on these factors since the beam flux number appears in the cross section formula as a denominator.

\subsection{Error Measurements}

When the cross-sections are calculated, statistical and systematical errors are computed as well. In this study, statistical error calculations are done by considering particle yields from full target and empty target, beam flux, and detector acceptance values. In terms of systematical errors, effects of interaction trigger efficiency variations, primary vertex z position cut, beam flux, and pileup events cut on cross-sections are studied.

To calculate systematical error that originates from trigger efficiency, I changed efficiency numbers at first to $3 \%$ and then to $5 \%$, but these changes did not affect cross-section numbers. Hpwever, $10 \%$ differences up and down from the nominal trigger efficiency numbers caused some changes to cross-sections. Using these updown and nominal cross section numbers, effects of trigger efficiency on systematics were calculated.

A primary vertex z position cut also gives systematic error values. As with the nominal numbers, I applied a cut between $-832 \mathrm{~cm}$ and $-822 \mathrm{~cm}$ on vertex $\mathrm{z}$ position and from this cut an empty target scale factor was obtained. When the cut places are varied by $+3 \mathrm{~cm}$ and $-3 \mathrm{~cm}$, new cross-sections are obtained different from the nominal values. This allows systematic errors coming from the primary vertex z position cut to be computed. 

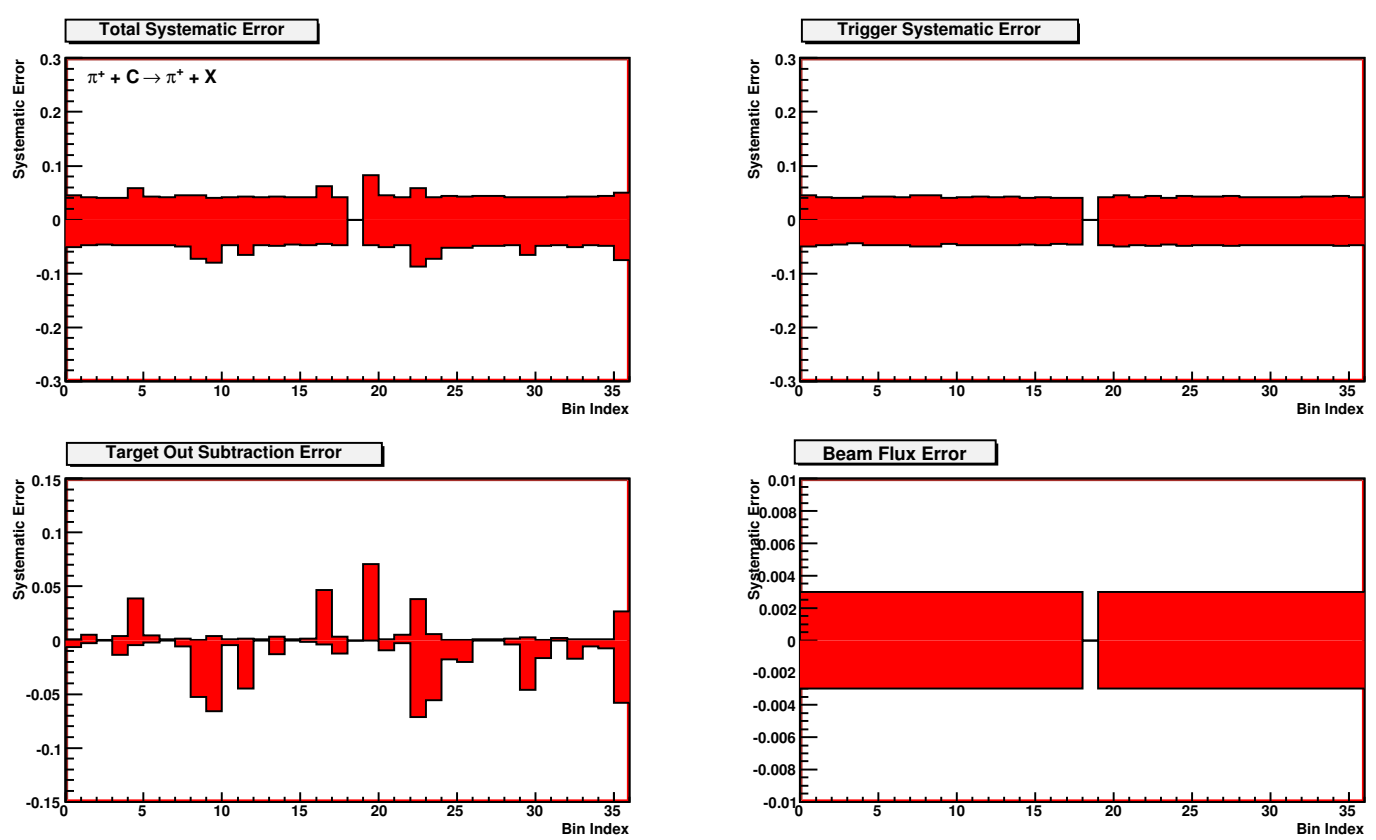

Figure 6.12: Systematic errors of the $\pi^{+}$cross-section that is produced by pioncarbon interactions at $58 \mathrm{GeV}$ energy.
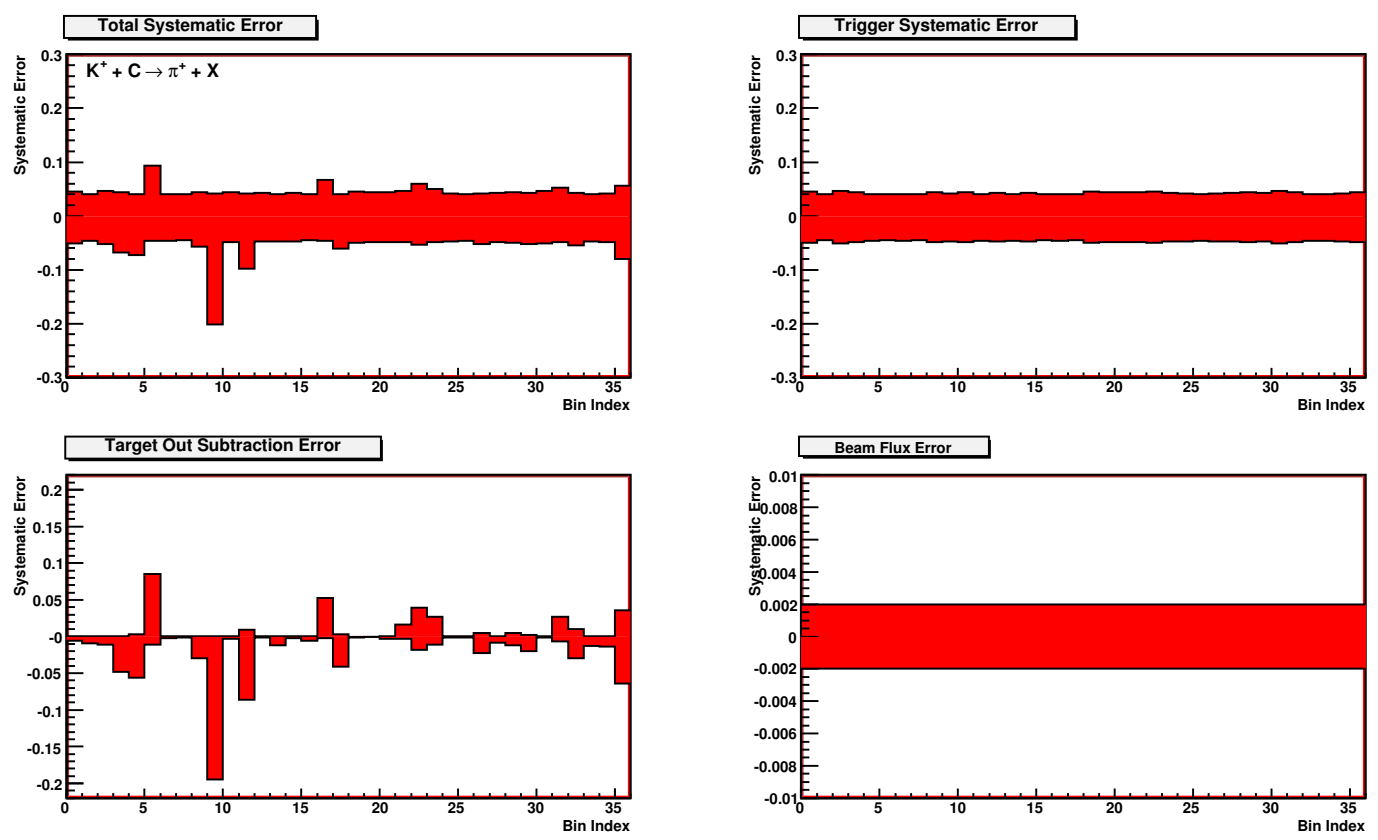

Figure 6.13: Systematic errors of the $\pi^{+}$cross-section that is produced by kaoncarbon interactions at $58 \mathrm{GeV}$ energy. 

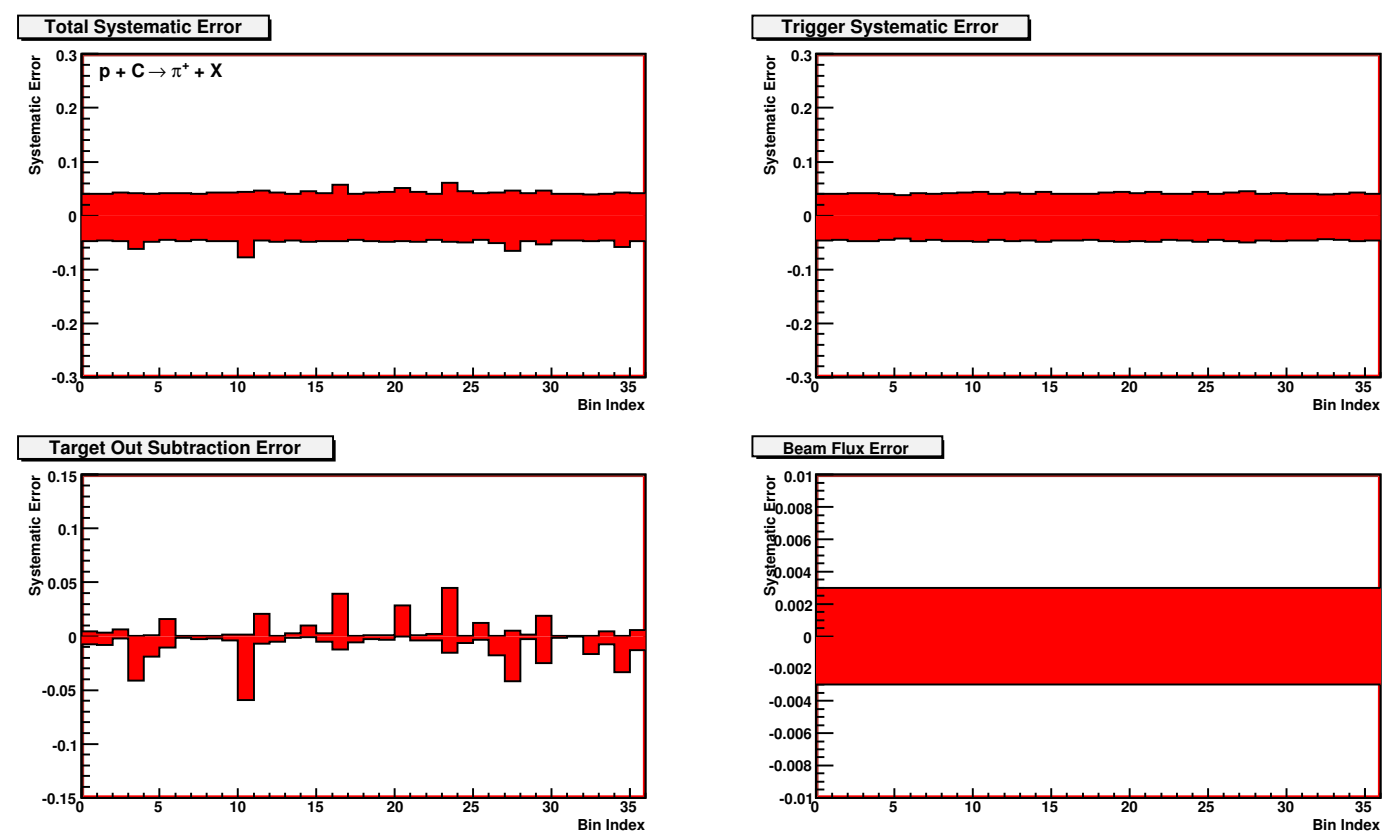

Figure 6.14: Systematic errors of the $\pi^{+}$cross-section that is produced by protoncarbon interactions at $58 \mathrm{GeV}$ energy.

The beam flux effect on systematic errors is computed by using two different beam flux calculation methods. These different values are presented in Tables 6.1 and 6.2. Using these differences, systematic errors caused by beam flux are calculated. All types of systematical errors are shown in chapter 7 for each anglemomentum bin.

Another systematic error source is a pileup events cut that also varies crosssection values after changing its parameters by $10 \%$ up and down. I only changed the required T0 ADC's minimum and maximum values to see the effect of pileup events cuts on cross-sections. Before doing these up and down changes, the nominal events number from my analysis was 9429, but the number of events were 9615 and 8972 after applying a pileup events cut 10\% up and 10\% down, respectively. These variations change the cross-section by $0.97 \%$ higher and $2.48 \%$ lower. 

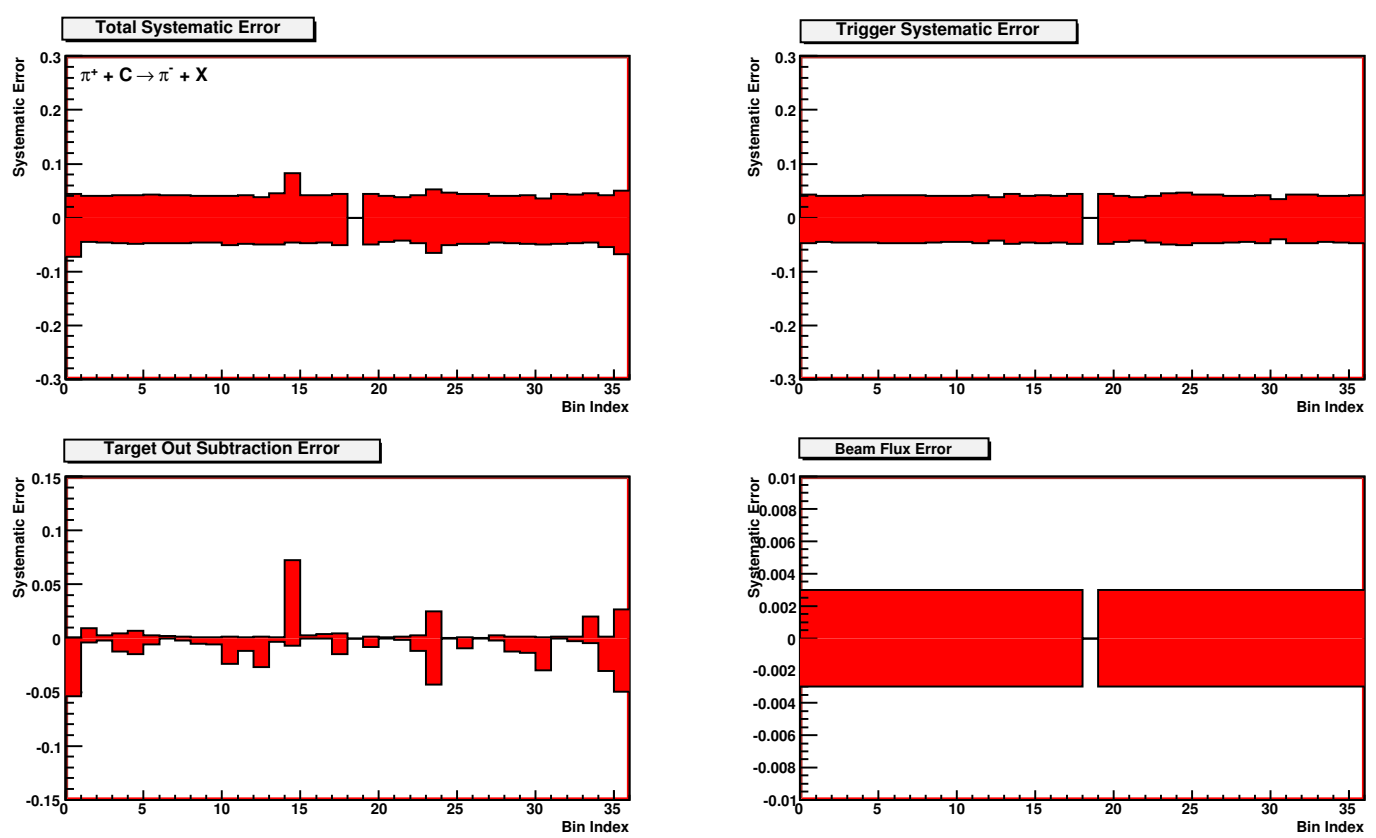

Figure 6.15: Systematic errors of the $\pi^{-}$cross-section that is produced by pioncarbon interactions at $58 \mathrm{GeV}$ energy.
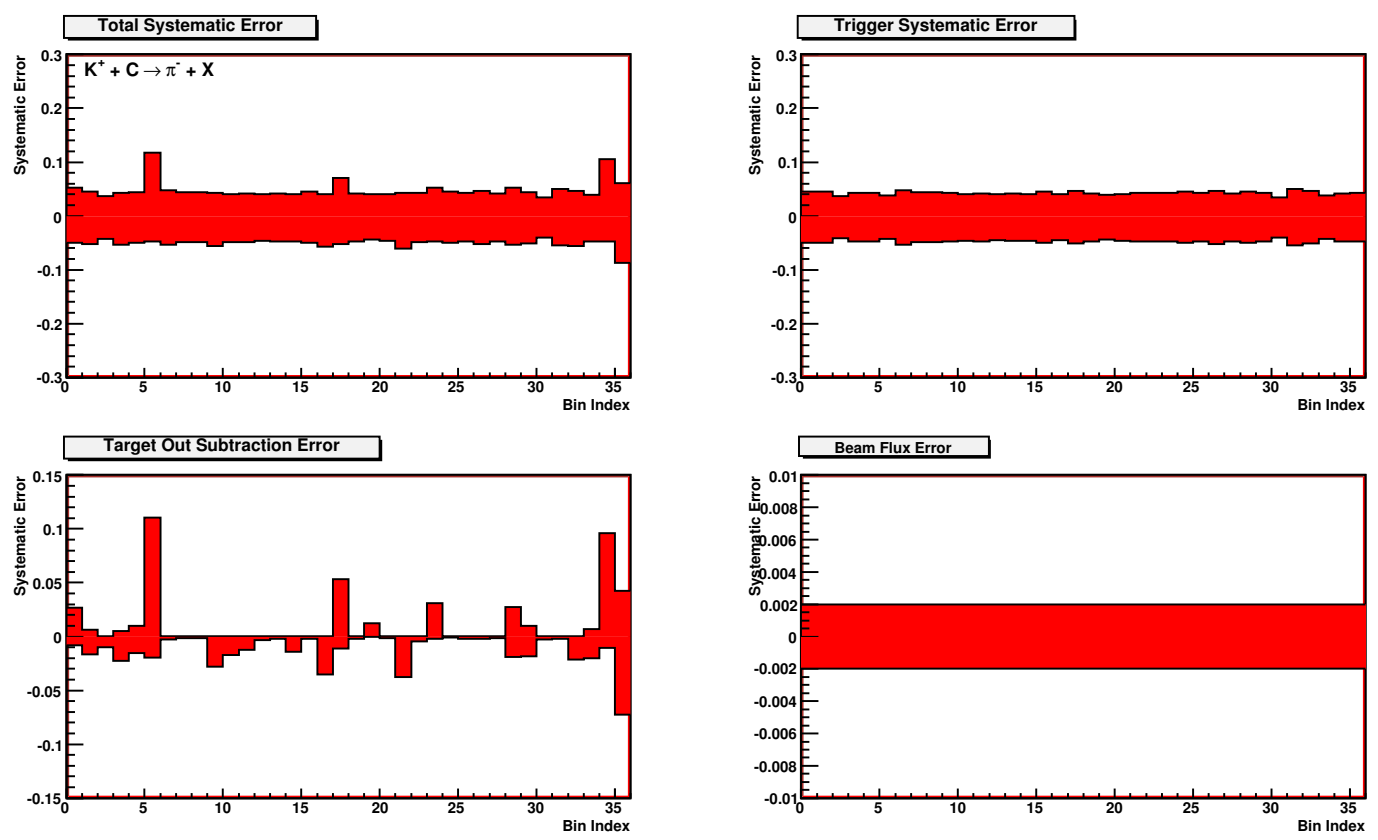

Figure 6.16: Systematic errors of the $\pi^{-}$cross-section that is produced by kaoncarbon interactions at $58 \mathrm{GeV}$ energy. 

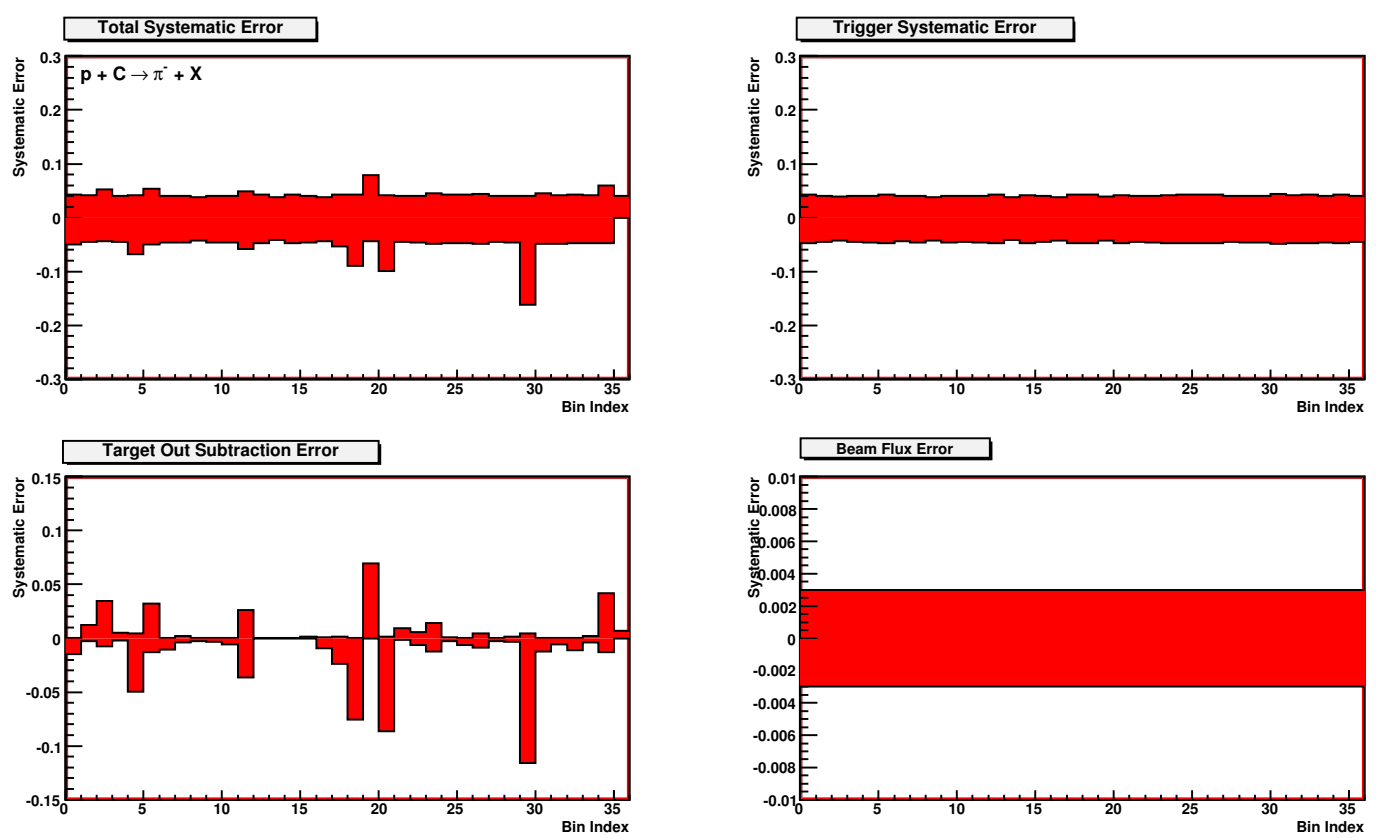

Figure 6.17: Systematic errors of the $\pi^{-}$cross-section that is produced by protoncarbon interactions at $58 \mathrm{GeV}$ energy.
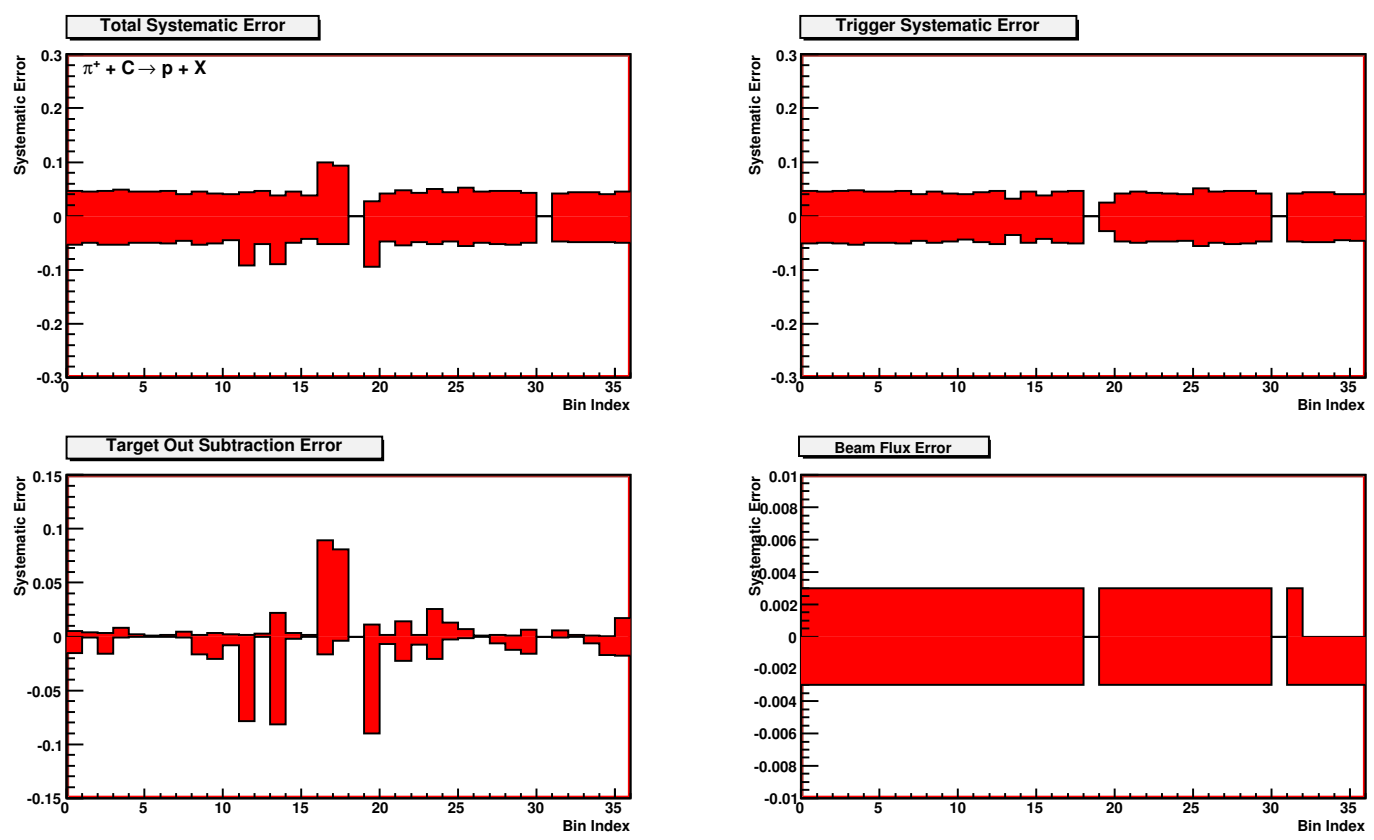

Figure 6.18: Systematic errors of the $\boldsymbol{p}$ cross-section that is produced by pioncarbon interactions at $58 \mathrm{GeV}$ energy. 

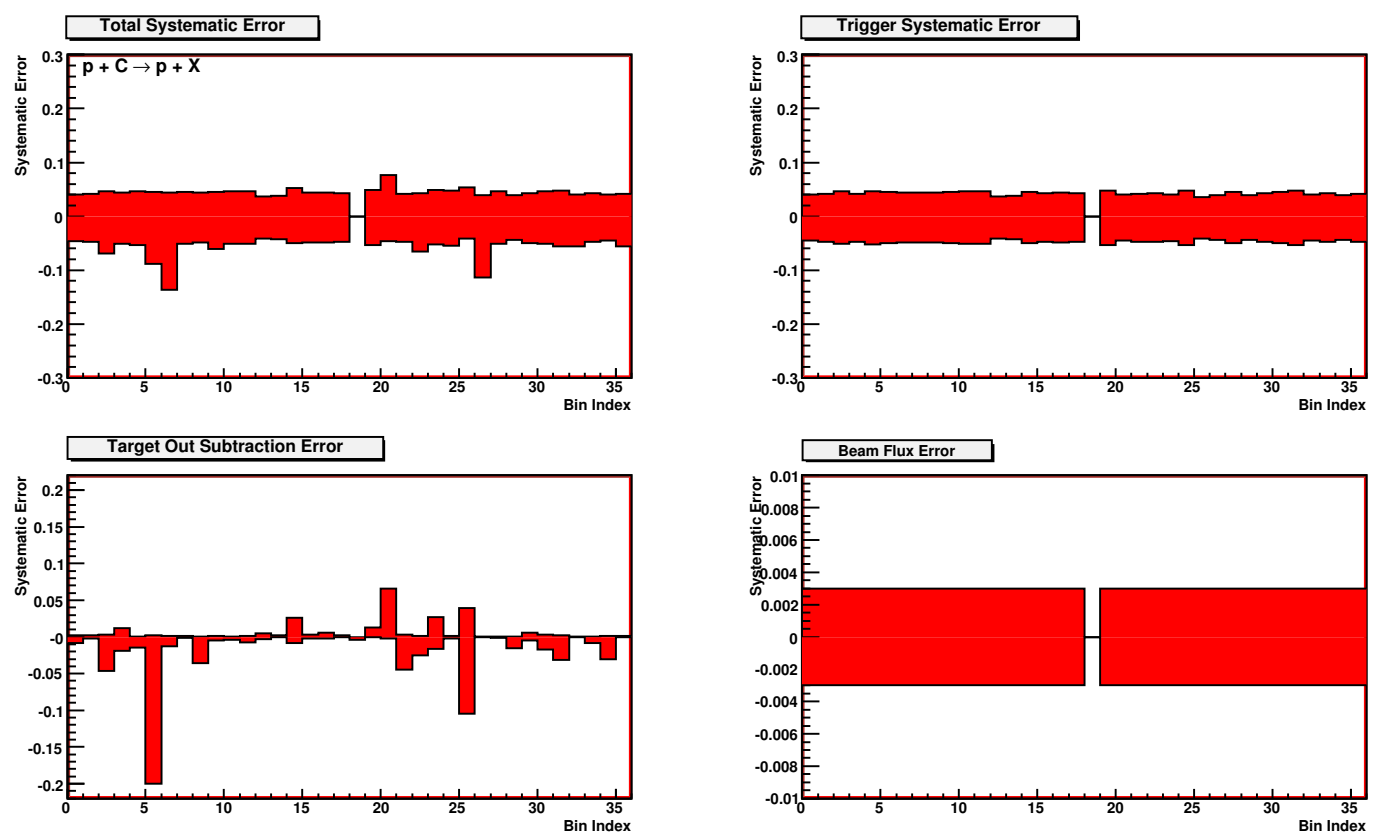

Figure 6.19: Systematic errors of the $\boldsymbol{p}$ cross-section that is produced by protoncarbon interactions at $58 \mathrm{GeV}$ energy. 


\section{CHAPTER 7 \\ RESULTS}

In this chapter, the MIPP's cross-section measurements are presented. Incoming beam particle momentum is set to $58 \mathrm{GeV} / \mathrm{c}$, and three positive species are used to compute cross sections.

First of all, angle bins and momentum bins are studied. I had to work on produced particles which are outgoing by small angles because of the detectors' acceptance. So, angle bins were selected between $0^{\circ}$ and $40^{\circ}$. When momentum bins were selected, the detectors' acceptance limited our working range. I used one particle identification detector, TPC, out of the four systems. Although PID can be done by each detectors separately with using maximum likelihood methods, it is not possible to do particle identification using the GlobalPid method. Based on the GlobalPid method, all PID detectors' information must be combined with their normalized likelihoods to compute cross-sections at all MIPP momentum ranges. However, this work has not been done yet. Therefore, I cannot show cross-section values beyond the $1.0 \mathrm{GeV} / \mathrm{c}$ momentum at this time.

To obtain cross-section results, angle bins versus momentum bins plots were created according to the produced particles' species. Produced $K^{ \pm}$and $\bar{p}$ are not presented in this work because there are fewer kaons and $\bar{p}$ produced, and more work needs to be done on those particle identifications. I also acquired angle-momentum bins from empty target data for background subtraction.

Using these angle bins, momentum bins and trigger efficiency values, cross sections are computed. Basically, in this momentum range, cross-section plots, (Figures 7.1 and 7.4) satisfy our expectations, but all systematic errors and detector acceptances need to be worked out meticulously. 

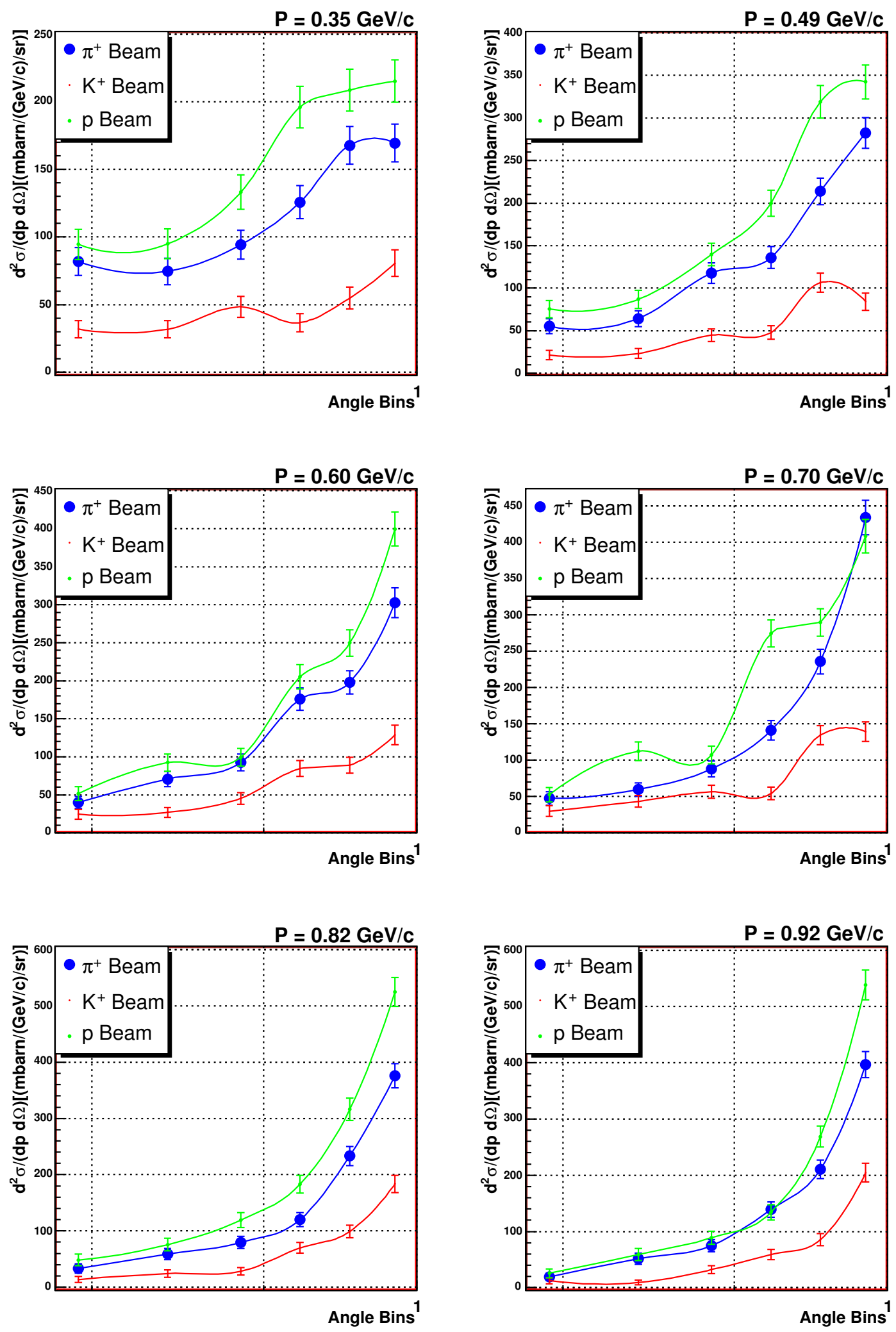

Figure 7.1: These are $\pi^{+}$cross section graphs that are created using impact of $p$, $K,{ }^{+} \pi^{+}$beams on a carbon target at $58 \mathrm{GeV}$ energy with respect to angle bins. The momentum bins can be found at the top right of each graph. 

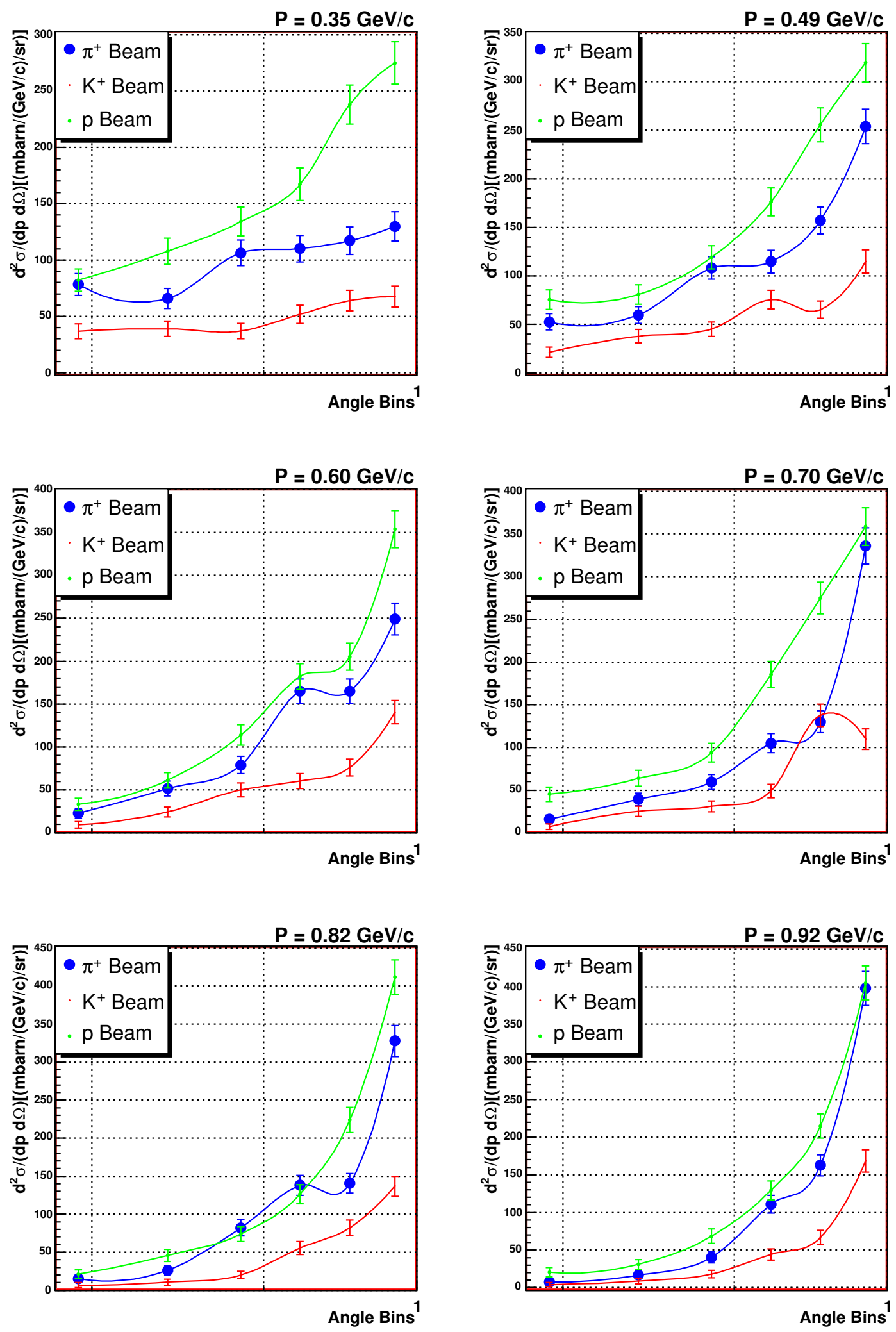

Figure 7.2: These are $\pi^{-}$cross section graphs that are created using impact of $p$, $K,{ }^{+} \pi^{+}$beams on a carbon target at $58 \mathrm{GeV}$ energy with respect to angle bins. The momentum bins can be found at the top right of each graph. 

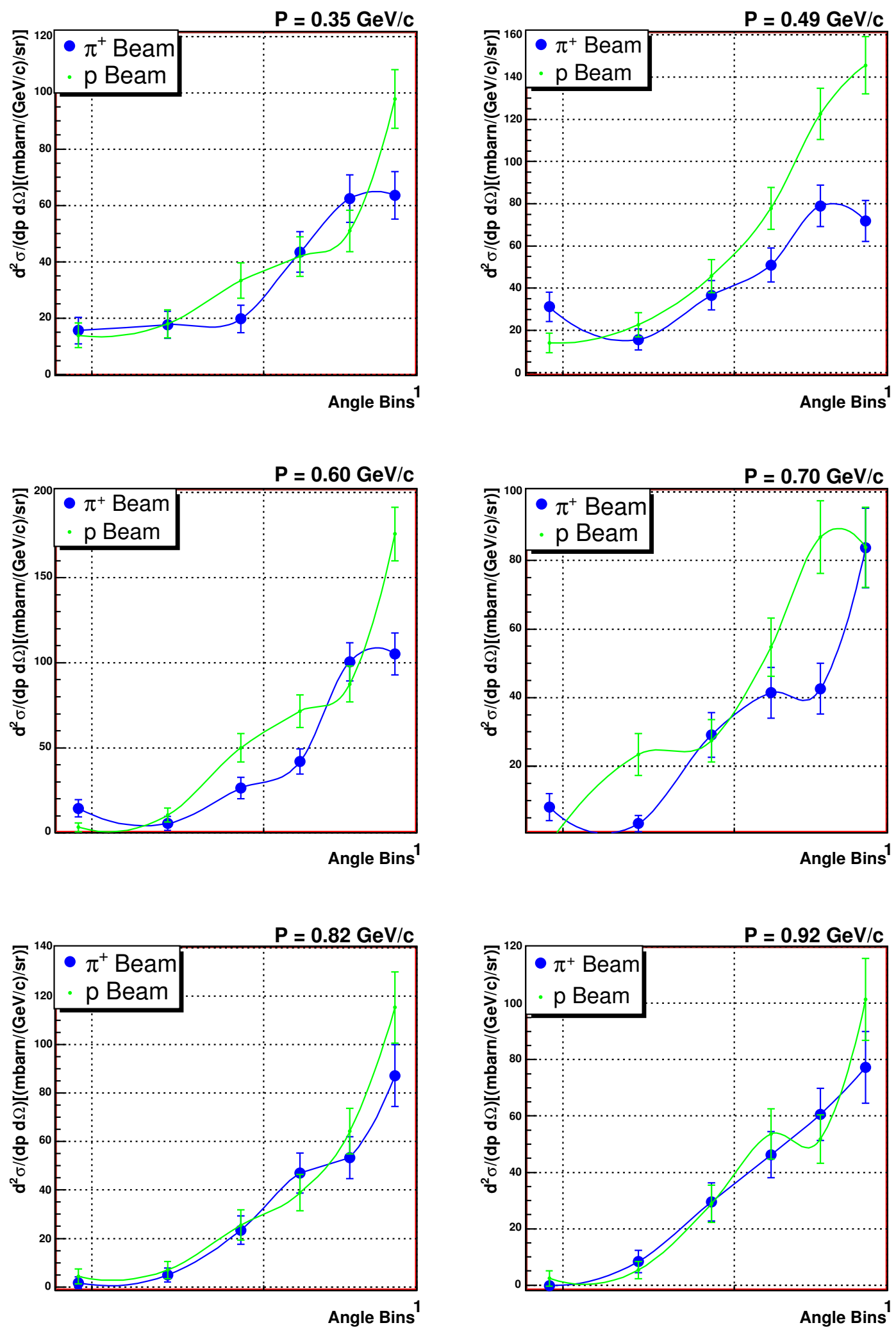

Figure 7.3: These are $p$ cross section graphs that are created using impact of $p$, and $\pi^{+}$beams on a carbon target at $58 \mathrm{GeV}$ energy with respect to angle bins. The momentum bins can be found at the top right of each graph. 

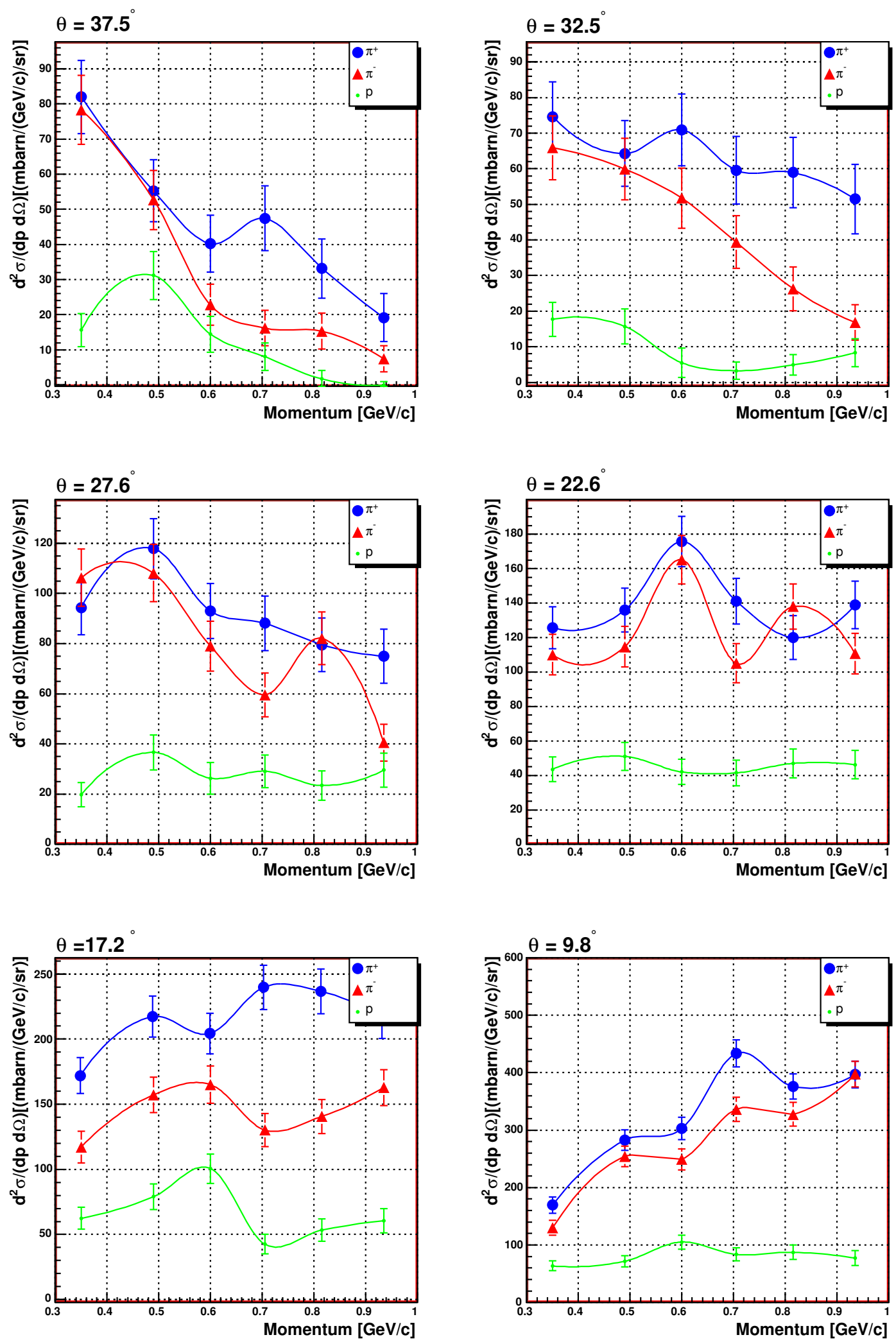

Figure 7.4: These are $\pi^{ \pm}$, and $p$ cross section graphs that are created using impact of $\pi^{+}$beam on a carbon target at $58 \mathrm{GeV}$ energy with respect to momentum bins. The angle bins can be found at the top left of each graph. 

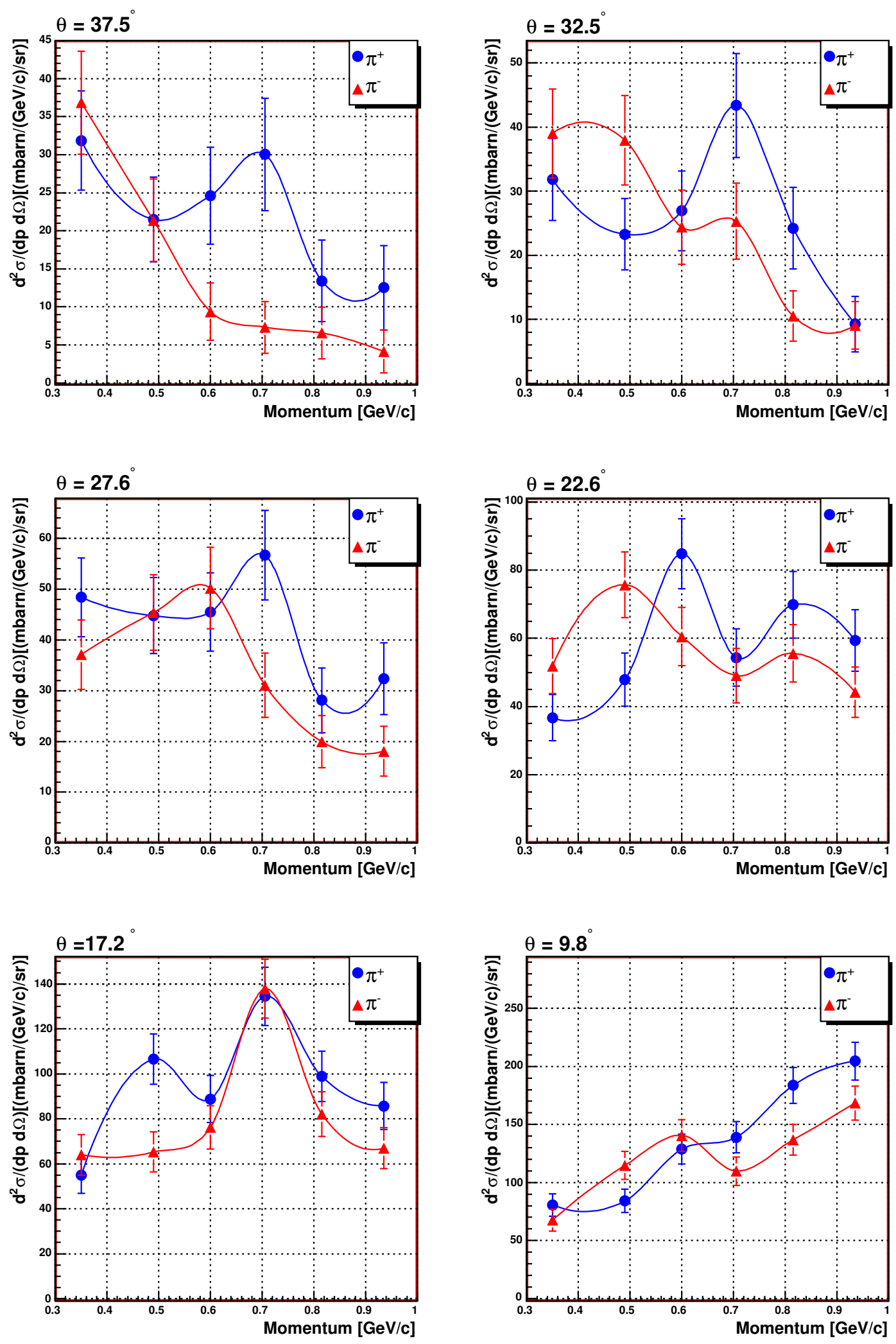

Figure 7.5: These are $\pi^{ \pm}$cross section graphs that are created using impact of $K^{+}$ beam on a carbon target at $58 \mathrm{GeV}$ energy with respect to momentum bins. The angle bins can be found at the top left of each graph. 

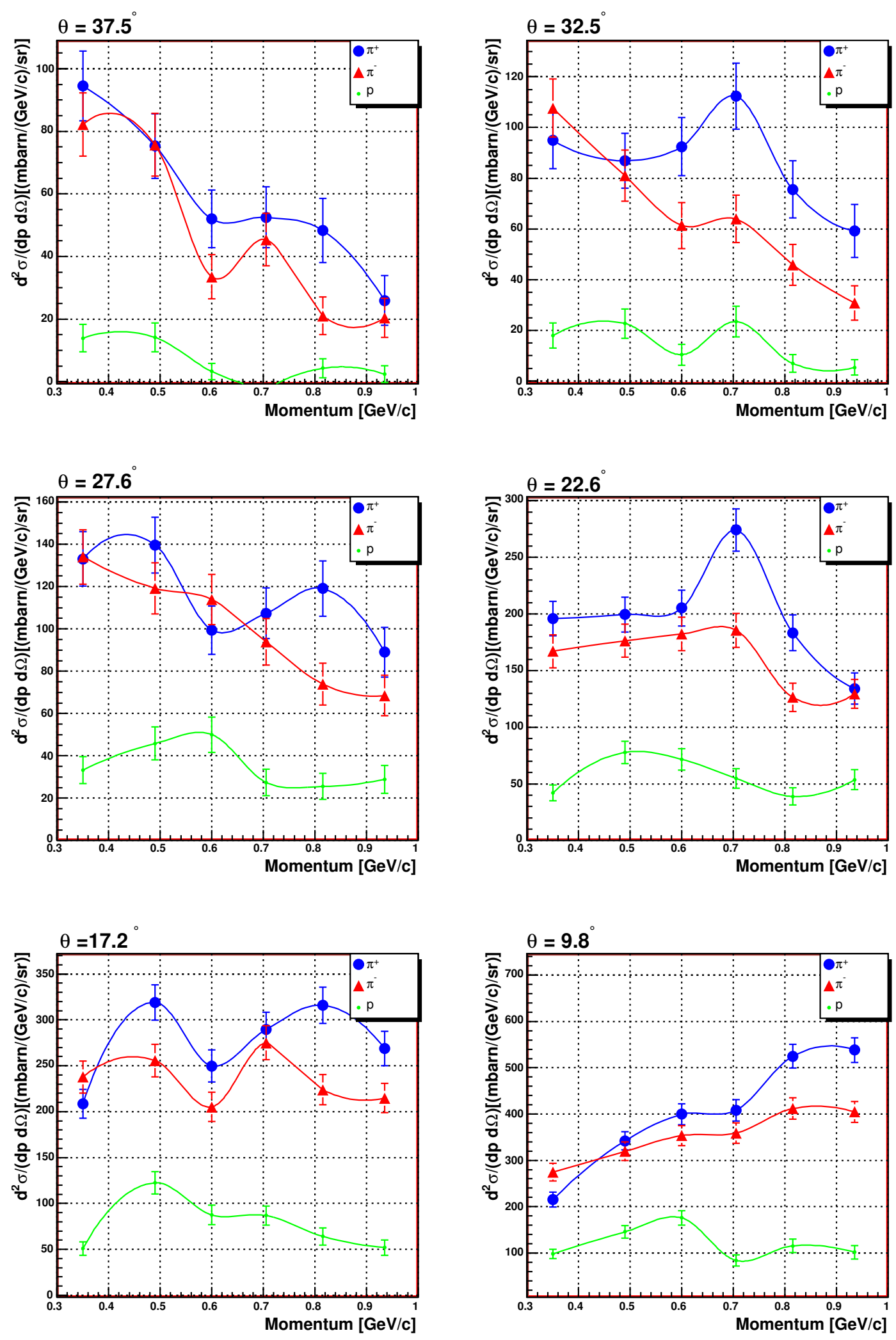

Figure 7.6: These are $\pi^{ \pm}$, and $p$ cross section graphs that are created using impact of $p$ beam on a carbon target at $58 \mathrm{GeV}$ energy with respect to momentum bins. The angle bins can be found at the top left of each graph. 

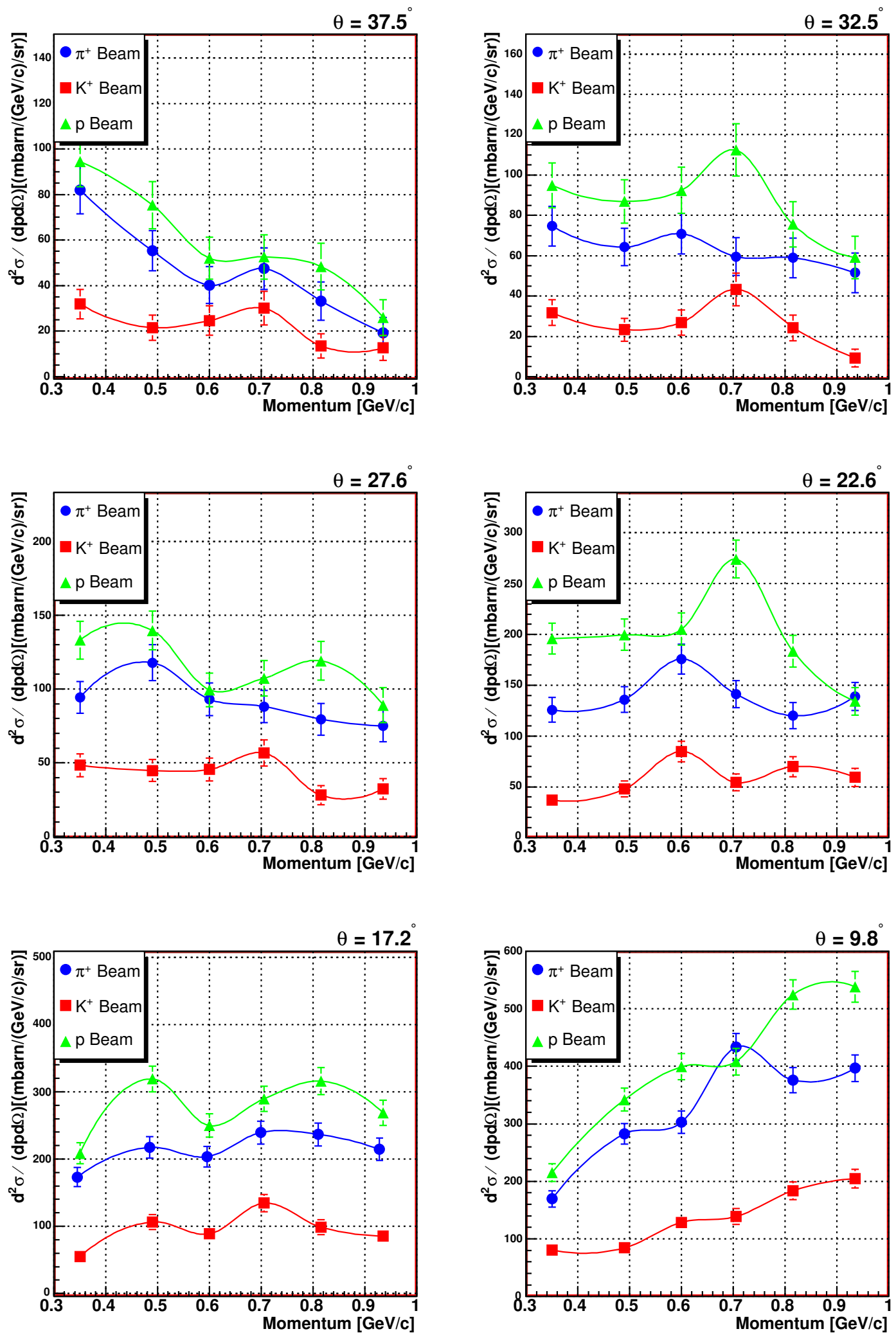

Figure 7.7: These are $\pi^{+}$cross section graphs that are created using impact of $p$, $K,{ }^{+}$and $\pi^{+}$beams on a carbon target at $58 \mathrm{GeV}$ energy with respect to momentum bins. The angle bins can be found at the top right of each graph. 

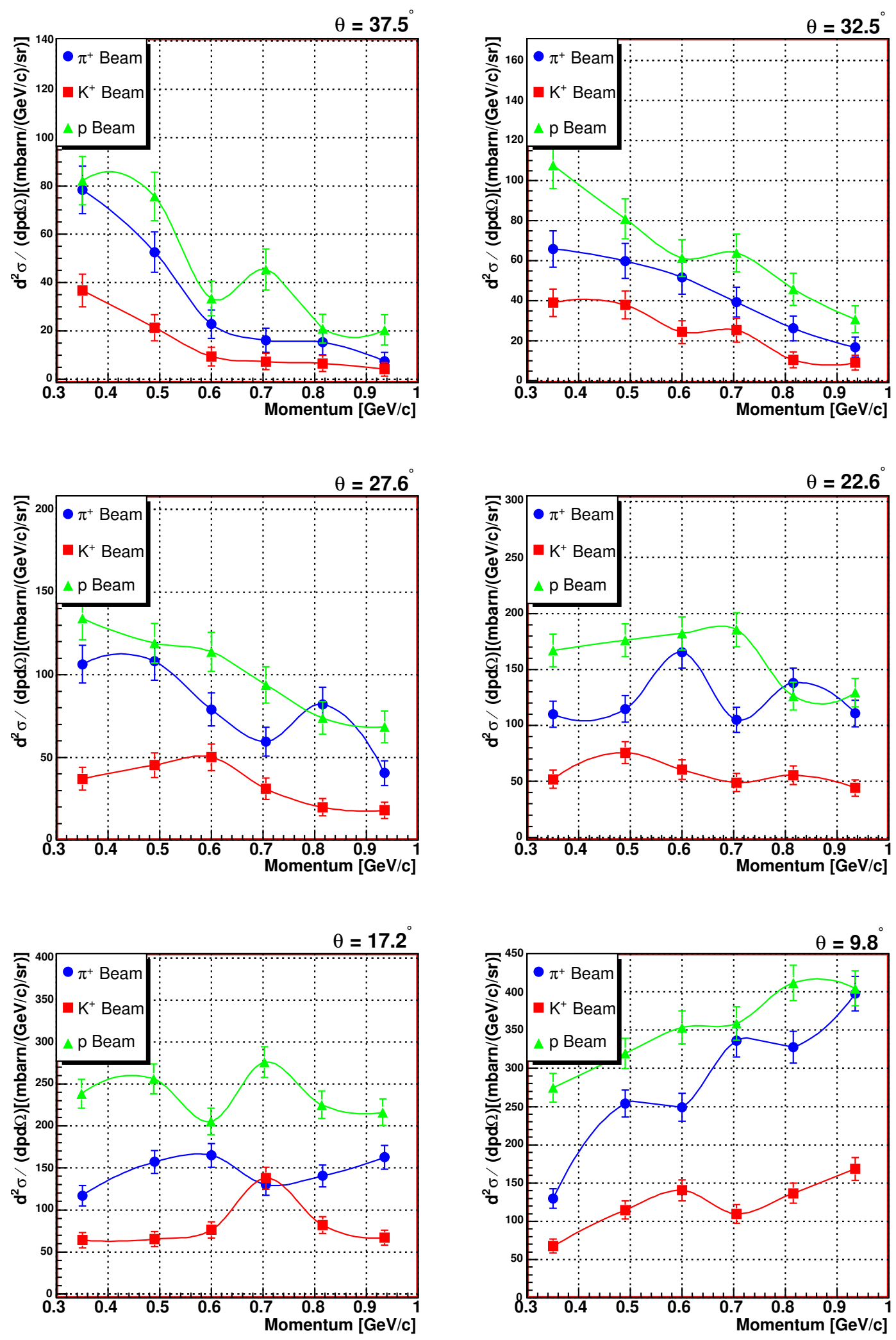

Figure 7.8: These are $\pi^{-}$cross section graphs that are created using impact of $p$, $K,{ }^{+}$and $\pi^{+}$beams on a carbon target at $58 \mathrm{GeV}$ energy with respect to momentum bins. The angle bins can be found at the top right of each graph. 

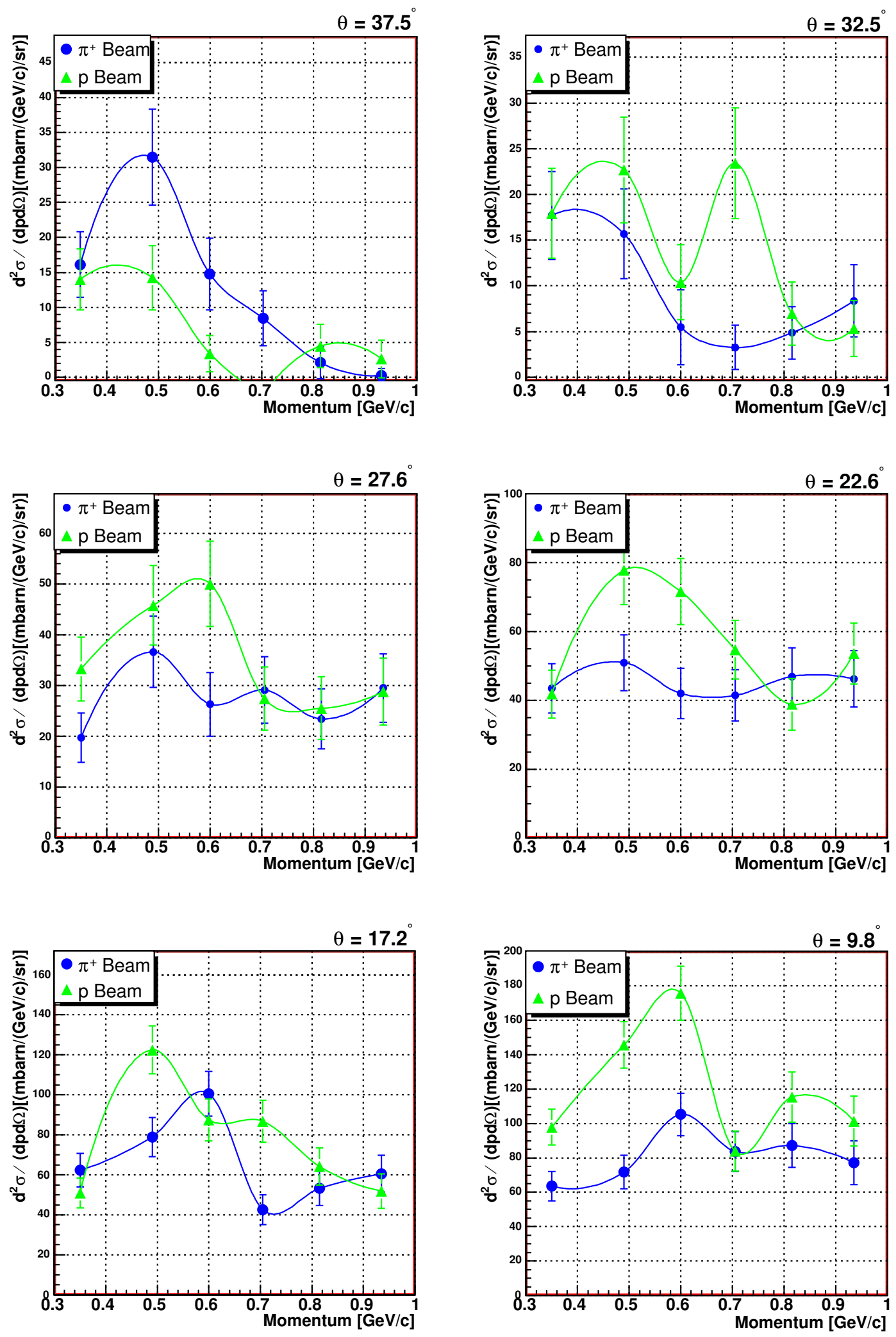

Figure 7.9: These are $p$ cross section graphs that are created using impact of $p$, and $\pi^{+}$beams on a carbon target at $58 \mathrm{GeV}$ energy with respect to momentum bins. The angle bins can be found at the top right of each graph. 

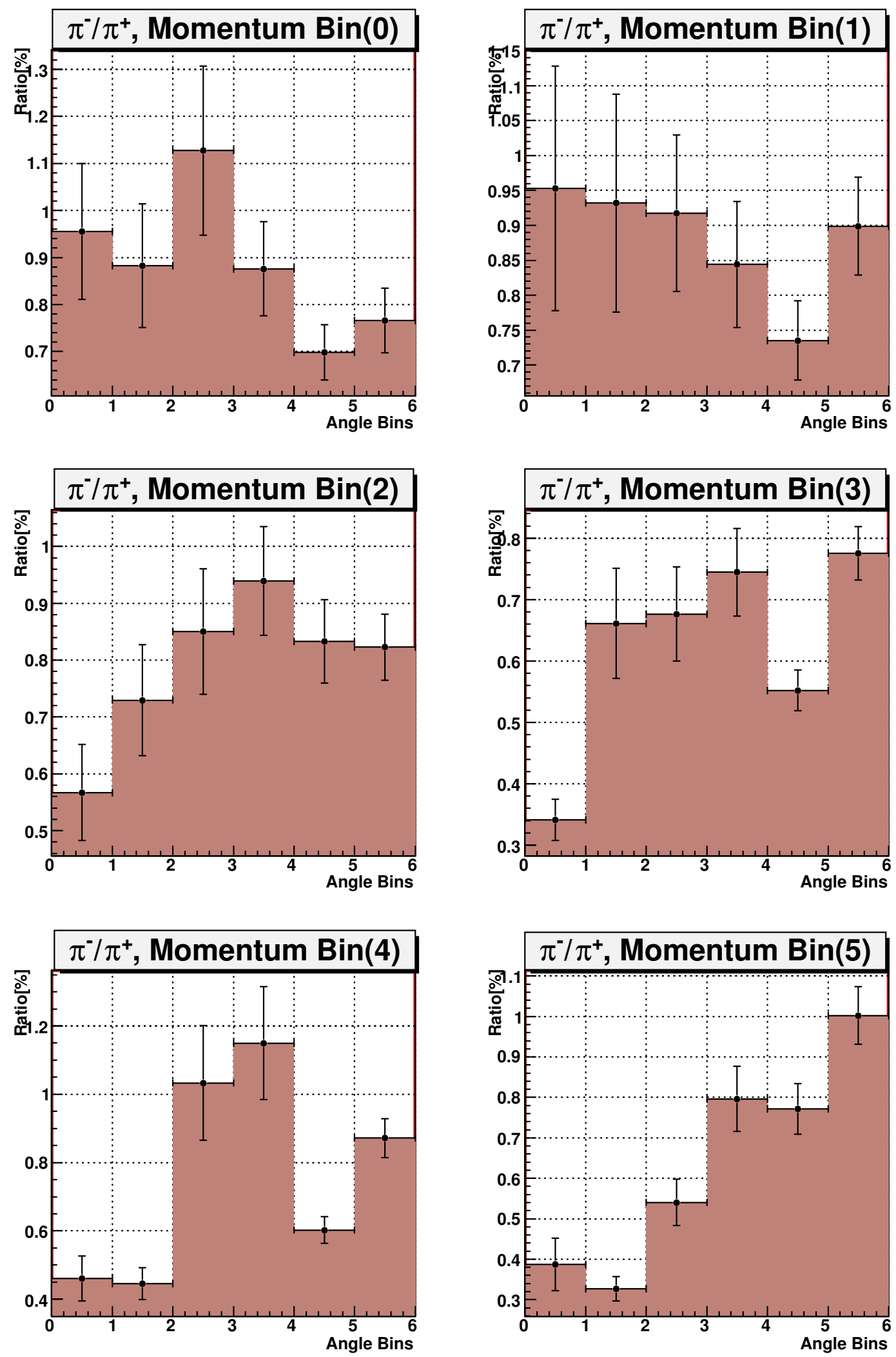

Figure 7.10: $\pi^{-} / \pi^{+}$ratio is extracted from $\pi^{+}$beam interactions on a carbon target at $58 \mathrm{GeV}$ energy. 

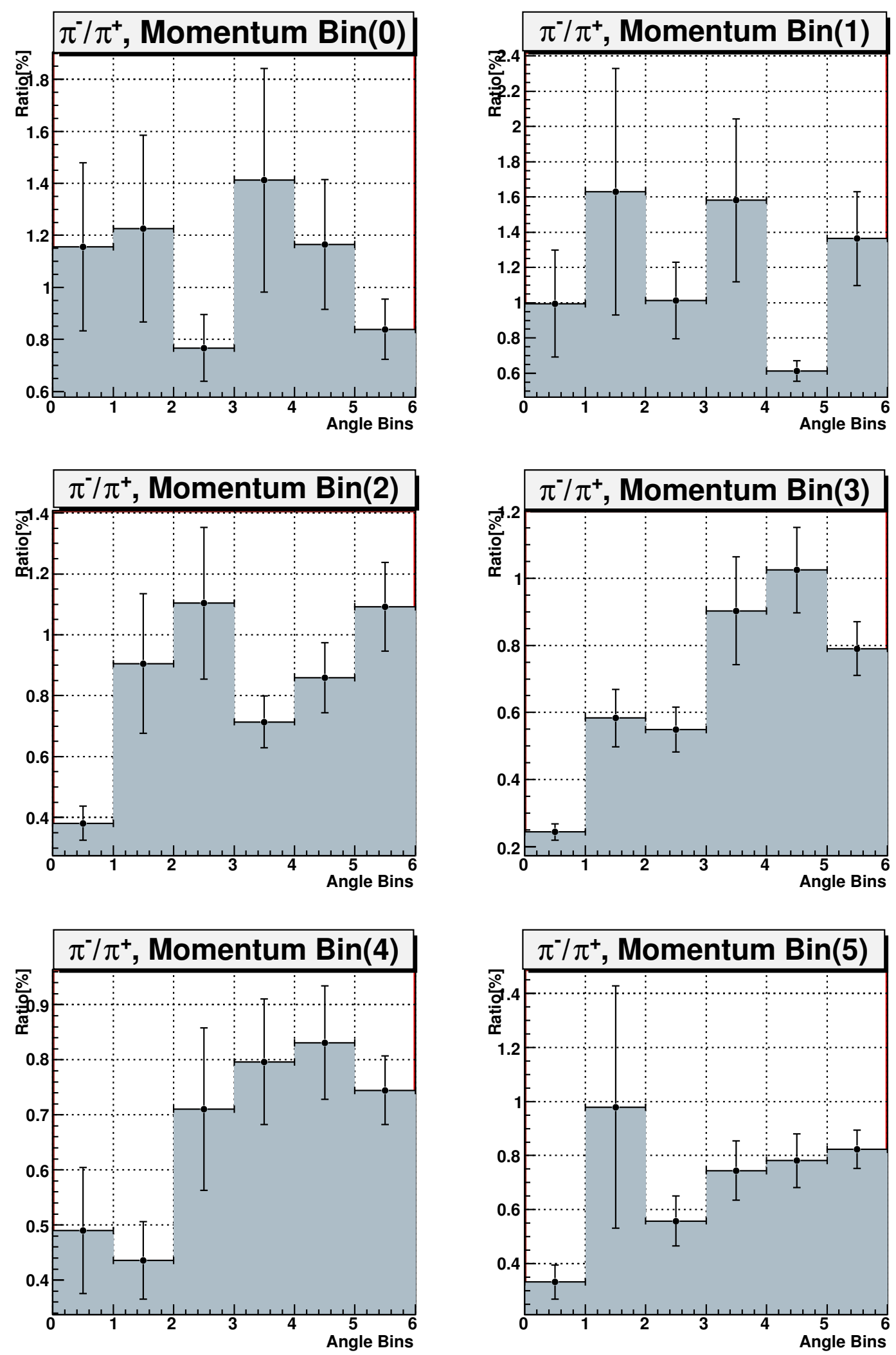

Figure 7.11: $\pi^{-} / \pi^{+}$ratio is extracted from $K^{+}$beam interactions on a carbon target at $58 \mathrm{GeV}$ energy. 

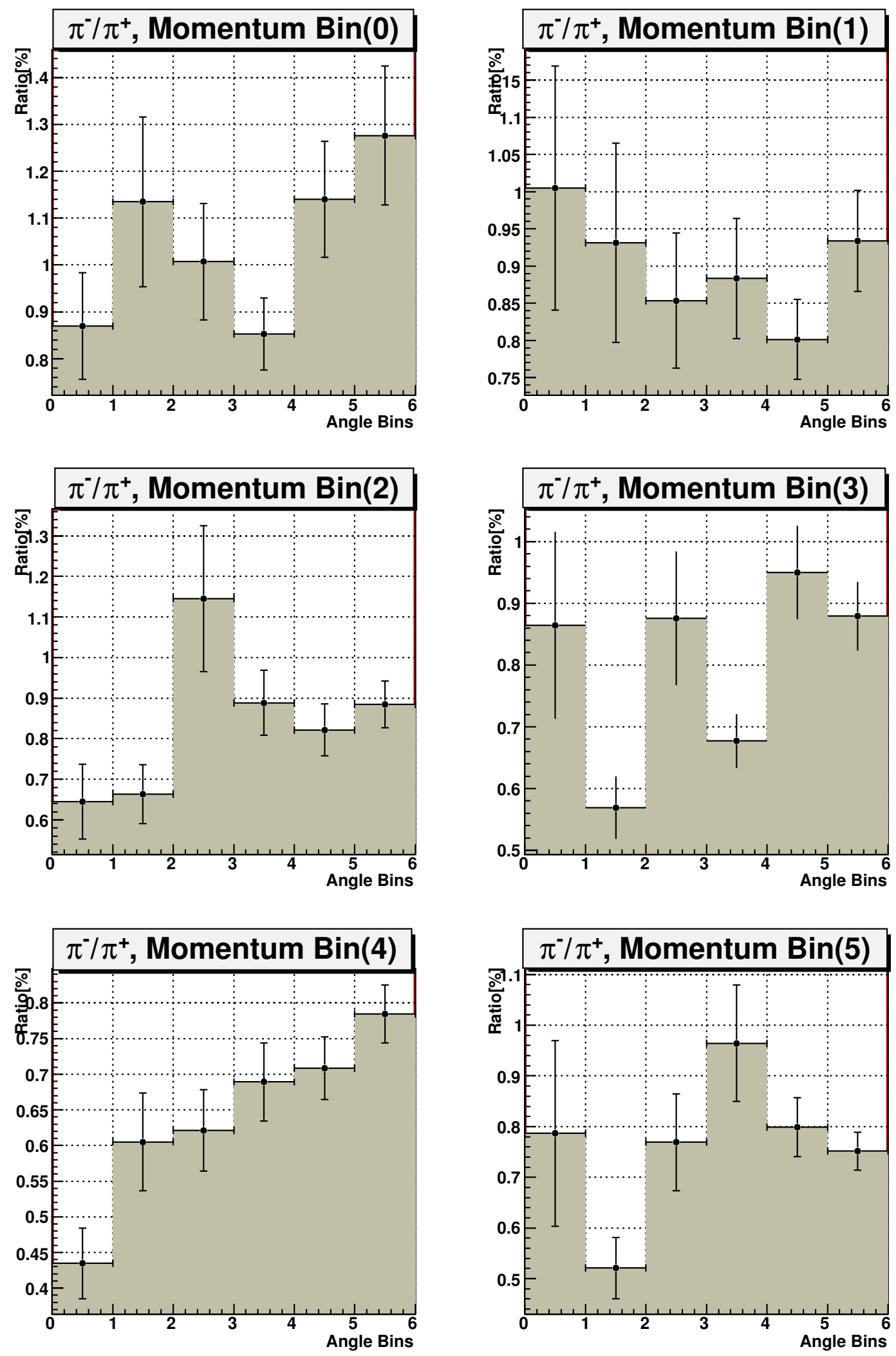

Figure 7.12: $\pi^{-} / \pi^{+}$ratio is extracted from $p$ beam iinteractions on a carbon target at $58 \mathrm{GeV}$ energy. 
Table 7.1: Cross section numbers and errors for $\pi^{+}+C \rightarrow \pi^{+}+X$. All errors are shown in percentage except the total errors that are shown next to the cross-section.

\begin{tabular}{|c|c|c|c|c|c|c|c|}
\hline \multirow[b]{2}{*}{ Bin } & \multirow[b]{2}{*}{$\begin{array}{l}\frac{0}{0} \\
\frac{0}{0} \\
\frac{0}{n} \\
0\end{array}$} & \multirow[b]{2}{*}{$\frac{d^{2} \sigma_{\pi^{+}}}{d p d \Omega}$} & \multicolumn{5}{|c|}{ Errors in Percentage } \\
\hline & & & 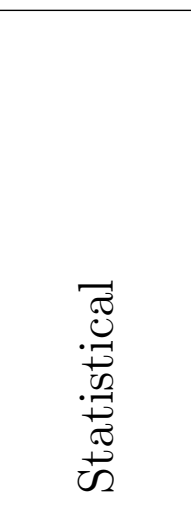 & 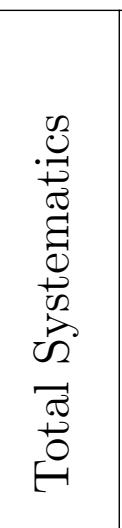 & 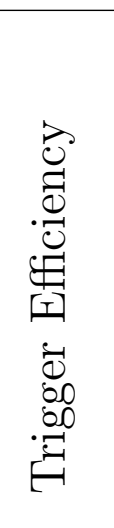 & 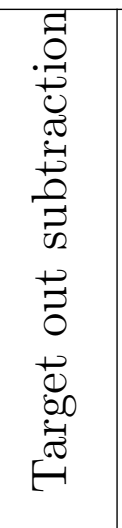 & 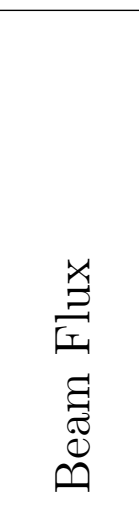 \\
\hline$(0,0)$ & $0.35,0.79$ & $81.98_{-11.20}^{+11.05}$ & \pm 12.7 & & ${ }_{-5}^{+4.5}$ & $\begin{array}{l}+0.09 \\
-0.63 \\
\end{array}$ & \pm 0.3 \\
\hline$(0,1)$ & $0.35,0.84$ & $74.65_{-10}^{+10}$ & \pm 13.16 & & & $\begin{array}{l}+0.52 \\
-0.27 \\
-0.7\end{array}$ & \pm 0.3 \\
\hline$(0,2)$ & $0.35,0.89$ & $94.32+11.44$ & \pm 11.42 & $\begin{array}{l}+4.09 \\
-4.58 \\
\end{array}$ & $\begin{array}{l}+4.08 \\
-4.57 \\
\end{array}$ & $\begin{array}{l}+0.04 \\
-0.03 \\
\end{array}$ & \pm 0.3 \\
\hline$(0,3)$ & $0.35,0.92$ & $125.74_{-13.56}^{+13.22}$ & \pm 9.73 & & $\begin{array}{l}+3.95 \\
-4.43 \\
\end{array}$ & $\begin{array}{l}+0.37 \\
-1.35 \\
\end{array}$ & \pm 0.3 \\
\hline$(0,4)$ & $0.35,0.95$ & $167.77_{-16.09}^{+17.00}$ & \pm 8.31 & $\begin{array}{l}+5.8 \\
-4.79 \\
\end{array}$ & $\begin{array}{l}+4.26 \\
-4.76 \\
\end{array}$ & $\begin{array}{l}+3.91 \\
-0.44 \\
\end{array}$ & \pm 0.3 \\
\hline$(0,5)$ & $0.35,0.99$ & $169.49_{-16.22}^{+15.83}$ & \pm 8.27 & $\begin{array}{l}+4.34 \\
-4.82 \\
\end{array}$ & $\begin{array}{l}+4.3 \\
-4.8 \\
\end{array}$ & $\begin{array}{l}+0.45 \\
-0.18 \\
\end{array}$ & \pm 0.3 \\
\hline$(1,0)$ & $0.49,0.79$ & $55.22_{-9.21}^{+9.14}$ & \pm 16 & & $\begin{array}{l}+4.2 \\
+4.7 \\
\end{array}$ & $\begin{array}{l}+0.08 \\
-0.02 \\
\end{array}$ & \pm 0.3 \\
\hline$(1,1)$ & $0.49,0.84$ & $64.27_{-9.79}^{+9.68}$ & \pm 14.38 & & $\begin{array}{l}+4.46 \\
-4.96 \\
\end{array}$ & $\begin{array}{l}+0.17 \\
-0.58 \\
\end{array}$ & \pm 0.3 \\
\hline$(1,2)$ & $0.49,0.89$ & $117.84_{-14.80}^{+13.19}$ & \pm 10.24 & $\begin{array}{l}+4.53 \\
-7.27\end{array}$ & $\begin{array}{l}+4.51 \\
-5.01\end{array}$ & $\begin{array}{l}+0.04 \\
-5.25\end{array}$ & \pm 0.3 \\
\hline$(1,3)$ & $0.49,0.92$ & $135.93_{-16.77}^{+13.91}$ & \pm 9.39 & $\begin{array}{l}+8.06 \\
-8\end{array}$ & $\begin{array}{l}+4.03 \\
-4.52 \\
\end{array}$ & $\begin{array}{l}+0.39 \\
-6.59 \\
\end{array}$ & \pm 0.3 \\
\hline$(1,4)$ & $0.49,0.95$ & $213.8_{-18.69}^{+18.12}$ & \pm 7.36 & $\begin{array}{l}+4.2 \\
-4.72 \\
\end{array}$ & & $\begin{array}{l}+0.11 \\
-0.44 \\
\end{array}$ & \pm 0.3 \\
\hline$(1,5)$ & $0.49,0.99$ & $282.599_{-25.90}^{+21.79}$ & \pm 6.38 & $\begin{array}{l}+4.33 \\
-6.58 \\
\end{array}$ & $\begin{array}{l}+4.31 \\
-4.81 \\
\end{array}$ & $\begin{array}{l}+0.17 \\
-4.49 \\
\end{array}$ & \pm 0.3 \\
\hline$(2,0)$ & $0.6,0.79$ & $40.18_{-8.30}^{+8.26}$ & \pm 20.13 & $\begin{array}{l}+4.2 \\
-4.69 \\
\end{array}$ & $\begin{array}{l}+4.18 \\
-4.68 \\
\end{array}$ & $\begin{array}{l}+0.08 \\
-0.02 \\
\end{array}$ & \pm 0.3 \\
\hline$(2,1)$ & $0.6,0.84$ & $70.92_{-10.68}^{+10.54}$ & \pm 14.23 & & & $\begin{array}{l}+0.36 \\
-1.27 \\
\end{array}$ & \pm 0.3 \\
\hline$(2,2)$ & $0.6,0.89$ & $92.999_{-11.82}^{+11.66}$ & \pm 11.83 & $\begin{array}{l}+4.15 \\
-4.64 \\
\end{array}$ & $\begin{array}{l}+4.13 \\
-4.63 \\
\end{array}$ & $\begin{array}{l}+0.09 \\
-0.02 \\
\end{array}$ & \pm 0.3 \\
\hline$(2,3)$ & $0.6,0.92$ & $175.79_{-16.86}^{+16.45}$ & \pm 8.36 & $\begin{array}{l}+4.21 \\
-4.7\end{array}$ & $\begin{array}{l}+4.19 \\
-4.69 \\
\end{array}$ & $\begin{array}{l}+0.13 \\
-0.14 \\
\end{array}$ & \pm 0.3 \\
\hline$(2,4)$ & $0.6,0.95$ & $198.13_{-17.87}^{+19.68}$ & & $\begin{array}{l}+6.15 \\
-4.53 \\
\end{array}$ & $\begin{array}{l}+4.01 \\
-4.5\end{array}$ & $\begin{array}{l}+4.65 \\
-0.41 \\
\end{array}$ & \pm 0.3 \\
\hline$(2,5)$ & $0.6,0.99$ & $302.86_{-24.40}^{+23.30}$ & \pm 6.47 & $\begin{array}{l}+4.16 \\
-4.8\end{array}$ & $\begin{array}{l}+4.13 \\
-4.62 \\
\end{array}$ & \begin{tabular}{l|}
${ }_{-1.23}^{+0.36}$ \\
\end{tabular} & \pm 0.3 \\
\hline
\end{tabular}


Table 7.1: continued

\begin{tabular}{|c|c|c|c|c|c|c|c|}
\hline \multirow[b]{2}{*}{ Bin } & \multirow[b]{2}{*}{ 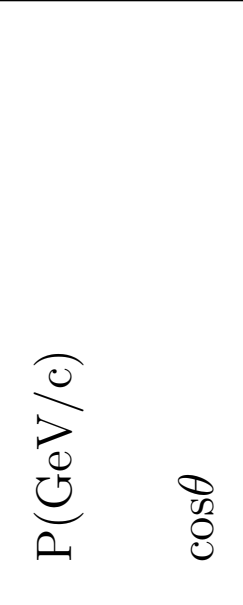 } & \multirow[b]{2}{*}{$\frac{d^{2} \sigma_{\pi^{+}}}{d p d \Omega}$} & \multicolumn{5}{|c|}{ Errors in Percentage } \\
\hline & & & 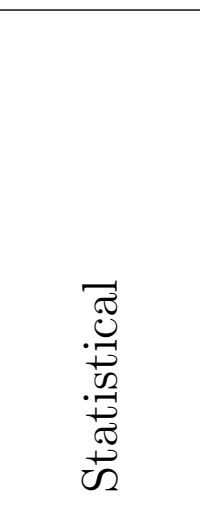 & 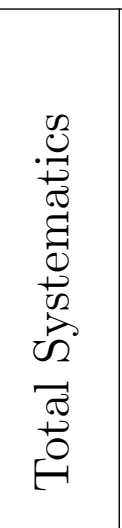 & 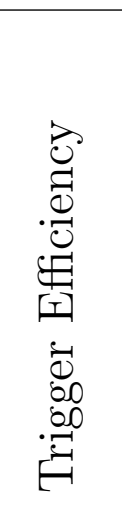 & 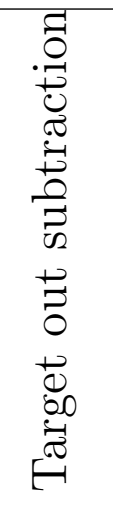 & 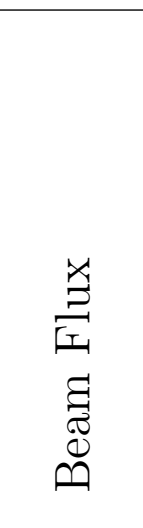 \\
\hline$(3,0)$ & $0.7,0.79$ & $47.43_{-9.20}^{+9.20}$ & \pm 19.39 & ${ }_{-0}^{+0}$ & ${ }_{-0}^{+0}$ & $\begin{array}{l}+0 \\
{ }_{-0}\end{array}$ & \pm 0 \\
\hline$(3,1)$ & $0.7,0.84$ & $59.58_{-9.84}^{+10.64}$ & \pm 15.85 & $\begin{array}{l}+8.23 \\
-4.67 \\
\end{array}$ & $\begin{array}{l}+4.16 \\
-4.65 \\
\end{array}$ & $\begin{array}{l}+7.1 \\
-0.05 \\
\end{array}$ & \pm 0.3 \\
\hline$(3,2)$ & $0.7,0.89$ & $88.13_{-11.74}^{+11.55}$ & \pm 12.32 & & $\begin{array}{l}+4.46 \\
-4.96 \\
\end{array}$ & $\begin{array}{l}+0.12 \\
-0.96\end{array}$ & \pm 0.3 \\
\hline$(3,3)$ & $0.7,0.92$ & $14110+14.59$ & \pm 9.43 & $\begin{array}{l}+4.23 \\
-4.7 \\
\end{array}$ & $\begin{array}{l}+4.18 \\
-4.68 \\
\end{array}$ & $\begin{array}{l}+0.53 \\
-0.24 \\
\end{array}$ & \pm 0.3 \\
\hline$(3,4)$ & $0.7,0.95$ & $235.79_{-26.64}^{+21.94}$ & \pm 7.22 & $\begin{array}{l}+5.87 \\
-8.69 \\
\end{array}$ & $\begin{array}{l}+4.43 \\
-4.93 \\
\end{array}$ & $\begin{array}{l}+3.83 \\
-7.15 \\
\end{array}$ & \pm 0.3 \\
\hline$(3,5)$ & $0.7,0.99$ & $433.56_{-39.37}^{+29.80}$ & \pm 5.44 & $\begin{array}{l}+4.2 \\
-7.27 \\
\end{array}$ & $\begin{array}{l}+4.14 \\
-4.64 \\
\end{array}$ & $\begin{array}{l}+0.58 \\
-5.58 \\
\end{array}$ & \pm 0.3 \\
\hline$(4,0)$ & $0.82,0.79$ & $33.16_{-8.61}^{+8.56}$ & \pm 25.43 & $\begin{array}{l}+4.42 \\
-5.22 \\
\end{array}$ & $\begin{array}{l}+4.4 \\
-4.9 \\
\end{array}$ & $\begin{array}{l}+0.06 \\
-1.75 \\
\end{array}$ & \pm 0.3 \\
\hline$(4,1)$ & $0.82,0.84$ & $58.95_{-10.38}^{+10.23}$ & \pm 16.81 & $\begin{array}{l}+4.33 \\
-5.24 \\
\end{array}$ & $\begin{array}{l}+4.32 \\
-4.82 \\
\end{array}$ & $\begin{array}{l}+0.06 \\
-2.02 \\
\end{array}$ & \pm 0.3 \\
\hline$(4,2)$ & $0.82,0.89$ & $79.48_{-11.37}^{+11.25}$ & \pm 13.46 & $\begin{array}{l}+4.36 \\
-4.85 \\
\end{array}$ & $\begin{array}{l}+4.34 \\
-4.84 \\
\end{array}$ & $\begin{array}{l}+0.1 \\
-0.02\end{array}$ & \pm 0.3 \\
\hline$(4,3)$ & $0.82,0.92$ & $120.06_{-13.98}^{+13.74}$ & \pm 10.55 & $\begin{array}{l}+4.43 \\
-4.92 \\
\end{array}$ & $\begin{array}{l}+4.41 \\
-4.91 \\
\end{array}$ & $\begin{array}{l}+0.11 \\
-0\end{array}$ & \pm 0.3 \\
\hline$(4,4)$ & $0.82,0.95$ & $233.28{ }_{-20.38}^{+19.75}$ & \pm 7.33 & $\begin{array}{l}+4.24 \\
-4.75 \\
\end{array}$ & $\begin{array}{l}+4.23 \\
-4.72 \\
\end{array}$ & $\begin{array}{l}+0.14 \\
-0.37 \\
\end{array}$ & \pm 0.3 \\
\hline$(4,5)$ & $0.82,0.99$ & $\begin{array}{c}376_{-32.90}^{+26.88} \\
\end{array}$ & \pm 5.8 & $\begin{array}{l}+4.18 \\
-6.55 \\
\end{array}$ & $\begin{array}{l}+4.16 \\
-4.65 \\
\end{array}$ & $\begin{array}{l}0.25 \\
-4.59 \\
\end{array}$ & \pm 0.3 \\
\hline$(5,0)$ & $0.94,0.79$ & $19.17_{-6.87}^{+6.85}$ & \pm 35.49 & $\begin{array}{l}+4.17 \\
-4.94 \\
\end{array}$ & $\begin{array}{l}+4.15 \\
-4.65 \\
\end{array}$ & $\begin{array}{l}+0.06 \\
-1.63 \\
\end{array}$ & \pm 0.3 \\
\hline$(5,1)$ & $0.94,0.84$ & $51.51_{-10.07}^{+10.01}$ & \pm 18.97 & $\begin{array}{l}+4.22 \\
-4.71 \\
\end{array}$ & $\begin{array}{l}+4.2 \\
-4.7 \\
\end{array}$ & $\begin{array}{l}+0.24 \\
-0.01 \\
\end{array}$ & \pm 0.3 \\
\hline$(5,2)$ & $0.94,0.89$ & $74.99_{-11.44}^{+11.26}$ & \pm 14.38 & ${ }_{-5.11}^{+4.32}$ & $\begin{array}{l}+4.3 \\
-4.8\end{array}$ & $\begin{array}{l}+0.08 \\
-1.71\end{array}$ & \pm 0.3 \\
\hline$(5,3)$ & $0.94,0.92$ & $139.03_{-15.35}^{+15.05}$ & \pm 9.94 & $\begin{array}{l}+4.28 \\
-4.81 \\
\end{array}$ & $\begin{array}{l}+4.26 \\
-4.76 \\
\end{array}$ & $\begin{array}{l}0.07 \\
-0.6\end{array}$ & \pm 0.3 \\
\hline$(5,4)$ & $0.94,0.95$ & $210.899_{-19.53}^{+18.93}$ & \pm 7.84 & $\begin{array}{l}+4.37 \\
-4.93 \\
\end{array}$ & $\begin{array}{l}+4.36 \\
-4.85 \\
\end{array}$ & $\begin{array}{l}+0.11 \\
-0.78 \\
\end{array}$ & \pm 0.3 \\
\hline$(5,5)$ & $0.94,0.99$ & $396.8_{-37.40}^{+30.19}$ & \pm 5.76 & $\begin{array}{l}+4.97 \\
-7.46\end{array}$ & $\begin{array}{l}+4.15 \\
-4.65\end{array}$ & $\begin{array}{l}+2.71 \\
{ }_{-5.82}\end{array}$ & \pm 0.3 \\
\hline
\end{tabular}


Table 7.2: Cross section numbers and errors for $\pi^{+}+C \rightarrow \pi^{-}+X$ All errors are shown in percentage except the total errors that are shown next to the cross-section.

\begin{tabular}{|c|c|c|c|c|c|c|c|}
\hline \multirow[b]{2}{*}{ Bin } & \multirow[b]{2}{*}{ 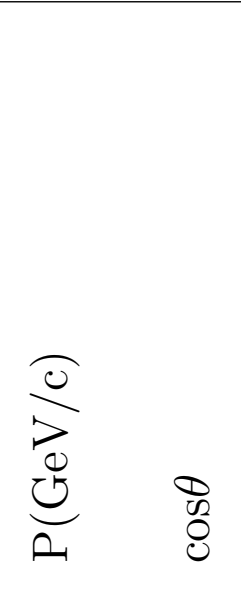 } & \multirow[b]{2}{*}{$\frac{d^{2} \sigma_{\pi^{-}}}{d p d \Omega}$} & \multicolumn{5}{|c|}{ Errors in Percentage } \\
\hline & & & 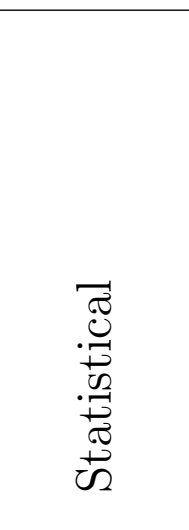 & 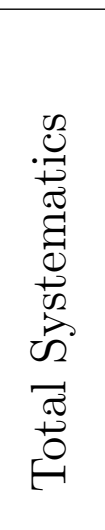 & 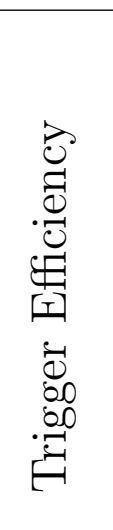 & 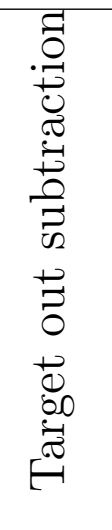 & 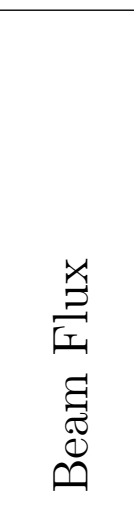 \\
\hline$(0,0)$ & $0.35,0.79$ & $78.32+10.39$ & \pm 12.53 & & $\begin{array}{l}+4.33 \\
-4.83 \\
\end{array}$ & & \pm 0.3 \\
\hline$(0,1)$ & $0.35,0.84$ & $65.89+9.40$ & \pm 13.66 & & $\begin{array}{l}+4.02 \\
-4.51\end{array}$ & $\begin{array}{l}+0.91 \\
-0.39\end{array}$ & \pm 0.3 \\
\hline$(0,2)$ & $0.35,0.89$ & $106.31_{-12.42}^{+12.23}$ & \pm 10.74 & $\begin{array}{l}+4.11 \\
-4.59\end{array}$ & $\begin{array}{l}+4.08 \\
-4.57\end{array}$ & $\begin{array}{l}+0.29 \\
-0.21\end{array}$ & \pm 0.3 \\
\hline$(0,3)$ & $0.35,0.92$ & $110.13_{-12.88}^{+12.61}$ & \pm 10.67 & & $\begin{array}{l}+4.12 \\
-4.61\end{array}$ & & \pm 0.3 \\
\hline$(0,4)$ & $0.35,0.95$ & $117.11_{-13.50}^{+13.18}$ & \pm 10.44 & & $\begin{array}{l}+4.15 \\
-4.64 \\
\end{array}$ & $\begin{array}{l}+0.67 \\
-1.47 \\
\end{array}$ & \pm 0.3 \\
\hline$(0,5)$ & $0.35,0.99$ & $129.87_{-14.34}^{+14.06}$ & \pm 9.95 & & $\begin{array}{l}+4.24 \\
-4.73 \\
\end{array}$ & $\begin{array}{l}+0.28 \\
-0.59 \\
\end{array}$ & \pm 0.3 \\
\hline$(1,0)$ & $0.49,0.79$ & $52.63_{-8.75}^{+8.68}$ & \pm 15.93 & & $\begin{array}{l}+4.22 \\
-4.72 \\
\end{array}$ & & \pm 0.3 \\
\hline$(1,1)$ & $0.49,0.84$ & $59.9 \begin{array}{r}+9.04 \\
-9.13 \\
\end{array}$ & \pm 14.5 & & $\begin{array}{l}+4.17 \\
-4.67 \\
\end{array}$ & $\begin{array}{l}+0.13 \\
-0.23 \\
\end{array}$ & \pm 0.3 \\
\hline$(1,2)$ & $0.49,0.89$ & $108.11_{-12.50}^{+12.29}$ & \pm 10.6 & & $\begin{array}{l}+4.08 \\
-4.58 \\
\end{array}$ & & \pm 0.3 \\
\hline$(1,3)$ & $0.49,0.92$ & $114.73_{-12.86}^{+12.62}$ & \pm 10.24 & & $\begin{array}{l}+4.01 \\
-4.5 \\
\end{array}$ & $\begin{array}{l}+0.11 \\
-0.55\end{array}$ & \pm 0.3 \\
\hline$(1,4)$ & $0.49,0.95$ & $157.18_{-15.95}^{+15.18}$ & \pm 8.76 & & $\begin{array}{l}+4.04 \\
-4.53 \\
\end{array}$ & & \pm 0.3 \\
\hline$(1,5)$ & $0.49,0.99$ & $254.033_{-21.68}^{+20.81}$ & \pm 7.02 & & $\begin{array}{l}+4.2 \\
-4.7 \\
\end{array}$ & $\begin{array}{l}+0.09 \\
-1.15 \\
\end{array}$ & \pm 0.3 \\
\hline$(2,0)$ & $0.6,0.79$ & $22.79_{-5.97}^{+5.92}$ & \pm 25.69 & & $\begin{array}{l}+3.79 \\
-4.27 \\
\end{array}$ & $\begin{array}{l}+0.16 \\
-2.66 \\
\end{array}$ & \pm 0.3 \\
\hline$(2,1)$ & $0.6,0.84$ & $51.74_{-8.80}^{+8.73}$ & \pm 16.27 & $\begin{array}{l}+4.45 \\
-4.95 \\
\end{array}$ & $\begin{array}{l}+4.43 \\
-4.93 \\
\end{array}$ & $\begin{array}{l}+0.12 \\
-0.3\end{array}$ & \pm 0.3 \\
\hline$(2,2)$ & $0.6,0.89$ & $79.05_{-10.62}^{+11.95}$ & \pm 12.61 & $\begin{array}{l}+8.34 \\
-4.63 \\
\end{array}$ & $\begin{array}{l}+4.08 \\
-4.57 \\
\end{array}$ & $\begin{array}{l}+7.27 \\
-0.67\end{array}$ & \pm 0.3 \\
\hline$(2,3)$ & $0.6,0.92$ & $165.16_{-16.12}^{+15.75}$ & \pm 8.56 & & $\begin{array}{l}+4.18 \\
-4.67 \\
\end{array}$ & $\begin{array}{l}+0.29 \\
-0.02 \\
\end{array}$ & \pm 0.3 \\
\hline$(2,4)$ & $0.6,0.95$ & $165.08_{-16.14}^{+15.79}$ & \pm 8.62 & $\begin{array}{l}+4.15 \\
-4.62 \\
\end{array}$ & $\begin{array}{l}+4.11 \\
-4.6\end{array}$ & $\begin{array}{l}+0.41 \\
-0.03\end{array}$ & \pm 0.3 \\
\hline$(2,5)$ & $0.6,0.99$ & $249.17_{-22.33}^{+21.38}$ & \pm 7.35 & $\begin{array}{l}+4.43 \\
-5.13 \\
\end{array}$ & $\begin{array}{l}+4.4 \\
-4.9 \\
\end{array}$ & $\begin{array}{l}+0.47 \\
-1.49 \\
\end{array}$ & \pm 0.3 \\
\hline
\end{tabular}


Table 7.2: continued

\begin{tabular}{|c|c|c|c|c|c|c|c|}
\hline \multirow[b]{2}{*}{ Bin } & \multirow[b]{2}{*}{ 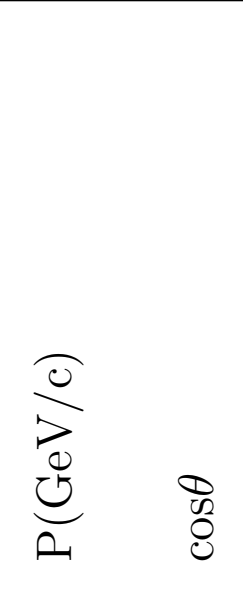 } & \multirow[b]{2}{*}{$\frac{d^{2} \sigma_{\pi-}}{d p d \Omega}$} & \multicolumn{5}{|c|}{ Errors in Percentage } \\
\hline & & & 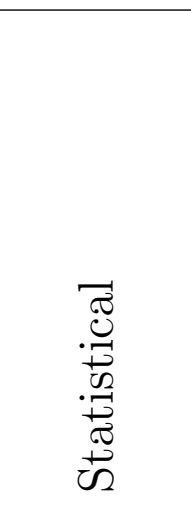 & 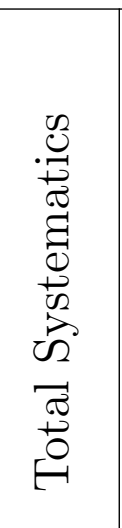 & 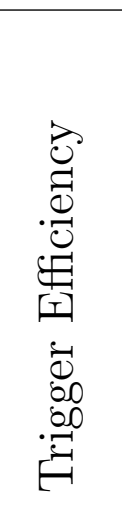 & 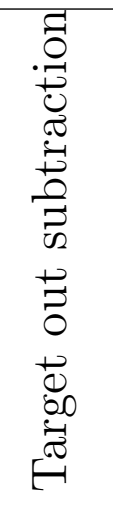 & 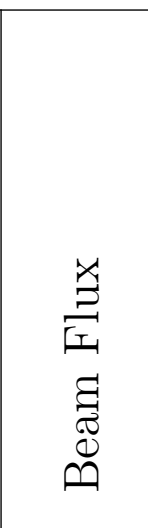 \\
\hline$(3,0)$ & $0.7,0.79$ & $16.19_{-5.03}^{+5.03}$ & \pm 31.07 & ${ }_{-0}^{+0}$ & ${ }_{-0}^{+0}$ & $\stackrel{+0}{+0}$ & \pm 0 \\
\hline$(3,1)$ & $0.7,0.84$ & $39.4_{-7.64}^{+7.59}$ & \pm 18.74 & $\begin{array}{l}+4.42 \\
-4.99 \\
\end{array}$ & $\begin{array}{l}+4.41 \\
-4.91 \\
\end{array}$ & $\begin{array}{l}+0.15 \\
-0.82 \\
\end{array}$ & \pm 0.3 \\
\hline$(3,2)$ & $0.7,0.89$ & & \pm 14.71 & & $\begin{array}{l}+4.02 \\
-4.51\end{array}$ & $\begin{array}{l}+0.12 \\
-0.02 \\
\end{array}$ & \pm 0.3 \\
\hline$(3,3)$ & $0.7,0.92$ & $105.12_{-12.19}^{+12.01}$ & \pm 10.77 & $\begin{array}{l}+3.81 \\
-4.29 \\
\end{array}$ & $\begin{array}{l}+3.79 \\
-4.27 \\
\end{array}$ & $\begin{array}{l}+0.15 \\
-0.16 \\
\end{array}$ & \pm 0.3 \\
\hline$(3,4)$ & $0.7,0.95$ & $130.19_{-14.09}^{+13.75}$ & \pm 9.71 & & $\begin{array}{l}+4.13 \\
-4.63 \\
\end{array}$ & $\begin{array}{l}+0.27 \\
-1.17 \\
\end{array}$ & \pm 0.3 \\
\hline$(3,5)$ & $0.7,0.99$ & $336.2_{-30.77}^{+27.44}$ & \pm 6.33 & $\begin{array}{l}+5.15 \\
-6.61 \\
\end{array}$ & $\begin{array}{l}+4.48 \\
+4.98 \\
\end{array}$ & $\begin{array}{l}+2.52 \\
-4.33 \\
\end{array}$ & \pm 0.3 \\
\hline$(4,0)$ & $0.82,0.79$ & $15.29_{-5.19}^{+5.18}$ & \pm 33.53 & $\begin{array}{l}+4.63 \\
-5.12 \\
\end{array}$ & $\begin{array}{l}+4.61 \\
-5.11\end{array}$ & $\begin{array}{l}+0.05 \\
-0.01 \\
\end{array}$ & \pm 0.3 \\
\hline$(4,1)$ & $0.82,0.84$ & $26.29_{-6.28}^{+6.25}$ & \pm 23.38 & $\begin{array}{l}+4.35 \\
-4.93 \\
\end{array}$ & $\begin{array}{l}+4.33 \\
-4.83 \\
\end{array}$ & $\begin{array}{l}+0.1 \\
-0.94 \\
\end{array}$ & \pm 0.3 \\
\hline$(4,2)$ & $0.82,0.89$ & $82.13_{-11.20}^{+11.06}$ & \pm 12.74 & & $\begin{array}{l}+4.34 \\
-4.84 \\
\end{array}$ & $\begin{array}{l}+0.05 \\
-0.01 \\
\end{array}$ & \pm 0.3 \\
\hline$(4,3)$ & $0.82,0.92$ & $138.04_{-14.55}^{+14.26}$ & \pm 9.49 & $\begin{array}{l}+4.09 \\
-4.58 \\
\end{array}$ & $\begin{array}{l}+4.07 \\
-4.56 \\
\end{array}$ & $\begin{array}{l}+0.26 \\
-0.21 \\
\end{array}$ & \pm 0.3 \\
\hline$(4,4)$ & $0.82,0.95$ & $140.6_{-14.62}^{+14.23}$ & \pm 9.29 & & $\begin{array}{l}+4 \\
-4.49 \\
\end{array}$ & $\begin{array}{l}+0.13 \\
-1.26 \\
\end{array}$ & \pm 0.3 \\
\hline$(4,5)$ & $0.82,0.99$ & $\begin{array}{l}327.72_{-26.06}^{+24.78} \\
\end{array}$ & \pm 6.28 & $\begin{array}{l}+4.21 \\
-4.88 \\
\end{array}$ & $\begin{array}{l}+4.19 \\
-4.69 \\
\end{array}$ & $\begin{array}{l}+0.18 \\
-1.33 \\
\end{array}$ & \pm 0.3 \\
\hline$(5,0)$ & $0.94,0.79$ & $7.43_{-3.75}^{+3.74}$ & \pm 50.27 & & $\begin{array}{l}+3.54 \\
-4.02 \\
\end{array}$ & $\begin{array}{l}+0.1 \\
-2.98 \\
\end{array}$ & \pm 0.3 \\
\hline$(5,1)$ & $0.94,0.84$ & $16.86_{-5.08}^{+5.07}$ & \pm 29.74 & $\begin{array}{l}+4.36 \\
-4.85 \\
\end{array}$ & $\begin{array}{l}+4.34 \\
-4.84 \\
\end{array}$ & $\begin{array}{l}+0.16 \\
-0.03 \\
\end{array}$ & \pm 0.3 \\
\hline$(5,2)$ & $0.94,0.89$ & $40.53_{-7.60}^{+7.55}$ & \pm 18.12 & $\begin{array}{l}+4.34 \\
-4.84\end{array}$ & $\begin{array}{l}+4.32 \\
{ }_{-4.82}\end{array}$ & $\begin{array}{l}+0.17 \\
-0.26\end{array}$ & \pm 0.3 \\
\hline$(5,3)$ & $0.94,0.92$ & $110.7_{-12.76}^{+12.74}$ & \pm 10.58 & $\begin{array}{l}+4.54 \\
-4.58 \\
\end{array}$ & $\begin{array}{l}+4.05 \\
-4.54 \\
\end{array}$ & $\begin{array}{l}+2.01 \\
-0.43 \\
\end{array}$ & \pm 0.3 \\
\hline$(5,4)$ & $0.94,0.95$ & $162.74_{-16.61}^{+15.50}$ & \pm 8.57 & $\begin{array}{l}+4.15 \\
-5.54 \\
\end{array}$ & $\begin{array}{l}+4.13 \\
-4.63 \\
\end{array}$ & $\begin{array}{l}+0.13 \\
-3.03 \\
\end{array}$ & \pm 0.3 \\
\hline$(5,5)$ & $0.94,0.99$ & $397.66_{-35.25}^{+29.95}$ & \pm 5.64 & $\begin{array}{l}+4.99 \\
{ }_{-6.84}\end{array}$ & ${ }_{-4.7}^{+4.21}$ & $\begin{array}{l}+2.66 \\
{ }_{-4.95}\end{array}$ & \pm 0.3 \\
\hline
\end{tabular}


Table 7.3: Cross section numbers and errors for $\pi^{+}+C \rightarrow p+X$ All errors are shown in percentage except the total errors that are shown next to the cross-section.

\begin{tabular}{|c|c|c|c|c|c|c|c|}
\hline \multirow[b]{2}{*}{ Bin } & \multirow[b]{2}{*}{ 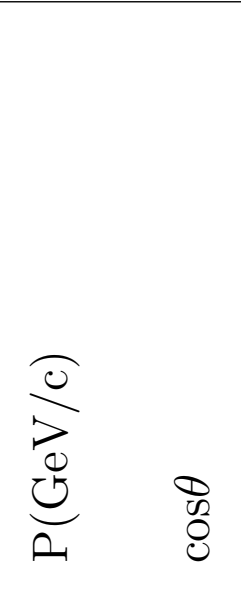 } & \multirow[b]{2}{*}{$\frac{d^{2} \sigma_{p}}{d p d \Omega}$} & \multicolumn{5}{|c|}{ Errors in Percentage } \\
\hline & & & 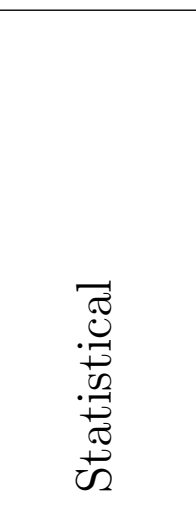 & 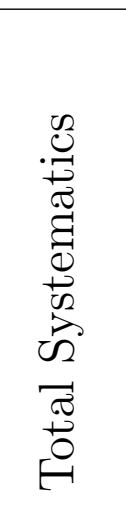 & 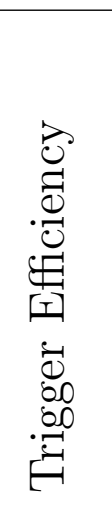 & 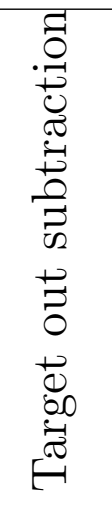 & 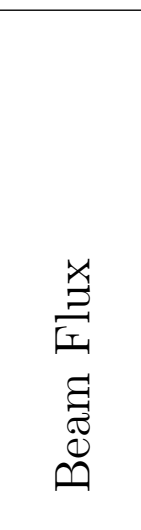 \\
\hline$(0,0)$ & $0.35,0.79$ & $15.64_{-4.77}^{+4.75}$ & \pm 30.02 & $\begin{array}{l}+4.66 \\
-5.35\end{array}$ & $\begin{array}{l}+4.62 \\
-5.13\end{array}$ & $\begin{array}{l}+0.51 \\
-1.51 \\
\end{array}$ & \pm 0.3 \\
\hline$(0,1)$ & $0.35,0.84$ & $17.69_{-4.88}^{+4.86}$ & \pm 27.11 & $\begin{array}{l}+4.49 \\
-4.97 \\
\end{array}$ & $\begin{array}{l}+4.46 \\
-4.96 \\
\end{array}$ & $\begin{array}{l}+0.42 \\
-0.08\end{array}$ & \pm 0.3 \\
\hline$(0,2)$ & $0.35,0.89$ & $19.73_{-4.96}^{+4.93}$ & \pm 24.55 & $\begin{array}{l}+4.65 \\
-5.38 \\
\end{array}$ & $\begin{array}{l}+4.63 \\
-5.13\end{array}$ & $\begin{array}{l}+0.36 \\
-1.6\end{array}$ & \pm 0.3 \\
\hline$(0,3)$ & $0.35,0.92$ & $\begin{array}{c}43.49+7.44 \\
-7.50\end{array}$ & \pm 16.4 & $\begin{array}{l}+4.9 \\
-5.33 \\
\end{array}$ & $\begin{array}{l}+4.82 \\
-5.32 \\
\end{array}$ & $\begin{array}{l}+0.81 \\
-0.1\end{array}$ & \pm 0.3 \\
\hline$(0,4)$ & $0.35,0.95$ & $62.42+8.86$ & \pm 13.46 & $\begin{array}{l}+4.52 \\
-5.01 \\
\end{array}$ & $\begin{array}{l}+4.51 \\
-5.01 \\
\end{array}$ & $\begin{array}{l}+0.22 \\
-0.05 \\
\end{array}$ & \pm 0.3 \\
\hline$(0,5)$ & $0.35,0.99$ & $63.54_{-9.04}^{+8.93}$ & \pm 13.31 & $\begin{array}{l}+4.52 \\
-5.02 \\
\end{array}$ & $\begin{array}{l}+4.52 \\
-5.02 \\
\end{array}$ & $\begin{array}{l}+0.09 \\
-0.04 \\
\end{array}$ & \pm 0.3 \\
\hline$(1,0)$ & $0.49,0.79$ & $31.16_{-7.04}^{+7.01}$ & \pm 22.01 & $\begin{array}{l}+4.58 \\
-5.07 \\
\end{array}$ & $\begin{array}{l}+4.56 \\
-5.07 \\
\end{array}$ & $\begin{array}{l}+0.18 \\
-0.04 \\
\end{array}$ & \pm 0.3 \\
\hline$(1,1)$ & $0.49,0.84$ & $15.68_{-4.97}^{+4.96}$ & \pm 31.34 & $\begin{array}{l}+4.11 \\
-4.58 \\
\end{array}$ & $\begin{array}{l}+4.08 \\
-4.57 \\
\end{array}$ & $\begin{array}{l}+0.45 \\
-0.09 \\
\end{array}$ & \pm 0.3 \\
\hline$(1,2)$ & $0.49,0.89$ & $36.64_{-7.26}^{+7.19}$ & \pm 19.1 & $\begin{array}{l}+4.52 \\
-5.29 \\
\end{array}$ & $\begin{array}{l}+4.51 \\
-5.01 \\
\end{array}$ & $\begin{array}{l}+0.14 \\
-1.67 \\
\end{array}$ & \pm 0.3 \\
\hline$(1,3)$ & $0.49,0.92$ & $50.98_{-8.52}^{+8.39}$ & \pm 15.91 & $\begin{array}{l}+4.18 \\
-5.11 \\
\end{array}$ & $\begin{array}{l}+4.16 \\
-4.65 \\
\end{array}$ & $\begin{array}{l}+0.31 \\
-2.1 \\
\end{array}$ & \pm 0.3 \\
\hline$(1,4)$ & $0.49,0.95$ & $\begin{array}{r}78.98+10.28 \\
-10.42 \\
\end{array}$ & \pm 12.4 & $\begin{array}{l}+3.96 \\
-4.52 \\
\end{array}$ & $\begin{array}{l}+3.95 \\
-4.44 \\
\end{array}$ & $\begin{array}{l}+0.23 \\
-0.84 \\
\end{array}$ & \pm 0.3 \\
\hline$(1,5)$ & $0.49,0.99$ & $\begin{array}{r}71.8+10.19 \\
-11.75 \\
\end{array}$ & \pm 13.5 & $\begin{array}{l}+4.4 \\
-9.24 \\
\end{array}$ & $\begin{array}{l}+4.39 \\
-4.89 \\
\end{array}$ & $\begin{array}{l}+0.18 \\
-7.84 \\
\end{array}$ & \pm 0.3 \\
\hline$(2,0)$ & $0.6,0.79$ & $14.42_{-5.19}^{+5.18}$ & \pm 35.6 & $\begin{array}{l}+4.72 \\
-5.21 \\
\end{array}$ & $\begin{array}{l}+4.71 \\
-5.21 \\
\end{array}$ & $\begin{array}{l}+0.26 \\
-0.05 \\
\end{array}$ & \pm 0.3 \\
\hline$(2,1)$ & $0.6,0.84$ & $5.47_{-4.14}^{+4.12}$ & \pm 75.17 & $\begin{array}{l}+3.83 \\
-8.9 \\
\end{array}$ & $\begin{array}{l}+3.15 \\
-3.6 \\
\end{array}$ & $\begin{array}{l}+2.17 \\
-8.14 \\
\end{array}$ & \pm 0.3 \\
\hline$(2,2)$ & $0.6,0.89$ & $26.34 \begin{array}{l}+6.40 \\
-6.42\end{array}$ & \pm 23.86 & $\begin{array}{l}+4.54 \\
-5.03 \\
\end{array}$ & $\begin{array}{l}+4.52 \\
-5.02 \\
\end{array}$ & $\begin{array}{l}+0.36 \\
-0.19 \\
\end{array}$ & \pm 0.3 \\
\hline$(2,3)$ & $0.6,0.92$ & $\begin{array}{r}42_{-7.55}^{+7.51} \\
\end{array}$ & \pm 17.47 & $\begin{array}{l}+3.79 \\
-4.26 \\
\end{array}$ & $\begin{array}{l}+3.77 \\
-4.25 \\
\end{array}$ & $\begin{array}{l}+0.16 \\
-0.04 \\
\end{array}$ & \pm 0.3 \\
\hline$(2,4)$ & $0.6,0.95$ & $100.57_{-12.42}^{+15.10}$ & \pm 11.19 & $\begin{array}{l}+10.01 \\
-5.23 \\
\end{array}$ & $\begin{array}{l}+4.45 \\
-4.95 \\
\end{array}$ & $\begin{array}{l}+8.97 \\
-1.67 \\
\end{array}$ & \pm 0.3 \\
\hline$(2,5)$ & $0.6,0.99$ & $105.2_{-13.38}^{+15.69}$ & \pm 11.62 & $\begin{array}{l}+9.35 \\
-5.16 \\
\end{array}$ & $\begin{array}{l}+4.64 \\
-5.14 \\
\end{array}$ & $\begin{array}{l}+8.12 \\
-0.39 \\
\end{array}$ & \pm 0.3 \\
\hline
\end{tabular}


Table 7.3: continued

\begin{tabular}{|c|c|c|c|c|c|c|c|}
\hline \multirow[b]{2}{*}{ Bin } & \multirow[b]{2}{*}{ 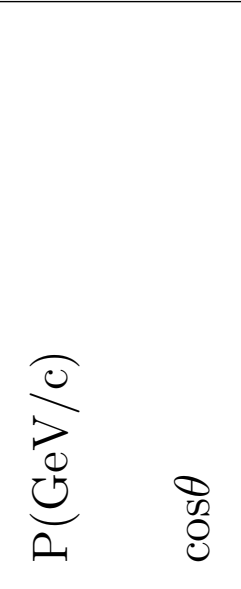 } & \multirow[b]{2}{*}{$\frac{d^{2} \sigma_{p}}{d p d \Omega}$} & \multicolumn{5}{|c|}{ Errors in Percentage } \\
\hline & & & 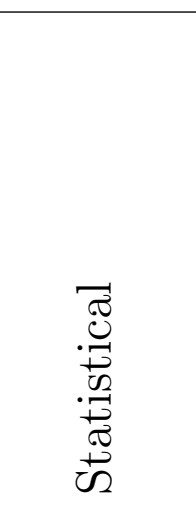 & 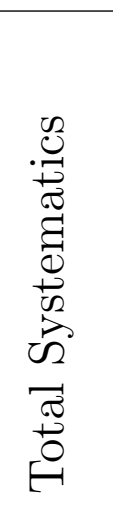 & 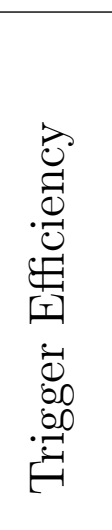 & 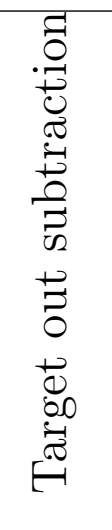 & 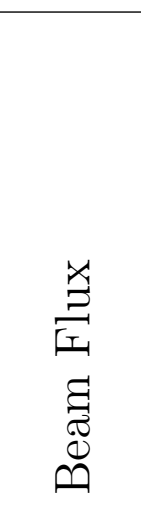 \\
\hline$(3,0)$ & $0.7,0.79$ & 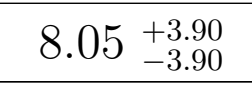 & \pm 48.39 & $\begin{array}{l}+0 \\
-0\end{array}$ & $\begin{array}{l}+0 \\
-0 \\
\end{array}$ & $\begin{array}{l}+0 \\
-0 \\
\end{array}$ & \pm 0 \\
\hline$(3,1)$ & $0.7,0.84$ & $3.26+2.43$ & \pm 74.4 & $\begin{array}{l}+2.71 \\
-9.42 \\
\end{array}$ & $\begin{array}{l}+2.45 \\
-2.84 \\
\end{array}$ & $\begin{array}{l}+1.13 \\
-8.98 \\
\end{array}$ & \pm 0.3 \\
\hline$(3,2)$ & $0.7,0.89$ & $29.14_{-6.67}^{+6.64}$ & \pm 22.4 & $\begin{array}{l}+4.19 \\
-4.74 \\
\end{array}$ & $\begin{array}{l}+4.18 \\
-4.67 \\
\end{array}$ & $\begin{array}{l}+0.15 \\
-0.71 \\
\end{array}$ & \pm 0.3 \\
\hline$(3,3)$ & $0.7,0.92$ & $41.44_{-7.75}^{+7.67}$ & \pm 17.88 & $\begin{array}{l}+4.75 \\
-5.52\end{array}$ & $\begin{array}{l}+4.53 \\
-5.03\end{array}$ & $\begin{array}{l}+1.43 \\
-2.26\end{array}$ & \pm 0.3 \\
\hline$(3,4)$ & $0.7,0.95$ & $42.61_{-7.71}^{+7.65}$ & \pm 17.41 & $\begin{array}{l}+4.34 \\
-4.89 \\
\end{array}$ & $\begin{array}{l}+4.33 \\
-4.83 \\
\end{array}$ & $\begin{array}{l}+0.18 \\
-0.73\end{array}$ & \pm 0.3 \\
\hline$(3,5)$ & $0.7,0.99$ & $83.67_{-12.36}^{+12.30}$ & \pm 13.84 & $\begin{array}{l}+4.97 \\
-5.18\end{array}$ & $\begin{array}{l}+4.23 \\
-4.73\end{array}$ & $\begin{array}{l}+2.59 \\
-2.09\end{array}$ & \pm 0.3 \\
\hline$(4,1)$ & $0.82,0.84$ & $\begin{array}{l}4.86+2.90 \\
-2.90\end{array}$ & \pm 59.38 & $\begin{array}{l}+5.19 \\
-5.64\end{array}$ & $\begin{array}{l}+5.13 \\
-5.63\end{array}$ & $\begin{array}{l}+0.72 \\
-0.15\end{array}$ & \pm 0.3 \\
\hline$(4,2)$ & $0.82,0.89$ & $23.44_{-6.02}^{+5.99}$ & \pm 25.17 & $\begin{array}{l}+4.53 \\
-5.03 \\
\end{array}$ & $\begin{array}{l}+4.52 \\
-5.02 \\
\end{array}$ & $\begin{array}{l}+0.12 \\
-0.02 \\
\end{array}$ & \pm 0.3 \\
\hline$(4,3)$ & $0.82,0.92$ & $46.95_{-8.64}^{+8.57}$ & \pm 17.65 & $\begin{array}{l}+4.67 \\
-5.21\end{array}$ & $\begin{array}{l}+4.67 \\
-5.17\end{array}$ & $\begin{array}{l}+0.13 \\
-0.64\end{array}$ & \pm 0.3 \\
\hline$(4,4)$ & $0.82,0.95$ & $53.3 \begin{array}{l}+8.92 \\
-9.03\end{array}$ & \pm 16.1 & $\begin{array}{l}+4.6 \\
-5.25 \\
\end{array}$ & $\begin{array}{l}+4.59 \\
-5.09 \\
\end{array}$ & $\begin{array}{l}+0.1 \\
-1.26 \\
\end{array}$ & \pm 0.3 \\
\hline$(4,5)$ & $0.82,0.99$ & $87.22+\begin{array}{r}+13.28 \\
-13.47 \\
\end{array}$ & \pm 14.62 & $\begin{array}{l}+4.26 \\
-4.98 \\
\end{array}$ & $\begin{array}{l}+4.21 \\
-4.71 \\
\end{array}$ & $\begin{array}{l}+0.61 \\
-1.61 \\
\end{array}$ & \pm 0.3 \\
\hline$(5,1)$ & $0.94,0.84$ & $8.34 \begin{array}{l}+3.96 \\
-3.97\end{array}$ & \pm 47.33 & $\begin{array}{l}+4.22 \\
-4.68\end{array}$ & $\begin{array}{l}+4.18 \\
-4.67\end{array}$ & $\begin{array}{l}+0.55 \\
-0.08\end{array}$ & \pm 0.3 \\
\hline$(5,2)$ & $0.94,0.89$ & $29.54 \begin{array}{l}+6.87 \\
-6.90\end{array}$ & \pm 22.84 & $\begin{array}{l}+4.36 \\
-4.86 \\
\end{array}$ & $\begin{array}{l}+4.35 \\
-4.85 \\
\end{array}$ & $\begin{array}{l}+0.13 \\
-0.03\end{array}$ & \pm 0.3 \\
\hline$(5,3)$ & $0.94,0.92$ & $\begin{array}{ll}46.21 & +8.43 \\
-8.49 \\
\end{array}$ & \pm 17.71 & $\begin{array}{l}+4.38 \\
-4.91 \\
\end{array}$ & $\begin{array}{l}+4.37 \\
-4.87 \\
\end{array}$ & $\begin{array}{l}+0.08 \\
-0.61 \\
\end{array}$ & \pm 0.3 \\
\hline$(5,4)$ & $0.94,0.95$ & $60.61_{-9.71}^{+9.57}$ & \pm 15.26 & $\begin{array}{l}+4.06 \\
-4.87 \\
\end{array}$ & $\begin{array}{l}+4.05 \\
-4.54 \\
\end{array}$ & $\begin{array}{l}+0.06 \\
-1.73 \\
\end{array}$ & \pm 0.3 \\
\hline$(5,5)$ & $0.94,0.99$ & $77.2+13.18$ & \pm 16.48 & $\begin{array}{l}+4.47 \\
-4.95\end{array}$ & $\begin{array}{l}+4.11 \\
-4.6\end{array}$ & $\begin{array}{l}+1.74 \\
-1.79\end{array}$ & \pm 0.3 \\
\hline
\end{tabular}


Table 7.4: Cross section numbers and errors for $K^{+}+C \rightarrow \pi^{+}+X$ All errors are shown in percentage except the total errors that are shown next to the cross-section.

\begin{tabular}{|c|c|c|c|c|c|c|c|}
\hline \multirow[b]{2}{*}{ Bin } & \multirow[b]{2}{*}{$\begin{array}{l}\frac{\partial}{D} \\
\frac{0}{0} \\
\underset{n}{J}\end{array}$} & \multirow[b]{2}{*}{$\frac{d^{2} \sigma_{\pi+}}{d p d \Omega}$} & \multicolumn{5}{|c|}{ Errors in Percentage } \\
\hline & & & 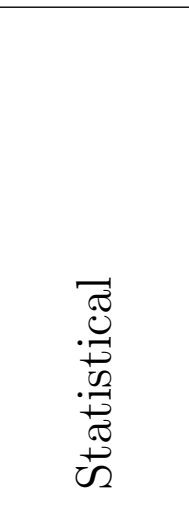 & 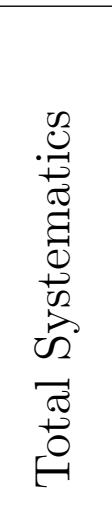 & 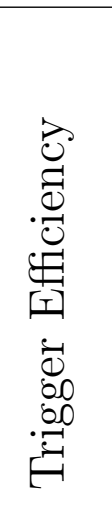 & 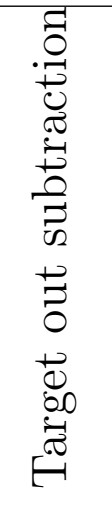 & 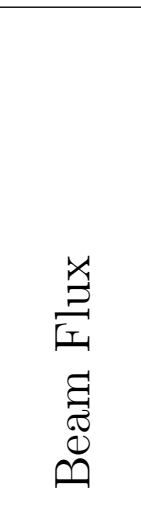 \\
\hline$(0,0)$ & $0.35,0.79$ & $31.86_{-6.71}^{+6.67}$ & \pm 20.45 & $\begin{array}{l}+4.54 \\
-5.07 \\
\end{array}$ & $\begin{array}{l}+4.54 \\
-5.04 \\
\end{array}$ & $\begin{array}{l}+0.01 \\
-0.56 \\
\end{array}$ & \pm 0.2 \\
\hline$(0,1)$ & $0.35,0.84$ & $31.83_{-6.59}^{+6.55}$ & \pm 20.17 & $\begin{array}{l}+4.04 \\
-4.62\end{array}$ & $\begin{array}{l}+4.03 \\
-4.52\end{array}$ & $\begin{array}{l}+0.02 \\
-0.95\end{array}$ & \pm 0.2 \\
\hline$(0,2)$ & $0.35,0.89$ & $48.38_{-8.15}^{+8.06}$ & \pm 16.01 & $\begin{array}{l}+4.6 \\
-5.21\end{array}$ & $\begin{array}{l}+4.59 \\
-5.09\end{array}$ & $\begin{array}{l}+0.01 \\
-1.09\end{array}$ & \pm 0.2 \\
\hline$(0,3)$ & $0.35,0.92$ & $\begin{array}{r}36.73_{-7.21}^{+6.95} \\
\end{array}$ & \pm 18.41 & $\begin{array}{l}+4.4 \\
-6.84\end{array}$ & $\begin{array}{l}+4.39 \\
-4.89 \\
\end{array}$ & $\begin{array}{l}+0.03 \\
-4.78 \\
\end{array}$ & \pm 0.2 \\
\hline$(0,4)$ & $0.35,0.95$ & $54.9+8.33$ & \pm 14.61 & $\begin{array}{l}+4.12 \\
-7.28\end{array}$ & $\begin{array}{l}+4.1 \\
-4.59\end{array}$ & $\begin{array}{l}+0.34 \\
-5.64\end{array}$ & \pm 0.2 \\
\hline$(0,5)$ & $0.35,0.99$ & $80.65_{-10.42}^{+12.35}$ & \pm 12.06 & $\begin{array}{l}+9.43 \\
-4.64 \\
\end{array}$ & $\begin{array}{l}+4.02 \\
-4.51 \\
\end{array}$ & $\begin{array}{l}+8.53 \\
-1.09 \\
\end{array}$ & \pm 0.2 \\
\hline$(1,0)$ & $0.49,0.79$ & $21.48_{-5.67}^{+5.65}$ & \pm 25.99 & $\begin{array}{l}+4.09 \\
-4.58 \\
\end{array}$ & $\begin{array}{l}+4.08 \\
-4.57 \\
\end{array}$ & $\begin{array}{l}+0.01 \\
-0.24 \\
\end{array}$ & \pm 0.2 \\
\hline$(1,1)$ & $0.49,0.84$ & $23.28{ }_{-5.67}^{+5.65}$ & \pm 23.95 & $\begin{array}{l}+4.04 \\
-4.54 \\
\end{array}$ & $\begin{array}{l}+4.04 \\
-4.53 \\
\end{array}$ & $\begin{array}{l}+0.01 \\
-0.14 \\
\end{array}$ & \pm 0.2 \\
\hline$(1,2)$ & $0.49,0.89$ & $\begin{array}{r}44.78+7.72 \\
-7.89 \\
\end{array}$ & \pm 16.65 & $\begin{array}{l}+4.43 \\
-5.74 \\
\end{array}$ & $\begin{array}{l}+4.42 \\
-4.92 \\
\end{array}$ & $\begin{array}{l}+0.01 \\
-2.94 \\
\end{array}$ & \pm 0.2 \\
\hline$(1,3)$ & $0.49,0.92$ & $47.88_{-12.38}^{+8.07}$ & \pm 16.31 & $\begin{array}{l}+4.24 \\
-20.06 \\
\end{array}$ & $\begin{array}{l}+4.24 \\
-4.73 \\
\end{array}$ & $\begin{array}{l}+0.03 \\
-19.5 \\
\end{array}$ & \pm 0.2 \\
\hline$(1,4)$ & $0.49,0.95$ & $106.52_{-12.33}^{+12.11}$ & \pm 10.48 & $\begin{array}{l}+4.4 \\
-4.91 \\
\end{array}$ & $\begin{array}{l}+4.4 \\
-4.89 \\
\end{array}$ & $\begin{array}{l}+0.01 \\
-0.35\end{array}$ & \pm 0.2 \\
\hline$(1,5)$ & $0.49,0.99$ & $\begin{array}{r}84.18_{-13.07}^{+10.78} \\
\end{array}$ & \pm 12.08 & $\begin{array}{l}+4.24 \\
-9.76 \\
\end{array}$ & $\begin{array}{l}+4.14 \\
-4.63 \\
\end{array}$ & $\begin{array}{l}+0.91 \\
-8.59 \\
\end{array}$ & \pm 0.2 \\
\hline$(2,0)$ & $0.6,0.79$ & $24.61_{-6.49}^{+6.47}$ & \pm 25.92 & $\begin{array}{l}+4.32 \\
-4.82 \\
\end{array}$ & $\begin{array}{l}+4.31 \\
-4.81 \\
\end{array}$ & $\begin{array}{l}+0.01 \\
-0.15 \\
\end{array}$ & \pm 0.2 \\
\hline$(2,1)$ & $0.6,0.84$ & $26.94{ }_{-6.34}^{+6.31}$ & \pm 23.06 & $\begin{array}{l}+4.13 \\
-4.78 \\
\end{array}$ & $\begin{array}{l}+4.13 \\
-4.62 \\
\end{array}$ & $\begin{array}{l}+0.01 \\
-1.19 \\
\end{array}$ & \pm 0.2 \\
\hline$(2,2)$ & $0.6,0.89$ & $45.49_{-8.02}^{+7.96}$ & \pm 16.97 & $\begin{array}{l}+4.28 \\
-4.78 \\
\end{array}$ & $\begin{array}{l}+4.27 \\
-4.77 \\
\end{array}$ & $\begin{array}{l}+0.01 \\
-0.23\end{array}$ & \pm 0.2 \\
\hline$(2,3)$ & $0.6,0.92$ & $84.78_{-10.95}^{+10.80}$ & \pm 12.11 & $\begin{array}{l}+3.96 \\
-4.49 \\
\end{array}$ & $\begin{array}{l}+3.96 \\
-4.45 \\
\end{array}$ & $\begin{array}{l}+0.01 \\
-0.56 \\
\end{array}$ & \pm 0.2 \\
\hline$(2,4)$ & $0.6,0.95$ & $\begin{array}{r}88.8_{-11.19}^{+11.98} \\
\end{array}$ & \pm 11.73 & $\begin{array}{l}+6.66 \\
-4.59 \\
\end{array}$ & $\begin{array}{l}+4.09 \\
-4.58 \\
\end{array}$ & $\begin{array}{l}+5.26 \\
-0.26 \\
\end{array}$ & \pm 0.2 \\
\hline$(2,5)$ & $0.6,0.99$ & $128.72_{-15.03}^{+13.82}$ & \pm 9.97 & $\begin{array}{l}+3.98 \\
-6.08 \\
\end{array}$ & $\begin{array}{l}+3.96 \\
-4.45 \\
\end{array}$ & $\begin{array}{l}+0.27 \\
-4.14 \\
\end{array}$ & \pm 0.2 \\
\hline
\end{tabular}


Table 7.4: continued

\begin{tabular}{|c|c|c|c|c|c|c|c|}
\hline \multirow[b]{2}{*}{ Bin } & \multirow[b]{2}{*}{ 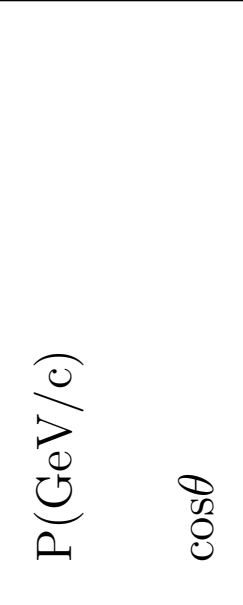 } & \multirow[b]{2}{*}{$\frac{d^{2} \sigma_{\pi^{+}}}{d p d \Omega}$} & \multicolumn{5}{|c|}{ Errors in Percentage } \\
\hline & & & 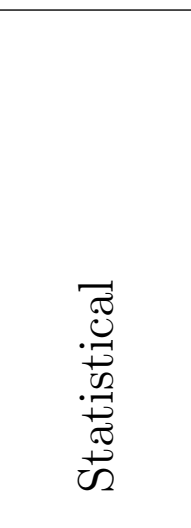 & 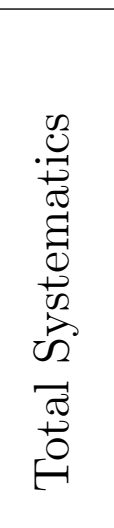 & 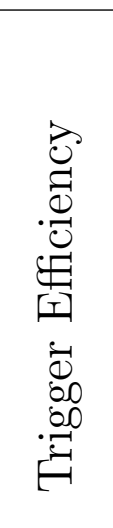 & 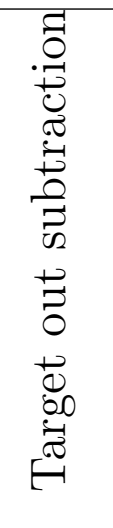 & 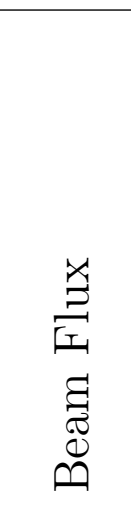 \\
\hline$(3,0)$ & $0.7,0.79$ & $30.04_{-7.52}^{+7.49}$ & \pm 24.53 & $\begin{array}{l}+4.53 \\
-5.03 \\
\end{array}$ & $\begin{array}{l}+4.52 \\
-5.02 \\
\end{array}$ & $\begin{array}{l}+0 \\
-0.09 \\
\end{array}$ & \pm 0.2 \\
\hline$(3,1)$ & $0.7,0.84$ & $43.37_{-8.39}^{+8.34}$ & \pm 18.72 & $\begin{array}{l}+4.4 \\
-4.9 \\
\end{array}$ & $\begin{array}{ll}+4.4 \\
-4.89 \\
\end{array}$ & $\begin{array}{l}+0 \\
-0.07 \\
\end{array}$ & \pm 0.2 \\
\hline$(3,2)$ & $0.7,0.89$ & $56.66_{-9.22}^{+9.14}$ & \pm 15.51 & $\begin{array}{l}+4.41 \\
-4.92 \\
\end{array}$ & $\begin{array}{l}+4.41 \\
-4.91 \\
\end{array}$ & $\begin{array}{l}+0.01 \\
-0.27\end{array}$ & \pm 0.2 \\
\hline$(3,3)$ & $0.7,0.92$ & $54.35_{-8.81}^{+8.77}$ & \pm 15.43 & $\begin{array}{l}+4.72 \\
-4.94 \\
\end{array}$ & $\begin{array}{l}+4.43 \\
-4.93 \\
\end{array}$ & $\begin{array}{l}+1.63 \\
-0.34 \\
\end{array}$ & \pm 0.2 \\
\hline$(3,4)$ & $0.7,0.95$ & $134.47_{-14.72}^{+15.19}$ & \pm 9.58 & $\begin{array}{l}+5.99 \\
-5.3\end{array}$ & $\begin{array}{l}+4.48 \\
-4.98 \\
\end{array}$ & $\begin{array}{l}+3.97 \\
-1.81 \\
\end{array}$ & \pm 0.2 \\
\hline$(3,5)$ & $0.7,0.99$ & $138.97_{-15.02}^{+15.12}$ & \pm 9.65 & $\begin{array}{l}+5.02 \\
-4.87 \\
\end{array}$ & $\begin{array}{l}+4.25 \\
-4.74 \\
\end{array}$ & $\begin{array}{l}+2.67 \\
-1.1\end{array}$ & \pm 0.2 \\
\hline$(4,0)$ & $0.82,0.79$ & $13.42_{-5.41}^{+5.41}$ & \pm 40.06 & $\begin{array}{l}+4.17 \\
-4.67 \\
\end{array}$ & $\begin{array}{l}+4.17 \\
-4.66 \\
\end{array}$ & $\begin{array}{l}+0.01 \\
-0.11 \\
\end{array}$ & \pm 0.2 \\
\hline$(4,1)$ & $0.82,0.84$ & $24.22_{-6.45}^{+6.43}$ & \pm 26.23 & $\begin{array}{l}+4.08 \\
-4.58 \\
\end{array}$ & $\begin{array}{l}+4.08 \\
-4.57 \\
\end{array}$ & $\begin{array}{l}+0.01 \\
-0.17 \\
\end{array}$ & \pm 0.2 \\
\hline$(4,2)$ & $0.82,0.89$ & $28.11_{-6.56}^{+6.50}$ & \pm 22.74 & $\begin{array}{l}+4.22 \\
-5.19 \\
\end{array}$ & $\begin{array}{l}+4.19 \\
-4.68 \\
\end{array}$ & $\begin{array}{l}+0.52 \\
-2.23 \\
\end{array}$ & \pm 0.2 \\
\hline$(4,3)$ & $0.82,0.92$ & $69.84_{-10.29}^{+10.16}$ & \pm 13.91 & $\begin{array}{l}+4.28 \\
-4.86 \\
\end{array}$ & $\begin{array}{l}+4.28 \\
-4.78 \\
\end{array}$ & $\begin{array}{l}+0.01 \\
-0.86 \\
\end{array}$ & \pm 0.2 \\
\hline$(4,4)$ & $0.82,0.95$ & $98.87_{-12.18}^{+11.95}$ & \pm 11.26 & $\begin{array}{l}+4.4 \\
-5\end{array}$ & $\begin{array}{l}+4.37 \\
-4.87 \\
\end{array}$ & $\begin{array}{l}+0.52 \\
-1.15 \\
\end{array}$ & \pm 0.2 \\
\hline$(4,5)$ & $0.82,0.99$ & $183.68_{-18.06}^{+17.24}$ & \pm 8.33 & $\begin{array}{l}+4.32 \\
-5.22 \\
\end{array}$ & $\begin{array}{r}+4.31 \\
-4.81 \\
\end{array}$ & $\begin{array}{l}+0.24 \\
-2.01 \\
\end{array}$ & \pm 0.2 \\
\hline$(5,0)$ & $0.94,0.79$ & $12.52_{-5.57}^{+5.56}$ & \pm 44.2 & $\begin{array}{l}+4.6 \\
-5.11 \\
\end{array}$ & $\begin{array}{l}+4.6 \\
-5.1\end{array}$ & $\begin{array}{l}+0.01 \\
-0.1\end{array}$ & \pm 0.2 \\
\hline$(5,1)$ & $0.94,0.84$ & $9.27_{-4.35}^{+4.36}$ & \pm 46.71 & $\begin{array}{l}+5.15 \\
-4.92 \\
\end{array}$ & $\begin{array}{l}+4.36 \\
-4.86 \\
\end{array}$ & $\begin{array}{l}+2.72 \\
-0.7 \\
\end{array}$ & \pm 0.2 \\
\hline$(5,2)$ & $0.94,0.89$ & $32.35_{-7.31}^{+7.22}$ & \pm 21.92 & $\begin{array}{l}+4.26 \\
{ }_{-5.49}\end{array}$ & $\begin{array}{l}+4.14 \\
-4.63\end{array}$ & ${ }_{-2.94}^{+1}$ & \pm 0.2 \\
\hline$(5,3)$ & $0.94,0.92$ & $59.34_{-9.46}^{+9.35}$ & \pm 15.22 & $\begin{array}{l}+4.1 \\
-4.76 \\
\end{array}$ & $\begin{array}{l}+4.1 \\
-4.59 \\
\end{array}$ & $\begin{array}{l}0.01 \\
-1.25 \\
\end{array}$ & \pm 0.2 \\
\hline$(5,4)$ & $0.94,0.95$ & $85.72_{-11.34}^{+11.14}$ & \pm 12.31 & $\begin{array}{l}+4.17 \\
-4.85 \\
\end{array}$ & $\begin{array}{l}+4.16 \\
-4.66 \\
\end{array}$ & $\begin{array}{l}+0.01 \\
-1.35 \\
\end{array}$ & \pm 0.2 \\
\hline$(5,5)$ & $0.94,0.99$ & $204.54_{-23.21}^{+20.08}$ & \pm 8.04 & $\begin{array}{l}+5.63 \\
{ }_{-8.01}\end{array}$ & $\begin{array}{l}+4.37 \\
-4.86\end{array}$ & $\begin{array}{l}+3.55 \\
-6.36\end{array}$ & \pm 0.2 \\
\hline
\end{tabular}


Table 7.5: Cross section numbers and errors for $K^{+}+C \rightarrow \pi^{-}+X$ All errors are shown in percentage except the total errors that are shown next to the cross-section.

\begin{tabular}{|c|c|c|c|c|c|c|c|}
\hline \multirow[b]{2}{*}{ Bin } & \multirow[b]{2}{*}{$\begin{array}{l}\frac{\partial}{D} \\
\frac{0}{0} \\
\underset{n}{J}\end{array}$} & \multirow[b]{2}{*}{$\frac{d^{2} \sigma_{\pi^{-}}}{d p d \Omega}$} & \multicolumn{5}{|c|}{ Errors in Percentage } \\
\hline & & & 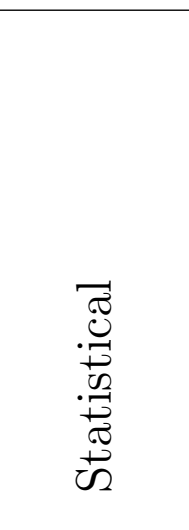 & 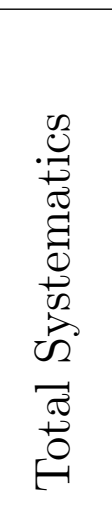 & 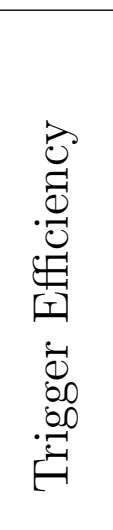 & 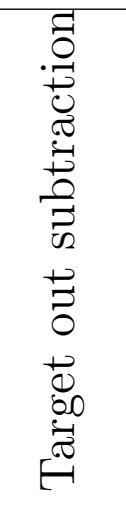 & 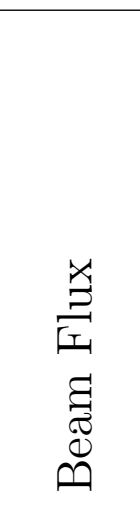 \\
\hline$(0,0)$ & $0.35,0.79$ & $36.83_{-7.00}^{+7.01}$ & \pm 18.32 & $\begin{array}{l}+5.2 \\
-5.04 \\
\end{array}$ & $\begin{array}{l}+4.46 \\
-4.96 \\
\end{array}$ & $\begin{array}{l}+2.66 \\
-0.83 \\
\end{array}$ & \pm 0.2 \\
\hline$(0,1)$ & $0.35,0.84$ & $\begin{array}{r}39.02+7.15 \\
-7.23 \\
\end{array}$ & \pm 17.77 & $\begin{array}{l}+4.51 \\
-5.24 \\
\end{array}$ & $\begin{array}{l}+4.46 \\
-4.96 \\
\end{array}$ & $\begin{array}{l}+0.64 \\
-1.67 \\
\end{array}$ & \pm 0.2 \\
\hline$(0,2)$ & $0.35,0.89$ & $37.08+6.99$ & \pm 18.49 & $\begin{array}{l}+3.67 \\
-4.27\end{array}$ & $\begin{array}{l}+3.66 \\
-4.14\end{array}$ & $\begin{array}{l}+0.03 \\
-1.01\end{array}$ & \pm 0.2 \\
\hline$(0,3)$ & $0.35,0.92$ & $51.86_{-8.55}^{+8.40}$ & \pm 15.62 & $\begin{array}{l}+4.32 \\
-5.3\end{array}$ & $\begin{array}{l}+4.29 \\
-4.79 \\
\end{array}$ & $\begin{array}{l}+0.49 \\
-2.27\end{array}$ & \pm 0.2 \\
\hline$(0,4)$ & $0.35,0.95$ & $63.98{ }_{-9.63}^{+9.50}$ & \pm 14.18 & $\begin{array}{l}+4.41 \\
-5.03 \\
\end{array}$ & $\begin{array}{l}+4.28 \\
-4.78 \\
\end{array}$ & $\begin{array}{l}+1.01 \\
-1.56 \\
\end{array}$ & \pm 0.2 \\
\hline$(0,5)$ & $0.35,0.99$ & $67.64_{-9.89}^{+12.25}$ & \pm 13.83 & $\begin{array}{l}+11.69 \\
-4.74 \\
\end{array}$ & $\begin{array}{l}+3.84 \\
-4.33 \\
\end{array}$ & $\begin{array}{l}+11.04 \\
-1.94 \\
\end{array}$ & \pm 0.2 \\
\hline$(1,0)$ & $0.49,0.79$ & $21.37_{-5.54}^{+5.52}$ & \pm 25.4 & $\begin{array}{l}+4.77 \\
-5.27 \\
\end{array}$ & $\begin{array}{l}+4.76 \\
-5.26 \\
\end{array}$ & $\begin{array}{l}+0.02 \\
-0.29 \\
\end{array}$ & \pm 0.2 \\
\hline$(1,1)$ & $0.49,0.84$ & $\begin{array}{r}37.94{ }_{-7.23}^{+7.18} \\
\end{array}$ & \pm 18.4 & $\begin{array}{l}+4.44 \\
-4.94 \\
\end{array}$ & $\begin{array}{l}+4.43 \\
-4.93 \\
\end{array}$ & $\begin{array}{l}+0.01 \\
-0.14 \\
\end{array}$ & \pm 0.2 \\
\hline$(1,2)$ & $0.49,0.89$ & $45.37_{-7.75}^{+7.68}$ & \pm 16.36 & $\begin{array}{l}+4.38 \\
-4.88 \\
\end{array}$ & $\begin{array}{l}+4.37 \\
-4.87 \\
\end{array}$ & $\begin{array}{l}+0.01 \\
-0.12 \\
\end{array}$ & \pm 0.2 \\
\hline$(1,3)$ & $0.49,0.92$ & $75.7 \begin{array}{l}+10.15 \\
-10.50 \\
\end{array}$ & \pm 12.69 & $\begin{array}{l}+4.34 \\
-5.6 \\
\end{array}$ & $\begin{array}{l}+4.34 \\
-4.83 \\
\end{array}$ & $\begin{array}{l}+0.01 \\
-2.82 \\
\end{array}$ & \pm 0.2 \\
\hline$(1,4)$ & $0.49,0.95$ & $\begin{array}{r}65.29+9.30 \\
-9.46 \\
\end{array}$ & \pm 13.65 & $\begin{array}{l}+4.07 \\
-4.87 \\
\end{array}$ & $\begin{array}{l}+4.06 \\
-4.56 \\
\end{array}$ & $\begin{array}{l}+0.02 \\
-1.7\end{array}$ & \pm 0.2 \\
\hline$(1,5)$ & $0.49,0.99$ & $114.81_{-13.23}^{+12.93}$ & \pm 10.45 & $\begin{array}{l}+4.21 \\
-4.86 \\
\end{array}$ & $\begin{array}{l}+4.2 \\
-4.7 \\
\end{array}$ & $\begin{array}{l}+0.01 \\
-1.21 \\
\end{array}$ & \pm 0.2 \\
\hline$(2,0)$ & $0.6,0.79$ & $\begin{array}{r}9.38+3.80 \\
-3.81 \\
\end{array}$ & \pm 40.32 & $\begin{array}{l}+4.05 \\
-4.55 \\
\end{array}$ & $\begin{array}{l}+4.05 \\
-4.54 \\
\end{array}$ & $\begin{array}{l}+0.02 \\
-0.33 \\
\end{array}$ & \pm 0.2 \\
\hline$(2,1)$ & $0.6,0.84$ & $24.39 \begin{array}{l}+5.84 \\
-5.86 \\
\end{array}$ & \pm 23.59 & $\begin{array}{l}+4.15 \\
-4.65 \\
\end{array}$ & $\begin{array}{l}+4.15 \\
-4.64 \\
\end{array}$ & $\begin{array}{l}+0.01 \\
-0.2 \\
\end{array}$ & \pm 0.2 \\
\hline$(2,2)$ & $0.6,0.89$ & $50.2+8.26$ & \pm 15.93 & $\begin{array}{l}+4.11 \\
-4.81 \\
\end{array}$ & $\begin{array}{l}+4.1 \\
-4.6 \\
\end{array}$ & $\begin{array}{l}+0.01 \\
-1.4 \\
\end{array}$ & \pm 0.2 \\
\hline$(2,3)$ & $0.6,0.92$ & $60.54{ }_{-9.09}^{+9.00}$ & \pm 14.17 & $\begin{array}{l}+4.49 \\
-4.99 \\
\end{array}$ & $\begin{array}{l}+4.48 \\
-4.98 \\
\end{array}$ & $\begin{array}{l}+0.01 \\
-0.21 \\
\end{array}$ & \pm 0.2 \\
\hline$(2,4)$ & $0.6,0.95$ & $76.23_{-10.61}^{+10.15}$ & \pm 12.7 & $\begin{array}{l}+4.02 \\
-5.71 \\
\end{array}$ & $\begin{array}{l}+4.01 \\
-4.5\end{array}$ & $\begin{array}{l}+0.01 \\
-3.5\end{array}$ & \pm 0.2 \\
\hline$(2,5)$ & $0.6,0.99$ & $140.599_{-15.55}^{+16.92}$ & \pm 9.77 & $\begin{array}{l}+7.03 \\
-5.18 \\
\end{array}$ & $\begin{array}{l}+4.55 \\
-5.05\end{array}$ & $\begin{array}{l}+5.35 \\
-1.14 \\
\end{array}$ & \pm 0.2 \\
\hline
\end{tabular}


Table 7.5: continued

\begin{tabular}{|c|c|c|c|c|c|c|c|}
\hline \multirow[b]{2}{*}{ Bin } & \multirow[b]{2}{*}{ 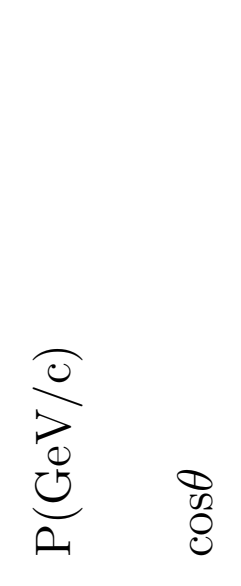 } & \multirow[b]{2}{*}{$\frac{d^{2} \sigma_{\pi^{-}}}{d p d \Omega}$} & \multicolumn{5}{|c|}{ Errors in Percentage } \\
\hline & & & 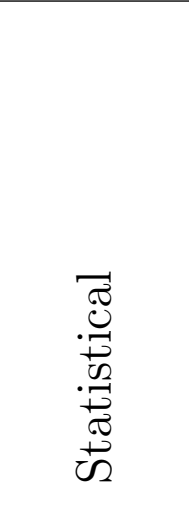 & 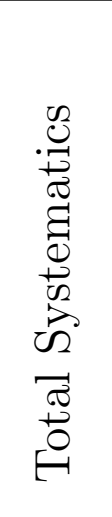 & 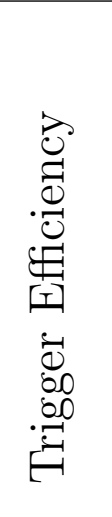 & 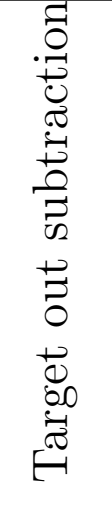 & 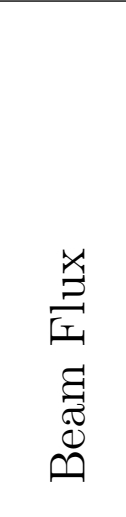 \\
\hline$(3,0)$ & $0.7,0.79$ & $7.33 \begin{array}{l}+3.41 \\
-3.42\end{array}$ & \pm 46.39 & $\begin{array}{l}+4.23 \\
-4.73\end{array}$ & $\begin{array}{l}+4.23 \\
-4.73\end{array}$ & $\begin{array}{l}+0.01 \\
-0.22\end{array}$ & \pm 0.2 \\
\hline$(3,1)$ & $0.7,0.84$ & $25.3{ }_{-6.03}^{+6.01}$ & \pm 23.41 & $\begin{array}{l}+4.13 \\
-4.43 \\
\end{array}$ & $\begin{array}{l}+3.94 \\
-4.43 \\
\end{array}$ & $\begin{array}{l}+1.23 \\
-0.05 \\
\end{array}$ & \pm 0.2 \\
\hline$(3,2)$ & $0.7,0.89$ & $31.1+6.47$ & \pm 20.4 & $\begin{array}{l}+4.13 \\
-4.62 \\
\end{array}$ & $\begin{array}{l}+4.12 \\
-4.62 \\
\end{array}$ & $\begin{array}{l}+0.01 \\
-0.14\end{array}$ & \pm 0.2 \\
\hline$(3,3)$ & $0.7,0.92$ & $49.07_{-8.51}^{+8.24}$ & \pm 16.23 & $\begin{array}{l}+4.31 \\
-6.1\end{array}$ & $\begin{array}{l}+4.3 \\
-4.8\end{array}$ & $\begin{array}{l}+0.02 \\
-3.76\end{array}$ & \pm 0.2 \\
\hline$(3,4)$ & $0.7,0.95$ & $137.8_{-14.68}^{+14.37}$ & \pm 9.48 & $\begin{array}{l}+4.34 \\
-4.86 \\
\end{array}$ & $\begin{array}{l}+4.33 \\
-4.83 \\
\end{array}$ & $\begin{array}{l}+0.01 \\
-0.46 \\
\end{array}$ & \pm 0.2 \\
\hline$(3,5)$ & $0.7,0.99$ & $109.85_{-13.29}^{+13.51}$ & \pm 11.09 & $\begin{array}{l}+5.32 \\
-4.83 \\
\end{array}$ & $\begin{array}{l}+4.32 \\
-4.82 \\
\end{array}$ & $\begin{array}{l}+3.1 \\
-0.2 \\
\end{array}$ & \pm 0.2 \\
\hline$(4,0)$ & $0.82,0.79$ & $\begin{array}{r}6.57+3.39 \\
-3.40 \\
\end{array}$ & \pm 51.45 & $\begin{array}{l}+4.52 \\
-5.02 \\
\end{array}$ & $\begin{array}{l}+4.52 \\
-5.02 \\
\end{array}$ & $\begin{array}{l}+0.01 \\
-0.11 \\
\end{array}$ & \pm 0.2 \\
\hline$(4,1)$ & $0.82,0.84$ & $10.55_{-3.94}^{+3.94}$ & \pm 37.08 & $\begin{array}{l}+4.28 \\
-4.78 \\
\end{array}$ & $\begin{array}{l}+4.28 \\
-4.77 \\
\end{array}$ & $\begin{array}{l}+0.01 \\
-0.2 \\
\end{array}$ & \pm 0.2 \\
\hline$(4,2)$ & $0.82,0.89$ & $19.97_{-5.27}^{+5.25}$ & \pm 25.86 & $\begin{array}{l}+4.72 \\
-5.22 \\
\end{array}$ & $\begin{array}{l}+4.72 \\
-5.22 \\
\end{array}$ & $\begin{array}{l}+0.01 \\
-0.18 \\
\end{array}$ & \pm 0.2 \\
\hline$(4,3)$ & $0.82,0.92$ & $55.62{ }_{-8.80}^{+8.72}$ & \pm 15.11 & $\begin{array}{l}+4.2 \\
-4.7 \\
\end{array}$ & $\begin{array}{l}+4.2 \\
-4.69 \\
\end{array}$ & $\begin{array}{l}+0.01 \\
-0.15 \\
\end{array}$ & \pm 0.2 \\
\hline$(4,4)$ & $0.82,0.95$ & $82.15_{-10.91}^{+10.88}$ & \pm 12.17 & $\begin{array}{l}+5.24 \\
-5.31 \\
\end{array}$ & $\begin{array}{l}+4.45 \\
-4.95 \\
\end{array}$ & $\begin{array}{l}+2.76 \\
-1.92 \\
\end{array}$ & \pm 0.2 \\
\hline$(4,5)$ & $0.82,0.99$ & $136.78_{-15.01}^{+14.58}$ & \pm 9.72 & $\begin{array}{l}+4.37 \\
-5.1 \\
\end{array}$ & $\begin{array}{l}+4.25 \\
-4.74 \\
\end{array}$ & $\begin{array}{l}+1.01 \\
-1.86 \\
\end{array}$ & \pm 0.2 \\
\hline$(5,0)$ & $0.94,0.79$ & $4.16_{-2.81}^{+2.81}$ & \pm 67.52 & $\begin{array}{l}+3.51 \\
-3.99 \\
\end{array}$ & $\begin{array}{l}+3.5 \\
-3.97 \\
\end{array}$ & $\begin{array}{l}+0.01 \\
-0.25 \\
\end{array}$ & \pm 0.2 \\
\hline$(5,1)$ & $0.94,0.84$ & $\begin{array}{r}9.07+3.72 \\
-3.73 \\
\end{array}$ & \pm 40.75 & $\begin{array}{l}+4.96 \\
-5.46 \\
\end{array}$ & $\begin{array}{l}+4.95 \\
-5.45 \\
\end{array}$ & $\begin{array}{l}+0.01 \\
-0.23 \\
\end{array}$ & \pm 0.2 \\
\hline$(5,2)$ & $0.94,0.89$ & $18.06_{-5.02}^{+4.99}$ & \pm 27.22 & $\begin{array}{l}+4.62 \\
-5.56 \\
\end{array}$ & $\begin{array}{l}+4.62 \\
-5.12 \\
\end{array}$ & $\begin{array}{l}+0.02 \\
-2.15 \\
\end{array}$ & \pm 0.2 \\
\hline$(5,3)$ & $0.94,0.92$ & $\begin{array}{r}44.18_{-7.68}^{+7.59} \\
\end{array}$ & \pm 16.73 & $\begin{array}{l}+3.87 \\
-4.74 \\
\end{array}$ & $\begin{array}{l}+3.8 \\
-4.28 \\
\end{array}$ & $\begin{array}{l}+0.7 \\
-2.02 \\
\end{array}$ & \pm 0.2 \\
\hline$(5,4)$ & $0.94,0.95$ & $66.99_{-9.67}^{+11.50}$ & \pm 13.61 & $\begin{array}{l}+10.46 \\
-4.81\end{array}$ & $\begin{array}{l}+4.19 \\
-4.69 \\
\end{array}$ & $\begin{array}{l}+9.58 \\
-1.05 \\
\end{array}$ & \pm 0.2 \\
\hline$(5,5)$ & $0.94,0.99$ & $168.47_{-20.69}^{+17.83}$ & \pm 8.68 & $\begin{array}{l}+6.06 \\
-8.69 \\
\end{array}$ & $\begin{array}{l}+4.31 \\
-4.8 \\
\end{array}$ & $\begin{array}{l}+4.26 \\
-7.23 \\
\end{array}$ & \pm 0.2 \\
\hline
\end{tabular}


Table 7.6: Cross section numbers and errors for $p+C \rightarrow \pi^{+}+X$ All errors are shown in percentage except the total errors that are shown next to the cross-section.

\begin{tabular}{|c|c|c|c|c|c|c|c|}
\hline \multirow[b]{2}{*}{ Bin } & \multirow[b]{2}{*}{ 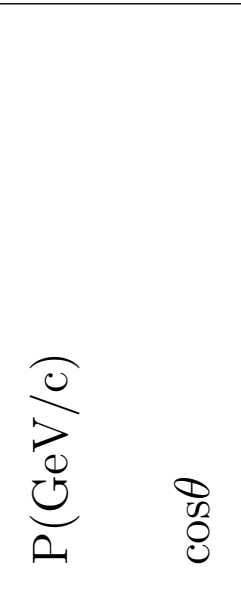 } & \multirow[b]{2}{*}{$\frac{d^{2} \sigma_{\pi+}}{d p d \Omega}$} & \multicolumn{5}{|c|}{ Errors in Percentage } \\
\hline & & & 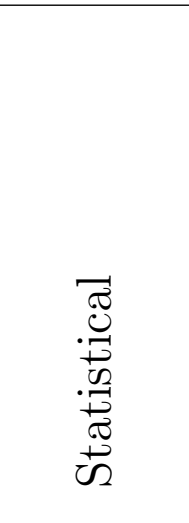 & 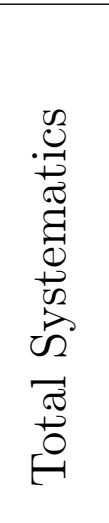 & 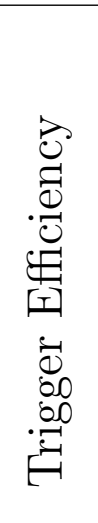 & 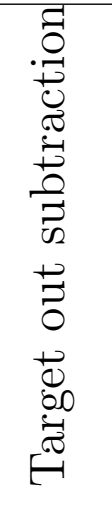 & 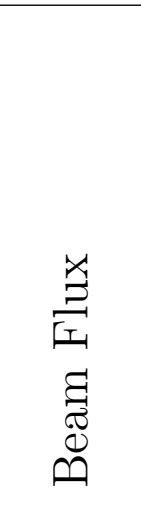 \\
\hline$(0,0)$ & $0.35,0.79$ & $94.511_{-12.01}^{+11.83}$ & \pm 11.81 & $\begin{array}{l}+4.14 \\
-4.68 \\
\end{array}$ & $\begin{array}{l}+4.1 \\
-4.6 \\
\end{array}$ & $\begin{array}{l}+0.44 \\
-0.78 \\
\end{array}$ & \pm 0.3 \\
\hline$(0,1)$ & $0.35,0.84$ & $94.89+11.69$ & \pm 11.65 & $\begin{array}{l}+4.01 \\
-4.56\end{array}$ & $\begin{array}{l}+3.99 \\
-4.48 \\
\end{array}$ & $\begin{array}{l}+0.33 \\
-0.83\end{array}$ & \pm 0.3 \\
\hline$(0,2)$ & $0.35,0.89$ & $133.09_{-14.26}^{+14.01}$ & \pm 9.61 & $\begin{array}{l}+4.29 \\
-4.74 \\
\end{array}$ & $\begin{array}{l}+4.23 \\
-4.72 \\
\end{array}$ & $\begin{array}{l}+0.63 \\
-0.2 \\
\end{array}$ & \pm 0.3 \\
\hline$(0,3)$ & $0.35,0.92$ & $195.99_{-19.54}^{+17.33}$ & \pm 7.79 & $\begin{array}{l}+4.18 \\
-6.22 \\
\end{array}$ & $\begin{array}{l}+4.17 \\
-4.66 \\
\end{array}$ & $\begin{array}{l}+0.05 \\
-4.1\end{array}$ & \pm 0.3 \\
\hline$(0,4)$ & $0.35,0.95$ & $208.59{ }_{-18.58}^{+17.65}$ & \pm 7.44 & $\begin{array}{l}+4.03 \\
-4.9\end{array}$ & $\begin{array}{l}+4.02 \\
-4.51 \\
\end{array}$ & $\begin{array}{l}+0.11 \\
-1.88\end{array}$ & \pm 0.3 \\
\hline$(0,5)$ & $0.35,0.99$ & $215.25_{-18.46}^{+18.15}$ & \pm 7.33 & $\begin{array}{l}+4.17 \\
-4.45\end{array}$ & $\begin{array}{l}+3.83 \\
-4.32 \\
\end{array}$ & $\begin{array}{l}+1.6 \\
-1.03\end{array}$ & \pm 0.3 \\
\hline$(1,0)$ & $0.49,0.79$ & $75.32{ }_{-10.91}^{+10.79}$ & \pm 13.69 & $\begin{array}{l}+4.23 \\
-4.72 \\
\end{array}$ & $\begin{array}{l}+4.21 \\
-4.71 \\
\end{array}$ & $\begin{array}{l}+0.03 \\
-0.17 \\
\end{array}$ & \pm 0.3 \\
\hline$(1,1)$ & $0.49,0.84$ & $86.91_{-11.43}^{+11.29}$ & \pm 12.37 & $\begin{array}{l}+3.97 \\
-4.47\end{array}$ & $\begin{array}{l}+3.96 \\
-4.45 \\
\end{array}$ & $\begin{array}{l}+0.04 \\
-0.29\end{array}$ & \pm 0.3 \\
\hline$(1,2)$ & $0.49,0.89$ & $139.65_{-14.71}^{+14.42}$ & \pm 9.41 & $\begin{array}{l}+4.25 \\
-4.74\end{array}$ & $\begin{array}{l}+4.23 \\
-4.73\end{array}$ & $\begin{array}{l}+0.03 \\
-0.18\end{array}$ & \pm 0.3 \\
\hline$(1,3)$ & $0.49,0.92$ & $199.58{ }_{-18.14}^{+17.64}$ & \pm 7.72 & $\begin{array}{l}+4.3 \\
-4.8\end{array}$ & $\begin{array}{l}+4.28 \\
-4.78\end{array}$ & $\begin{array}{l}+0.15 \\
-0.37\end{array}$ & \pm 0.3 \\
\hline$(1,4)$ & $0.49,0.95$ & $319.14_{-31.07}^{+23.74}$ & \pm 6.02 & $\begin{array}{l}+4.37 \\
-7.65 \\
\end{array}$ & $\begin{array}{l}+4.35 \\
-4.85 \\
\end{array}$ & $\begin{array}{l}+0.18 \\
-5.9\end{array}$ & \pm 0.3 \\
\hline$(1,5)$ & $0.49,0.99$ & $342.3_{-25.33}^{+25.25}$ & \pm 5.79 & $\begin{array}{l}+4.57 \\
-4.61 \\
\end{array}$ & $\begin{array}{l}+4.05 \\
-4.54 \\
\end{array}$ & $\begin{array}{l}+2.09 \\
-0.69 \\
\end{array}$ & \pm 0.3 \\
\hline$(2,0)$ & $0.6,0.79$ & $51.96_{-9.55}^{+9.48}$ & \pm 17.72 & $\begin{array}{l}+4.33 \\
-4.85 \\
\end{array}$ & $\begin{array}{l}+4.31 \\
-4.81 \\
\end{array}$ & $\begin{array}{l}+0.02 \\
-0.51 \\
\end{array}$ & \pm 0.3 \\
\hline$(2,1)$ & $0.6,0.84$ & $92.43_{-12.25}^{+12.11}$ & \pm 12.43 & $\begin{array}{l}+4.13 \\
-4.61 \\
\end{array}$ & $\begin{array}{l}+4.1 \\
-4.6 \\
\end{array}$ & $\begin{array}{l}+0.3 \\
-0.17\end{array}$ & \pm 0.3 \\
\hline$(2,2)$ & $0.6,0.89$ & $99.44_{-12.40}^{+12.26}$ & \pm 11.46 & $\begin{array}{l}+4.54 \\
-4.92 \\
\end{array}$ & $\begin{array}{l}+4.41 \\
-4.91 \\
\end{array}$ & $\begin{array}{l}+1.02 \\
-0.09\end{array}$ & \pm 0.3 \\
\hline$(2,3)$ & $0.6,0.92$ & $205.19_{-18.53}^{+18.00}$ & \pm 7.73 & $\begin{array}{l}+4.15 \\
-4.67 \\
\end{array}$ & $\begin{array}{l}+4.13 \\
-4.63 \\
\end{array}$ & $\begin{array}{l}+0.26 \\
-0.51 \\
\end{array}$ & \pm 0.3 \\
\hline$(2,4)$ & $0.6,0.95$ & $249.81_{-21.01}^{+22.38}$ & \pm 6.92 & $\begin{array}{l}+5.69 \\
-4.78 \\
\end{array}$ & $\begin{array}{l}+4.11 \\
-4.6\end{array}$ & $\begin{array}{l}+3.93 \\
-1.24 \\
\end{array}$ & \pm 0.3 \\
\hline$(2,5)$ & $0.6,0.99$ & $399.63_{-28.83}^{+27.55}$ & \pm 5.63 & $\begin{array}{l}+3.98 \\
-4.51 \\
\end{array}$ & $\begin{array}{l}+3.97 \\
-4.46 \\
\end{array}$ & $\begin{array}{l}+0.01 \\
-0.59 \\
\end{array}$ & \pm 0.3 \\
\hline
\end{tabular}


Table 7.6: continued

\begin{tabular}{|c|c|c|c|c|c|c|c|}
\hline \multirow[b]{2}{*}{ Bin } & \multirow[b]{2}{*}{ 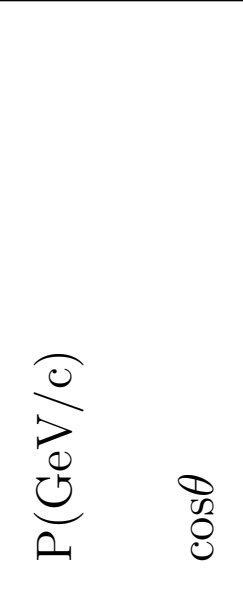 } & \multirow[b]{2}{*}{$\frac{d^{2} \sigma_{\pi^{+}}}{d p d \Omega}$} & \multicolumn{5}{|c|}{ Errors in Percentage } \\
\hline & & & 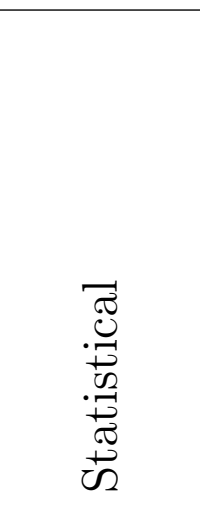 & 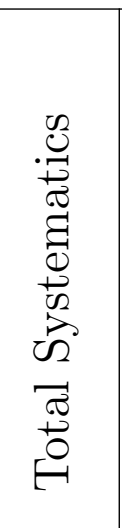 & 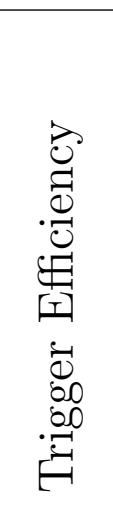 & 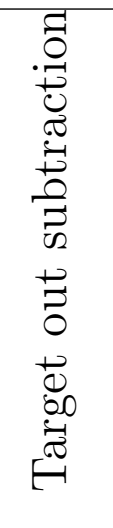 & 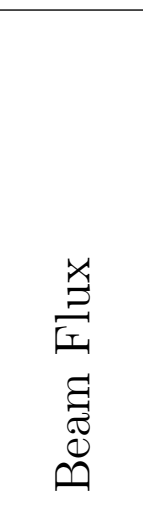 \\
\hline$(3,0)$ & $0.7,0.79$ & $52.544_{-10.01}^{+9.95}$ & \pm 18.44 & & $\begin{array}{l}+4.27 \\
-4.77 \\
\end{array}$ & & \pm 0.3 \\
\hline$(3,1)$ & $0.7,0.84$ & $112.38_{-14.08}^{+13.87}$ & \pm 11.54 & $\begin{array}{l}+4.38 \\
-4.89 \\
\end{array}$ & $\begin{array}{l}+4.37 \\
-4.86 \\
\end{array}$ & $\begin{array}{l}+0.1 \\
-0.34 \\
\end{array}$ & \pm 0.3 \\
\hline$(3,2)$ & $0.7,0.89$ & $107.32_{-12.98}^{+13.15}$ & \pm 11.15 & & $\begin{array}{l}+4.18 \\
-4.67 \\
\end{array}$ & $\begin{array}{l}+2.87 \\
-0.03\end{array}$ & \pm 0.3 \\
\hline$(3,3)$ & $0.7,0.92$ & $274.11_{-22.93}^{+22.14}$ & \pm 6.78 & & $\begin{array}{l}+4.37 \\
-4.87 \\
\end{array}$ & $\begin{array}{l}+0.1 \\
-0.39 \\
\end{array}$ & \pm 0.3 \\
\hline$(3,4)$ & $0.7,0.95$ & $289.57_{-22.96}^{+22.18}$ & \pm 6.5 & & $\begin{array}{l}+4.02 \\
-4.52 \\
\end{array}$ & $\begin{array}{l}+0.23 \\
-0.36 \\
\end{array}$ & \pm 0.3 \\
\hline$(3,5)$ & $0.7,0.99$ & $408.19_{-30.38}^{+33.83}$ & \pm 5.61 & $\begin{array}{l}+6.1 \\
-4.89 \\
\end{array}$ & $\begin{array}{l}+4.14 \\
-4.63 \\
\end{array}$ & $\begin{array}{l}+4.47 \\
-1.52 \\
\end{array}$ & \pm 0.3 \\
\hline$(4,0)$ & $0.82,0.79$ & $48.32_{-10.47}^{+10.41}$ & \pm 21.08 & $\begin{array}{l}+4.46 \\
-4.99 \\
\end{array}$ & $\begin{array}{l}+4.44 \\
-4.94 \\
\end{array}$ & $\begin{array}{l}+0.02 \\
-0.63 \\
\end{array}$ & \pm 0.3 \\
\hline$(4,1)$ & $0.82,0.84$ & $75.6_{-11.71}^{+11.64}$ & \pm 14.81 & $\begin{array}{l}+4.23 \\
-4.54 \\
\end{array}$ & $\begin{array}{l}+4.02 \\
-4.51 \\
\end{array}$ & $\begin{array}{l}+1.26 \\
-0.35 \\
\end{array}$ & \pm 0.3 \\
\hline$(4,2)$ & $0.82,0.89$ & $119.07_{-14.40}^{+14.01}$ & \pm 10.96 & & $\begin{array}{l}+4.27 \\
-4.76 \\
\end{array}$ & $\begin{array}{l}+0.02 \\
-1.8\end{array}$ & \pm 0.3 \\
\hline$(4,3)$ & $0.82,0.92$ & $183.38_{-19.75}^{+17.79}$ & \pm 8.55 & $\begin{array}{l}+4.58 \\
-6.55 \\
\end{array}$ & $\begin{array}{l}+4.54 \\
-5.04 \\
\end{array}$ & $\begin{array}{l}+0.5 \\
-4.17 \\
\end{array}$ & \pm 0.3 \\
\hline$(4,4)$ & $0.82,0.95$ & $315.95_{-24.71}^{+23.81}$ & \pm 6.29 & & $\begin{array}{l}+4.14 \\
-4.63 \\
\end{array}$ & $\begin{array}{l}+0.15 \\
-0.24 \\
\end{array}$ & \pm 0.3 \\
\hline$(4,5)$ & $0.82,0.99$ & $\begin{array}{l}524.9{ }_{-38.00}^{+35.35} \\
\end{array}$ & \pm 4.91 & $\begin{array}{l}+4.61 \\
-5.32 \\
\end{array}$ & $\begin{array}{r}+4.19 \\
-4.68 \\
\end{array}$ & $\begin{array}{l}+1.89 \\
-2.51 \\
\end{array}$ & \pm 0.3 \\
\hline$(5,0)$ & $0.94,0.79$ & $25.95_{-8.00}^{+7.98}$ & \pm 30.47 & & $\begin{array}{l}+4.09 \\
-4.58 \\
\end{array}$ & $\begin{array}{l}+0.02 \\
-0.16 \\
\end{array}$ & \pm 0.3 \\
\hline$(5,1)$ & $0.94,0.84$ & $59.2_{-10.83}^{+10.76}$ & \pm 17.7 & $\begin{array}{l}+4.13 \\
-4.63 \\
\end{array}$ & $\begin{array}{l}+4.12 \\
-4.61 \\
\end{array}$ & $\begin{array}{l}+0.02 \\
-0.04 \\
\end{array}$ & \pm 0.3 \\
\hline$(5,2)$ & $0.94,0.89$ & $89.05_{-12.47}^{+12.25}$ & \pm 13.2 & $\begin{array}{l}+3.88 \\
-4.67 \\
\end{array}$ & $\begin{array}{l}+3.86 \\
-4.35 \\
\end{array}$ & $\begin{array}{l}+0.03 \\
-1.67 \\
\end{array}$ & \pm 0.3 \\
\hline$(5,3)$ & $0.94,0.92$ & $134.15_{-14.91}^{+14.63}$ & \pm 10.11 & $\begin{array}{l}+4.09 \\
-4.62 \\
\end{array}$ & $\begin{array}{l}+4.05 \\
-4.54 \\
\end{array}$ & $\begin{array}{l}+0.46 \\
-0.75 \\
\end{array}$ & \pm 0.3 \\
\hline$(5,4)$ & $0.94,0.95$ & $268.9_{-24.37}^{+21.91}$ & \pm 6.94 & $\begin{array}{l}+4.27 \\
-5.83 \\
\end{array}$ & $\begin{array}{l}+4.25 \\
-4.75 \\
\end{array}$ & $\begin{array}{l}+0.02 \\
-3.36 \\
\end{array}$ & \pm 0.3 \\
\hline$(5,5)$ & $0.94,0.99$ & $538.47_{-37.09}^{+34.81}$ & \pm 4.94 & $\begin{array}{l}+4.17 \\
-4.8\end{array}$ & $\begin{array}{l}+4.12 \\
{ }_{-4.61}\end{array}$ & $\begin{array}{l}+0.56 \\
-1.3\end{array}$ & \pm 0.3 \\
\hline
\end{tabular}


Table 7.7: Cross section numbers and errors for $p+C \rightarrow \pi^{-}+X$ All errors are shown in percentage except the total errors that are shown next to the cross-section.

\begin{tabular}{|c|c|c|c|c|c|c|c|}
\hline \multirow[b]{2}{*}{ Bin } & \multirow[b]{2}{*}{$\begin{array}{l}\frac{\partial}{D} \\
\frac{0}{0} \\
\underset{n}{J}\end{array}$} & \multirow[b]{2}{*}{$\frac{d^{2} \sigma_{\pi^{-}}}{d p d \Omega}$} & \multicolumn{5}{|c|}{ Errors in Percentage } \\
\hline & & & 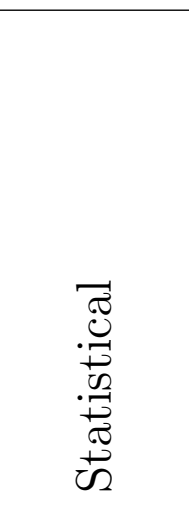 & 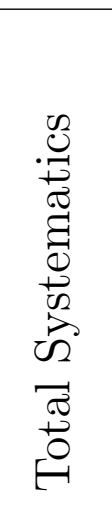 & 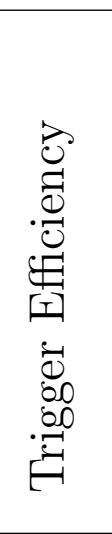 & 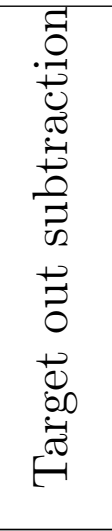 & 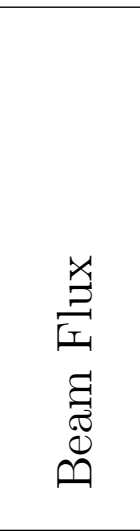 \\
\hline$(0,0)$ & $0.35,0.79$ & $\begin{array}{r}82.2_{-10.86}^{+10.65} \\
\end{array}$ & \pm 12.23 & $\begin{array}{l}+4.28 \\
-5\end{array}$ & $\begin{array}{l}+4.27 \\
-4.76 \\
\end{array}$ & $\begin{array}{l}+0.04 \\
-1.47 \\
\end{array}$ & \pm 0.3 \\
\hline$(0,1)$ & $0.35,0.84$ & $107.67_{-12.50}^{+12.36}$ & \pm 10.68 & $\begin{array}{l}+4.22 \\
-4.54\end{array}$ & $\begin{array}{l}+4.03 \\
-4.52\end{array}$ & $\begin{array}{l}+1.21 \\
-0.25\end{array}$ & \pm 0.3 \\
\hline$(0,2)$ & $0.35,0.89$ & $134.07_{-14.13}^{+14.60}$ & \pm 9.57 & $\begin{array}{l}+5.19 \\
-4.42\end{array}$ & $\begin{array}{l}+3.86 \\
-4.34\end{array}$ & $\begin{array}{l}+3.45 \\
-0.74\end{array}$ & \pm 0.3 \\
\hline$(0,3)$ & $0.35,0.92$ & $167.1_{-16.34}^{+16.00}$ & \pm 8.66 & $\begin{array}{l}+4.08 \\
-4.54 \\
\end{array}$ & $\begin{array}{l}+4.03 \\
-4.52 \\
\end{array}$ & & \pm 0.3 \\
\hline$(0,4)$ & $0.35,0.95$ & $237.82_{-23.66}^{+19.95}$ & \pm 7.29 & $\begin{array}{l}+4.15 \\
-6.77 \\
\end{array}$ & $\begin{array}{l}+4.11 \\
-4.61 \\
\end{array}$ & $\begin{array}{l}+0.46 \\
-4.95\end{array}$ & \pm 0.3 \\
\hline$(0,5)$ & $0.35,0.99$ & $274.71_{-23.31}^{+23.99}$ & \pm 6.84 & $\begin{array}{l}+5.43 \\
-5.02 \\
\end{array}$ & $\begin{array}{l}+4.34 \\
-4.84 \\
\end{array}$ & $\begin{array}{l}+3.24 \\
-1.29 \\
\end{array}$ & \pm 0.3 \\
\hline$(1,0)$ & $0.49,0.79$ & $75.67_{-10.60}^{+10.46}$ & \pm 13.24 & $\begin{array}{l}+3.97 \\
-4.58 \\
\end{array}$ & $\begin{array}{l}+3.95 \\
-4.44 \\
\end{array}$ & $\begin{array}{l}+0.02 \\
-1.06 \\
\end{array}$ & \pm 0.3 \\
\hline$(1,1)$ & $0.49,0.84$ & $80.94_{-10.76}^{+10.62}$ & \pm 12.46 & $\begin{array}{l}+4.11 \\
-4.62 \\
\end{array}$ & $\begin{array}{l}+4.09 \\
-4.59 \\
\end{array}$ & $\begin{array}{l}+0.22 \\
-0.4 \\
\end{array}$ & \pm 0.3 \\
\hline$(1,2)$ & $0.49,0.89$ & $119.16_{-13.06}^{+12.84}$ & \pm 10.07 & $\begin{array}{l}+3.84 \\
-4.33 \\
\end{array}$ & $\begin{array}{l}+3.83 \\
-4.31 \\
\end{array}$ & $\begin{array}{l}+0.05 \\
-0.26\end{array}$ & \pm 0.3 \\
\hline$(1,3)$ & $0.49,0.92$ & $176.27_{-16.70}^{+16.29}$ & \pm 8.26 & $\begin{array}{l}+4.14 \\
-4.64 \\
\end{array}$ & $\begin{array}{l}+4.12 \\
-4.62 \\
\end{array}$ & $\begin{array}{l}+0.01 \\
-0.32 \\
\end{array}$ & \pm 0.3 \\
\hline$(1,4)$ & $0.49,0.95$ & $255.73_{-21.09}^{+20.37}$ & \pm 6.87 & $\begin{array}{l}+4.03 \\
-4.56 \\
\end{array}$ & $\begin{array}{l}+4.02 \\
-4.51 \\
\end{array}$ & & \pm 0.3 \\
\hline$(1,5)$ & $0.49,0.99$ & $319.599_{-27.29}^{+25.28}$ & \pm 6.25 & $\begin{array}{l}+4.85 \\
-5.82 \\
\end{array}$ & $\begin{array}{l}+4.06 \\
-4.55 \\
\end{array}$ & $\begin{array}{l}+2.62 \\
-3.61 \\
\end{array}$ & \pm 0.3 \\
\hline$(2,0)$ & $0.6,0.79$ & $33.51_{-7.27}^{+7.23}$ & \pm 21.16 & $\begin{array}{l}+4.29 \\
-4.79 \\
\end{array}$ & $\begin{array}{l}+4.28 \\
-4.77 \\
\end{array}$ & $\begin{array}{l}+0.05 \\
-0.02 \\
\end{array}$ & \pm 0.3 \\
\hline$(2,1)$ & $0.6,0.84$ & $61.34_{-9.46}^{+9.38}$ & \pm 14.82 & $\begin{array}{l}+3.76 \\
-4.24 \\
\end{array}$ & $\begin{array}{l}+3.75 \\
-4.23 \\
\end{array}$ & $\begin{array}{l}+0.03 \\
-0.03 \\
\end{array}$ & \pm 0.3 \\
\hline$(2,2)$ & $0.6,0.89$ & $113.89{ }_{-13.05}^{+12.83}$ & \pm 10.43 & $\begin{array}{l}+4.25 \\
-4.74 \\
\end{array}$ & $\begin{array}{l}+4.23 \\
-4.73 \\
\end{array}$ & $\begin{array}{l}+0.03 \\
-0.01\end{array}$ & \pm 0.3 \\
\hline$(2,3)$ & $0.6,0.92$ & $182.28_{-17.01}^{+16.59}$ & \pm 8.14 & $\begin{array}{l}+4.07 \\
-4.56 \\
\end{array}$ & $\begin{array}{l}+4.05 \\
-4.54 \\
\end{array}$ & $\begin{array}{l}+0.14 \\
-0.05\end{array}$ & \pm 0.3 \\
\hline$(2,4)$ & $0.6,0.95$ & $205.28_{-18.27}^{+17.71}$ & \pm 7.74 & $\begin{array}{l}+3.81 \\
-4.39 \\
\end{array}$ & $\begin{array}{l}+3.8 \\
-4.28\end{array}$ & $\begin{array}{l}+0.08 \\
-0.91\end{array}$ & \pm 0.3 \\
\hline$(2,5)$ & $0.6,0.99$ & $353.55_{-28.82}^{+26.57}$ & \pm 6.15 & $\begin{array}{l}+4.32 \\
-5.35 \\
\end{array}$ & $\begin{array}{l}+4.3 \\
-4.8 \\
\end{array}$ & $\begin{array}{l}+0.17 \\
-2.35 \\
\end{array}$ & \pm 0.3 \\
\hline
\end{tabular}


Table 7.7: continued

\begin{tabular}{|c|c|c|c|c|c|c|c|}
\hline \multirow[b]{2}{*}{ Bin } & \multirow[b]{2}{*}{ 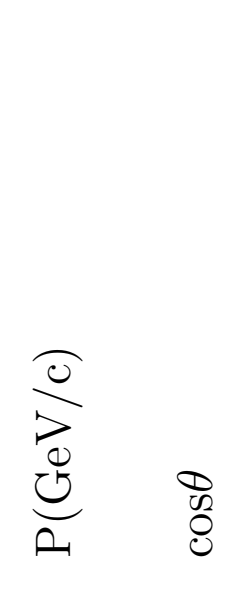 } & \multirow[b]{2}{*}{$\frac{d^{2} \sigma_{\pi^{-}}}{d p d \Omega}$} & \multicolumn{5}{|c|}{ Errors in Percentage } \\
\hline & & & 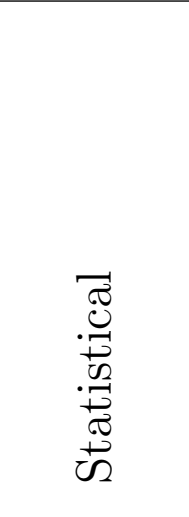 & 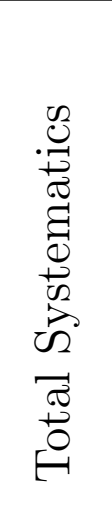 & 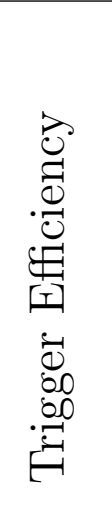 & 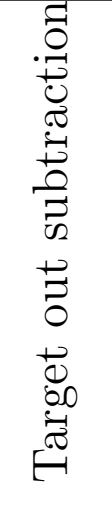 & 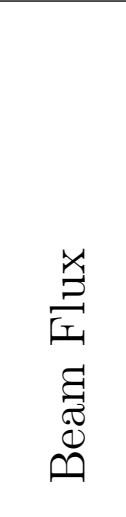 \\
\hline$(3,0)$ & $0.7,0.79$ & $45.41_{-9.35}^{+8.65}$ & \pm 18.55 & $\begin{array}{l}+4.3 \\
-8.93\end{array}$ & $\begin{array}{l}+4.29 \\
-4.79\end{array}$ & $\begin{array}{l}+0.02 \\
-7.53\end{array}$ & \pm 0.3 \\
\hline$(3,1)$ & $0.7,0.84$ & $63.95{ }_{-9.82}^{+10.69}$ & \pm 14.72 & $\begin{array}{l}+7.93 \\
-4.35 \\
\end{array}$ & $\begin{array}{l}+3.85 \\
-4.34 \\
\end{array}$ & $\begin{array}{l}+6.93 \\
-0.02 \\
\end{array}$ & \pm 0.3 \\
\hline$(3,2)$ & $0.7,0.89$ & $93.95_{-14.38}^{+11.70}$ & \pm 11.72 & $\begin{array}{l}+4.21 \\
-9.85 \\
\end{array}$ & $\begin{array}{l}+4.19 \\
-4.69 \\
\end{array}$ & $\begin{array}{l}+0.14 \\
-8.66\end{array}$ & \pm 0.3 \\
\hline$(3,3)$ & $0.7,0.92$ & $185.57{ }_{-17.21}^{+16.88}$ & \pm 8.1 & $\begin{array}{l}+4.14 \\
-4.52\end{array}$ & $\begin{array}{l}+4.02 \\
-4.51\end{array}$ & $\begin{array}{l}+0.93 \\
-0.15\end{array}$ & \pm 0.3 \\
\hline$(3,4)$ & $0.7,0.95$ & $275.04_{-22.31}^{+21.57}$ & \pm 6.68 & $\begin{array}{l}+4.11 \\
-4.6 \\
\end{array}$ & $\begin{array}{l}+4.06 \\
-4.55 \\
\end{array}$ & $\begin{array}{l}+0.58 \\
-0.62 \\
\end{array}$ & \pm 0.3 \\
\hline$(3,5)$ & $0.7,0.99$ & $358.83_{-28.11}^{+27.19}$ & \pm 6.12 & $\begin{array}{l}+4.47 \\
-4.89 \\
\end{array}$ & $\begin{array}{l}+4.22 \\
-4.71 \\
\end{array}$ & $\begin{array}{l}+1.44 \\
-1.24 \\
\end{array}$ & \pm 0.3 \\
\hline$(4,0)$ & $0.82,0.79$ & $21 \begin{array}{r}+6.07 \\
-6.09\end{array}$ & \pm 28.6 & $\begin{array}{l}+4.28 \\
-4.78 \\
\end{array}$ & $\begin{array}{l}+4.26 \\
-4.76 \\
\end{array}$ & $\begin{array}{l}+0.1 \\
-0.29\end{array}$ & \pm 0.3 \\
\hline$(4,1)$ & $0.82,0.84$ & $45.75_{-8.38}^{+8.32}$ & \pm 17.68 & $\begin{array}{l}+4.26 \\
-4.8 \\
\end{array}$ & $\begin{array}{l}+4.25 \\
-4.74 \\
\end{array}$ & $\begin{array}{l}+0.02 \\
-0.63 \\
\end{array}$ & \pm 0.3 \\
\hline$(4,2)$ & $0.82,0.89$ & $74 \begin{array}{l}+10.40 \\
-10.53\end{array}$ & \pm 13.35 & $\begin{array}{l}+4.38 \\
-4.93 \\
\end{array}$ & $\begin{array}{l}+4.34 \\
-4.84 \\
\end{array}$ & $\begin{array}{l}+0.47 \\
-0.85 \\
\end{array}$ & \pm 0.3 \\
\hline$(4,3)$ & $0.82,0.92$ & $126.38_{-13.75}^{+13.50}$ & \pm 9.89 & $\begin{array}{l}+4.03 \\
-4.53 \\
\end{array}$ & $\begin{array}{l}+4.02 \\
-4.51 \\
\end{array}$ & $\begin{array}{l}+0.03 \\
-0.26 \\
\end{array}$ & \pm 0.3 \\
\hline$(4,4)$ & $0.82,0.95$ & $223.79{ }_{-19.43}^{+18.86}$ & \pm 7.35 & $\begin{array}{l}+4.12 \\
-4.62 \\
\end{array}$ & $\begin{array}{l}+4.1 \\
-4.59 \\
\end{array}$ & $\begin{array}{l}+0.17 \\
-0.33 \\
\end{array}$ & \pm 0.3 \\
\hline$(4,5)$ & $0.82,0.99$ & $\begin{array}{r}411.77_{-30.20}^{+28.56} \\
\end{array}$ & \pm 5.58 & $\begin{array}{l}+4.12 \\
-4.76 \\
\end{array}$ & $\begin{array}{l}+4.08 \\
-4.58 \\
\end{array}$ & $\begin{array}{l}+0.45 \\
-1.28 \\
\end{array}$ & \pm 0.3 \\
\hline$(5,0)$ & $0.94,0.79$ & $20.41+6.29$ & \pm 30.48 & $\begin{array}{l}+4.45 \\
-11.43 \\
\end{array}$ & $\begin{array}{l}+4.43 \\
-4.93 \\
\end{array}$ & $\begin{array}{l}+0.04 \\
-10.31 \\
\end{array}$ & \pm 0.3 \\
\hline$(5,1)$ & $0.94,0.84$ & $\begin{array}{r}30.85{ }_{-6.93}^{+6.89} \\
\end{array}$ & \pm 21.92 & $\begin{array}{l}+4.21 \\
-4.86 \\
\end{array}$ & $\begin{array}{l}+4.19 \\
-4.69 \\
\end{array}$ & $\begin{array}{l}+0.03 \\
-1.21 \\
\end{array}$ & \pm 0.3 \\
\hline$(5,2)$ & $0.94,0.89$ & $68.48_{-10.07}^{+9.95}$ & \pm 13.87 & $\begin{array}{l}+4.34 \\
-4.87 \\
\end{array}$ & $\begin{array}{l}+4.33 \\
-4.83 \\
\end{array}$ & $\begin{array}{l}+0.02 \\
-0.59 \\
\end{array}$ & \pm 0.3 \\
\hline$(5,3)$ & $0.94,0.92$ & $129.38_{-14.05}^{+13.71}$ & \pm 9.75 & $\begin{array}{l}+4.16 \\
-4.78 \\
\end{array}$ & $\begin{array}{l}+4.14 \\
-4.63 \\
\end{array}$ & $\begin{array}{l}+0.19 \\
-1.12 \\
\end{array}$ & \pm 0.3 \\
\hline$(5,4)$ & $0.94,0.95$ & $214.81_{-19.09}^{+20.61}$ & \pm 7.46 & $\begin{array}{l}+6.03 \\
-4.83 \\
\end{array}$ & $\begin{array}{l}+4.31 \\
-4.8 \\
\end{array}$ & $\begin{array}{l}+4.21 \\
-0.41 \\
\end{array}$ & \pm 0.3 \\
\hline$(5,5)$ & $0.94,0.99$ & $404.7_{-29.56}^{+28.03}$ & \pm 5.59 & $\begin{array}{l}+4.09 \\
-4.7 \\
\end{array}$ & $\begin{array}{l}+4.02 \\
-4.51 \\
\end{array}$ & $\begin{array}{l}+0.67 \\
-1.29 \\
\end{array}$ & \pm 0.3 \\
\hline
\end{tabular}


Table 7.8: Cross section numbers and errors for $p+C \rightarrow p+X$ All errors are shown in percentage except the total errors that are shown next to the cross-section.

\begin{tabular}{|c|c|c|c|c|c|c|c|}
\hline \multirow[b]{2}{*}{ Bin } & \multirow[b]{2}{*}{ 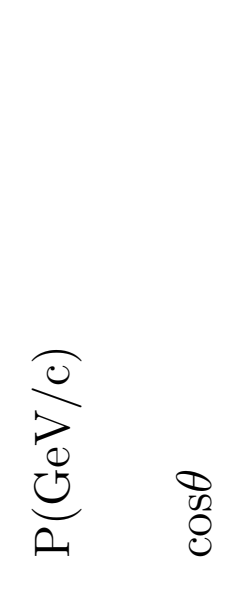 } & \multirow[b]{2}{*}{$\frac{d^{2} \sigma_{p}}{d p d \Omega}$} & \multicolumn{5}{|c|}{ Errors in Percentage } \\
\hline & & & 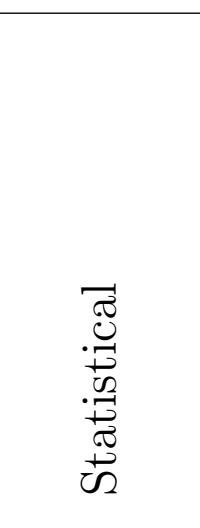 & 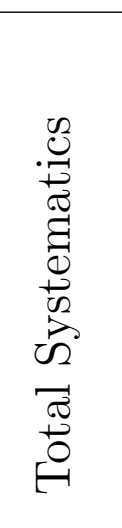 & 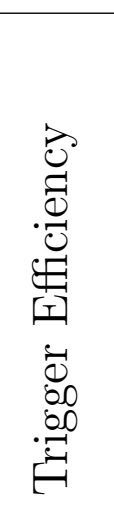 & 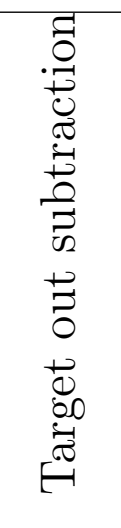 & 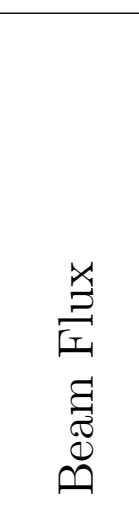 \\
\hline$(0,0)$ & $0.35,0.79$ & $13.92_{-4.39}^{+4.38}$ & \pm 31.23 & $\begin{array}{l}+4.03 \\
-4.59\end{array}$ & $\begin{array}{l}+4.01 \\
-4.5\end{array}$ & $\begin{array}{l}+0.2 \\
-0.82\end{array}$ & \pm 0.3 \\
\hline$(0,1)$ & $0.35,0.84$ & $17.93_{-5.00}^{+4.98}$ & \pm 27.47 & $\begin{array}{l}+4.18 \\
-4.67 \\
\end{array}$ & $\begin{array}{l}+4.16 \\
-4.65 \\
\end{array}$ & $\begin{array}{l}+0.2 \\
-0.25\end{array}$ & \pm 0.3 \\
\hline$(0,2)$ & $0.35,0.89$ & $33.29_{-6.71}^{+6.49}$ & \pm 18.92 & $\begin{array}{l}+4.65 \\
-6.94\end{array}$ & $\begin{array}{l}+4.63 \\
{ }_{-5} .13\end{array}$ & $\begin{array}{l}+0.31 \\
-4.65\end{array}$ & \pm 0.3 \\
\hline$(0,3)$ & $0.35,0.92$ & $41.87_{-7.29}^{+7.21}$ & \pm 16.64 & $\begin{array}{l}+4.4 \\
-5.09\end{array}$ & $\begin{array}{l}+4.21 \\
-4.7\end{array}$ & $\begin{array}{l}+1.23 \\
{ }_{-1.92}\end{array}$ & \pm 0.3 \\
\hline$(0,4)$ & $0.35,0.95$ & $50.95_{-7.91}^{+7.80}$ & \pm 14.57 & & $\begin{array}{l}+4.68 \\
-5.18\end{array}$ & $\begin{array}{l}+0.06 \\
-1.41\end{array}$ & \pm 0.3 \\
\hline$(0,5)$ & $0.35,0.99$ & $97.8_{-13.52}^{+11.33}$ & \pm 10.67 & & $\begin{array}{l}+4.49 \\
-4.99 \\
\end{array}$ & $\begin{array}{l}+0.23 \\
-7.22 \\
\end{array}$ & \pm 0.3 \\
\hline$(1,0)$ & $0.49,0.79$ & $14.13_{-4.98}^{+4.63}$ & \pm 32.48 & & $\begin{array}{l}+4.42 \\
-4.92 \\
\end{array}$ & $\begin{array}{l}+0.11 \\
-12.73 \\
\end{array}$ & \pm 0.3 \\
\hline$(1,1)$ & $0.49,0.84$ & $22.68_{-5.91}^{+5.88}$ & \pm 25.54 & $\begin{array}{l}+4.45 \\
-5.1\end{array}$ & $\begin{array}{l}+4.43 \\
-4.93 \\
\end{array}$ & $\begin{array}{l}+0.14 \\
{ }_{-1.24}\end{array}$ & \pm 0.3 \\
\hline$(1,2)$ & $0.49,0.89$ & $45.82_{-8.14}^{+8.08}$ & \pm 17.07 & $\begin{array}{l}+4.41 \\
-4.91 \\
\end{array}$ & $\begin{array}{l}+4.4 \\
-4.9 \\
\end{array}$ & $\begin{array}{l}+0.06 \\
-0.13 \\
\end{array}$ & \pm 0.3 \\
\hline$(1,3)$ & $0.49,0.92$ & $77.82_{-11.00}^{+10.51}$ & \pm 12.73 & $\begin{array}{l}+4.52 \\
-6.14 \\
\end{array}$ & $\begin{array}{l}+4.51 \\
-5.01\end{array}$ & $\begin{array}{l}+0.1 \\
-3.54 \\
\end{array}$ & \pm 0.3 \\
\hline$(1,4)$ & $0.49,0.95$ & $122.52{ }_{-13.60}^{+13.31}$ & \pm 9.84 & & $\begin{array}{l}+4.59 \\
-5.09\end{array}$ & $\begin{array}{l}+0.03 \\
{ }_{-0.48}\end{array}$ & \pm 0.3 \\
\hline$(1,5)$ & $0.49,0.99$ & $145.59_{-15.49}^{+15.14}$ & \pm 9.33 & $\begin{array}{l}+4.6 \\
-5.11 \\
\end{array}$ & $\begin{array}{l}+4.58 \\
-5.08 \\
\end{array}$ & $\begin{array}{l}+0.15 \\
-0.39 \\
\end{array}$ & \pm 0.3 \\
\hline$(2,0)$ & $0.6,0.79$ & $3.3_{-2.60}^{+2.60}$ & \pm 78.62 & & $\begin{array}{l}+3.68 \\
-4.16 \\
\end{array}$ & $\begin{array}{l}+0.49 \\
-0.73 \\
\end{array}$ & \pm 0.3 \\
\hline$(2,1)$ & $0.6,0.84$ & $10.39_{-4.13}^{+4.12}$ & \pm 39.51 & $\begin{array}{l}+3.81 \\
-4.3\end{array}$ & $\begin{array}{l}+3.79 \\
-4.27 \\
\end{array}$ & $\begin{array}{l}+0.21 \\
-0.31 \\
\end{array}$ & \pm 0.3 \\
\hline$(2,2)$ & $0.6,0.89$ & $50.04_{-8.74}^{+8.77}$ & \pm 16.74 & $\begin{array}{l}+5.21 \\
-5\end{array}$ & $\begin{array}{l}+4.49 \\
-4.99 \\
\end{array}$ & $\begin{array}{l}+2.61 \\
-0.07\end{array}$ & \pm 0.3 \\
\hline$(2,3)$ & $0.6,0.92$ & $71.62_{-10.23}^{+10.11}$ & \pm 13.42 & $\begin{array}{l}+4.36 \\
-4.91 \\
\end{array}$ & $\begin{array}{l}+4.33 \\
-4.83 \\
\end{array}$ & $\begin{array}{l}+0.31 \\
-0.81 \\
\end{array}$ & \pm 0.3 \\
\hline$(2,4)$ & $0.6,0.95$ & $87.49_{-11.32}^{+11.17}$ & \pm 11.97 & $\begin{array}{l}+4.44 \\
-4.9\end{array}$ & $\begin{array}{l}+4.38 \\
-4.88 \\
\end{array}$ & $\begin{array}{l}+0.62 \\
-0.21 \\
\end{array}$ & \pm 0.3 \\
\hline$(2,5)$ & $0.6,0.99$ & $175.69_{-17.81}^{+17.41}$ & \pm 8.93 & $\begin{array}{l}+4.3 \\
-4.8 \\
\end{array}$ & $\begin{array}{l}+4.28 \\
-4.78 \\
\end{array}$ & $\begin{array}{l}{ }_{-0.19}^{+0.18} \\
\end{array}$ & \pm 0.3 \\
\hline
\end{tabular}


Table 7.8: continued

\begin{tabular}{|c|c|c|c|c|c|c|c|}
\hline \multirow[b]{2}{*}{ Bin } & \multirow[b]{2}{*}{ 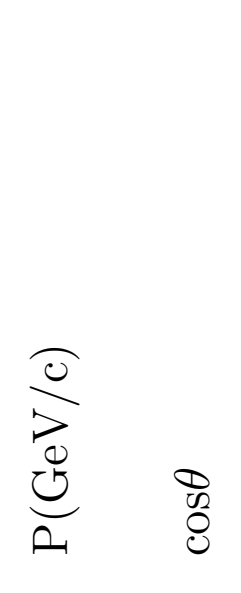 } & \multirow[b]{2}{*}{$\frac{d^{2} \sigma_{p}}{d p d \Omega}$} & \multicolumn{5}{|c|}{ Errors in Percentage } \\
\hline & & & 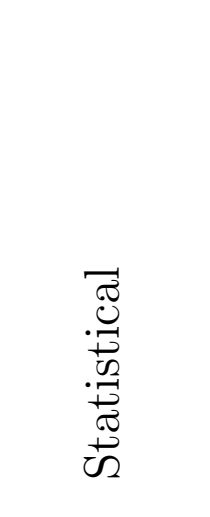 & 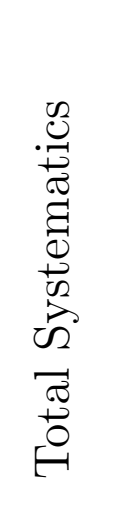 & 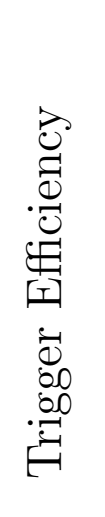 & 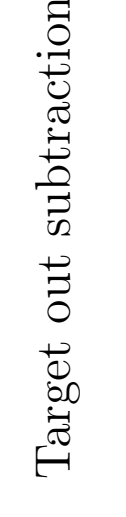 & 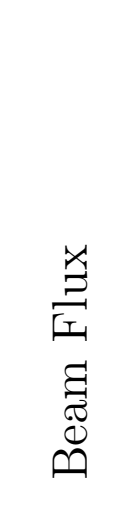 \\
\hline$(3,1)$ & $0.7,0.84$ & $23.4_{-6.19}^{+6.18}$ & \pm 25.93 & $\begin{array}{l}+4.94 \\
-5.28\end{array}$ & $\begin{array}{l}+4.75 \\
-5.25\end{array}$ & $\begin{array}{l}+1.3 \\
-0.43\end{array}$ & \pm 0.3 \\
\hline$(3,2)$ & $0.7,0.89$ & $27.44_{-6.34}^{+6.56}$ & \pm 22.64 & $\begin{array}{l}+7.72 \\
-4.55\end{array}$ & $\begin{array}{l}+4.04 \\
-4.53\end{array}$ & $\begin{array}{l}+6.57 \\
-0.08\end{array}$ & \pm 0.3 \\
\hline$(3,3)$ & $0.7,0.92$ & $54.74{ }_{-8.89}^{+8.82}$ & \pm 15.55 & $\begin{array}{l}+4.23 \\
-4.71 \\
\end{array}$ & $\begin{array}{l}+4.2 \\
-4.7 \\
\end{array}$ & $\begin{array}{l}+0.33 \\
-0.22 \\
\end{array}$ & \pm 0.3 \\
\hline$(3,4)$ & $0.7,0.95$ & $86.84_{-11.98}^{+11.19}$ & \pm 12.14 & $\begin{array}{l}+4.33 \\
-6.55 \\
\end{array}$ & $\begin{array}{l}+4.32 \\
-4.81 \\
\end{array}$ & $\begin{array}{l}+0.16 \\
-4.43\end{array}$ & \pm 0.3 \\
\hline$(3,5)$ & $0.7,0.99$ & $83.85_{-12.45}^{+12.35}$ & \pm 13.9 & $\begin{array}{l}+4.87 \\
-5.22 \\
\end{array}$ & $\begin{array}{l}+4.06 \\
-4.55 \\
\end{array}$ & $\begin{array}{l}+2.67 \\
-2.53 \\
\end{array}$ & \pm 0.3 \\
\hline$(4,0)$ & $0.82,0.79$ & $4.29 \begin{array}{l}+3.09 \\
-3.09\end{array}$ & \pm 71.84 & $\begin{array}{l}+4.77 \\
-5.5\end{array}$ & $\begin{array}{l}+4.75 \\
-5.25\end{array}$ & $\begin{array}{l}+0.15 \\
-1.6\end{array}$ & \pm 0.3 \\
\hline$(4,1)$ & $0.82,0.84$ & $6.96{ }_{-3.49}^{+3.50}$ & \pm 50.04 & $\begin{array}{l}+5.37 \\
-4.13 \\
\end{array}$ & $\begin{array}{l}+3.63 \\
-4.11 \\
\end{array}$ & $\begin{array}{l}+3.93 \\
-0.24 \\
\end{array}$ & \pm 0.3 \\
\hline$(4,2)$ & $0.82,0.89$ & $25.53_{-6.84}^{+6.27}$ & \pm 24.25 & $\begin{array}{l}+3.9 \\
-11.35 \\
\end{array}$ & $\begin{array}{l}+3.88 \\
-4.36 \\
\end{array}$ & $\begin{array}{l}+0.07 \\
-10.47 \\
\end{array}$ & \pm 0.3 \\
\hline$(4,3)$ & $0.82,0.92$ & $\begin{array}{r}38.87^{+7.74} \\
-7.79 \\
\end{array}$ & \pm 19.38 & $\begin{array}{l}+4.56 \\
-5.06 \\
\end{array}$ & $\begin{array}{l}+4.54 \\
-5.04 \\
\end{array}$ & $\begin{array}{l}+0.05 \\
-0.06\end{array}$ & \pm 0.3 \\
\hline$(4,4)$ & $0.82,0.95$ & $64.21_{-9.83}^{+9.74}$ & \pm 14.65 & $\begin{array}{l}+3.93 \\
-4.42 \\
\end{array}$ & $\begin{array}{l}+3.91 \\
-4.4 \\
\end{array}$ & $\begin{array}{l}+0.05 \\
-0.09 \\
\end{array}$ & \pm 0.3 \\
\hline$(4,5)$ & $0.82,0.99$ & $115.37_{-15.79}^{+15.52}$ & \pm 12.74 & $\begin{array}{l}+4.33 \\
-5.01 \\
\end{array}$ & $\begin{array}{l}+4.27 \\
-4.77 \\
\end{array}$ & $\begin{array}{l}+0.61 \\
-1.5 \\
\end{array}$ & \pm 0.3 \\
\hline$(5,0)$ & $0.94,0.79$ & $\begin{array}{r}2.39+2.71 \\
-2.71 \\
\end{array}$ & \pm 113.22 & $\begin{array}{l}+4.56 \\
-5.06 \\
\end{array}$ & $\begin{array}{l}+4.53 \\
-5.03 \\
\end{array}$ & $\begin{array}{l}+0.31 \\
-0.45 \\
\end{array}$ & \pm 0.3 \\
\hline$(5,1)$ & $0.94,0.84$ & $\begin{array}{r}5.34+3.07 \\
-3.07 \\
\end{array}$ & \pm 57.24 & $\begin{array}{l}+4.79 \\
-5.58 \\
\end{array}$ & $\begin{array}{l}+4.78 \\
-5.28 \\
\end{array}$ & $\begin{array}{l}+0.19 \\
-1.76 \\
\end{array}$ & \pm 0.3 \\
\hline$(5,2)$ & $0.94,0.89$ & $28.85{ }_{-6.81}^{+6.72}$ & \pm 22.95 & $\begin{array}{l}+4.06 \\
-5.55 \\
\end{array}$ & $\begin{array}{l}+4.05 \\
-4.54 \\
\end{array}$ & $\begin{array}{l}+0.05 \\
-3.17 \\
\end{array}$ & \pm 0.3 \\
\hline$(5,3)$ & $0.94,0.92$ & $53.63_{-9.22}^{+9.14}$ & \pm 16.5 & $\begin{array}{l}+4.3 \\
-4.8 \\
\end{array}$ & $\begin{array}{l}+4.29 \\
-4.79 \\
\end{array}$ & $\begin{array}{l}+0.06 \\
-0.06\end{array}$ & \pm 0.3 \\
\hline$(5,4)$ & $0.94,0.95$ & $51.86_{-8.89}^{+8.82}$ & \pm 16.53 & $\begin{array}{l}+3.96 \\
-4.52 \\
\end{array}$ & $\begin{array}{l}+3.94 \\
-4.43 \\
\end{array}$ & $\begin{array}{l}+0.16 \\
-0.82 \\
\end{array}$ & \pm 0.3 \\
\hline$(5,5)$ & $0.94,0.99$ & $101.39_{-15.64}^{+15.19}$ & \pm 14.37 & $\begin{array}{l}+4.22 \\
-5.62 \\
\end{array}$ & $\begin{array}{l}+4.2 \\
-4.7 \\
\end{array}$ & $\begin{array}{l}+0.13 \\
-3.06 \\
\end{array}$ & \pm 0.3 \\
\hline
\end{tabular}




\section{CHAPTER 8 CONCLUSION}

In my study, I used the MIPP hadron-carbon interaction data at $58 \mathrm{GeV}$ energy, which has approximately $0.26 \times 10^{6}$ events. When I began to work on my analysis, my main motivation was the benefits of my work for the other neutrino experiments, such as MINOS. However, at the this point, I could only look at low energy produced particle cross sections, which barely decay as a neutrino for use in neutrino experiments. I used only TPC, using the GlobalPid package to get particle identity. TPC can identify particles between $0.2 \mathrm{GeV} / \mathrm{c}$ and $1.2 \mathrm{GeV} / \mathrm{c}$ momenta. Other PID detectors have not been implemented to use with GlobalPid package.

Also, I had several limitations to getting better results due to the fact that at this energy, secondary beam particles are used that create fewer events than primary beam particles. In my case, there are three different beam species (pion, kaon, and proton at $58 \mathrm{GeV} / \mathrm{c}$ momentum on carbon-2\%) that produce new particles. In our experimental setting, there was a pre-scale on interactions that varied by beam type and beam intensity, and our detector system was triggered only when these pre-scale requirements were satisfied.

With these limitations, I made cross-section measurements with consideration of trigger efficiency, detectors' acceptance, particle identity efficiency, filtering unwanted events, momentum migrations, track finding efficiency, and purity efficiency. I selected six angle bins and six momentum bins with sizes determined by Monte Carlo truth PID distribution to have enough entries. Then, two different particle yields were calculated based on target in and out for all types of beam particle species. From these yields, I calculated cross sections using equation 6.2.

Regarding another issue, there has been no work done at $58 \mathrm{GeV}$ energy for the hadron-carbon interaction. So, I could not compare my results to previous work. There is a paper published by the HARP [14] experiment about the proton-carbon 
interaction, but its beam energy was $12 \mathrm{GeV}$.

Indeed, to better serve neutrino experiments, the MIPP data should be analyzed for higher energy produced particles using other PID detectors. However, my study is a confirmation of how cross sections are calculated for low energy produced particles with this amount of data. For further investigations, the MIPP experiment must have more data. Once the upgrade is accepted, MIPP can collect more events on a larger number of targets, which will provide more statistics and give a better understanding of particle flow. 


\section{REFERENCES}

[1] MINOS Technical Design Report. Technical Report MINOS-doc-337, 1998.

[2] The NuMI Facility Tehnical Design Report. Technical Report NuMI-L-337, 1998.

[3] Fred Bieser, Ron Jones, and Charles McParland. Data Links for the EOS TPC. IEEE Trans Nucl. Sci., 38:335-336, 1991.

[4] A. Bravar, A. Penzo, and Y. Onel. A Short Description of the RMH Readout System for the E704 MWPCS. 1993.

[5] D. C. Christian. High rate drift chambers. Nucl. Instrum. Meth., A345:62-71, 1994.

[6] G. Rai et al. A TPC detector for the study of high multiplicity heavy ion collisions. IEEE Trans Nucl. Sci., 37:56-64, 1990.

[7] H. Wieman et al. A TPC detector for the study of high multiplicity heavy ion collisions. Nucl. Phys., A525:617c-620c, 1991.

[8] J. Engelfried et al. The RICH Detector of the SELEX Experiment. Nucl. Instrum. Meth., A433:149-152, 1999.

[9] K. L. Lee et al. Analog-to-Digital Conversion Using Costum CMOS Analog Memory for the EOS Time Projection Chamber. IEEE Trans Nucl. Sci., 38:344-347, 1991.

[10] M. De Palma et al. A System of Large Multiwire Proportional Chambers for A High Intensity Experiment. Nucl. Instrum. Meth., 217:135-139, 1983.

[11] T. Nigmanov et al. Electromagnetic and hadron calorimeters in the MIPP experiment. Nucl. Instrum. Meth., 598(2):394-399, 2009.

[12] J. Engelfried et al. [E781]. The E781 (SELEX) RICH Detector. Nucl. Instrum. Meth., A409:439-442, 1998.

[13] J. Engelfried et al. [SELEX]. The SELEX Phototube RICH Detector. Nucl. Instrum. Meth., A431:53-69, 1999.

[14] M.G. Catanesi etc. al. Measurement of the production cross-sections of $\pi^{ \pm}$in pc and $\pi^{ \pm}$c interactions at 12 gev/c. Astroparticle Physics, 29:257-281, 2008.

[15] Application Software Group. GEANT Detector Description and Simulation Tool. CERN Program Library Long Writeup W5013, 1994.

[16] E. Gulmez, A. Penzo, and Y. Onel. RMH System an the Acompanying Chambers in E791. HNOTE:H-757, May 1996. 
[17] P.D. Barnes M. Heffnier J. Klay J. Paley, R.Soltz and D. Miller. MIPP TPC Reconstruction. 2006.

[18] Stuart A. Kleinfelder. A 4096 cell switched capacitor analog waveform storage integrated circuit. IEEE Trans Nucl. Sci., 37:1230-1236, 1990.

[19] A. Lebedev. Ratio of Pion Kaon Production in Proton Carbon Interaction. PhD thesis, Harvard University, May 2007.

[20] H. Meyer. Physics of the MIPP experiment. Nuclear Physics B, 142:453-458, 2005.

[21] H. Meyer. How to get Cross Sections from MIPP data. 2009.

[22] N. V. Mokhov. The MARS Code System User's Guide, 1995. Fermila-FN-628.

[23] M. Nakamura, D. A. Landis, and G. Rai. Lower Power Shaper Amplifier for the EOS TPC Detector. IEEE Trans Nucl. Sci., 38:50-52, 1991.

[24] R. Raja. Fermilab Experiment E907 Proposal, 1997.

[25] S. M. Seun. Measurement of $\pi-K$ Ratios from NuMI Target. PhD thesis, Harvard University, July 2007. 